UNIVERSIDADE DE SÃO PAULO

ESCOLA DE EDUCAÇÃO FÍSICA E ESPORTE

DESENVOLVIMENTO DE J UDOCAS B RASILE IROS TALENTOSOS

Marcelo Massa

SÃO PAULO

2006

Easy PDF Creator is professional software to create PDF. If you wish to remove this line, buy it now. 
DESENVOLVIMENTO DE JUDOCAS BRASILEIROS TALENTOSOS

MARCELO MASSA

Tese apresentada à Escola de Educação Física e Esporte da Universidade de São Paulo, como requisito parcial para obtenção do grau de Doutor em Educação Física.

ORIENTADORA: PROFA. DRA. MARIA TEREZA SILVEIRA BÖHME CO-ORIENTADOR: PROF. DR. FERNANDO LEFĖVRE 


\section{AGRADECIMENTOS}

Aos ilustres judocas participantes da pesquisa, pela receptividade e carinho.

Aos acadêmicos Rodrigo S. F. Oliveira, Judá Eckert Berto e aos amigos Prof. Ms. José Renato Campanelli e Prof. Dr. Jorge D. Knijnik.

Ao Prof. Dr. Maurício Teodoro de Souza, percursor dessa caminhada desde o primeiro ano de graduação. Muito obrigado!

Ao Prof. Dr. Júlio Cerca Serrão, companheiro de todos esses anos.

Ao Prof. Eduardo Bacellar, por todo seu carinho e amizade. Obrigado!

Aos amigos Alessandro Hervaldo Nicolai Ré, Luiz Roberto Rigolin da Silva e Rudney Uezu, é uma honra compartilhar desta trajetória com vocês. Ela é nossa!

Ao grande amigo Fernando Marcondes...obrigado! Você é um irmão!

Ao amigo Marcos Merida, todo meu respeito, carinho e admiração. Obrigado!

Ao Prof. Dr. Ruy Jornada Krebs, ao Prof. Dante de Rose Júnior, à Profa. Dra. Kátia Rúbio e ao Prof. Dr. Emerson Franchini, pela colaboração na construção e lapidação deste trabalho.

À EEFEUSP e especialmente à Lúcia, Lourdes, Ilza e Márcio.

Ao Prof. Dr. Fernando Lefèvre, por sua receptividade, interesse e paciência.

À Profa. Dra. Maria Tereza Silveira Böhme, parece que foi ontem que começamos! Obrigado pela generosidade em compartilhar comigo toda a sua experiência, sabedoria e serenidade!

À minha mãe Emiliana e a meu pai Percival, obrigado pelo tempero do amor e da garra que colocaram em minha vida! A J oão Pedro, meu super filho, que já me ensina tanto! 
SUMÁRIO

Página

LISTA DE TABELAS ................................................. vi

LISTA DE FIGURAS .............................................. ix

LISTA DE ANEXOS ..................................................... xi

RESUMO …….................................................

ABSTRACT ..................................................... xiv

$1 \quad$ INTRODUÇÃO ......................................................... 1

1.1 O problema e sua importância......................................... 1

1.2 Justificativa ..................................................................... 8

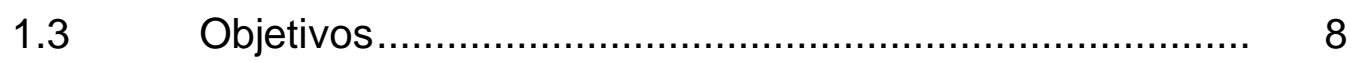

2 REVISÃO DE LITERATURA ......................................... 9

$2.1 \quad$ O Talento ......................................................... 9

2.1.1 Modelos de desenvolvimento de talento......................... 13

2.1.1.1 Modelo de Bloom ....................................................... 14

2.1.1.2 Modelo de Csikszentmihalyi .......................................... 19

2.1.1.3 Modelo de Ericsson ....................................................... 22

2.2 O Talento Esportivo e o treinamento a longo prazo.......... 27

2.2.1 Determinação do talento esportivo ................................... 34

2.2.2 Deteç̧ão do talento esportivo ....................................... 36

2.2.3 Seleção do talento esportivo.......................................... 39

2.2.4 Promoção do talento esportivo ...................................... 40

2.2.5 O processo de treinamento a longo prazo - TLP .............. 44

2.2.6 Considerações acerca do desempenho esportivo ............ 52

2.2.7 Considerações sobre os fatores psicossociais ................ 59

$2.3 \quad$ O Judô ......................................................................... 62

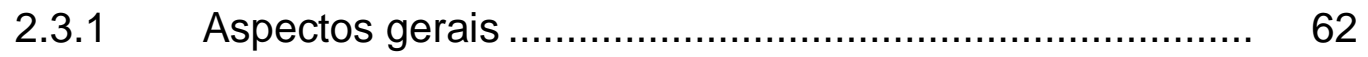

2.3.2 O desempenho no Judô.............................................. 65 
2.3.2.1 Características morfológicas no judô................................ 65

2.3.2.1.1 Composição corporal ................................................... 66

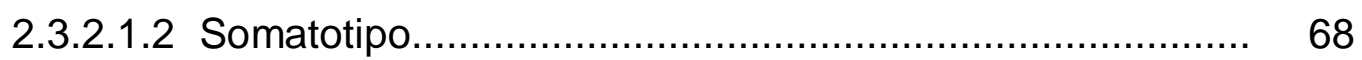

2.3.2.2 Considerações acerca do desempenho físico no judô...... 69

2.3.2.3 Considerações sobre a iniciação esportiva no judô.......... 74

3 PROCEDIMENTOS METODOLÓGICOS ....................... 77

3.1 Amostra ................................................................. 77

3.2 Instrumento da pesquisa.......................................... 78

3.3 Estudo Piloto.......................................................... 80

$4 \quad$ RESULTADOS E DISCUSSÃO …................................ 80

4.1 Idade de iniciação e tempo de prática ............................. 81

4.2 Iniciação no judô............................................................... 84

$4.3 \quad$ Talento precoce ....................................................... 90

$4.4 \quad$ Fatores motivacionais .................................................. 95

4.5 Relações sociais ....................................................... 100

4.6 Outras atividades..................................................... 104

4.7 Aspectos financeiros ................................................ 110

4.8 Genética X meio ambiente............................................ 115

4.9 Competência profissional............................................ 119

4.10 Prescrição, avaliação e controle do TLP......................... 122

4.11 Papel da competição ................................................. 126

4.12 Estresse competitivo................................................. 130

$5 \quad$ CONSIDERAÇÕES FINAIS ......................................... 134

REFERÊNCIAS ....................................................... 140

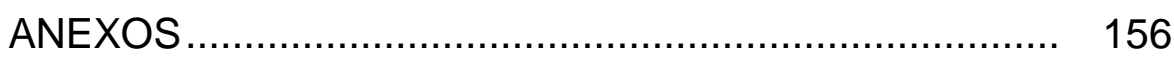




\section{LISTA DE TABELAS}

Página

TABELA 1 - Idades médias de início e de início dos melhores resultados de atletas alemães (MARTIN, CARL \& LEHNERTZ ${ }^{9}, 1991$ apud BÖHME, 2000)

TABELA 2 - Desempenho no teste de Wingate para membros superiores em atletas de diferentes níveis e nacionalidades, valores de média e desvio padrão (FRANCHINI, 2001)

TABELA 3 - Idade de iniciação e tempo de prática de judocas olímpicos brasileiros

TABELA 4 - Caracterização das idéias centrais, freqüência e percentual de respostas para a pergunta: Você pode me contar como foi seu começo no judô? .....

TABELA 5 - Caracterização das idéias centrais, freqüência e percentual de respostas para a pergunta: No começo da sua formação você acha que se destacava dos demais praticantes de judô?

TABELA 6 - Caracterização das idéias centrais, freqüência e percentual de respostas para a pergunta: Você pode me contar o que te fez manter o tempo todo o teu interesse no judô? 96 
TABELA 7 - Caracterização das idéias centrais, freqüência e percentual de respostas para a pergunta: Me conte como era a participação dos seus pais, familiares e amigos em relação ao judô.

TABELA 8 - Caracterização das idéias centrais, freqüência e percentual de respostas para a pergunta: Me conte como era o seu dia a dia e diga o que você fazia no tempo livre restante em que não estava no judô.

TABELA 9 - Caracterização das idéias centrais, freqüência e percentual de respostas para a pergunta: $\mathrm{Me}$ conte como foi o teu sustento financeiro desde o seu início no judô até os dias atuais

TABELA 10 - Caracterização das idéias centrais, freqüência e percentual de respostas para a pergunta: A que você atribui o teu talento para o judô?

TABELA 11 - Caracterização das idéias centrais, freqüência e percentual de respostas para a pergunta: Fale um pouco sobre os teus professores e/ou técnicos e o papel deles na sua formação. 120 
TABELA 12 - Caracterização das idéias centrais, freqüência e percentual de respostas para a pergunta: $\mathrm{O}$ teu treinamento era planejado ou não: fale sobre ele

TABELA 13 - Caracterização das idéias centrais, freqüência e percentual de respostas para a pergunta: Como foram as competições no seu treinamento? Você se destacava logo no começo ou o destaque veio com o tempo?

TABELA 14 - Caracterização das idéias centrais, freqüência e percentual de respostas para a pergunta: Toda competição é meio estressante não é? Como é isso para você? 


\section{LISTA DE FIGURAS}

Página

FIGURA 1 - Talento em esporte como a relação dinâmica entre os níveis de desempenho competitivo do indivíduo no início, na atualidade e no final (HOHMANN et alii ${ }^{5}, 2001$ apud BÖHME, 2004).....

FIGURA 2 - Modelo de formação esportiva a longo prazo MARTIN $^{7}$ (1988) apud BÖHME (2000)

FIGURA 3 - $\quad$ Processo de seleção e formação esportiva modificado de HOFMANN e SCHNEIDER ${ }^{8}$ (1985) apud WEINECK (1999)

FIGURA 4 - Principais fases da detecção e seleção de talentos esportivos - $\mathrm{CARL}^{3}$ (1988) apud BÖHME (1999)

FIGURA 5 - Modelo das relações dos componentes de desempenho esportivo no treinamento a longo prazo (MARTIN et alii $^{4}, 1999$ apud BÖHME, submetido a publicação). 53

FIGURA 6 - Relações entre os componentes atuais da Ciência do Treinamento (SCHNABELL, HARRE \& BORDE $^{10}, 1994$ apud BÖHME, 1999). 
FIGURA 7 - Relações gerais do desempenho esportivo (FRIEDRICH, GROSSER \& PREISING ${ }^{11}, 1988$ apud BÖHME, 1994) ........................................ 55

FIGURA 8 - Esquema das condições pessoais de desempenho e sucesso esportivo $\left(\mathrm{CARL}^{3}, 1988\right.$ apud BÖHME, 1999)

FIGURA 9 - Condições limitantes do desempenho esportivo (CARL ${ }^{3}, 1988$ apud BÖHME, 1999) 58 


\section{LISTA DE ANEXOS}

Página

ANEXO I - $\quad$ Roteiro de entrevista .................................... 156

ANEXO II- Quadros (de 1 até 12) do Instrumento de Análise do Discurso (IAD) ............................... 158

ANEXO III - $\quad$ Aprovação do Comitê de Ética em Pesquisa ......... 196

ANEXO IV - $\quad$ Termo de Consentimento Livre e Esclarecido........ 197 
RESUMO

\title{
DESENVOLVIMENTO DE JUDOCAS BRASILEIROS TALENTOSOS
}

\author{
Autor: MARCELO MASSA \\ Orientadora: PROFA. DRA. MARIA TEREZA SILVEIRA BÖHME \\ Co-orientador: PROF. DR. FERNANDO LEFĖVRE
}

\begin{abstract}
O judô brasileiro é uma modalidade que possui tradição olímpica. Entretanto, sobre o processo de formação de judocas brasileiros, não se conhece os fatores contribuem para o desenvolvimento do talento na modalidade. O objetivo do presente estudo foi analisar o desenvolvimento de judocas olímpicos brasileiros e a relação entre o desenvolvimento de judocas olímpicos brasileiros e os modelos de desenvolvimento de talento descritos na literatura. Para tanto, se utilizou uma amostra de seis judocas, pertencentes a seleção brasileira olímpica nos Jogos Olímpicos de Atenas, 2004. A pesquisa foi constituída através de um delineamento qualitativo, que utilizou como instrumento uma entrevista composta por 12 perguntas abertas, elaboradas para explorar o contexto de desenvolvimento do talento no judô. Para a análise dos resultados foi utilizado o "Discurso do Sujeito Coletivo". Os discursos indicaram que a trajetória de desenvolvimento dos judocas não se aproximou dos modelos de desenvolvimento de talento descritos na literatura, sobretudo devido a ausência de programas nacionais de desenvolvimento esportivo. Contudo, no que tange os aspectos relacionados ao apoio da família, ao prazer pela prática e a determinação dos judocas, o presente estudo corrobora com a literatura,
\end{abstract}


revelando a importância que os fatores psicossociais exerceram no desenvolvimento do judoca brasileiro talentoso.

Palavras-chave: judô, desenvolvimento do talento, talento esportivo. 


\title{
ABSTRACT \\ DEVELOPMENT OF BRAZILIAN TALENTED JUDOKAS
}

\author{
Author: MARCELO MASSA \\ Adviser: PROFA. DRA. MARIA TEREZA SILVEIRA BÖHME \\ Co-adviser: PROF. DR. FERNANDO LEFÈVRE
}

The Brazilian Judo is a sport modality that has an Olympic tradition. However, about Brazilian judokas development process, it is unknown the facts that contribute for the talent development in this modality. The main purpose of the present study was to analyze the Brazilian Olympic Judokas development process and the relation between Brazilian Olympic Judokas and the patterns of talent reported in the literature. In order to do the research, it was used a sample of six judokas from the Brazilian Olympic Team of Atenas, 2004. The study was built through a qualitative inquiry, that used as instrument a interview composed by twelve open questions, elaborated to explore the context of the judo talent development. In order to analyze the results acquired, it was used the "Discurso do Sujeito Coletivo". The speeches showed that the judokas development trajectory didn't reach the development models described in the literature, especially because of the lack of national sport development programs. Although, concerning the aspects related to family support, the pleasure of practice and the judokas determination, the present study corroborates with the literature, revealing the importance that psychosocial facts exerted in the development of Brazilian talented judokas.

Keywords: judo, talent development, sport talent. 


\section{O problema e sua importância}

Nos últimos anos diversos pesquisadores têm discutido as questões que permeiam os processos de detecção, seleção e promoção de talentos para o esporte de alto nível (ABBOTT \& COLLINS, 2004; BENDA, 1998; BENTO, 1989; BÖHME, 1994, 1995, 1996, 2000; BÖHME, BOJIKIAN, MARTINS, TEIXEIRA, MASSA \& KISS, 2001; BOMPA, 1985, 2000; BURWITZ, MOORE \& WILKINSON, 1994; FERNANDES FILHO \& ABRAMOVA, 1997; FILIN \& VOLKOV, 1998; FRANCHINI, 1999; HEBBELINCK, 1989; HOHMANN \& SEIDEL, 2003; LANARO FILHO, 2001; MAIA, 1996; MALINA, 1997; MARQUES, 1991, 1993; MASSA, 1999; MATSUDO, 1996, 1999; MORAES, DURAND-BUSH \& SALMELA, 1999; RÉGNIER, SALMELA \& RUSSEL, 1993; SALMELA \& MORAES, 2003; SOBRAL, 1993; TANAKA \& BERTI, 1998), havendo consenso quanto à carência de estudos presentes nesta área.

Neste sentido, um dos maiores obstáculos da ciência em relação a essa problemática é a natureza desses processos. Ao penetrar no contexto que envolve a promoção de talentos para o esporte de alto nível, depara-se com uma imensa complexidade de fatores (relativos ao contexto biopsicossocial) por vezes não imaginados e extremamente relevantes para o sucesso do processo.

Porém, enquanto isso, na atuação prática, ainda é comum que esses processos sejam norteados apenas pela própria experiência e intuição dos técnicos esportivos (HEBBELINCK, 1989). Assim, cria-se um referencial de escolha que corre o risco de estar sendo atrelado apenas à consciência empírica de cada técnico, livre de qualquer padrão ou procedimento fundamentado, extremamente simplificado, e perigosamente sujeito a interpretações equivocadas e, pior de tudo, com um fim em si próprias.

Evidentemente, o peso da crítica não deve ser tão contundente a ponto de generalizar toda prática efetuada como desprovida de competência e ausente de sucesso. Muito pelo contrário, alguns técnicos são competentes e merecem ser respeitados em função de seu trabalho, de sua experiência incontestável, de seu 
"olhar" e, sobretudo, pelo mérito comprovado nos resultados obtidos. São verdadeiros "experts" e, sem a menor dúvida, detentores de um conhecimento inestimável em relação à especificidade da modalidade esportiva em que trabalham.

Mesmo assim, se por um lado a prática empírica, inconsistente e equivocada de alguns técnicos pode trazer prejuízos incalculáveis para a promoção de talentos, por outro a prática vitoriosa do "expert" também possui a dicotomia de não se tornar mais acalentadora. Ou seja, apesar de seu resultado ter o poder de satisfazer a anseios imediatos, no que tange ao processo de promoção do talento pode colaborar para a permanência da mesma lacuna (resultado X processo). Salvo quando tais resultados são precedidos de uma rotina metodológica consistente, fundamentada, multifatorial, de acompanhamento cíclico e contínuo, provida de avaliações e registros, em longo prazo. Isto é, quando o resultado é fruto de um "motivo" e não apenas do "acaso".

É simples notar isso, o Brasil possui resultados internacionais em diversas modalidades esportivas, o que denota alguma competência e, mesmo assim, não se observam na literatura científica, nas confederações e federações, ou mesmo nos clubes, estudos sistemáticos sobre a evolução dos atletas em variáveis relativas ao crescimento, desenvolvimento, maturação, treinamento e desempenho e, tão pouco, da interação entre esses processos, o que seria fundamental para o estabelecimento de critérios fundamentados em cada modalidade esportiva (BÖHME, 1996; HEBBELINCK, 1989; MASSA, 1999).

Ademais, até se pode questionar sobre a existência de algum arquivo confiável (banco de dados) que possa fornecer dados retrospectivos sobre os atletas que passaram por processos de treinamento a longo prazo (TLP) e chegaram ao alto desempenho esportivo. Se existem, estão dispersos, inconsistentes, incompletos, desorganizados, esquecidos e desprezados. Não foram compartilhados na comunidade acadêmica e esportiva, se transformaram em arquivo morto.

Neste sentido, um trabalho realizado por VIEIRA, VIEIRA e KREBS (1999), a respeito da trajetória de desenvolvimento de um talento esportivo brasileiro, reflete essa carência de estudos, onde o mesmo reserva-se a uma análise retrospectiva sobre um estudo de caso, que, através de depoimentos colhidos por meio de entrevistas semi-estruturadas e material de revistas (com o próprio atleta, 
familiares e técnicos) busca reconstruir como teria sido a trajetória de desenvolvimento do talento.

Assim, conforme MASSA (1999):

A busca de talentos tem apoiado-se em fatores subjetivos, pelos quais os profissionais que atuam nessa área utilizam como instrumento de detecção, seleção e promoção de talentos a própria experiência e intuição. $\mathrm{Na}$ verdade, muitos desses profissionais e até "pseudo-profissionais" têm que se adaptar (seja pela carência de estudos nessa área, pela má formação ou até pela falta de formação) a uma situação em que, através da tentativa e do erro, buscam chegar a um caminho próximo do que eles "acham" correto.

Mais recentemente, mesmo diante de um modelo de desenvolvimento do esporte tradicionalmente classificado como assistemático (MATSUDO, 1999), o governo brasileiro, através do Ministério do Esporte, tem procurado incentivar o desenvolvimento de pesquisas científicas e tecnológicas na área do esporte, treinamento e aperfeiçoamento de atletas. Neste sentido, algumas Instituições de Ensino Superior devidamente capacitadas e com recursos humanos, físicos e materiais disponíveis para este fim, foram avaliadas e intituladas pelo Ministério do Esporte como Centros de Excelência Esportiva (CENESP), com o objetivo de detectar, selecionar e desenvolver talentos, especialmente nas modalidades olímpicas e paraolímpicas (CENTRO..., 2005).

Outra ação recente do Ministério do Esporte, por intermédio da Secretaria Nacional de Esporte de Alto Rendimento, é o programa denominado "Descoberta do Talento Esportivo", que possui a finalidade de identificar jovens e adolescentes matriculados na rede escolar que apresentam níveis de desempenho motor compatíveis com a prática do esporte de competição e de alto rendimento. Para tanto, o programa baseia-se na avaliação de variáveis cineantropométricas (ex. estatura, peso, envergadura, flexibilidade, força, agilidade, velocidade e resistência). Neste sentido, os dados colhidos serão lançados em um programa de computador, que compara com as informações dos atletas campeões, em cada modalidade, apontando os possíveis talentos 
esportivos. Por sua vez, serão destacados os $2 \%$ melhores resultados e migrados para o banco de dados, chamado Banco de Talentos. O Banco de Talentos será disponibilizado para confederações, federações, clubes e demais entidades que possuem equipes esportivas. Por conseguinte, a Rede CENESP fará 0 acompanhamento dos talentos absorvidos pelo Banco de Talentos (DESCOBERTA..., 2005).

Assim, estas iniciativas do Ministério do Esporte podem contribuir para o processo de seleção e promoção do talento esportivo. Contudo, alguns problemas ainda permanecem:

- o programa não democratiza oportunidades para que a grande maioria da população tenha o acesso garantido a um processo de formação esportiva geral básica, fundamental para a elaboração de um programa completo de desenvolvimento de talentos;

- o programa não prevê melhorias nas estruturas físicas, materiais e de recursos humanos nas escolas públicas, cerceando o direito da maioria da população se desenvolver em seus ambientes;

- o programa desconsidera que alguns jovens podem prevalecer nos testes em função de uma maior experiência na tarefa e não de um potencial comprovado;

- o programa desconsidera que algumas variáveis observadas não se comportam de maneira estável durante o processo de crescimento, desenvolvimento e maturação. Portanto, prematuramente, se pode excluir futuros potenciais e incluir no programa jovens com potenciais momentâneos, colocando em dúvida a eficácia do método adotado;

- de acordo com o objetivo do programa, caso haja êxito, antes mesmo de se pensar na inclusão democrática da população, apenas uma minoria de $2 \%$ terá acesso a uma estrutura esportiva devidamente preparada para o desenvolvimento do talento, demonstrando o caráter elitista da ação.

Por outro lado, o processo de promoção de talentos e o treinamento a longo prazo (TLP) quando bem estruturados, possuem como objetivo elementar a formação esportiva de futuras gerações de atletas para o esporte de rendimento, considerando-se o intervalo compreendido entre as categorias de base e o esporte 
de alto nível, desempenhando papel fundamental no processo de detecção, seleção e promoção de talentos esportivos. Para tanto, há necessidade de procedimentos sistêmicos, devidamente fundamentados, durante todo processo de treinamento a longo prazo (BÖHME et alii, 2001).

Outro fator que merece ser comentado, é que o esporte de alto nível pertence a um contexto multifatorial em que abordar uma única variável de maneira unilateral pode ser um grande engano (ABBOTT \& COLLINS, 2004; BÖHME, 2001; HEBBELINCK, 1989; MASSA, 1999). Alguns autores, mesmo diante de um campo de estudo que ainda carece ser desbravado, já têm demonstrado a sua preocupação, buscando tratar o esporte dentro deste prisma de características biopsicossociais. BÖHME (1996) propôs o desenvolvimento de um projeto longitudinal de detecção, seleção e promoção de talentos esportivos preocupado com a determinação de critérios de desempenho relacionados a aspectos biopsicossociais, no entanto o mesmo foi desenvolvido somente nos aspectos cineantropométricos; DE ROSE JUNIOR (1993) tem levantado a importância da observação psicológica no esporte de alto nível; hoje as equipes de alto nível têm demonstrado grande interesse em associar técnicos e preparadores físicos a uma equipe multiprofissional (psicólogos, nutricionistas, fisioterapeutas, médicos, etc.) para tentar obter o melhor de cada atleta em cada variável que possa trazer a melhoria do seu desempenho.

Assim, além da complexidade descrita diante dos processos de promoção de talentos, eis que surge um outro problema, ou seja, o trabalho de analisar este contexto envolvido por múltiplas variáveis também se torna algo de desafiador para o pesquisador do esporte.

A maioria dos estudos realizados com o esporte interpretam seus resultados através de análises univariadas que não respeitam a complexidade do fenômeno e, sobretudo, a "importância" e a interação entre as distintas variáveis (BÖHME et alii, 2001; MASSA, 1999; MASSA, BÖHME, UEZU, SILVA \& TANAKA, 2000; MASSA, TANAKA, BERTI, BÖHME \& MASSA, 1999). Um exemplo clássico desse fato é a proposta metodológica de detecção de talentos apresentada por MATSUDO, RIVET e PEREIRA (1987), chamada "Estratégia-Z CELAFISCS", que continua sendo difundida na literatura da área (MATSUDO, 1996, 1999) sem nenhuma alteração, atualização ou proposta em relação ao seu modelo original. Tal 
procedimento de análise "fragmenta o atleta" em várias partes, sem considerar que o desempenho é produto da interação destas partes. Além disso, essa interação entre as partes não pode ser dada através de um simples somatório ou ser deixada a encargo de interpretações e combinações subjetivas. Aliás, intercorrer nessa prática é a demonstração mais precisa da falta de capacidade das análises univariadas diante da complexidade desses processos. Ou seja, até um determinado ponto as análises univariadas auxiliam, após, tudo deve correr novamente por conta do empírico.

Conforme o estudo de MASSA (1999), as análises univariadas podem corroborar com os processos de promoção de talentos, todavia não oferecem maiores perspectivas para o entendimento da complexidade que envolve estes processos, sendo limitadas para este fim.

Neste sentido, MASSA (1999), MASSA et alii (1999), TANAKA e BERTI (1998), verificaram, através do emprego de análises multivariadas, que em grupos altamente seletos como o de atletas envolvidos em processos de promoção de talentos, parece não existir "pesos" iguais entre as variáveis e, estes "pesos", quando observados, tem demonstrado se alternar de posição durante os períodos de crescimento, desenvolvimento, maturação e treinamento, parecendo indicar que para se determinar qual atleta possui uma melhor combinação de variáveis não basta apenas observá-las lado a lado, mas sim entender como as mesmas se distinguem, combinam e geram melhores desempenhos nos diferentes períodos do processo de treinamento a longo prazo (TLP).

Atualmente, seguindo esta tendência de análise, alguns estudos realizados no Laboratório de Desempenho Esportivo/ Grupo de Estudos e Pesquisa em Esporte e Treinamento Infanto-Juvenil da Escola de Educação Física e Esporte da Universidade de São Paulo (LADESP/ GEPETIJ - EEFEUSP), vem sendo apresentados buscando interpretar os processos de promoção de talentos de acordo com sua premência multifatorial, destacando a utilização de análises multivariadas como elemento fundamental e perspectivo de acompanhamento dos processos de promoção de talentos (BÖHME et alii, 2001; MASSA, 1999; MASSA et alii,1999, 2000; SILVA, MARI, UEZU, BÖHME \& MASSA, 2000). 
Embora passos iniciais e satisfatórios estejam sendo encaminhados através destes estudos, os mesmos ainda não incorporam em seus delineamentos observações psicológicas, sociais e até mesmo relativas a aspectos como a inteligência e a técnica específica para o desempenho naquela modalidade. Assim, a maioria destes estudos têm considerado em seus modelos multivariados as variáveis de crescimento físico, composição corporal e desempenho motor.

Um outro fator relevante que deve ser considerado, é a necessidade de elaboração de estudos de acompanhamento com dados longitudinais, pois, em programas de promoção de talentos, deve-se atentar que previsões de aptidão são aceitas como válidas, em geral, por apenas dois a quatro anos (HEBBELINCK, 1989) e, portanto, devem ser observadas como parte de um processo evolutivo e conter constantes revisões, formando um processo contínuo, cíclico e a longo prazo (BÖHME, 1994; RÉGNIER, SALMELA \& RUSSEL, 1993).

Conforme SENF (1990), esse processo cíclico e contínuo de avaliações deve-se principalmente à variabilidade morfológica, funcional e psíquica do período pubertário, não permitindo que se façam previsões mais consistentes e duradouras neste período do crescimento e desenvolvimento humano, reforçando a necessidade de acompanhamentos longitudinais.

No entanto, devido a essa complexidade que envolve o esporte de alto nível, tomou-se o cuidado de, no presente trabalho, delimitar o campo de estudo. Assim, a abrangência deste trabalho limita-se aos aspectos referentes à análise (a) dos modelos de desenvolvimento do talento esportivo presentes na literatura e (b) das trajetórias de judocas olímpicos brasileiros. Ou seja, foi seguido um caminho de análise centrado numa abordagem retrospectiva valiosa e pontual da trajetória de atletas que confirmaram o alto desempenho e o talento esportivo. Nesta perspectiva, é possível verificar e analisar, em confronto com a literatura pertinente, os caminhos desenvolvidos por esses atletas desde a iniciação na modalidade esportiva em questão até as estruturas físicas, materiais e pessoais de desempenho, o apoio de pais, familiares, professores e treinadores.

Portanto, com referência aos pressupostos abordados, é que surgiu a problemática desta pesquisa com relação ao processo de promoção de talentos esportivos brasileiros, onde se pretende discutir as seguintes questões: 
a) Qual a natureza dos modelos de desenvolvimento do talento apresentados na literatura?

b) Quais as relações existentes entre os modelos de desenvolvimento do talento esportivo e a realidade brasileira?

c) Como é o desenvolvimento de judocas olímpicos brasileiros?

d) Qual a relação entre a trajetória de judocas olímpicos brasileiros e os modelos de desenvolvimento do talento descritos na literatura?

\section{$1.2 \quad$ J ustificativa}

1. Carência de pesquisas realizadas sobre a análise dos modelos de desenvolvimento do talento;

2. Inexistência de estudos que permitam o levantamento e a análise da trajetória de judocas brasileiros talentosos relacionada aos modelos de desenvolvimento do talento.

\section{$1.3 \quad$ Objetivos}

Com o propósito de buscar subsídios para entender e auxiliar o processo de detecção, seleção e promoção de talentos esportivos no judô, foram considerados os seguintes objetivos:

a) Analisar o desenvolvimento de judocas olímpicos brasileiros.

b) Analisar a relação entre o desenvolvimento de judocas olímpicos brasileiros e os modelos de desenvolvimento de talento descritos na literatura. 


\section{REVISÃO DE LITERATURA}

Em função do propósito deste estudo, que é a análise dos modelos de desenvolvimento de talento presentes na literatura e a sua relação com a trajetória de judocas olímpicos brasileiros, preliminarmente foram abordados na revisão de literatura os aspectos históricos específicos e contextuais que permeiam o debate sobre o termo talento e os modelos de desenvolvimento de talento. Posteriormente, foram abordados os aspectos relativos ao desenvolvimento do talento esportivo, ao treinamento de longo prazo e à caracterização do judô.

\section{$2.1 \quad 0$ Talento}

A temática do talento tem sido considerada em diferentes áreas do conhecimento humano. Esta relevância pode ser observada em contextos relacionados às áreas da psicologia, educação, administração de empresas (recursos humanos), matemática, artes e inclusive no esporte.

Recentemente, confirmando a premência do tema, uma revista de atualidades destinada ao grande público brasileiro, ancorou em sua matéria de capa o tema talento, considerado sob o prisma do mercado de trabalho (LIMA, 2004).

Embora seja um assunto que desperte a atenção da comunidade em geral e dos estudiosos, na elaboração teórica e no domínio do significado do talento existem considerações distintas e sobreposições que trazem no seu bojo a problemática que cerca a determinação do termo talento. Neste ínterim, atrelados, emergem significados que remetem o talento a abordagens relacionadas aos termos aptidão e dom.

Conforme FERREIRA (1996), no sentido etimológico, talento origina-se do grego tálaton e do latim talentu, apresentando o significado de "peso e moeda da antigüidade grega e romana", "aptidão natural ou habilidade adquirida" e "inteligência excepcional, engenho". Por sua vez, a palavra aptidão origina-se do latim aptitudine, que significa "disposição inata; habilidade ou capacidade resultante de 
conhecimentos adquiridos". Já dom, origina-se do latim donu, significando "dote ou qualidade natural inata".

No contexto da psicologia, talento é a "denominação geral para o dom natural” (BÖHME, 2004). Neste sentido, no Dicionário Oxford da Língua Inglesa, a diferenciação entre os termos dom e talento é dificultada, pois "dom é uma capacidade natural ou talento - talentoso por natureza", sendo que "talento é uma forma particular de poder natural de fazer alguma coisa bem" (BÖHME, 2004).

Conforme BÖHME (2004), na linguagem popular denomina-se talento o indivíduo que possui uma aptidão específica acima da média em determinado campo de ação ou aspecto considerado, a qual é possível de ser treinada e desenvolvida. De acordo com HAHN ${ }^{1}$ (1982) apud BEYER (1987), numa pessoa talentosa as estruturas neurofisiológicas e anatômicas, assim como as capacidades motoras e psicológicas estão presentes no nascimento, podem ser detectadas no processo de socialização e serem estimuladas e desenvolvidas no meio onde está inserida, desde que este forneça condições para tal.

Desta maneira, de acordo com as apresentações supracitadas, aptidão, talento e dom sobrepõem-se em seus significados e parecem termos interrelacionados, envolvendo conceitualmente os aspectos inatos (naturais) do ser humano mas, porém, considerando em seu desenvolvimento e manifestação (do talento) a dependência da interação favorável com o meio ambiente.

Neste sentido, para GUENTHER (2000), denomina-se como talento pessoas com atributos ou características admiradas e valorizadas pela cultura e pelo momento histórico. BÖHME (1994) e CSIKSZENTMIHALYI, RATHUNDE e WHALEN (1997) acrescentam que além de valores culturais, na caracterização do talento, deve-se considerar a constituição individual herdada ou adquirida, e as condições sociais. A proporção que cada uma das características inatas, adquiridas, sociais e culturais exerce sobre a formação de um talento, bem como suas inter-relações, faz parte da problemática do tema e causa divergências entre os pesquisadores.

Historicamente, conforme CSIKSZENTMIHALYI, RATHUNDE e WHALEN (1997), a palavra talento tem origem bíblica. De acordo com a história, talento era

\footnotetext{
${ }^{1}$ E. Hahn, Kindertraining, München, VLB Verlagsgesellschaft, 1982.
} 
uma unidade monetária, uma moeda de valor amplamente utilizada na época. Ademais, o termo talento possui um significado metafórico, o qual deriva-se da Parábola dos Talentos (Mateus, 25) do Novo Testamento, na qual Jesus discorre sobre a estória de um fazendeiro que, saindo para uma viagem, deu para cada um de seus três empregados alguns talentos, que "todo homem deve usar de acordo com suas habilidades", acrescentando que deveriam fazer um bom uso dos mesmos. Quando o fazendeiro retornou de sua viagem, pediu aos empregados para prestarem contas dos talentos que haviam recebido. Os dois primeiros dobraram as moedas que receberam, enquanto o terceiro, que teve medo de perder a soma recebida, escondeu as mesmas num lugar seguro e devolveu-as ao fazendeiro. $O$ fazendeiro elogiou os dois empregados que utilizaram a maior parte de seus talentos e repreendeu aquele que simplesmente guardou os mesmos.

Embora a cultura atual seja distinta em relação a da época, alguns elementos da Parábola dos Talentos refletem atitudes com relação às diferenças individuais das habilidades humanas. Há o respeito de que algumas pessoas, nas distintas áreas do conhecimento humano, variando desde a música, dança, literatura, esporte, matemática, ciência, xadrez ou aquisição de línguas estrangeiras, diferenciam-se umas das outras, apresentando uma maior facilidade para desenvolver e alcançar a excelência em determinado campo de ação. Muitos também acrescentam, fundamentalmente, que não só a quantidade de dom inicial deva ser considerado, mas também o que cada pessoa faz do mesmo. Neste sentido, um dom natural que não é aperfeiçoado durante a vida pode ser desperdiçado, como a oportunidade do último empregado de aumentar o seu talento (CSIKSZENTMIHALYI, RATHUNDE \& WHALEN, 1997; GUENTHER, 2000; HOWE, 1999).

Entretanto, desde o início da história das civilizações os filósofos especulavam sobre a origem dos altos atributos individuais como beleza física, sabedoria, capacidade poética, habilidades em trabalhos manuais e força. A idéia presente na época era de que esses atributos fossem "dons dos deuses" e que "os deuses não concediam mais que um dom para cada pessoa". Desta maneira, esta perspectiva permaneceu no pensamento grego, sendo a intervenção divina substituída pelas causas naturais e, desde então, a existência de altas habilidades 
tem sido atribuída mais a presença de um dom do que a experiência (ERICSSON \& CHARNESS, 1994).

Corroborando com o delineamento de que talento é um dom natural, sobre os atributos dos artistas, conforme ERICSSON e CHARNESS (1994), há o registro do trabalho clássico de Vasari, publicado em 1568, denominado The Lives of the Artist, o qual propagava a idéia de que "o artista é alguém providencialmente nascido com uma vocação do céu, designado para o reconhecimento, remuneração e respeito". Nos séculos posteriores, com as mudanças e a mobilidade social, o surgimento da classe média, o progresso e o acúmulo do conhecimento científico, tornou-se gradualmente mais evidente que os indivíduos poderiam aumentar o seu desempenho através da educação e do treinamento, se tivessem motivação, objetivo e direcionamento.

Deste momento em diante, começaram a surgir as especulações sobre a natureza do talento. Emergia a preocupação em distinguir realizações devidas a dons naturais de outras realizações resultantes de aprendizagem e treinamento (BÖHME, 2004; ERICSSON \& CHARNESS, 1994).

Neste sentido, Sir Francis Galton foi o primeiro cientista, no século XIX, a investigar empiricamente a possibilidade de que a excelência em distintos campos e domínios tivesse uma série comum de causas. Através da análise de homens eminentes e seus parentes, numa ampla variação de domínios, Galton argumentou que três fatores devem estar presentes: capacidade inata, ânsia para trabalhar e um poder adequado de fazer muito trabalho laborioso. Posteriormente, devido à importância dos dois últimos fatores - motivação e esforço - os investigadores concentraram-se em demonstrar que, primariamente, as capacidades e talentos inatos são necessários para o alcance dos mais altos níveis de desempenho. Desta forma, Galton reconheceu o papel necessário mas não auto-suficiente da instrução e da prática para o alcance de desempenhos excepcionais (BÖHME, 2004; ERICSSON \& CHARNESS, 1994).

Assim como Galton, outros pesquisadores contemporâneos geralmente assumem que o treinamento pode afetar alguns componentes do desempenho, mas pode não afetar outros. Se o desempenho obtido após treinamento extensivo é limitado por componentes que não podem ser modificados, é adequado afirmar que 
fatores estáveis, geneticamente determinados, determinam o nível final de desempenho. Se todas as mudanças possíveis de desempenho relacionadas com o treinamento são obtidas após um período limitado de prática, logicamente as diferenças finais de desempenho devem refletir talentos inatos e capacidades naturais (BÖHME, 2004; ERICSSON \& CHARNESS, 1994).

No final do século XX, Howard Gardner, um dos mais proeminentes e influentes cientistas desta época (ERICSSON \& CHARNESS, 1994; HOWE, 1999), apresentou uma série de publicações sobre o desenvolvimento psicológico do ser humano, propagando a teoria conhecida como Teoria das Inteligências Múltiplas (GARDNER, 1996, 1999, 2002), onde propôs sete inteligências: lingüística, musical, espacial, lógico-matemática, corporal cinestésica, interpessoal e intrapessoal, cada uma num sistema independente com sua própria base biológica. Acerca do desempenho extraordinário de artistas, cientistas e atletas, Gardner delineou evidências para uma teoria biológica de talento, definindo-o como "um sinal de um potencial precoce biopsicossocial em um domínio particular". Assim, "o aspecto principal do talento deixa de ser mais a estrutura inata (dom), mas o potencial de alcance e a capacidade de aprender material relevante para determinada inteligência rapidamente" (BÖHME, 2004; ERICSSON \& CHARNESS, 1994; HOWE, 1999).

\subsubsection{Modelos de desenvolvimento de talento}

De acordo com BÖHME (2004), uma característica marcante do ser humano é sua admirável diversidade bio-psico-motora, decorrente de aspectos hereditários e da interação destes com o meio ambiente. Esta gama multifacetada de potenciais é uma característica da estratégia adaptativa da espécie humana, que no decorrer da história evolucionária permitiu desenvolver a capacidade de adaptação do homem nas diferentes condições que o meio ambiente oferece, assim como nas diferentes áreas do conhecimento humano, seja na ciência, na arte, na matemática ou no esporte.

Assim, conforme abordado no item anterior, estudos mais recentes sobre o talento ainda revelam em seu bojo a inquietação acerca da dicotomia e/ou da 
interação entre as parcelas do inato e do adquirido (ERICSSON \& CHARNESS, 1994; HOWE, 1999), porém têm apontado para importância das influências ambientais e da motivação como aspectos centrais para o desenvolvimento de talento.

Diante desta inquietação, uma pergunta que começa a ser realizada com maior freqüência por parte daqueles que estudam o fenômeno de talento, revelando o respeito pela interação com as oportunidades do meio, tange a abordagem sobre os aspectos que poderiam explicar como o talento se desenvolve numa área específica do conhecimento.

Para MORAES, DURAND-BUSH e SALMELA (1999), corroborando com os demais autores citados, é preciso discutir em relação a literatura existente o que diz respeito ao desenvolvimento de uma área específica de um conhecimento, dando ênfase no impacto que determinadas forças de apoio poderiam estar provocando neste processo. Conforme o levantamento realizado pelos mesmos autores, pesquisadores contemporâneos têm afirmado que o talento adquirido é o maior responsável pela realização do alto desempenho. Acrescentam ainda, que vários estudos têm apontado para a importância de fatores como nutrição, influências ambientais e motivação, como elementos centrais para o bom envolvimento do processo de desenvolvimento de talento.

Neste sentido, visando permitir uma melhor observação dos modelos de desenvolvimento de talentos, os itens seguintes compreenderão a apresentação dos distintos autores e modelos que têm contribuído para a discussão deste campo de conhecimento.

\subsubsection{Modelo de Bloom}

Em meados da década de oitenta, uma publicação significativa veio contribuir com a discussão acerca da temática do talento. Numa obra intitulada "Developing talent in young people", de autoria de Benjamin S. Bloom, foi apresentado um trabalho de investigação do desenvolvimento de talento em jovens (BLOOM, 1985). 
Antes mesmo de se fazer qualquer apresentação sobre os detalhes do estudo de Bloom, adiantando a essência do trabalho, cabe observar que o próprio título da obra carrega o pensamento revelado de que o talento pode ser desenvolvido.

O delineamento da investigação de BLOOM (1985), compreendeu um estudo longitudinal de duração de quatro anos, contando com a participação de uma amostra intencional (selecionada) de 86 homens e 36 mulheres, considerados talentos em suas respectivas áreas de conhecimento e que haviam atingido o alto desempenho antes dos 35 anos de idade. Respeitando os domínios específicos da área de conhecimento, foram escolhidos pianistas de concerto, escultores, matemáticos, pesquisadores neurológicos, nadadores olímpicos e tenistas.

O que Bloom pretendia com essa abordagem, era obter elementos que permitissem investigar se 0 alto desempenho atingido era conseqüência de treinamento e encorajamento ou se estava apenas relacionado aos talentos naturais dos sujeitos.

Para tanto, BLOOM (1985) utilizou como recurso metodológico de exploração do universo de desenvolvimento do talento, a aplicação de entrevistas que carregaram em seu bojo os seguintes aspectos determinantes:

1) Características físicas, intelectuais e outras evidentes e relevantes características individuais relativas ao período precoce do desenvolvimento do talento.

2) O papel da família na orientação e suporte do talento desde os anos precoces até os últimos estágios de desenvolvimento do talento.

3) O tipo e a qualidade da instrução e orientação disponível no campo individual do talento em diferentes estágios do seu desenvolvimento.

4) As fontes e os tipos de motivação e recompensa, bem como circunstâncias especiais de encorajamento e suporte para o indivíduo em diferentes estágios do seu desenvolvimento.

5) A importância do tempo diligente (ativo) de aprendizagem e prática, bem como de outros esforços de aprendizagem investidos pelo indivíduo em cada estágio do seu desenvolvimento. 
6) Quaisquer outros fatores individuais considerados como relevantes para sua descoberta, desenvolvimento e encorajamento em relação ao campo particular do desempenho.

7) A maneira através da qual os indivíduos desenvolveram hábitos, interesses e valores que aumentaram o comprometimento no seu capo especial de talento e o levaram aos limites da aprendizagem em cada campo.

Conforme as considerações de BLOOM (1985), na amostra observada, a qualidade do apoio foi o fator principal para o progresso em direção ao alto desempenho e consolidação do talento. Desta forma, a evolução do desempenho de cada criança era dependente da quantidade de estímulos que recebia de pais, professores de qualidade, treinadores, mentores e de ambientes satisfatórios de desenvolvimento.

O autor ainda acrescenta que estes fatores devem ser considerados críticos no decorrer do processo de aprendizagem, até que se alcance o alto grau de desempenho numa área específica de conhecimento.

Neste sentido, em relação à qualidade do apoio creditada como relevante para manifestação do talento, o modelo de BLOOM (1985) apresenta três fases distintas que marcaram o processo de evolução do talento em todos os grupos:

(1) Anos iniciais de aprendizagem: período de introdução a prática de várias atividades divertidas e prazerosas, no qual as crianças aprenderam a gostar das atividades. Neste período as crianças receberam apoio e incentivo considerável dos pais, professores e treinadores. O interesse pela atividade foi fundamental para a permanência da criança neste estágio inicial e para alcançarem o próximo estágio de desenvolvimento, dependendo fortemente do apoio e da orientação de técnicos e professores. Era nesse período que as crianças começavam a ser vistas e rotuladas como aparentemente especiais ou talentosas. Conforme Bloom, para muitas crianças, esse contexto parecia agir como um fator motivacional relevante para o desenvolvimento da área de interesse 
futuro. Outra característica interessante que deve ser ressaltada, é que ainda que os professores e treinadores não fossem os mais tecnicamente habilidosos, sob o ponto de vista do trabalho com crianças eram profissionais extremamente capacitados e forneciam reforços afetivos positivos às necessidades inerentes ao período da infância, mantendo a aprendizagem e o desempenho nas atividades.

(2) Anos intermédios de aprendizagem: entre 11 e 15 anos de idade muitos praticantes atingiram níveis até mais altos de desempenho, obtidos através da prática que se tornava mais intensa. Estes jovens adolescentes demonstravam maiores graus de concentração e comprometimento com as metas, devido a permanência do apoio dos pais, treinadores e professores. De acordo com Bloom, era nesse período que os adolescentes eram absorvidos em suas atividades prediletas e iniciavam uma prática deliberada que passava a ser o foco central desta fase da aprendizagem. É preciso destacar, neste momento, que o sustento moral e financeiro dos filhos era de papel dos pais e que tal apoio garantia a aderência direcionada dos adolescentes em relação aos aspectos motivacionais da aprendizagem, a realização, o comprometimento, o sacrifício e o tempo de prática deliberada, fundamentais nesse estágio.

(3) Anos finais de aprendizagem: período caracterizado por uma prática mais diligente, específica e com o foco voltado para a busca da perfeição e do sucesso. Conforme Bloom, foi uma fase onde o empenho e a concentração dominou a vida dos futuros talentos. As realizações e esforços dentro de um domínio específico do conhecimento discriminaram graus de desempenho excepcionais de outros menos elevados. Ademais, os talentos apresentavam em sua rotina a mudança freqüente para ter acesso aos melhores professores, treinamentos e ambientes competitivos mais apropriados. Por sua vez, neste estágio, os professores e treinadores 
sempre buscavam motivar e elaborar atividades que pudessem promover desafios crescentes e, consequentemente, permitir maiores graus de prática, direcionados para o sucesso futuro. Entretanto, de acordo com Bloom, nem todos os adolescentes conseguiam atingir esse grau de desempenho e desistiam por vários motivos. Contudo, os mais persistentes e dedicados, atingiam graus elevados de desempenho.

Embora pareça haver coerência entre as fases descritas no Modelo de Bloom, o autor complementa que no decorrer do percurso entre as fases os jovens se deparavam com inúmeras situações negativas. Estas situações eram fomentadas pelo ambiente de desenvolvimento escolhido pelos próprios jovens, que conseqüentemente mantinham altas expectativas, intensa demanda de treino e competitividade extrema. Ademais, para alguns sujeitos, os fatores econômicos familiares e/ou institucionais eram escassos durante o percurso e muitos não conseguiam associar um trabalho complementar na rotina de treinos diários, aumentando a pressão para a obtenção do sucesso.

Desta maneira, é possível notar que a trajetória de desenvolvimento dos talentos investigados nem sempre esteve necessariamente associada à experiências prazerosas. Conforme BLOOM (1985), as situações negativas oriundas do processo de desenvolvimento do talento contribuem para uma mudança do estado-de-espírito, com extensões psicológicas capazes de gerar índices elevados de desistência do envolvimento na área específica de interesse.

Outro fator relevante da investigação de BLOOM (1985), é que do total de 120 sujeitos participantes do estudo, poucos foram considerados crianças talentosas por seus professores, treinadores e familiares; e mesmo aqueles considerados talentosos em idades iniciais, posteriormente não foram capazes de demonstrar desempenho comparável a pessoas talentosas maduras numa determinada área de conhecimento. Isto contribui para o pensamento de que ser considerado um talento precoce não é garantia de sucesso, altos desempenhos e talento futuro. Portanto, a demonstração do talento precoce deve ser interpretada como um estágio inicial do desenvolvimento do talento. Associados a essa interpretação de precocidade, o 
sujeito carecerá de aderência a um processo de desenvolvimento de longo prazo, do contrário esse sujeito ficará cada vez mais distanciado dos demais sujeitos talentosos que continuaram se aperfeiçoando no domínio específico do conhecimento.

Numa análise realizada por MORAES, DURAND-BUSH e SALMELA (1999), a respeito do Modelo de Bloom, os autores corroboram e enfatizam que o sucesso de uma pessoa talentosa depende do seu comprometimento, motivação e paixão pela sua área de atuação e, ao mesmo tempo, do apoio de diversos segmentos da sociedade como, a própria família, bons mentores e professores e também bons treinadores no caso do esporte.

\subsubsection{Modelo de Csikszentmihalyi}

CSIKSZENTMIHALYI, RATHUNDE e WHALEN (1997), numa publicação intitulada "Talented Teenagers: the roots of success \& failure", estudaram por um período de cerca de quatro anos, 116 garotas e 92 rapazes, todos adolescentes de grupos pertencentes aos domínios específicos da matemática, arte, esporte, música e ciência. O objetivo do trabalho foi compreender possíveis causas para o sucesso e o fracasso destes adolescentes.

Conforme se observa no título da obra, os adolescentes em questão já eram considerados talento e, portanto, a investigação teria o teor de entender os motivos que poderiam confirmar ou rejeitar a determinação do alto desempenho futuro. Desta maneira, corroborando com BLOOM (1985), CSIKSZENTMIHALYI, RATHUNDE e WHALEN (1997) estavam interessados em averiguar fatores comportamentais, pensamentos e experiências que estes sujeitos teriam atingido até a fase que Bloom denominou de "anos intermédios de aprendizagem". A idéia básica do estudo, portanto, era observar o desenrolar das experiências contínuas destes jovens para compreender como eles desenvolviam seus talentos.

De acordo com CSIKSZENTMIHALYI, RATHUNDE e WHALEN (1997), o talento pode ser melhor observado sobre a perspectiva desenvolvimentista ao invés de um fenômeno do tudo ou nada. Neste sentido, no lugar de assumir apenas 
características genéticas herdadas e imutáveis durante a vida, o talento estaria associado a processos de desdobramentos duradouros, que levam muitos anos, e que podem ser alterados pelas experiências vivenciadas no meio.

Desta maneira, crianças podem ser consideradas talento apenas como indicativo de um potencial futuro. Para alcançar este potencial, elas têm que aprender como desempenhar os padrões do "estado-da-arte" e encontrar oportunidades de utilizar seus talentos para que depois suas habilidades sejam desenvolvidas (CSIKSZENTMIHALYI, RATHUNDE \& WHALEN, 1997). Conforme os autores, as condições históricas sempre afetam o fluxo do talento. Algumas vezes, um determinado domínio possui um suporte social atraente e promissor para o talento se desenvolver. Entretanto, alguns anos depois o suporte pode ser retirado e o sujeito pode ficar desprovido da possibilidade de encontrar um trabalho e/ou um ambiente que permita desenvolver, de acordo com as suas potencialidades, o seu talento.

Sendo assim, o Modelo de Csikszentmihalyi concentrou como foco de seu desenvolvimento a interação entre indivíduos, domínios e áreas. Como conseqüência desta pesquisa os autores apresentaram um modelo denominado de Fluxo de Experiência Ótima ("Flow"). Neste modelo, dois conceitos são relatados: a integração e a diferenciação. A integração refere-se às condições facilitadoras para que a criança resolva um problema. Durante a resolução desse problema a criança perde a noção do tempo, ignora a fadiga e qualquer outro agente que interfira na atividade. Já a diferenciação, refere-se às dificuldades proporcionadas com a intenção de causar desafios e mudanças que exigirão novas adaptações. O equilíbrio entre a integração e a diferenciação está na motivação das crianças para superar os desafios frente à dificuldade exigida.

Ademais, O Fluxo de Experiência Ótima parece coerente à importância da prática deliberada como elemento responsável pelo desenvolvimento do talento, bem como os outros princípios sugeridos, a saber:

(i) Nenhum adolescente desenvolve seu talento sem uma recompensa imediata ou a longo prazo;

(ii) Nenhum adolescente desenvolverá talentos se ele ou ela não se divertirem trabalhando nessa área; 
(iii) Nenhum adolescente pode evitar os conflitos inerentes ao desenvolvimento do talento;

(iv) A escola é um espaço essencial para se cultivar talentos, sendo ainda um lugar peculiar para desenvolvê-los;

(v) Nenhuma criança chega ao sucesso se não for apoiada por adultos.

Portanto, conforme MORAES, DURAND-BUSH e SALMELA (1999), a respeito do Fluxo de Experiência Ótima e dos conceitos de integração e diferenciação (CSIKSZENTMIHALYI, RATHUNDE \& WHALEN, 1997), as crianças precisam de um amplo repertório de estímulos para se manterem no nível de motivação necessário para a execução de novas tarefas e assim continuar desenvolvendo suas potencialidades em relação a um determinado domínio.

Neste sentido, os estudos de BLOOM (1985) e CSIKSZENTMIHALYI, RATHUNDE e WHALEN (1997) se aproximam na medida em que em ambos a maioria das crianças começava a instrução com um professor local e posteriormente, quando em níveis superiores de desempenho, absorviam o impacto positivo e motivacional de mentores, professores e treinadores cada vez mais qualificados. A motivação estabelecida nesse apoio era capaz de gerar e desenvolver comportamentos de autodisciplina e confiança, fundamentais para o confronto diante dos obstáculos inerentes ao processo de aprendizagem. Sendo assim, conforme os estudos de BLOOM (1985) e CSIKSZENTMIHALYI, RATHUNDE e WHALEN (1997), as crianças eram estimuladas a praticarem uma gama variada de atividades que as motivassem a superar diferentes obstáculos e ao mesmo tempo tinham prazer em executá-las.

Tais aspectos podem ser associados entre os dois autores em relação aos períodos iniciais da aprendizagem apresentados por BLOOM (1985), que corroboram com os processos de integração e diferenciação propostos no Fluxo de Experiência Ótima apresentado por CSIKSZENTMIHALYI, RATHUNDE e WHALEN (1997) e reconhecem o papel relevante que as forças de apoio exercem no processo.

Outro ponto comum e que merece destaque entre os trabalhos de BLOOM (1985) e CSIKSZENTMIHALYI, RATHUNDE e WHALEN (1997), está relacionado à problemática presente no registro de que muitos estudantes excelentes 
não puderam desenvolver seus talentos devido a presença de fatores contextuais inadequados em uma área, limitando o desenvolvimento de suas potencialidades e o sucesso futuro. Em algumas situações as tarefas ficavam muito difíceis de realizar devido a carência de informação e preparo por parte de professores e treinadores inseridos e disponíveis naquele domínio de conhecimento específico, prejudicando o desenvolvimento do mesmo. Conforme CSIKSZENTMIHALYI, RATHUNDE e WHALEN (1997), o isolamento de muitos jovens estudantes talentosos de biologia, matemática e física fizeram com que eles desistissem do processo, pois trabalhavam sozinhos nos laboratórios. Por sua vez, no esporte e na arte os fatores negativos inerentes à competição ocorriam em detrimento do processo de desenvolvimento de alguns jovens promissores.

Portanto, em síntese, instituições e centros de aprendizagem podem exercer influência favorável no desenvolvimento do talento quando a integração contextual positiva do ambiente, determinada pela composição de cada área e o tipo de informação alocada dentro de cada domínio específico, está presente e ocupa caráter fundamental sobre o processo aprendizagem.

\subsubsection{Modelo de Ericsson}

Ainda sobre o debate permanente da visão social histórica de que o alto desempenho é obtido através de um dom natural transmitido geneticamente, ERICSSON, KRAMPE e TESCH-RÖMER (1993) e ERICSSON e CHARNESS (1994) contestam essa perspectiva de maneira extremista. Os referidos autores, em detrimento das heranças genéticas, preconizam o papel fundamental que a prática deliberada exerce sobre a aquisição do alto desempenho. Nesta ótica, ao refutar a crença social de que o talento é inato, acrescentam que o desempenho ótimo pode ser alcançado a partir de um processo de desenvolvimento de 10 anos ou 10.000 horas de prática intensiva. Neste sentido, procurando se fundamentar em pesquisas recentes, os autores afirmam que características anatômicas (ex.: tamanho do coração, componentes metabólicos contráteis dos músculos, entre outros) e psicológicas podem ser alteradas com a prática intensa e que os resultados 
alcançados nos Jogos Olímpicos não estão atrelados a uma evolução genética, mas a uma melhor estrutura do treinamento esportivo.

Os estudos de ERICSSON, KRAMPE e TESCH-RÖMER (1993) com amostras de sujeitos violonistas e pianistas demonstraram que a prática deliberada exerce papel determinante na diferenciação da qualidade entre os músicos. Conforme os resultados encontrados, quanto maior o número de horas de prática, melhor a qualidade do músico. Os autores acrescentam, corroborando com BLOOM (1985) e CSIKSZENTMIHALYI, RATHUNDE e WHALEN (1997), que as características inatas identificadas de forma prematura não são determinantes na carreira de um futuro talento, mas alguns fatores como as condições do ambiente, o suporte familiar, a motivação do praticante e a pré-disposição para a prática, associados à prática deliberada, são fundamentais para a promoção de um talento.

Em um outro estudo realizado acerca da prática deliberada, HELSEN, STARKES e HODGES (1998) investigaram amostras de atletas adultos de futebol e de hockey. Para o delineamento da pesquisa, os atletas foram divididos entre os grupos internacional, nacional e provinciano. Para a avaliação da prática deliberada foi considerado o total de horas acumuladas ao longo da carreira e das horas de prática por semana com a equipe e individualmente. Os resultados apuraram que os atletas de futebol começaram a jogar com cinco anos de idade e foram encontradas diferenças significativas entre os três grupos aos 12 e 13 anos de carreira na prática individual. Em relação à prática coletiva, foram encontradas diferenças significativas a partir dos 12 anos de carreira entre os três grupos. Após 18 anos de carreira os atletas internacionais somaram 9332 horas, os nacionais 7449 horas e os provincianos 5079 horas de prática. Por sua vez, os atletas de hóquei começaram a jogar com nove anos de idade e foram encontradas diferenças significativas aos 15 anos de carreira do nível internacional para o nacional e o provinciano na prática individual. Não foram encontradas diferenças significativas do nível nacional para o provinciano durante toda a carreira na prática individual. Em relação à prática coletiva, foram encontradas diferenças significativas entre o nível nacional e provinciano aos seis e nove anos de carreira. Aos 12 anos de carreira o nível internacional e nacional não apresentaram diferença, mas ambos apresentaram diferença significativa em relação ao nível provinciano. Somente aos 18 anos de 
carreira os três níveis apresentaram diferenças significativas. Após 18 anos de carreira, os jogadores internacionais somaram 10233 horas, os nacionais 9147 horas e os provincianos 6048 horas de prática. Conforme a amostra utilizada no estudo, os autores acrescentam que as horas de prática junto à equipe têm que possuir um peso elevado na prática deliberada, pois a prática individual não é tão determinante para modalidades esportivas coletivas como deve ser para as modalidades individuais e para violinistas e pianistas, de acordo com observado no estudo de ERICSSON, KRAMPE e TESCH-RÖMER (1993).

É possível relatar ainda, que o estudo de HELSEN, STARKES e HODGES (1998) apresenta valores totais que parecem comprovar a teoria da prática deliberada. Entretanto, quanto às horas de prática coletiva e individual, só houve diferença significativa entre os 12 e 13 anos de carreira no futebol e aos 15 anos de carreira no hóquei na prática individual, sendo que o nível nacional e provinciano não apresentou diferença ao longo de toda a carreira. Já na prática coletiva, houve diferença significativa após 12 anos de carreira para os jogadores de futebol e após os 18 anos de carreira para os jogadores de hóquei. Nesse sentido, DAVIDS, LEES e BURWITZ (2000) sugerem a elaboração de estudos que refutem a prática deliberada. Os estudos buscariam atletas com alto desempenho e poucas horas de prática, assim como, atletas com baixo desempenho e muitas horas de prática.

Corroborando com os pressupostos de BLOOM (1985) e CSIKSZENTMIHALYI, RATHUNDE e WHALEN (1997), ERICSSON, KRAMPE e TESCH-RÖMER (1993) também se reportaram a diversas restrições que podem exercer influência crítica para o alcance do alto desempenho. Entre as restrições citadas, pode-se destacar: (a) a restrição de recursos, que refere-se à quantidade de tempo e energia disponíveis, bem como à possibilidade de acesso a recursos físicos, materiais, ambientais e pessoais como instalações, professores e treinadores; (b) restrição de esforço, que se refere ao empenho e ao envolvimento individual que exige por parte do jovem um processo de dedicação total capaz de prover o acúmulo da quantidade necessária de prática deliberada e, por sua vez, por parte dos professores e treinadores, exige o conhecimento preciso e a capacidade de controlar adequadamente os aspectos relacionados à quantidade e à qualidade dos estímulos de aprendizagem prestados na busca do desenvolvimento do talento. $E$ (c), a 
restrição de motivação, que se refere ao reconhecimento de que o processo de treinamento não é inerentemente prazeroso ou imediatamente recompensado. Algumas vezes, jovens talentosos se mantinham motivados diante do processo em função da percepção de que a prática deliberada, mesmo não oferecendo necessariamente uma recompensa imediata, poderia oferecer um apoio instrumental extremamente representativo para a evolução em direção ao alto desempenho. Durante o processo espera-se que ocorram algumas formas de recompensa a longo prazo, capazes de manter a prática e a melhoria do desempenho. Neste sentido, a perseverança e a aplicação do jovem para continuar melhorando o desempenho em tarefas desafiadoras são fundamentais para o desenvolvimento do processo da prática deliberada.

Neste sentido, conforme MORAES, DURAND-BUSH e SALMELA (1999) e apoiado nas colocações de BLOOM (1985), CSIKSZENTMIHALYI, RATHUNDE e WHALEN (1997), ERICSSON, KRAMPE e TESCH-RÖMER (1993), os treinadores e professores envolvidos na especificidade de um determinado domínio devem estar sensíveis ao declínio potencial da motivação e aos possíveis efeitos negativos que se manifestam durante o processo de aprendizagem e que podem restringir o desenvolvimento no decorrer dos estágios de transição do talento.

Sendo assim, embora a prática deliberada se demonstre como um processo atraente e democrático quanto às potencialidades dos seres humanos, a idéia de que apenas uma grande quantidade de prática é capaz de levar qualquer sujeito ao alto desempenho, sem levar em consideração a genética, parece incomodar aqueles que respeitam a origem puramente inata do talento ou mesmo aqueles que apoiam a interação entre o inato e o adquirido. Na prática, seria possível observar inúmeros exemplos de indivíduos cujo desempenho parece nunca ou pouco evoluir, mesmo com mais de 10 anos de prática constante. Portanto, parece ser sensato guardar cautela quanto à hipótese pura de que apenas o tempo de treinamento leva ao alto desempenho. Ademais, em relação ao esporte, existem diferenças significativas entre as distintas modalidades esportivas e os seus pressupostos de desempenho, que merecem ser estudados, analisados e considerados para uma planificação do processo de aprendizagem e treinamento. Desta maneira, diante da carência de pesquisas neste campo de conhecimento, 
estudos sobre a trajetória de atletas de alto desempenho merecem ser considerados de acordo com as especificidades de cada modalidade esportiva, evitando-se assim os riscos de generalizações e permitindo a evolução das pesquisas dentro de um determinado domínio.

Contudo, conforme SALMELA e MORAES (2003), no que tange a prática deliberada, outro fator que merece ser considerado é a característica contextual presente em um determinado país para o desenvolvimento específico de uma modalidade esportiva. Assim, os países de Primeiro Mundo podem prover um ambiente mais democrático e rico, formado por professores habilidosos e pais comprometidos com os processo de desenvolvimento dos filhos. Por sua vez, os países em desenvolvimento podem ser diferentes quanto aos aspectos educacionais e financeiros.

Especificamente no Brasil, de acordo com SALMELA e MORAES (2003), se pode comentar sobre o sucesso de atletas que não são treinados por um técnico qualificado, que não possuem acesso a treinamentos formais, que não utilizam de apoio financeiro adequado e tão pouco usufruem de apoio consistente dos pais. Mesmo diante deste contexto teoricamente inconsistente, estes atletas perseguem a excelência esportiva em modalidades que podem gerar benefícios financeiros futuros e que são de fácil acesso, baixo custo, alto grau de conhecimento popular e, consequentemente, que permitem o emprego de estratégias não estruturadas de instrução, passíveis de serem aplicadas por algum companheiro, facilitando o aprendizado (ex.: futebol brasileiro).

Utilizando o exemplo do futebol brasileiro, mesmo com pouco ou nenhum treinamento estruturado, crianças e adolescentes dedicam todo o seu tempo jogando futebol informal, por vezes sem bola e calçado adequados e, invariavelmente, num campo de futebol adaptado. Mesmo assim, conforme SALMELA e MORAES (2003), os jovens brasileiros praticam o futebol de forma apaixonada e espontânea, promovendo um processo de auto-aprendizagem em forma de "futebol Darwiniano", onde apenas o melhor sobrevive.

Portanto, diferentemente do Modelo de BLOOM (1985) ou mesmo das colocações de ERICSSON, KRAMPE e TESCH-RÖMER (1993) acerca da prática deliberada, este tipo de influência contextual observada em países em 
desenvolvimento (como o caso do Brasil), pode suprir, ou até superar, os benefícios de um treinamento devidamente estruturado e planejado (SALMELA \& MORAES, 2003), evidenciando a dificuldade de se estabelecer um modelo universal de desenvolvimento do talento que tenha valor para ser aplicado em todos os países e que possa ser extrapolado para todas as modalidades esportivas.

Desta maneira, verificar o processo no qual os judocas olímpicos brasileiros se desenvolveram parece ser fundamental para que se possa observar e discutir a natureza do contexto de desenvolvimento do talento nesta modalidade.

\subsection{0 talento esportivo e o treinamento a longo prazo}

Assim como o debate genérico do talento abordado nos itens anteriores deste trabalho, com apoio nos modelos teóricos de desenvolvimento apresentados por estudiosos da área da psicologia em diferentes domínios do conhecimento (BLOOM, 1985; CSIKSZENTMIHALYI, RATHUNDE \& WHALEN, 1997; ERICSSON, KRAMPE \& TESCH-RÖMER, 1993), a temática do talento esportivo também tem chamado atenção específica daqueles que trabalham e pesquisam no ambiente do esporte de alto nível (BÖHME, 1994, 2000, 2002, 2004).

MARQUES (1993) em um artigo relacionado à temática específica do talento esportivo, define que talento é um indivíduo que apresenta características biopsicossociais, que diante de determinadas situações deixa antever com segurança a possibilidade de adquirir altos desempenhos.

Também se reportando ao talento esportivo, BENTO (1989) sintetiza que este pode ser entendido como um fato complexo, determinado qualitativa e quantitativamente de características individuais para desempenhos, abrangendo várias capacidades interrelacionadas, sistemas de conhecimento, atitudes, qualidades evolutivas e psíquicas e que, em condições ambientais favoráveis, otimizam a realização de desempenhos correspondentes ao nível e direção do talento.

Desta forma, corroborando com as discussões de BLOOM (1985), CSIKSZENTMIHALYI, RATHUNDE e WHALEN (1997), ERICSSON, KRAMPE e 
TESCH-RÖMER (1993) e considerando as características genéticas, pode-se compreender que talento é um complexo de fatores biopsicossociais que depende tanto de constituições herdadas como de disposições motoras, cognitivas e afetivas favoráveis, desenvolvidas em condições sociais e ambientais adequadas.

De acordo com o dicionário de esporte SCHÜLLERDUDEN SPORT (1987), ao conceituar os principais termos envolvidos na área de determinação de talentos esportivos, o talento depende tanto da constituição herdada como dos fatores sociais e ambientais, ou seja, se uma pessoa talentosa tiver oportunidade de ser estimulada no momento certo e da forma correta, ela poderá apresentar, a longo prazo, resultados acima da média normal da população no aspecto em que é talentosa.

No que diz respeito a aspectos específicos do esporte, pode-se classificar a manifestação do talento em três grupos (SCHÜLLERDUDEN SPORT, 1987; WEINECK, 1991):

- talento motor geral: indivíduos que apresentam facilidade na aprendizagem de movimentos, ocasionando maior facilidade no domínio de movimentos e conseqüente aumento do repertório motor.

- talento esportivo: indivíduos que apresentam potencial acima da média populacional podendo chegar a realizar altos desempenhos esportivos.

- talento esportivo específico: indivíduos que apresentam requisitos físicos e psicológicos prévios para um determinado esporte.

Para BARBANTI (1996), os indivíduos devem ser considerados talentosos quando apresentarem uma aptidão geral elevada para que a aprendizagem seja otimizada, pois são as capacidades motoras que favorecem o desenvolvimento das habilidades motoras.

Logo, para atender as particularidades da modalidade esportiva, passa a ser relevante a presença de um talento esportivo específico. O talento se manifesta ligado à individualidade e se torna melhor quando consegue utilizar as capacidades para desempenhos específicos (BENTO, 1989).

Segundo SCHMIDT (1993), a capacidade deve ser entendida como um traço estável, geneticamente definido, relativamente permanente, não modificada pela prática ou experiência e que é o alicerce, ou sustenta vários tipos de atividades 
motoras ou cognitivas, ou habilidades. As capacidades podem ser consideradas "0 equipamento básico com o qual as pessoas nascem, para executar diversas tarefas do mundo real". Portanto, conforme MAGILL (1980) e SCHMIDT (1993), capacidades são fatores que estabelecem limites para o desempenho, ou seja, todos os indivíduos possuem todas as capacidades, mas as capacidades podem ser mais fortes em alguns indivíduos do que em outros, podendo trazer implicações para o sucesso ou não em uma determinada habilidade. Além disso, tarefas específicas utilizam-se de um conjunto de capacidades para o desempenho e, desta maneira, um mesmo indivíduo pode ser particularmente bom em uma determinada tarefa e ruim em outra, corroborando com o conceito de um talento esportivo específico.

$\mathrm{Na}$ determinação e promoção de um talento esportivo de alto nível é preciso haver conhecimentos de aspectos teóricos que possibilitem direcionar a atuação dos profissionais de Educação Física e Esporte. É através dessa área de atuação que, a longo prazo, serão promovidas as novas gerações de atletas (BÖHME, 1994).

Conforme $\mathrm{JOCH}^{2}$ (1994) apud BÖHME (2000), se pode considerar o talento sobre a perspectiva de dois componentes, o estático e o dinâmico. Conforme o autor, o componente estático compreende quatro fatores: (i) disponibilidade; (ii) disposição, isto é, o poder e a vontade do jovem de realizar e se submeter a um treinamento com o objetivo de desenvolver seu potencial esportivo; (iii) as possibilidades reais presentes no meio ambiente onde está inserido, onde estão incluídas as condições de treinamento a longo prazo - TLP - oferecidas ou não pelo sistema social em que vive, assim como (iv) a apresentação de resultados adequados conforme a etapa do TLP. Por sua vez, o componente dinâmico refere-se ao processo ativo de mudanças biopsicossociais pelos quais o talento transita, em decorrência do seu desenvolvimento; este deve ser conduzido através de treinamento e competição realizados adequadamente, de acordo com princípios e métodos pedagógicos adequados.

\footnotetext{
${ }^{2}$ W. Joch, Das sportliche Talent: talenterkennung - talentförderung - talentperspektiven, Aachen, Meyer und Meyer, 1994.
} 
Portanto, é possível verificar que os componentes e fatores acima destacados por $\mathrm{JOCH}^{2}$ (1994) apud BÖHME (2000) se aproximam dos elementos fundamentais apresentados nos modelos de BLOOM (1985), CSIKSZENTMIHALYI, RATHUNDE e WHALEN (1997), ERICSSON, KRAMPE e TESCH-RÖMER (1993) no que tange a importância da motivação e da vontade em participar de um processo de treinamento associado, sobretudo, a condições ambientais favoráveis num dado domínio e orientação adequada para o desenvolvimento do talento.

Segundo $\mathrm{CARL}^{3}$ (1988) apud BÖHME (1999), para saber se um determinado indivíduo em um determinado tempo pode ou não ser promovido como um talento esportivo de alto nível, é importante que sejam consideradas suas condições pessoais e limitantes de desempenho e sucesso esportivo, assim como suas potencialidades de formação e treinamento esportivo. Portanto, considera-se importante respeitar a totalidade biopsicossocial do esportista na detecção de talentos de alto nível. Neste sentido, RÉGNIER, SALMELA e RUSSEL (1993) salientam que a determinação e desenvolvimento do talento esportivo deve ser observada como um processo contínuo, interrelacionado e cíclico, devendo ser verificadas e combinadas mensurações físicas, psicológicas e habilidades técnicas.

Neste sentido, MARTIN, NICOLAUS, OSTROWSKI e ROST ${ }^{4}$ (1999) apud BÖHME (2002, 2004) apresentaram uma definição operacional de talento esportivo $(\mathrm{T})$, como sendo o resultado individual de um processo dependente das relações temporais existentes $(R)$ entre as disposições genéticas $(d G)$, a idade relacionada com a fase do seu desenvolvimento (iD), as exigências de desempenho esportivo no treinamento $(\mathrm{dT})$, assim como de qualidades psicológicas $(\mathrm{qP})$, as quais são verificadas através de uma aptidão individual acima da média, determinadas através de tarefas esportivo-motoras específicas (testes de aptidão, competição). Esta definição pode ser representada esquematicamente da seguinte forma:

\section{$T=R(d G, i D, D t, q P)$}

\footnotetext{
${ }^{3}$ K. Carl, Talentsuche, Talentauswahl und Talentförderung, Schorndorf, Hofmann-Verlag, 1988.

${ }^{4}$ D. Martin, J. Nicolaus, C. Ostrowski, K. Rost, Handbuch Kinder-und Jugendtraining, Verlag Hofmann, Schorndorf, 1999.
} 
HOHMANN, WICK e CARL (2001) $)^{5}$ apud BÖHME (2004), apresentaram um modelo de talento em esporte como uma relação dinâmica entre o nível individual inicial, o atual e o final de desempenho competitivo. Neste modelo são considerados os potenciais de desenvolvimento, de desempenho e de promoção do talento, assim como a reserva e o estado de desempenho. A descrição deste modelo é apresentada na FIGURA 1.

Essas determinações de talento envolvem tanto o caráter estático como o dinâmico de talento esportivo revelados por $\mathrm{JOCH}^{2}$ (1994) apud BÖHME (2000), levando em consideração as características fenotípicas, as condições de treinamento (volume, intensidade e especificidade), a idade biológica de desenvolvimento, as capacidades motoras, a técnica, a constituição corporal, os componentes psicológicos, ou seja, a motivação, a disponibilidade para o desempenho, esforço e estabilidade psicológica, assim como o suporte social (família, escola, clube, a organização da modalidade esportiva), corroborando neste sentido com BLOOM (1985), CSIKSZENTMIHALYI, RATHUNDE e WHALEN (1997), ERICSSON, KRAMPE e TESCH-RÖMER (1993).

${ }^{5}$ A. Hohmann, D. Wick, K. Carl, Talent in sport, Schorndorf, Verlag Karl Hoffmann, 2001. 


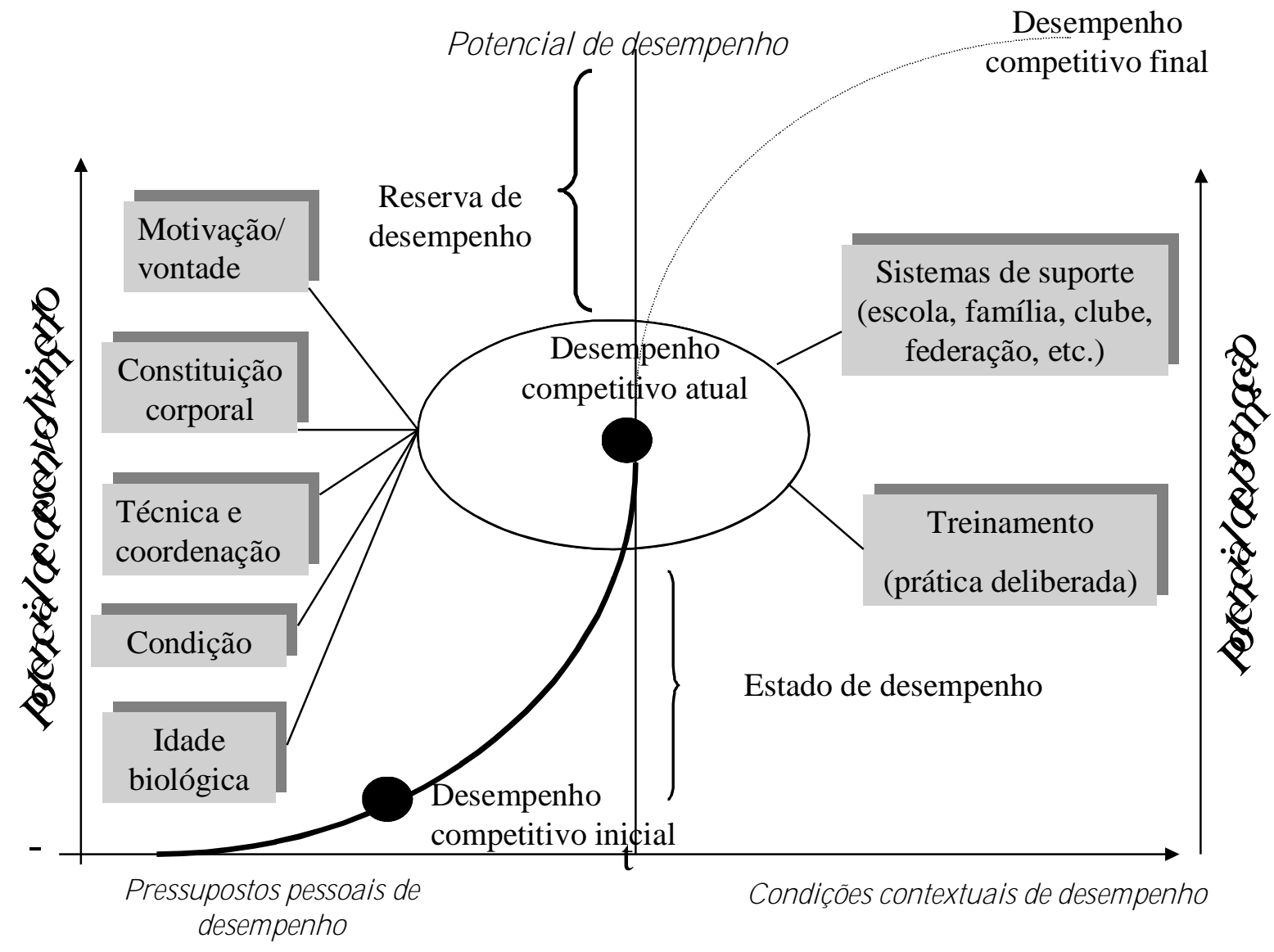

FIGURA 1 - Talento em esporte como a relação dinâmica entre os níveis de desempenho competitivo do indivíduo no início, na atualidade e no final (HOHMANN, WICK \& CARL $^{5}, 2001$ apud BÖHME, 2004).

HEBBELINCK (1989) acrescenta que determinação, busca, seleção e promoção de talentos devem ser não apenas processos complementares, inseparáveis e cíclicos, mas também envolver estágios que incluam desde a seleção em massa (com base em testes de desempenho físico geral) até o desenvolvimento de qualidades específicas a cada modalidade (com base em treinamentos sistemáticos e competições). Assim, observa-se a importância de estratégias que otimizem a identificação e desenvolvimento de talentos. Segundo o próprio autor, "quanto maior a amostra da população para a seleção, maiores serão as chances para a identificação de talentos". 
Para RÉGNIER, SALMELA e RUSSEL (1993), a detecção do talento esportivo está baseada na predição de um futuro desempenho, e essa predição é que permitirá dizer se uma criança ou adolescente de hoje tornar-se-á um futuro atleta, tendo seu desempenho máximo testado em competições que duram duas semanas ou, em alguns casos, poucos minutos e/ou segundos.

Assim, pode-se notar que a trajetória de um atleta de alto nível é valorizada quando este consegue lograr êxito em competições que muitas vezes duram um tempo irrisório (ex.: 100 metros nado livre, torneios de voleibol, combates de judô etc.) frente ao processo de preparação que esse atleta teve que superar para estar ali, naquele momento, disputando os louros de uma conquista. Essa conquista, vista de forma tão imediatista pela sociedade em geral, possui em seu alicerce anos de preparação (muitas vezes desde a infância até a idade adulta), e é justamente com esse período (processo de promoção de talentos) que os profissionais de Educação Física e Esporte devem estar se preocupando e interferindo, de forma fundamentada, para que não só melhores resultados sejam obtidos, mas também que a individualidade das pessoas seja respeitada.

Para SCHMIDT (1993), pode ser simples estimar quem atualmente é bom executante, mas saber quem após o crescimento, maturação e o treinamento adicional irá tornar-se o mais eficiente é algo consideravelmente mais difícil de predizer. Segundo o autor, o processo de predição requer que se conheça quais capacidades são importantes para a tarefa critério (ex.: futebol, voleibol, judô) e qual processo envolve a medida ou estimativa das capacidades presentes nos vários candidatos, podendo decidir quem entre os candidatos possui o padrão de capacidades fundamentais que corresponde mais completamente à habilidade critério. Conforme MAGILL (1980), o método seria conhecer com exatidão quais capacidades estão mais relacionadas com o desempenho de alto nível de uma habilidade bem aprendida e, com base nestes conhecimentos, testar os indivíduos nestas capacidades, para posteriormente receberem treinamento específico na habilidade e desenvolverem o potencial do indivíduo na atividade-alvo.

Desta maneira, para melhor estimar as qualidades de uma criança e/ou adolescente, quando identificadas as potencialidades e particularidades de cada uma, é preciso compará-la com a população em questão, para que seja possível 
fazer uma qualificação da criança dentro dos diferentes níveis de talento esportivo existentes, quais sejam: competição escolar, municipal, estadual, nacional ou internacional (BÖHME, 1994).

De acordo com o abordado neste item do trabalho e com as nuanças que emergem do tema talento, existem também presentes na procura do talento esportivo quatro fatores que merecem um maior esclarecimento, pois são aspectos considerados fundamentais para o sucesso do trabalho, ou seja, as fases de: determinação, detecção, seleção e promoção do talento esportivo (HEBBELINCK, 1989) que serão apresentadas conforme os tópicos seguintes.

\subsubsection{Determinação do talento esportivo}

A determinação do talento esportivo:

...baseia-se nas evidências abstratas e discussões teóricas que resultam na descrição e identificação de possíveis condições e características que possam identificar, caracterizar as pessoas como talento esportivo dentro da população (GABLER \& RUOFF, 1979).

Com relação aos critérios utilizados na prática para a determinação do talento no esporte, ainda há um longo caminho a ser percorrido. Diversos profissionais ainda fazem da experiência e da intuição os dois únicos métodos utilizados para a determinação de talentos e, portanto, um método altamente subjetivo, sem consistência e insuficiente para a devida promoção do talento.

Segundo GABLER e RUOFF (1979), na determinação fundamentada do talento esportivo, dois problemas importantes devem ser considerados: primeiro, o problema dos critérios de desempenho, e segundo, o problema do prognóstico de desempenho.

O problema dos critérios de desempenho baseia-se na determinação de cada característica de desempenho que o atleta deve possuir e que permitirá a ele obter um alto desempenho no esporte considerado. Para tanto, é importante observar a complexidade que envolve as características a serem verificadas na determinação de um talento esportivo. Pode-se citar: fatores constitucionais, sociais, 
físicos e psicológicos e a dependência da capacidade de desempenho da idade biológica, os quais, para WEINECK (1991), devem ser considerados como critérios de desempenho no diagnóstico ou determinação da aptidão do indivíduo a ser avaliado como possível talento esportivo.

O problema do prognóstico de desempenho do talento esportivo, que pode ser entendido como uma previsão fundamentada do maior desempenho individual possível de ser atingido em uma determinada modalidade esportiva, referese a obter fatos do passado ou do presente do atleta que permitam tornar a detecção de talentos esportivos mais segura, ou seja, toma-se contato com conhecimentos biopsicossociais e dados sobre o desenvolvimento individual do atleta, objetivando a predição do mais alto desempenho (BÖHME, 1996).

Portanto, o problema da determinação do talento esportivo requer estudos que possibilitem caracterizar as diferentes modalidades esportivas nos aspectos biopsicossociais com o objetivo de encontrar critérios de desempenho para a determinação da aptidão e, assim, favorecer um prognóstico precoce e fiel da futura capacidade de desempenho esportivo.

Neste sentido, alguns autores como HEBBELINCK (1989) e WEINECK (1991) destacam que qualquer técnico iria preferir seguir um catálogo de critérios específicos a cada modalidade para a identificação de talentos. No entanto, ainda existe uma carência de estudos que permitam definir as características das diferentes modalidades e assim poder catalogá-las segundo aspectos interdisciplinares, ou seja, aspectos específicos a cada modalidade e que basicamente envolvem qualidades morfológicas, biomecânicas, fisiológicas e psicológicas.

Desta forma, considerando-se todos estes fatores, é possível verificar que a dificuldade de identificar um atleta que apresente características específicas a uma modalidade é grande, principalmente quando não se dispõe ou não se utiliza de conhecimentos que permitam fazer algum tipo de previsão mais apurada. Portanto, a dificuldade aumenta à medida que não se conta com a ajuda de medidas, testes e padrões de referência para a avaliação dos atletas que estão envolvidos em treinamento sistemático. PRETO (1990) ressalta que no processo de TLP, a importância da avaliação reside nas operações que se podem efetuar após posse 
dos dados provenientes de qualquer situação de avaliação. A avaliação é a arte que respeita os julgamentos cientificamente efetuados de acordo com algumas normas preestabelecidas. Sendo assim, numa seqüência de ações de testagens contínuas passa a ser possível identificar certas características em atletas que podem vir a ser necessárias para a determinação, detecção, seleção e promoção do talento esportivo.

\subsubsection{Detecção do talento esportivo}

Conforme RÉGNIER, SALMELA e RUSSEL (1993), a detecção do talento esportivo refere-se à tentativa de encontrar características inatas ou com efeito do desenvolvimento e treinamento, através de fatores antropométricos, físicos, fisiológicos e psicológicos. De acordo com os autores, nos estudos acerca da detecção de talentos, dois conceitos são empregados: o "Top Down" e o "Bottow Up". O conceito "Top Down" refere-se à utilização de uma teoria, desconsiderando-se pressupostos práticos e o conceito "Bottow Up", refere-se à utilização de pressupostos práticos para a elaboração de uma teoria, independente de conhecimentos anteriores. Embasados nos modelos de autores da área de detecção de talentos, RÉGNIER, SALMELA e RUSSEL (1993) sugerem que:

a) O desempenho deve ser avaliado levando-se em conta as diferentes modalidades esportivas;

b) As mudanças no desempenho devem ser interpretadas, considerando-se o crescimento e desenvolvimento, bem como, o efeito do treinamento;

c) A hereditariedade possui um caráter determinante nos estudos de detecção do talento esportivo;

d) Os estudos devem ser multidisciplinares e as análises multivariadas.

Por sua vez, conforme BÖHME (1995), a detecção do talento esportivo baseia-se na utilização de medidas e meios que permitam encontrar um número suficientemente grande de pessoas que se mostrem dispostas a participar de um 
programa de formação esportiva geral básica - considerado como primeira etapa do TLP. Neste sentido, MARQUES (1991) corroborando com BÖHME (1995) e HEBBELINCK (1989), uma forma de otimizar os processos de detecção de talentos esportivos é propiciar a prática esportiva para um número cada vez maior de pessoas, independentemente da classe social que ocupem. Ademais, ao considerar que o talento possui uma aptidão individual para o desempenho esportivo acima da média, o diagnóstico da aptidão pode ser considerado o principal problema da detecção de talentos esportivos.

Portanto, uma grande base esportiva é um fator que auxilia e melhora a possibilidade de uma boa detecção de atletas de alto nível. Segundo MARQUES (1991), não é recomendável ter o foco de detecção de talentos centralizado apenas nos clubes; é preciso que existam observações e estudos mais abrangentes que envolvam sobretudo as escolas, principalmente nas fases iniciais, por se tratar de um espaço por onde, se não todas, a grande maioria das crianças passa, o que faz da escola um local privilegiado e promissor para a detecção de talentos. Pode-se dizer ainda que esta observação não se deve restringir apenas àquelas crianças que participam das competições escolares, mas também obter o maior número de dados envolvendo todo o conjunto de crianças que participam das aulas de Educação Física.

Neste sentido, corroborando com MARQUES (1991), HOHMANN e SEIDEL (2003) afirmam que o primeiro passo do processo de detecção de talentos deve estar voltado para crianças que ainda não estejam envolvidas com procedimentos de treinamento sistemático.

HEBBELINCK (1989) acrescenta que para a escola cumprir com essa expectativa de tornar-se um foco de detecção de talentos esportivos é preciso que as crianças, desde os primeiros anos de vida, tenham possibilidade de acesso a programas de atividades físicas variadas e Educação Física, permitindo assim a implementação dos processos de seleção de talentos. Nesse sentido, corroborando com BLOOM (1985), CSIKSZENTMIHALYI, RATHUNDE e WHALEN (1997) e ERICSSON, KRAMPE e TESCH-RÖMER (1993), BENTO (1989) aponta uma ampla função da escola, que abrangeria desde a fase das descobertas das potencialidades 
e deficiências de cada criança, até os processos de seleção de talentos esportivos e o preparo específico para uma determinada modalidade esportiva através do TLP.

No entanto, no Brasil, observa-se que a quase totalidade dessas instituições citadas como elementos otimizadores da busca de novos talentos, ou seja, a escola, os clubes e as escolas de esporte, não possuem atualmente uma estrutura (física e pessoal) e/ou uma política de ação coerente às necessidades e interesses da criança (GRECO, 1997). O que predomina nesse campo de atuação é um número ainda muito grande de erros dentro do processo de formação. Especializa-se no esporte muito cedo, exigem-se altos níveis de desempenho mesmo em idades precoces e, como será colocado a seguir, tais fatores acabam limitando o sucesso da busca de novos talentos.

Neste sentido, em relação ao estabelecimento de um sistema que possa subsidiar o processo de TLP e a formação do talento esportivo, o procedimento chamado "pirâmide esportiva" pode ser verificado em países que possuem uma estrutura esportiva sistemática e que visam resultados obtidos através do TLP. Esses países podem ser divididos em dois tipos de sistemas: o sistemático estatal e o sistemático não estatal. Países como Cuba e a antiga URSS, utilizam ou utilizaram o programa sistemático estatal, no qual o estado é responsável direto pela monitorização do talento esportivo. Já os Estados Unidos e o Japão, utilizam o programa sistemático não estatal, em que as universidades e as empresas são responsáveis pela formação do talento esportivo (MATSUDO, 1999; MATSUDO \& MATSUDO, 1997).

No caso específico do Brasil, o programa verificado é o assistemático, no qual estado, empresas, clubes e a própria família, dividem a responsabilidade de subsidiar a estrutura esportiva para o talento esportivo (MATSUDO, 1999; MATSUDO \& MATSUDO, 1997). Sendo assim, até o presente momento, não há no Brasil uma política esportiva e consequentemente uma estrutura esportiva de TLP. O desempenho esportivo é monitorado através de uma visão imediatista, ou seja, o que interessa é o resultado naquele momento. Poucos atletas têm a oportunidade de chegar ao alto nível na mesma instituição. Em muitos casos, a trajetória de um atleta de alto nível acaba sendo equivocadamente árdua, pois ele tem que passar pelas 
chamadas "peneiras" em poucos clubes que as oferecem e que, em sua maioria, utilizam apenas o técnico como norteador do processo.

Neste sentido, ao se deparar com uma visão imediatista de desempenho esportivo, emerge de maneira discrepante um sistema de detecção e seleção de atletas fundamentado somente na elaboração de perfis (com a intenção de utilizá-lo como prognóstico de desempenho esportivo). Desta forma, não existem condições estruturais para um acompanhamento contínuo do processo, e assim, somente os melhores atletas, naquele momento, são detectados e selecionados. Creditar-se-ia a esses atletas atributos momentâneos que seriam suficientes para qualificá-los como futuros talentos esportivos. Essa visão de talento relaciona-se com a herança genética, pois as influências do meio ambiente estariam sendo desconsideradas ou subestimadas.

Por outro lado, o desenvolvimento do talento esportivo deve considerar em seu alicerce o trabalho cíclico e contínuo de todas as qualidades da personalidade dos jovens talentos esportivos através do TLP. Portanto, é necessário que o jovem atleta apresente paciência e esforço, receba métodos pedagógicos de treinamento adequados, assim como apresentação de forma gradativa de sucessos competitivos no decorrer do processo.

\subsubsection{Seleção do talento esportivo}

O processo de seleção do talento esportivo fundamenta-se na denominação dos meios utilizados para a determinação dos indivíduos que têm condições em determinado momento e período, de serem admitidos/aceitos em níveis mais elevados de TLP em determinada modalidade esportiva, o qual objetiva um desempenho esportivo de alto nível $\left(\mathrm{CARL}^{3}\right.$, 1988 apud BÖHME, 1999; GABLER \& RUOFF, 1979; WEINECK, 1991).

Conforme (SENF, 1990), para se conhecer um talento esportivo tornamse necessárias a observação e a avaliação do mesmo; assim, é primordial a existência de um processo de seleção que permita fazer este diagnóstico. Neste processo, três estágios devem ser observados: 
a) no processo inicial de seleção do talento esportivo, não se deve apenas observar as exigências específicas das modalidades esportivas, mas sim procurar obter informações sobre a amplitude da aptidão geral. Isto se aplica ao fato de ser muito difícil, nas fases iniciais, selecionar o tipo ideal de criança que consiga acumular em suas características índices ótimos de qualidades morfológicas, funcionais e psíquicas desejáveis para obter o maior desempenho esportivo em uma modalidade específica. Apenas na puberdade é que se torna possível observar com maior estabilidade os fatores preditores de aptidão para o alto desempenho (HOHMANN \& SEIDEL, 2003; SENF, 1990);

b) nesta fase de seleção do talento esportivo, considera-se importante o processo de avaliação e orientação dos mais capacitados para uma determinada modalidade esportiva (HEBBELINCK, 1989). Devem ser procuradas e avaliadas características de desempenhos que serão úteis para o futuro do talento, ou seja, características que no momento temporal da avaliação já são passíveis de predição e apresentam-se de forma fundamental e, devido a isso, se tornam avaliáveis e demonstram estabilidade no processo de desenvolvimento.

c) é o momento em que se deve, através de normas e tipologias, saber diferenciar e selecionar indivíduos estabelecendo valores discriminantes que favoreçam a identificação dos mais e dos menos aptos para a prática esportiva. Significa desencadear em prática o processo de seleção do talento esportivo.

\subsubsection{Promoção do talento esportivo}

Conforme BEYER (1987), BÖHME (1995) e GABLER e RUOFF (1979) o conceito de promoção do talento esportivo refere-se à utilização de medidas objetivas que venham a favorecer o desenvolvimento de capacidades e habilidades esportivas em jovens talentosos para o esporte, permitindo-lhes a obtenção do seu 
desempenho esportivo ótimo, a longo prazo, de acordo com a modalidade esportiva considerada.

Para LANARO FILHO (2001), a promoção do talento se relaciona diretamente com o desempenho esportivo dos atletas em cada uma das etapas da periodização do TLP. Conforme o autor, este desempenho, quando acompanhado de maneira cíclica e contínua, exercerá papel fundamental na elevação dos atletas a categorias ou equipes de nível superior dentro da modalidade específica.

BÖHME (1995), corroborando com os conceitos apresentados, acrescenta que a promoção do talento esportivo deve envolver condições de treinamento adequadas, com treinadores capacitados para trabalharem no processo de TLP, assim como condições sociais adequadas, desde o micro sistema familiar, a escola e as possibilidades de prática e treinamento esportivo oferecidas pela sociedade onde o jovem talento está inserido.

Assim, de acordo com GROSSER, BRUGGEMANN e ZINTL $^{6}$ (1988) apud GRECO (1997), apenas uma planificação do rendimento a longo prazo (TLP), construída de forma consciente e sistemática faz sentido e pode levar ao êxito, sendo ao mesmo tempo eficaz e humana.

Para BENDA (1998) e VIEIRA e VIEIRA (2000) corroborando com BLOOM (1985), CSIKSZENTMIHALYI, RATHUNDE e WHALEN (1997) e ERICSSON, KRAMPE e TESCH-RÖMER (1993), detectar e revelar talentos é apenas a uma das etapas de um processo contínuo que envolve a elaboração e o planejamento de programas, através dos quais possam ser proporcionadas as melhores condições para o desenvolvimento das potencialidades detectadas, buscando garantir, no futuro, o aprofundamento máximo das suas capacidades e, consequentemente, o melhor desempenho.

Neste sentido, conforme MARQUES (1993), durante os períodos que envolvem o processo de promoção de talentos, cada etapa do TLP deve ser observada considerando-se o referencial da etapa imediatamente superior, pois cada estágio desenvolve os pressupostos para o período seguinte do processo. A exemplo disso, em um estudo realizado por MASSA et alii (1999), com atletas de voleibol

${ }^{6}$ M. Grosser; P. Bruggemann; F. Zintl, Alto rendimiento deportivo: planificación y desarollo, Barcelona, Martinez Roca, 1988. 
envolvidos em processos de promoção de talentos, foi verificado que entre uma categoria inferior e outra imediatamente superior o que discriminava os atletas eram variáveis que se alternavam durante processo. Isto é, não eram as mesmas variáveis que permaneciam ocupando o papel de "relevantes ou críticas". Reforçando, portanto, a colocação de MARQUES (1993), onde se deve considerar cada etapa do TLP, evitando traçar predições diretas entre uma determinada categoria de base e a categoria adulta. Além disso, conforme HEBBELINCK (1989), as predições oferecem uma confiabilidade de até dois a quatro anos, indo de encontro com os demais autores, que defendem a realização de observações e interpretações periódicas durante os processos de promoção de talentos.

Desta maneira, conforme as necessidades inerentes ao processo de promoção de talentos, a iniciação precoce deve ser vista com extrema cautela. Os trabalhos que priorizam resultados a curto prazo, preparação específica precoce, cargas unilaterais, monótonas e intensas de treinamento promovem riscos que afetam o sucesso da promoção de talentos esportivos (MASSA, 1999; RODRIGUES \& BARBANTI, 1994; WEINECK, 1999).

Assim, conforme GUENTHER (2000) e corroborando com BLOOM (1985) CSIKSZENTMIHALYI, RATHUNDE e WHALEN (1997) e ERICSSON, KRAMPE e TESCH-RÖMER (1993), a precocidade parece não ser um sinal confiável para a predição do talento. De acordo com GUENTHER (2000), estudos da área indicam que menos de um terço das pessoas que são consideradas talentosas em algum domínio do conhecimento foram crianças precoces e exemplifica:

a) Einstein: falou apenas com quatro anos e aprendeu a ler aos sete anos;

b) Newton: apresentou desenvolvimento atrasado durante escola primária;

c) Churchil: foi reprovado na sexta série;

d) Tolstoy: não terminou a graduação universitária;

e) Pasteur: foi considerado um aluno medíocre em química durante o período em que freqüentou o Royal College;

Ademais, procedimentos equivocados durante a fase de promoção do talento, podem fazer com que o jovem atleta abandone a prática esportiva devido a alguns fatores como as sobrecargas elevadas sobre os mesmos sistemas, provocando lesões e, com isso, o afastamento ou interrupção definitiva da prática 
esportiva (MARQUES, 1991; WEINECK, 1999); a saturação psicológica devido a quantidades inadequadas e exaustivas de treinamento, que afastam as crianças da atividade (WEINECK, 1999) e, principalmente, conforme MASSA (1999):

Os jovens atletas que não abandonam a prática esportiva, mas que por terem vivenciado a inadequação desses processos - na maioria dos casos sem consciência do ocorrido - acabam por não atingir, no momento que deveria ser 0 ápice da forma física, o seu melhor resultado de desempenho. Ou seja, a criança foi detectada como talento, mas não foi acompanhada, desenvolvida e promovida da forma adequada para que, quando adulta, apresentasse o desempenho prognosticado na infância e/ou adolescência.

Desta maneira, ao pensar no processo de promoção de talentos, encontra-se na especialização precoce um elemento limitante e comprometedor da vida útil do futuro talento, fazendo com que este muitas vezes nem sequer alcance o alto nível.

Portanto, de acordo com o que foi observado nessas quatro fases que discriminam os processos de determinação, detecção, seleção e promoção do talento esportivo, e também com o que foi brevemente abordado sobre os perigos de uma especialização precoce, deve-se destacar e enfatizar a importância de não apenas saber identificar com exatidão os melhores talentos para uma determinada modalidade esportiva, mas principalmente buscar conhecimentos que permitam assegurar, de forma fundamentada, o crescimento e desenvolvimento desses talentos para que os mesmos, através do TLP, tenham condições de exibir o seu mais alto desempenho.

Pelo exposto, os processos de detecção, seleção e promoção do talento esportivo estão diretamente relacionados com as fases do TLP, o qual realizado de forma planejada e sistemática, exerce uma função fundamental na formação de futuras gerações de atletas talentosos para o esporte de rendimento nas diversas modalidades e níveis de competição esportiva. 


\subsubsection{0 processo de treinamento a longo prazo - TLP}

A prática esportiva mundial tem demonstrado que o desempenho esportivo para o alto nível de rendimento só pode ser alcançado, quando os fundamentos relevantes para o mesmo são desenvolvidos durante os períodos da infância e adolescência, o que pressupõe o planejamento sistemático de um processo de TLP (BÖHME, 2000, 2002; WEINECK, 1999).

Desta maneira, o treinamento para o esporte de alto nível, fundamenta-se num processo de TLP com duração média de 6 a 10 anos, conforme a modalidade esportiva considerada. De acordo com a literatura, o processo de TLP (BARBANTI, 1997; BÖHME, 2000, 2002, 2004; BOMPA, 1999, 2000; WEINECK, 1999), pode ser dividido em três níveis:

Primeiro nível : Formação básica geral (entre sete e 12/13 anos de idade) - envolve predominantemente 0 desenvolvimento das capacidades coordenativas; tem por objetivo a melhoria geral do desempenho esportivo, despertar um interesse estável orientado para ações de desempenho em treinamento e competição, e também o conhecimento do esporte escolhido;

Segundo nível: Treinamento específico (entre 13 e 17 anos de idade) possui por objetivo geral a melhoria, planejada a longo prazo, do desempenho esportivo específico da modalidade escolhida, até um nível que possibilite o início do treinamento de alto nível de desempenho; a estabilização de uma motivação para o desempenho voltada para uma determinada modalidade esportiva; e uma participação bem sucedida nas categorias competitivas de idade e desempenho semelhantes. É subdividido em três etapas:

Primeira etapa: treinamento básico ou de iniciantes - tem por objetivos:

- melhorar o estado de desempenho esportivo de modo geral e variado;

- desenvolver as capacidades básicas da modalidade específica e aprender as técnicas básicas de movimento;

- conhecer e experimentar cada método de treinamento da modalidade;

- despertar uma motivação para o desempenho no esporte, no treinamento e competição. 
Segunda etapa: treinamento de síntese ou de adiantados - tem por objetivos:

- melhorar o desempenho esportivo específico da modalidade;

- dominar as técnicas mais importantes do esporte;

- conhecer os métodos de treinamento específicos do esporte;

- estabilizar a motivação de desempenho para o esporte específico;

- participação bem sucedida em competições a nível nacional.

Terceira etapa: treinamento de transição - tem por objetivos:

- aumento dos aspectos de desempenho esportivo passíveis de condicionamento;

- domínio do repertório das técnicas da modalidade esportiva;

- tolerância às cargas de treinamento exigidas nos diferentes ciclos de treinamento;

- participação bem sucedida em campeonatos nacionais e internacionais da mais alta categoria de idade do segundo nível de treinamento;

- perspectiva de alcançar altos desempenhos esportivos no treinamento de alto nível.

Terceiro nível - Treinamento de alto nível (a partir dos 17/ 18 anos de idade) - possui como objetivo geral o alcance do alto desempenho individual; aumento otimizado do volume e intensidade de treinamento; outros métodos e conteúdos específicos de treinamento; a perfeição, estabilização e disponibilidade máxima da técnica esportiva; melhoria e manutenção da mais alta capacidade de desempenho pelo maior período de tempo possível.

Desta forma, procurando estabelecer um referencial padrão das faixas etárias adequadas para cada etapa do TLP, MARTIN ${ }^{7}$ (1988) apud BÖHME (2000) apresentou, de forma genérica, um modelo ideal das idades propícias para cada nível do TLP e, em paralelo, o que costuma ser observado na realidade da prática esportiva (FIGURA 2).

Conforme este modelo, em termos ideais, a formação básica geral, referente ao primeiro nível do TLP, deveria ocorrer no período da grande infância, no

${ }^{7}$ D. Martin, Training im Kindes-und Jugendalter, Schorndorf, Hofmann-Verlag, 1988. 
qual a criança seria estimulada a desenvolver e diversificar a amplitude do seu acervo motor, através de uma gama variada de vivências motoras, ocorrendo de forma simples e combinada. Assim, se deve dar prioridade para o desenvolvimento das capacidades coordenativas, com a utilização da maior variabilidade possível de materiais esportivos (BÖHME, 2000).

Portanto, a escola, através da Educação Física curricular e extracurricular pode ocupar um espaço privilegiado para o desenvolvimento do primeiro nível, ou seja, a formação básica geral, ao lado da ação das demais entidades esportivas, como clubes, academias, centros esportivos municipais e estaduais.

A partir deste ponto, conforme BÖHME (2000), de forma seqüencial, a criança deveria passar por um treinamento básico referente à primeira etapa do segundo nível anteriormente descrito (treinamento básico ou de iniciantes do nível específico), o qual poderia ser na própria escola ou no clube, para posteriormente especializar-se em determinada modalidade, referente às etapas segunda e terceira do nível dois (respectivamente treinamento de síntese ou de adiantados, e, treinamento de transição do nível específico), até alcançar o treinamento de alto nível, ou nível três do TLP.

Entretanto, de acordo com BÖHME (2000), na prática esportiva as etapas se sobrepõem, tendendo a iniciar em idades mais avançadas, devendo o responsável pelo treinamento procurar estratégias que possam compensar as deficiências existentes na formação esportiva dos jovens atletas, que não tiveram a oportunidade de vivenciar cada fase adequadamente (FIGURA 2). 
IDADE

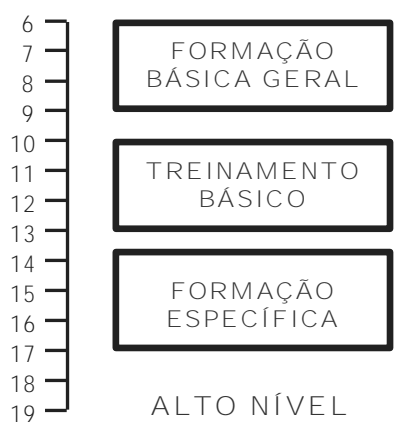

IDEAL
IDADE

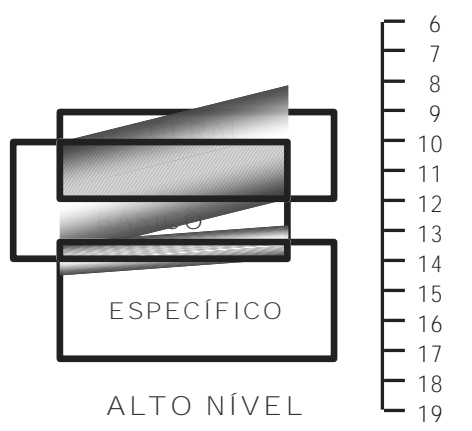

PRÁTICA

FIGURA 2 - Modelo de formação esportiva a longo prazo - MARTIN ${ }^{7}$ (1988) apud BÖHME (2000).

Em relação aos referenciais presentes na literatura brasileira acerca do TLP, GRECO (1997) apresentou um sistema de formação e treinamento esportivo, através do qual o TLP é proposto como uma estrutura temporal. Nesta concepção, o autor descreve nove fases de rendimento esportivo, sendo que (i) a fase universal eqüivale ao nível um; (ii) as fases de orientação, direção, especialização e aproximação ao nível dois; e (iii) a fase de alto nível ao nível três anteriormente apresentados (BARBANTI, 1997; BOMPA, 1999, 2000; MARTIN ${ }^{7}, 1988$ apud BÖHME, 2000; WEINECK, 1999).

Conforme BÖHME (2000), um fator importante da proposta de GRECO (1997) é que ela considera a formação esportiva orientada não só para o esporte de alto nível, como também o encaminhamento da grande maioria dos participantes do processo de TLP para o esporte participativo, de lazer, pois no processo de afunilamento da pirâmide do esporte de alto nível, somente os indivíduos realmente talentosos no Esporte alcançarão o sucesso. Ademais, no modelo proposto, o autor 
também sugere a reintegração do atleta de alto nível no esporte participativo, após o término de sua vida esportiva no esporte de alto rendimento.

Alguns autores russos (FILIN, 1996; MATVEEV, 1997; ZAKHAROV \& GOMES, 1992) propõem quatro níveis para o TLP. FILIN (1996) apresenta os níveis do TLP como: (a) etapa preliminar de preparação, (b) etapa inicial de especialização desportiva, (c) etapa de aprofundamento do desporto e (d) etapa de aperfeiçoamento desportivo; o autor faz também indicações quanto as idades propícias para cada etapa, respeitando-se o gênero e a especificidade de algumas modalidades esportivas. MATVEEV (1997), faz uma descrição semelhante destas fases apresentando: (a) etapa de preparação desportiva prévia, (b) etapa de especialização inicial, (c) etapa de aperfeiçoamento profundo e (d) etapa da longevidade desportiva. Já ZAKHAROV e GOMES (1992), fraciona o mesmo princípio em cinco etapas: preparação preliminar, especialização inicial, especialização aprofundada; resultados superiores e manutenção de resultados.

Neste sentido, de acordo com os distintos referenciais anteriormente descritos acerca do TLP, BÖHME (2000) considera que comparando-se as diferentes fases, níveis ou etapas do TLP descritas na literatura da área de Ciência/Teoria do Treinamento, observa-se que de modo geral os mesmos são semelhantes, porém com terminologias diferenciadas, podendo ser organizados em três principais níveis: de iniciação, infanto-juvenil e de alto nível, correspondentes ao primeiro, segundo e terceiro níveis anteriormente descritos, respectivamente formação básica geral, treinamento específico (com três etapas) e treinamento de alto nível.

Desta maneira é possível associar que processo de detecção, seleção e promoção de talentos esportivos está intimamente relacionado com 0 TLP. HOFMANN e SCHNEIDER ${ }^{8}$ (1985) apud WEINECK (1999) apresentaram um modelo esquemático na forma de pirâmide do processo de seleção e formação esportiva, (FIGURA 3) onde estão representados os papéis dos diferentes segmentos da organização da sociedade, como a escola, o clube e grupos comunitários, assim como os três níveis do TLP, desde a iniciação até o alto nível, e os respectivos períodos médios de duração de cada um. 


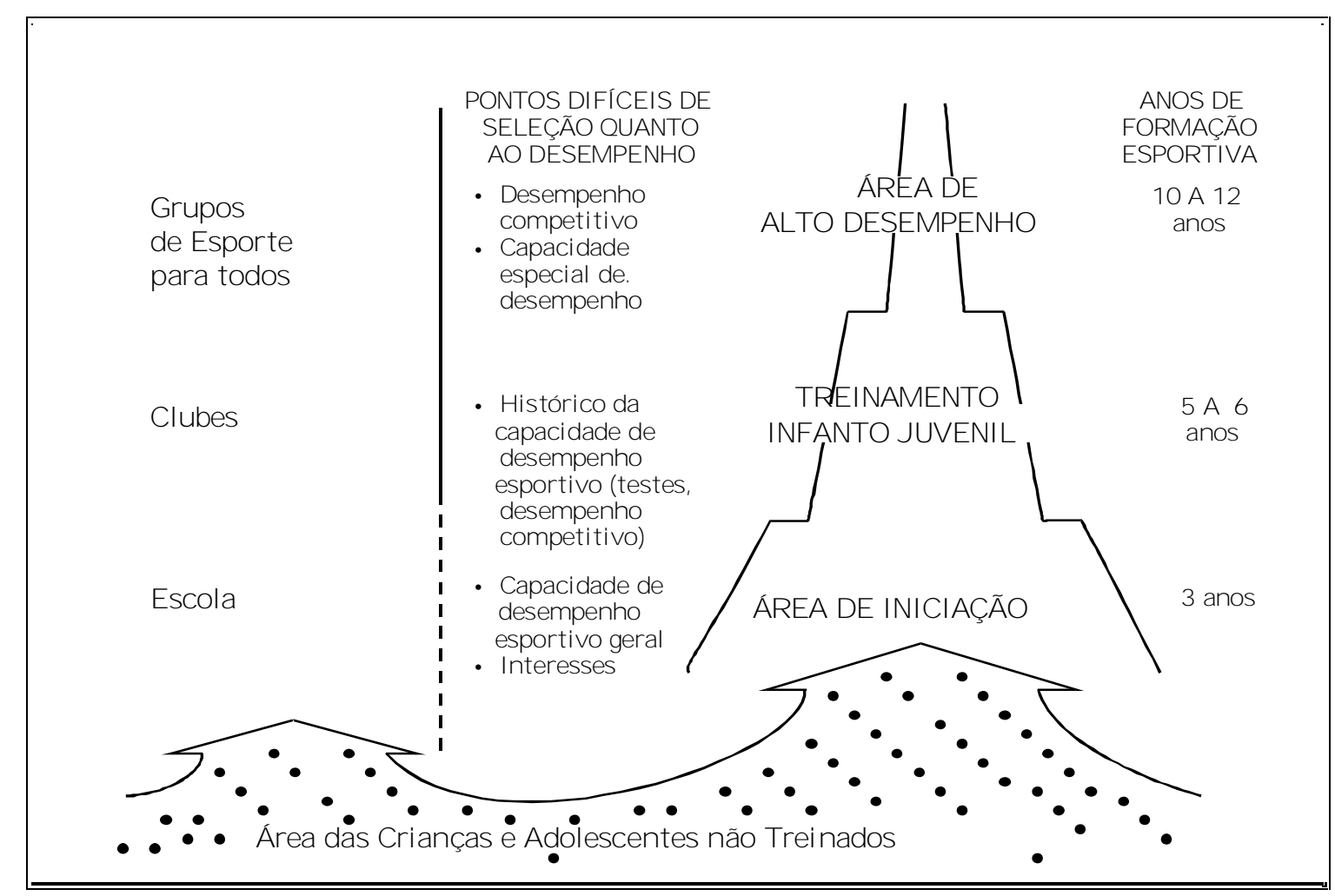

FIGURA 3 - Processo de seleção e formação esportiva - HOFMANN e SCHNEIDER $^{8}$ (1985) apud WEINECK (1999).

Ainda sobre a ótica da relação entre os processos de detecção e seleção de talentos esportivos e o processo de TLP, CARL ${ }^{3}$ (1988) apud BÖHME (1999), sob a forma de um funil, representou graficamente as fases principais da detecção e seleção, desde a iniciação até o alto nível fundamentadas no TLP (FIGURA 4).

\footnotetext{
${ }^{8}$ H. Hofmann,G. Schneider, Eignungsbeurteilung und Auswahl im Nachwuchsleistungssport. Theorie und Práxis der Körperkultur, v.34, p.44-52, 1985.
} 


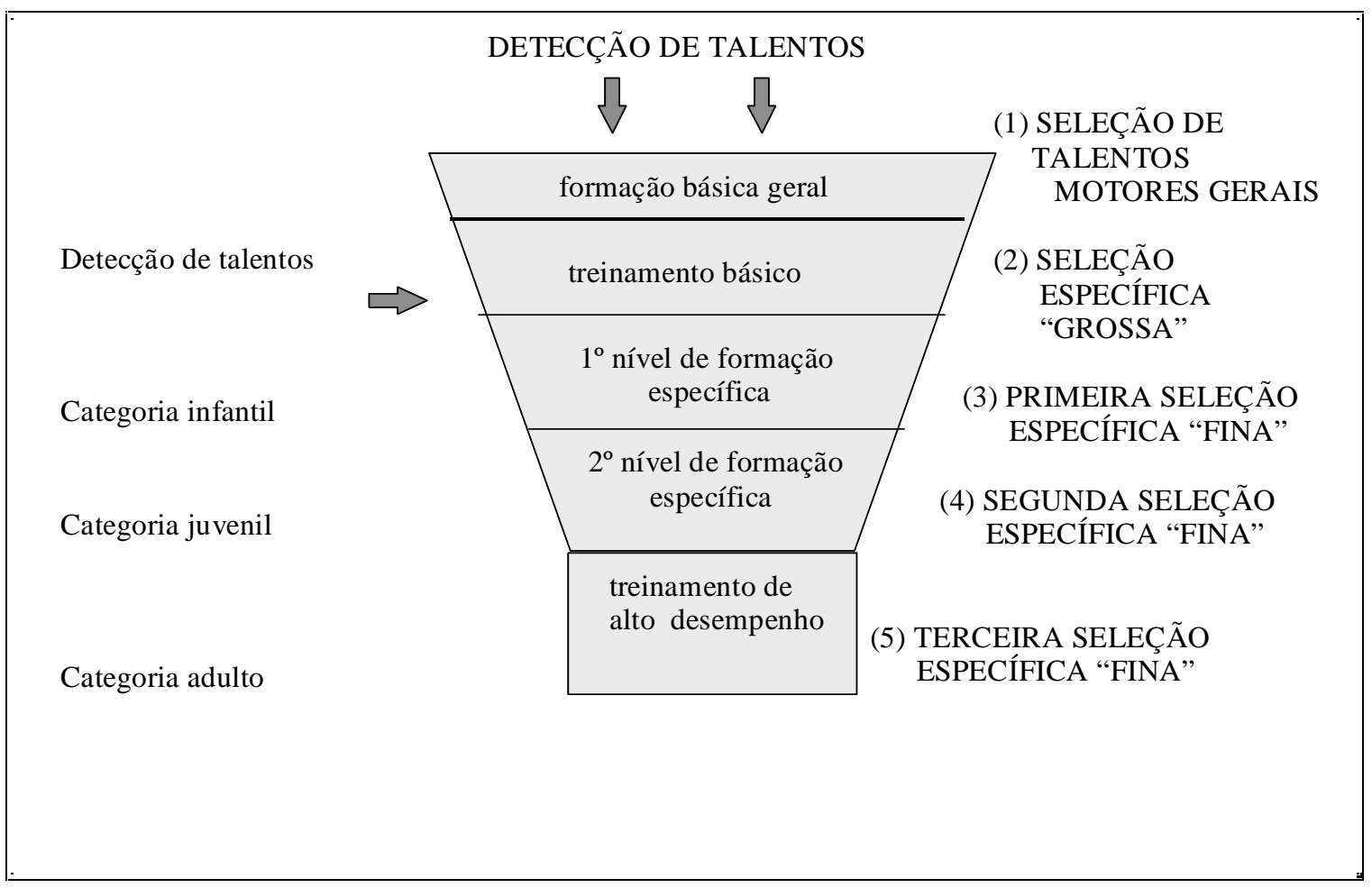

FIGURA 4 - Principais fases da detecção e seleção de talentos esportivos - $\mathrm{CARL}^{3}$ (1988) apud BÖHME (1999).

Outro fator que merece ser considerado diante das perspectivas do TLP, é que entre as distintas modalidades esportivas há uma variação quanto ao início e a duração do TLP e de seus respectivos níveis, assim como os processos de detecção, seleção e promoção de talentos esportivos. Esta variação, em média, é da ordem de seis a dez anos de duração. Na TABELA 1 são apresentados os valores médios e desvios padrão das idades de início do segundo nível, ou treinamento básico específico de atletas alemães de nível internacional assim como a idade de alcance dos primeiros melhores resultados, baseado num levantamento feito pelo Instituto Alemão de Ciência do Esporte. 
TABELA 1 - Idades médias de início e de início dos melhores resultados de atletas alemães (MARTIN, CARL \& LEHNERTZ ${ }^{9}, 1991$ apud BÖHME, 2000).

\begin{tabular}{|c|c|c|c|c|c|c|c|c|}
\hline \multirow[b]{3}{*}{ ESPORTE } & \multicolumn{4}{|c|}{ MASCULINO } & \multicolumn{4}{|c|}{ FEMININO } \\
\hline & \multicolumn{2}{|c|}{$\mathrm{INICIO}$} & \multicolumn{2}{|c|}{$\begin{array}{c}\text { MELHORES } \\
\text { RESULTADOS }\end{array}$} & \multicolumn{2}{|c|}{ INÍCIO } & \multicolumn{2}{|c|}{$\begin{array}{c}\text { MELHORES } \\
\text { RESULTADOS }\end{array}$} \\
\hline & Média & $\begin{array}{l}\text { Desvio } \\
\text { padrão }\end{array}$ & Média & $\begin{array}{l}\text { Desvio } \\
\text { padrão }\end{array}$ & Média & $\begin{array}{l}\text { Desvio } \\
\text { padrão }\end{array}$ & Média & $\begin{array}{l}\text { Desvio } \\
\text { padrão }\end{array}$ \\
\hline BOXE & 12,7 & 3,3 & 20,3 & 2,0 & & & & \\
\hline ESGRIMA & 10,7 & 2,1 & 19,2 & 1,3 & & & & \\
\hline JUDÔ & 7,1 & 2,3 & 19,8 & 2,1 & 8,1 & 1,0 & 17,9 & 1,3 \\
\hline $\begin{array}{l}\text { LEVANTA- } \\
\text { MENTO DE }\end{array}$ & 13,1 & 2,5 & 18,8 & 1,0 & & & & \\
\hline $\begin{array}{c}\text { PESO } \\
\text { ATLETISMO }\end{array}$ & 13,3 & 2,7 & 19.1 & 1.6 & 12.6 & 2.3 & 17.9 & 1.4 \\
\hline CICLISMO & 10,6 & 3,2 & 18,4 & 2,0 & 11,2 & 3,2 & 18,1 & 1,4 \\
\hline REMO & 14,2 & 0,9 & 19,4 & 1,4 & 15,6 & 2,4 & 20,0 & 2,1 \\
\hline CANOAGEM & 13,1 & 2,5 & 19,6 & 2,3 & 12,3 & 2,4 & 19,0 & 2,5 \\
\hline NATAÇÃO & 9,8 & 2,3 & 16,9 & 0,8 & 9,4 & 1,9 & 15,6 & 0,9 \\
\hline $\begin{array}{l}\text { TÊNIS DE } \\
\text { MESA }\end{array}$ & 7,6 & 1,8 & 13,6 & 1,7 & 8,6 & 1,2 & 14,6 & 1,2 \\
\hline VOLEIBOL & 11,6 & 1,6 & 17,1 & 0,7 & 12,0 & 2,3 & 17,1 & 0,9 \\
\hline $\begin{array}{l}\text { GINÁSTICA } \\
\text { OLÍMPICA }\end{array}$ & 8,9 & 1,8 & 16,9 & 2,0 & 7,9 & 2,0 & 13,3 & 1,3 \\
\hline $\begin{array}{l}\text { SALTOS } \\
\text { ORNAMEN- }\end{array}$ & 9,7 & 1,9 & 17,4 & 2,4 & 9,3 & 2,7 & 16,6 & 1,7 \\
\hline $\begin{array}{c}\text { TAIS } \\
\text { PÓLO } \\
\text { AQUÁTICO }\end{array}$ & 10,7 & 1 & 0,2 & 17,4 & 0,9 & & & \\
\hline
\end{tabular}

Sendo assim, ao se considerar o planejamento do TLP para a especificidade de cada modalidade esportiva deve-se estabelecer um sentido de orientação voltado do final para o começo, ou seja: com orientação na idade de início do alcance dos melhores resultados, faz-se uma retrospectiva de qual deve ser a idade de início do treinamento para formação específica na modalidade considerada. Em média, o período do treinamento básico específico (nível dois) inicia-se por volta dos dez/onze anos de idade. Os níveis e respectivas etapas do TLP estão intimamente relacionados, e não ocorrem independentemente uma da(s) outra(s); o que pode acontecer é que o jovem atleta não tenha vivenciado de maneira apropriada uma ou mais etapas na seqüência temporal adequada, e que a(s) sua(s) deficiência(s) de formação esportiva tenham que ser de algum modo "compensadas" posteriormente. Em termos ideais, o jovem atleta deveria passar por um processo completo de formação esportiva, no(s) período(s) adequado(s) para este(s) fim(s), conforme sugerido por MARTIN (1988) apud BÖHME (2000) na FIGURA 2.

${ }^{9}$ D. Martin, K. Carl, K. Lehnertz, Handbuch Trainingslehre, Schorndorf, Verlag Karl Hofmann, 1991. 


\subsubsection{Considerações acerca do desempenho esportivo}

Ao conceber que o talento esportivo possui um potencial para realizar um desempenho esportivo acima da média, torna-se necessário apresentar os fatores que se relacionam com desempenho esportivo. Diferentes modelos de desempenho esportivo são encontrados na literatura da teoria do treinamento para o esporte de rendimento, alguns foram descritos por BÖHME (1994, 1999, 2000, 2004).

MARTIN et alii ${ }^{4}$ (1999) apud BÖHME (2004) propuseram uma forma de operacionalização do conceito de desempenho esportivo para o treinamento a longo prazo - TLP - , na qual a complexidade do mesmo pode ser considerada através de três aspectos básicos, respectivamente: (a) capacidade de desempenho esportivo, (b) pressupostos individuais de desempenho e (c) solicitações de desempenho. De acordo com estes autores, existem relações entre a capacidade de desempenho esportivo, os pressupostos individuais de desempenho esportivo e as solicitações de desempenho, as quais podem ser representadas em dois planos, de acordo com o apresentado na FIGURA 5. 


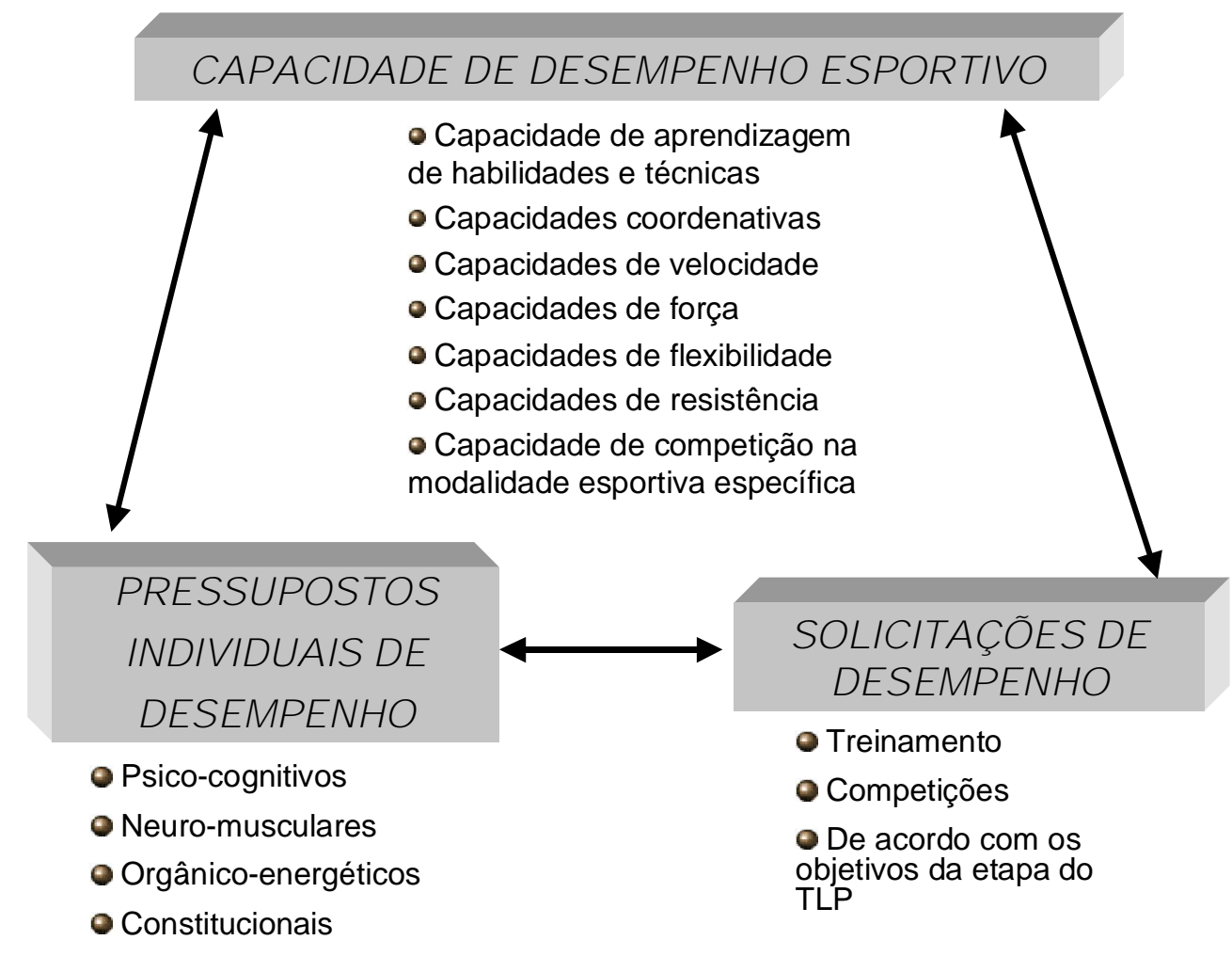

FIGURA 5 - Modelo das relações dos componentes de desempenho esportivo no treinamento a longo prazo (MARTIN et aliii, 1999 apud BÖHME, submetido a publicação)

Neste sentido, SCHNABELL, HARRE e BORDE ${ }^{10}$ (1994) apud BÖHME (1999) consideram o desempenho esportivo, o treinamento esportivo e a competição esportiva como os três componentes principais do estado científico atual da Ciência/Teoria do Treinamento. Conforme os autores, as relações existentes entre estes três componentes podem ser representadas graficamente pela FIGURA 6.

${ }^{10}$ G. Schnabell, D. Harre, A. Borde (Eds.), Trainingswissenschaft. Leistung - Training - Wettkampf, Berlin, Sportverlag, 1994.

Easy PDF Creator is professional software to create PDF. If you wish to remove this line, buy it now. 


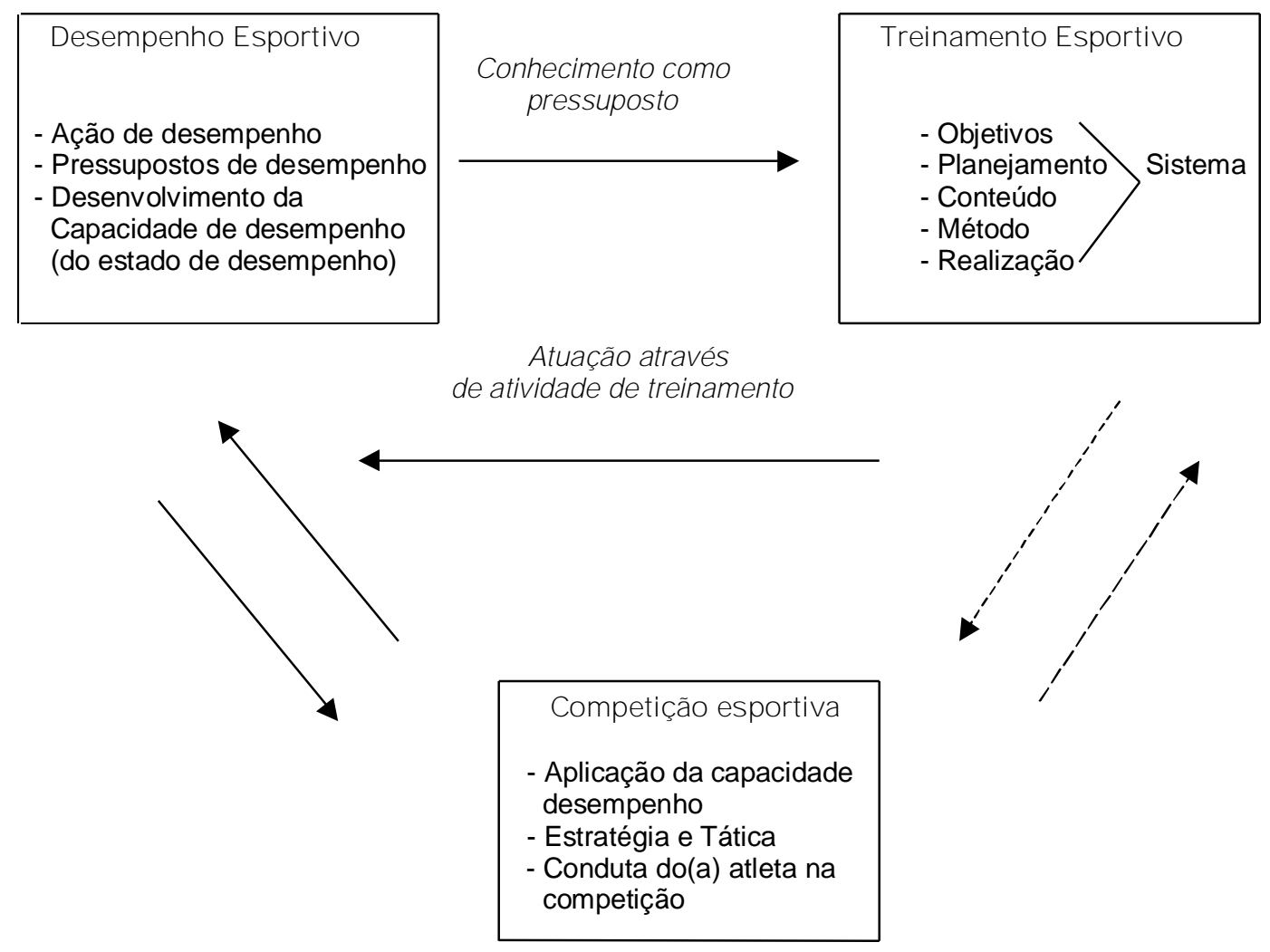

FIGURA 6 - Relações entre os componentes atuais da Ciência do Treinamento (SCHNABELL, HARRE \& BORDE ${ }^{10}, 1994$ apud BÖHME, 1999)

Conforme FRIEDRICH, GROSSER e PREISING ${ }^{11}$ (1988) apud BÖHME (1994), desempenho refere-se a um conjunto de processos e resultados de uma ação esportiva, orientado conforme uma dada norma social. Entretanto, para MARTIN, CARL e LEHNERTZ9 (1991) apud BÖHME (2000), desempenho esportivo é o resultado de uma ação esportiva, que encontra a medida de sua manifestação especialmente nos esportes de competição, a qual tem suas ações de movimento coordenadas por regras preestabelecidas.

Desta forma, na interpretação do desempenho esportivo, observa-se que o mesmo pode ser considerado distintamente na área de treinamento esportivo.

${ }^{11}$ E. Friedrich, M. Grosser, R. Preising, Einführung in die Ausbildung von Trainem an der Trainerakademie, Schorndorf, Hoffmann-Verlag, 1988. 
Conforme os referidos autores citados, o desempenho esportivo pode ser visto tanto como processo e resultado, quanto como relacionado somente ao resultado obtido na ação esportiva, quando se considera que a análise do resultado e o prognóstico do resultado são os problemas principais a serem estudados e pesquisados pela teoria e considerados na prática do treinamento.

Ademais, o desempenho esportivo depende de normas sociais estabelecidas, o que significa que 0 atleta carrega consigo a sua personalidade, 0 seu meio social, suas fraquezas e suas forças humanas. O treinador também é confrontado com expectativas sociais: em relação ao seu comportamento e em relação ao que se espera como desempenho esportivo na escala de valores da sociedade; essas relações são representadas na FIGURA 7 , modificado de FRIEDRICH, GROSSER e PREISING ${ }^{11}$ (1988) apud BÖHME (1999).

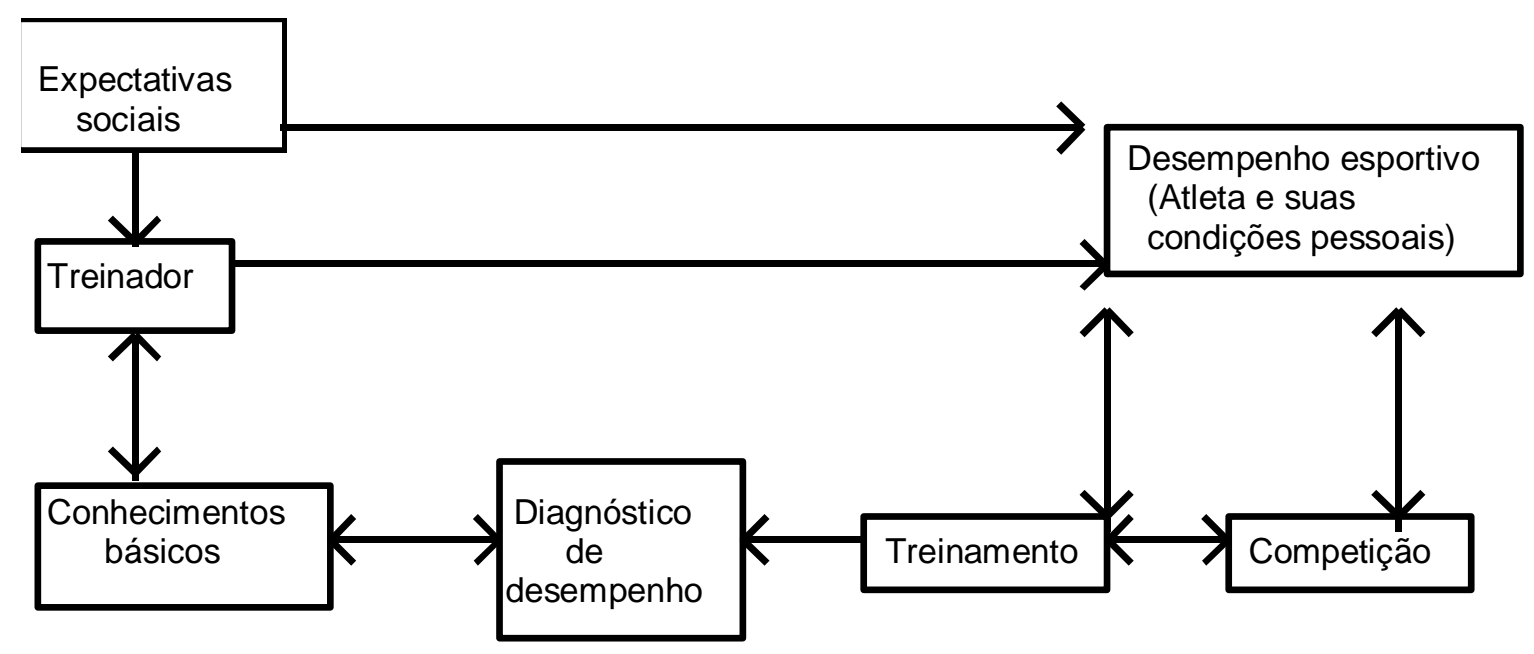

FIGURA 7 - Relações gerais do desempenho esportivo (FRIEDRICH, GROSSER \& PREISING ${ }^{11}, 1988$ apud BÖHME, 1999).

Especificamente na literatura alemã, referente à Ciência do Treinamento, são encontrados diferentes modelos elaborados com o objetivo de representar a estrutura do desempenho esportivo (FRIEDRICH, GROSSER \& PREISING ${ }^{11}, 1988$ 
apud BÖHME, 1999) os quais foram descritos por BÖHME (1994, 2004), em paralelo aos de outros autores (WEINECK, 1999).

Na FIGURA 8 é apresentado o esquema das condições pessoais internas (diretas e indiretas) de desempenho esportivo e sucesso esportivo, e na FIGURA 9, as condições limitantes do desempenho esportivo propostos por $C A R L^{3}$ (1988) apud BÖHME (1999).

As condições pessoais são os pressupostos pessoais do desempenho esportivo, expressas através da aptidão e influência do meio ambiente; o seu estado é em parte influenciado pelo treinamento. Algumas variáveis tem o seu desenvolvimento pré-fixado ou fixado por características genéticas ou do meio ambiente, consideradas até então. As regras de treinamento pressupõem o conhecimento da treinabilidade de cada condição individualmente.

De acordo com CARL ${ }^{3}$ (1988) apud BÖHME (1999), as condições pessoais internas indiretas de desempenho são compostas por sistemas, órgãos e tecidos, formando a base de sustentação da constituição corporal e das capacidades orgânicas, motoras, cognitivas e afetivas, e essas por sua vez, sustentam as condições pessoais internas diretas, respectivamente a condição, a técnica e a tática.

A característica principal que diferencia as condições pessoais diretamente das indiretamente observáveis, é a dependência das primeiras em relação às últimas; em cada condição pessoal diretamente observável, existe a atuação de complexos componentes das capacidades de desempenho psíquicas e corporais. Nas condições pessoais indiretamente observáveis, por outro lado, é possível a distinção das funções específicas de cada variável. 


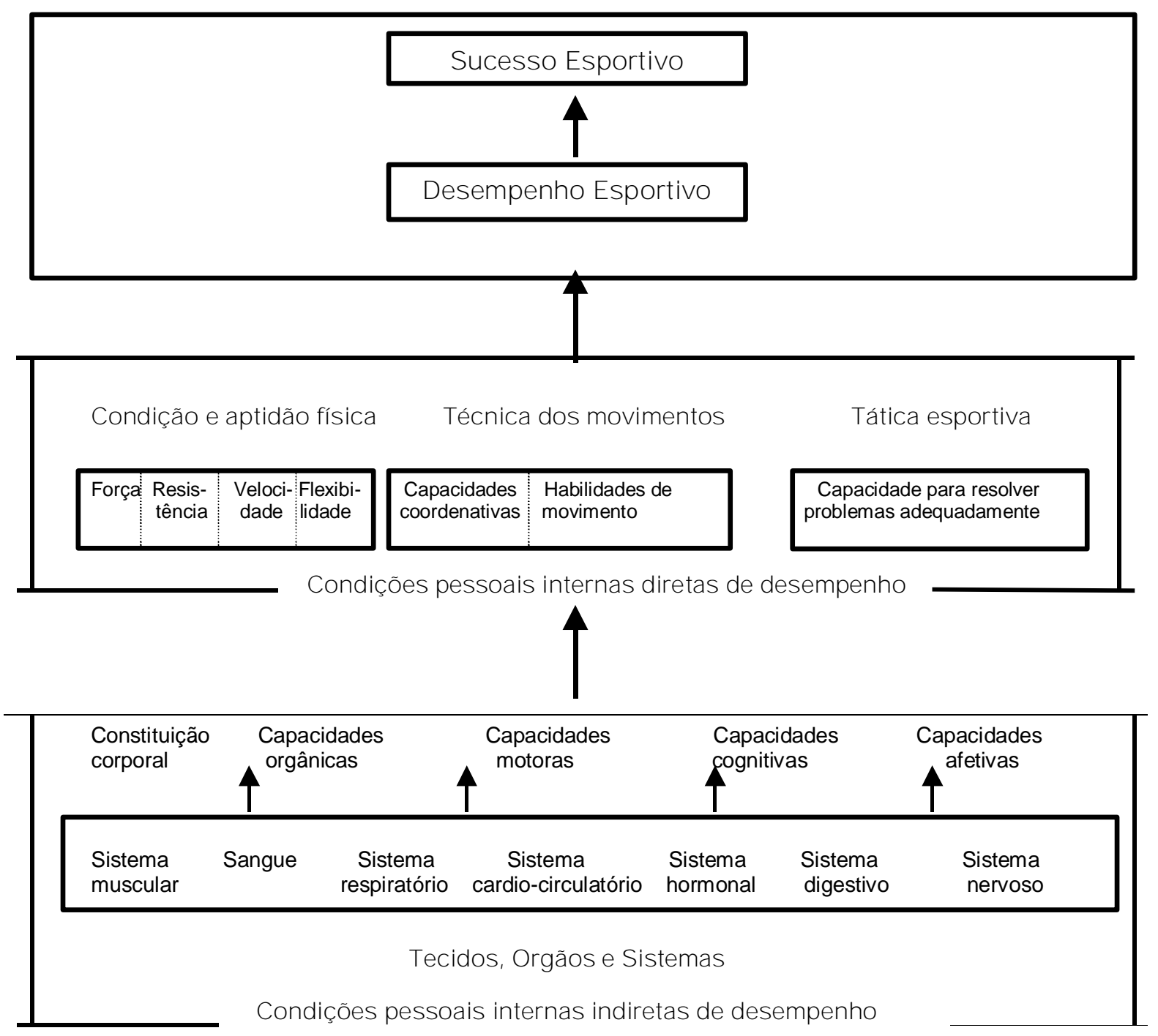

FIGURA 8 - Esquema das condições pessoais de desempenho e sucesso esportivo (CARL $^{3}, 1988$ apud BÖHME, 1999) 
As condições limitantes do desempenho esportivo subdividem-se em condições limitantes pessoais, relativas ao próprio atleta, e, condições limitantes sociais, relativas às condições materiais e sociais do seu meio ambiente (FIGURA 9).

\begin{tabular}{|l|l}
\hline Condições limitantes pessoais & \multicolumn{1}{c}{ Condições limitantes sociais } \\
\hline - Escola/Estudo & - Atitudes da sociedade para o \\
- Profissão & desempenho \\
- Amigos/ Lazer & - Valor da modalidade esportiva na sociedade \\
- Família & - Meios financeiros disponíveis \\
& - Treinador disponível \\
& - Sistema de formação do treinador \\
& - Nível de conhecimento na Ciência do Esporte \\
\hline
\end{tabular}

FIGURA 9 - Condições limitantes do desempenho esportivo (CARL ${ }^{3}, 1988$ apud BÖHME, 1999).

Portanto, a literatura específica relacionada ao desempenho esportivo manifesta que as condições pessoais são os pressupostos do desempenho esportivo e que para tanto a influência do meio ambiente, e particularmente do treinamento, é fundamental. Desta maneira, se considera a importância dos aspectos genéticos associados às oportunidades e à qualidade dos estímulos oferecidos dentro de um domínio específico do treinamento. Assim, se por um lado a teoria relacionada ao desempenho esportivo expõe a relevância das características genéticas para o resultado, por outro a caracterização do ambiente gerando forças de apoio para a perspectiva de desempenho como produto de um processo planejado de treinamento sistemático, também se demonstra como fundamental para o desempenho esportivo, corroborando com BLOOM (1985), CSIKSZENTMIHALYI, RATHUNDE e WHALEN (1997) e ERICSSON, KRAMPE e TESCH-RÖMER (1993), sobretudo ao considerar a influência das condições limitantes do desempenho esportivo apresentadas por $\mathrm{CARL}^{3}$ (1988) apud BÖHME (1999) e a importância de profissionais que conheçam o processo de treinabilidade de cada condição pessoal do desempenho, contribuindo para a construção de um processo fundamentando de treinamento a longo prazo e promoção de talentos esportivos. 


\subsubsection{Considerações sobre os fatores psicossociais}

Por se tratar de um contexto multifatorial, o esporte de alto nível tem sido considerado por diversos autores como um fenômeno dinâmico e complexo (ABBOTT \& COLLINS, 2004; BÖHME, 2000, 2001; HEBBELINCK, 1989; HOHMANN \& SEIDEL, 2003; MASSA, 1999).

Inseridos nessa complexidade, de acordo com os itens anteriores do presente trabalho, foi possível verificar na literatura relacionada ao talento, ao talento esportivo, ao treinamento a longo prazo e ao desempenho esportivo, a relevância atribuída por diferentes autores aos aspectos psicossociais (BÖHME, 1996; BLOOM, 1985; CSIKSZENTMIHALYI, RATHUNDE \& WHALEN, 1997; DE ROSE JUNIOR, 1993; ERICSSON, KRAMPE \& TESCH-RÖMER, 1993; JOCH², 1994 apud BÖHME, 2000; MARQUES, 1993).

Assim, conforme MORAES, DURAND-BUSH e SALMELA (1999), o sucesso de uma pessoa talentosa depende do seu comprometimento, motivação e paixão pela sua área de atuação e, ao mesmo tempo, do apoio de diversos segmentos da sociedade como, a própria família, bons mentores e professores e também bons treinadores no caso do esporte.

Para BÖHME (2002), motivação, disponibilidade para o desempenho, esforço e estabilidade psicológica são apontados como componentes psicológicos do talento esportivo.

Assim, conforme SILVA e RÚBIO (2003), a história de vida de atletas brasileiros medalhistas olímpicos possui um discurso marcado por indicações de persistência e perseverança diante dos obstáculos inerentes ao processo de treinamento e competições.

FERREIRA, MARKUNAS e NASCIMENTO (2004) comentam que durante 0 processo de formação esportiva se deve considerar na preparação psicológica, o controle emocional em treinamento e competições, a busca de níveis adequados de concentração e técnicas de controle de estresse e ansiedade, bem como um programa que se ocupe inclusive da avaliação, acompanhamento e formação da identidade profissional dos atletas. 
Para STARKES (2000), o sucesso do processo de treinamento consiste em manter o atleta potencialmente motivado, competitivo e envolvido o suficiente para adquirir a prática necessária que o conduzirá ao alto desempenho.

Sendo assim, MARKUNAS (2005) salienta que os aspectos psicológicos do desenvolvimento de talentos esportivos se referem àquelas características e fatores emocionais, cognitivos e psicossociais presentes no treinamento a longo prazo, tais como motivação e apoio social (da família ao treinador, entre outros) e também prazer e alegria, expressando o nível de satisfação presentes nos processos de desenvolvimento.

Neste sentido, CÔTÉ (1999) realizou um estudo acerca da influência da família no desenvolvimento do talento no esporte. Os resultados indicaram que entre os seis e 13 anos de idade os familiares geravam oportunidades e despertavam o interesse das crianças pela prática esportiva. Além disso, as crianças e suas famílias também participavam de atividades esportivas extracurriculares, experimentando de maneira prazerosa a uma variedade de opções de prática.

Conforme VIEIRA e VIEIRA (2001), em um estudo realizado com atletas paranaenses de atletismo, durante os anos iniciais da aprendizagem, as crianças se interessavam pela prática de atividades motoras sobretudo pelo incentivo do pai $(21,4 \%)$ ou de irmãos que também praticavam atletismo $(57,1 \%)$.

Um estudo retrospectivo realizado por LIDOR e LAVYAN (2002) com atletas de elite de Israel, verificou que a família (48\%), os amigos (13\%) e os professores de educação física (11\%) foram fundamentais para o envolvimento da criança com a modalidade. Ademais, os resultados indicaram que a maioria das famílias oferecia suporte $(71 \%)$ para a criança participar dos programas de treinamento, tanto financeiro (55\%) quanto emocional (45\%). Em relação aos fatores motivacionais, a principal fonte era a intrínseca (87\%).

Neste sentido, em um estudo realizado por HOLT e MORLEY (2004) foram observados os fatores psicossociais associados ao sucesso esportivo durante os anos da infância. Entre outros resultados, se pode destacar a influência que pai e irmãos $(35,9 \%)$, oportunidades na escola $(20,5 \%)$ e eventos esportivos $(12,8 \%)$ exerceram sobre a escolha da modalidade esportiva pela criança. Quanto aos motivos que levaram as crianças a participarem da modalidade escolhida, o prazer 
pela atividade $(61,5 \%)$ e pela competição $(30,8 \%)$ foram os fatores mais apontados. O suporte emocional da família $(53,8 \%)$ e de professores $(10,3 \%)$ também se manifestaram como fatores relevantes para a participação da criança no treinamento esportivo. Quanto à atribuição do sucesso esportivo, a maioria das respostas tendeu a considerar a prática $(74,4 \%)$, os atributos físicos $(48,8 \%)$ e a determinação $(23,1 \%)$, como determinantes do alto desempenho.

Em um amplo estudo realizado entre os anos de 1984 e 1998, sobre o processo de desenvolvimento de 816 atletas olímpicos norte-americanos, foi aplicado um questionário intitulado "Questionário de Identificação e Desenvolvimento do Talento". Entre outros resultados obtidos, foi possível verificar que a maioria dos atletas olímpicos começou a sua formação em comunidades locais que geravam oportunidades de prática, revelando a importância que programas esportivos descentralizados podem exercer nos anos iniciais da aprendizagem. A exemplo dos estudos anteriormente citados, nos anos iniciais da aprendizagem, a ênfase adotada nos programas esportivos era sobre a prática prazerosa e divertida, fazendo com que o amor ao esporte cultivado neste período gerasse o motivo principal para a continuidade da criança nas demais fases do TLP. Ademais, foi possível verificar nos atletas olímpicos norte-americanos, que o amor ao esporte e a influência dos familiares e técnicos exerceram importância sobre o encaminhamento esportivo na modalidade escolhida. Quanto aos fatores que motivaram os atletas a participarem da modalidade, o amor pela competição, o divertimento, o desejo pelo sucesso, competir em outras cidades e outros valores intrínsecos se revelaram como preponderantes para o desenvolvimento do talento. Por sua vez, os fatores de maior impacto na permanência durante o processo de TLP foram a dedicação e o compromisso, o foco mental, o sucesso competitivo, a família, os treinadores, os colegas de treinamento, entre outros. Por outro lado, conflitos com trabalhos paralelos, suporte financeiro deficitário, tempo escasso, lesões e pressão dos parentes fomentaram os principais motivos para o abandono da prática nos pares dos atletas olímpicos norte-americanos (GIBBONS, HILL, MCCONNELL, FORSTER \& MOORE, 2002).

Desta maneira, é possível verificar que os resultados encontrados por CÔTÉ (1999), VIEIRA e VIEIRA (2001), LIDOR e LAVYAN (2002) e HOLT e 
MORLEY (2004) corroboram com as colocações de BLOOM (1985) e CSIKSZENTMIHALYI, RATHUNDE e WHALEN (1997) acerca da importância dos fatores psicossociais nos anos iniciais da aprendizagem e durante o processo de desenvolvimento do talento. Portanto, diante da relevância atribuída a estes fatores, se justifica a necessidade de verificar a implicação que os mesmos podem ter gerado para o processo de desenvolvimento de judocas olímpicos brasileiros.

\section{$2.3 \quad 0$ J udô}

\subsubsection{Aspectos gerais}

Criado em 1882 pelo professor Jigoro Kano, o Judô (caminho suave) teve sua concepção no Japão. Conforme dados históricos, o Judô teria surgido a partir da arte marcial Jiu-Jitsu (capacidade de ceder para vencer), desenvolvida pelos nobres guerreiros do feudalismo japonês, denominados Samurais. Jigoro Kano, na busca de alternativas para eliminar a possibilidade de contusões inerentes à prática do JiuJitsu, buscou criar uma arte marcial distinta, composta por valores remodelados numa nova filosofia de vida. Para tanto, aproveitou os valores positivos do Jiu-Jitsu, agregando valores de qualidade, respeito e preservação do oponente. Desta maneira, o Judô passou a se preocupar não apenas com o físico, mas sobretudo com componentes de ordem filosófica, psicológica, cultural e até política, reunindo pessoas interessadas no desenvolvimento humano e na interação entre os povos (DELIBERADOR, 1996). De acordo com MONTEIRO (1998), Jigoro Kano procurou elaborar um sistema de Educação Física que proporcionasse a formação do caráter, estudando todos os sistemas de defesa pessoal existentes e constatando a carência de um fator espiritual em quase todos.

Portanto, quando foi criado, o Judô possuía como princípio ser uma luta desportiva, porém servindo como canalização da excessiva combatividade, acalmando o espírito e o nervosismo e cultivando as qualidades morais (MONTEIRO, 1998). 
No Brasil, seu ingresso ocorreu por volta de 1908, quando os primeiros imigrantes japoneses se introduziram no país. Desta forma, o Judô, disseminado por professores imigrantes japoneses, chega ao Brasil como um elemento da cultura nipônica presente e fundamental para enriquecer a formação dos jovens imigrantes japoneses e o futuro das próximas gerações (DELIBERADOR, 1996; MONTEIRO, 1998).

Neste sentido, além de toda contribuição filosófico-cultural que pode estar presente diante dos processos de aprendizagem desta modalidade, o Judô enquanto modalidade olímpica participa de forma obrigatória desde a Olimpíada de Munique 1972, demonstrando sua efetivação no cenário mundial e sua aculturação, sobretudo se caracterizando como uma modalidade esportiva de alto rendimento.

Atualmente, mesmo com isenção de uma abordagem mais profunda, é possível constatar que o Judô penetrou na cultura brasileira. O número de Escolas de Judô e de praticantes dispersos pelo Brasil é considerável, sobretudo no período formativo da modalidade. Conforme CASTROPIL (1996), o Judô tem sido praticado por pessoas de diversas faixas etárias e com diferentes objetivos, contudo a maioria dos praticantes inicia o processo de aprendizagem durante a segunda infância.

Em contrapartida, conforme FRANCHINI (1998), o processo ensinoaprendizagem do Judô no Brasil tem sido realizado com pouca ou nenhuma fundamentação teórica, comprometendo sua otimização.

Mesmo assim, contrariando qualquer hipótese mais pessimista sobre a perspectiva do Judô enquanto modalidade esportiva de alto rendimento, diversos resultados expressivos vem sendo obtidos por judocas brasileiros nas últimas décadas, inclusive fazendo parte da história dos Jogos Olímpicos.

Em 1972, nos Jogos Olímpicos de Munique, Chiaki Ishii trouxe a primeira de uma série de medalhas olímpicas para o judô brasileiro - medalha de bronze. Entretanto, na sua trajetória até a medalha, Chiaki Ishii esteve originalmente imerso em um processo de desenvolvimento e treinamento característico da escola japonesa e chegou a participar do processo classificatório para os Jogos Olímpicos de Tóquio (1964) pelo Japão. Contudo, diante de sua derrota no processo classificatório e conseqüente frustração, abandonou o Japão e veio como imigrante ao Brasil. No Brasil, em busca de um novo caminho, aproximou-se da agricultura e, 
mesmo em circunstâncias ainda pouco desenvolvidas no país (modalidade restrita aos locais com imigrantes japoneses, ausência de confederação própria, baixo índice técnico dos praticantes, entre outros), seu caminho acabou se cruzando novamente com o judô. A partir de então, a trajetória de Chiaki Ishii exerceu importância fundamental para o processo de desenvolvimento do judô no Brasil, pois sua medalha olímpica tornou o judô brasileiro uma modalidade esportiva de expressão internacional e, nacionalmente, alavancou a divulgação da modalidade, o processo de proliferação das academias de judô pelo país, bem como de sua estrutura organizacional (RUBIO, 2004).

O resultado desta epopéia trouxe, 12 anos mais tarde, frutos que se tornaram maduros nos Jogos Olímpicos de Los Angeles (1984). Conforme RUBIO (2004), o judô brasileiro nunca mais seria o mesmo após Los Angeles. Neste sentido, apesar da relevância da tradição dos imigrantes japoneses para o desenvolvimento da modalidade no Brasil, definitivamente a escola brasileira de judô começaria a se firmar como uma das mais potentes e talentosas do mundo, trazendo três medalhas de Los Angeles: uma de prata, com Douglas Vieira e duas de bronze, com Luis Onmura e Walter Carmona.

Nos Jogos Olímpicos de Seoul (1988), o ouro foi conquistado por Aurélio Miguel. Em Barcelona (1992), Rogério Sampaio também reafirmou a força da escola brasileira e trouxe o ouro. Nos Jogos Olímpicos de Atlanta (1996), o bronze foi de Aurélio Miguel e Henrique Guimarães. Em Sydney (2000), vieram as medalhas de prata de Carlos Honorato e Tiago Camilo e, mais recentemente, nos Jogos Olímpicos de Atenas (2004), as medalhas de bronze de Leandro Guilheiro e Flávio Canto.

Entretanto, afora a observação pura desses resultados, se numa face da moeda percebe-se pouca ou nenhuma fundamentação teórica na aplicação do treinamento, a outra face da mesma moeda também não é mais acolhedora, ou seja, conforme CALLISTER, CALLISTER, FLECK e DUDLEY (1990) e FRANCHINI (2001), poucos são os estudos relacionados aos processos de treinamento de atletas de Judô. Portanto, diante desta dicotomia, muitos técnicos acabam ministrando seus treinamentos da mesma forma como aprenderam com seus antigos mestres (FRANCHINI, 2001; FREITAS, 1989). 
Em uma obra publicada por RUBIO (2004), a história de vida de atletas medalhistas olímpicos brasileiros é resgatada. Entre os distintos discursos, há o registro dos judocas brasileiros medalhistas entre os Jogos Olímpicos de Munique (1972) e Sydney (2000). A referida obra trouxe como objetivo discutir o que faz do atleta um herói e, através desta perspectiva, reconstituir a história do esporte brasileiro a partir da trajetória daqueles que, com medalha, gravaram seus nomes na história olímpica.

Sendo assim, de maneira distinta, através de uma congruência dirigida para a exploração do universo de desenvolvimento do talento esportivo no judô e para efeito do presente estudo, analisar e discutir a trajetória de judocas olímpicos brasileiros, considerando os modelos de desenvolvimento de talento presentes na literatura, parece ser fundamental para a compreensão do fenômeno de formação e sucesso do atleta na referida modalidade, sobretudo, considerando a especificidade do contexto brasileiro.

\subsection{2 $\quad 0$ desempenho no judô}

Embora o desempenho no judô mereça ser caracterizado conforme a divisão das categorias por peso, bem como das variáveis relacionadas à condição física, aos aspectos técnico-táticos e aos aspectos relacionados ao contexto psicológico, poucos estudos abrangentes são encontrados na literatura sobre os referidos contextos (FRANCHINI, 2001), permitindo uma observação fracionada e por vezes até limitada do desempenho na modalidade. Portanto, em função dessas considerações, os tópicos seguintes se reservarão a uma breve caracterização do judô em função das características morfológicas e de desempenho físico.

\subsubsection{Características morfológicas no judô}

As características morfológicas dos atletas também se relacionam com o desempenho. No judô especificamente, se percebe com distinção a diferença em 
relação às características morfológicas de judocas pertencentes a diferentes categorias competitivas, sobretudo entre os atletas de categorias mais leves e mais pesadas. De acordo com FRANCHINI (2001), esses fatores se relacionam com a adaptação mecânica das técnicas empregadas por esses atletas. Entretanto, os aspectos biomecânicos do judô não têm sido muito observados na literatura, comprometendo a elaboração de conceitos mais claros sobre a relação entre as características morfológicas e a adaptação mecânica a determinadas técnicas. Portanto, a presente revisão limitar-se-á a apresentar os aspectos morfológicos relacionados à composição corporal e ao somatotipo de judocas.

\subsection{Composição corporal}

A composição corporal se refere às massas constituintes de cada indivíduo. Desta maneira, a composição corporal é caracterizada por tecidos adiposo, ósseo, muscular, visceral e fluidos extracelulares. Esses componentes encontram-se distribuídos em diferentes proporções devido a fatores genéticos, hormonais e ambientais (MALINA \& BOUCHARD, 1991), sendo que o estudo dos mesmos pode trazer informações importantes sobre a influência dessas variáveis no cotidiano humano e no desempenho esportivo.

GUEDES e GUEDES (1997) complementam afirmando que entre os componentes corporais, o tecido adiposo é o que possui a característica de ser o mais instável, responsabilizando-se pelas principais variações individuais entre os seres humanos.

Em função do judô ser dividido em categorias de peso, se torna relevante verificar a estimativa da composição corporal dos atletas.

Conforme FRANCHINI e TAKITO (1997), a predição da composição corporal, principalmente do percentual de gordura, permite conhecer se é possível para um determinado atleta diminuir seu peso corporal com o objetivo de lutar em uma categoria mais leve, sem que para isso ocorra redução da massa muscular e/ ou desidratação, mesmo porque assume-se que uma baixa quantidade de gordura seja desejável para o sucesso na maioria das modalidades esportivas. Neste sentido, 
conforme MASSA (1999), em algumas modalidades esportivas o tecido adiposo tem sido considerado um fator prejudicial para o desempenho, pois constitui-se de uma massa inerte que requer constante trabalho mecânico para acelerá-la e desacelerála.

De acordo com McARDLE, KATCH e KATCH (1991), um sujeito do gênero masculino, saudável, apresenta cerca de $15 \%$ de gordura corporal, sendo que $4 \%$ é considerado o valor mínimo de gordura corporal para homens saudáveis. Neste sentido, em um estudo realizado por CALLISTER, CALLISTER, STARON, FLECK, TESCH e DUDLEY (1991), atletas norte-americanos de elite melhores classificados no ranking dos Estados Unidos, apresentaram menores valores de gordura corporal $(5,1 \pm 0,6 \%)$ quando comparados com atletas de classificações inferiores no ranking.

De acordo com FRANCHINI (2001), a maioria dos estudos realizados com judocas masculinos de alto nível indica para um baixo percentual de gordura (abaixo de 10\%), com exceção das categorias meio-pesado e pesado. Portanto, um baixo percentual de gordura parece ser relevante para o desempenho no judô, sobretudo em função da divisão das categorias por peso.

No trabalho realizado por IIDA, WAKAYAMA, NAKAJIMA \& MATSUMOTO (1998), o percentual de gordura foi estimado a partir das medidas de dobra cutâneas. Conforme os resultados obtidos, as categorias meio-pesado e pesado apresentam percentual de gordura quase duas vezes maior do que o verificado em atletas de categorias mais leves. Neste sentido, pode-se salientar que alguns atletas da categoria pesado apresentaram um percentual de gordura elevado, aproximando-se da classificação de obesidade para o gênero masculino, ou seja, acima de $25 \%$, indicando a necessidade de redução deste fator, não apenas pela vantagem relacionada ao desempenho como também para prevenir problemas de saúde associados ao elevado índice de gordura corporal (McARDLE, KATCH \& KATCH, 1991). 


\subsection{Somatotipo}

O estudo do somatotipo refere-se à configuração morfológica, expressa nos componentes de endomorfia (que faz referência à gordura), mesomorfia (que faz referência à massa muscular) e ectomorfia (que faz referência à relação entre estatura e massa corporal) e que caracterizam com particular propriedade o tipo físico do indivíduo em uma dado instante (CARTER, 1984). Na antropometria, esse estudo tem sido um instrumento largamente utilizado para classificar pessoas e atletas conforme o tipo de atividade ou função que desempenham dentro de uma determinada modalidade esportiva (ROCHA, DOURADO \& GONÇALVES, 1996).

Em modalidades esportivas de luta, o componente de mesomorfia tem sido destacado como o mais relevante para o desempenho nos gêneros masculino e feminino, permitindo inclusive discriminar atletas de diferentes graus de desempenho (GUALDI-RUSSO \& GRAZIANI, 1993).

Em um estudo realizado por ARAÚJO, GOMES e NOVAES (1978), compreendendo 34 judocas participantes do Campeonato Brasileiro de 1977, foi verificada a predominância do componente de mesomorfia em $91,18 \%$ dos sujeitos, constatando a importância do desenvolvimento musculoesquéletico para 0 alto desempenho no judô. Ademais, no referido estudo, o componente de endomorfia aumentou e a ectomorfia diminuiu (exceto na categoria leve) com o aumento da categoria de peso.

CLAESSENS, BEUNEN, WELLENS e GELDOF (1987) em um estudo realizado com um total de 38 judocas (entre os quais: $18 \mathrm{com}$ menos de $71 \mathrm{~kg}$, nove entre $71 \mathrm{~kg}$ e $86 \mathrm{~kg}$ e 11 superiores a $86 \mathrm{~kg}$ ) participantes do Campeonato Mundial Sênior de 1981, corroborando com os achados de ARAÚJO, GOMES e NOVAES (1978), também verificaram a predominância do componente de mesomorfia em todos os grupos pesquisados. Conforme os autores, do total avaliado de 38 judocas, 28 deles apresentaram a classificação de endo-mesomorfia, cinco mesomorfia equilibrada, quatro ecto-mesomorfia e um meso-endomorfia. Ademais, de acordo com o aumento do peso corporal, verificou-se aumento do componente de endomorfia e diminuição do componente de ectomorfia, porém com todos os judocas apresentando índices de mesomorfia acima de 5,6. 
Neste sentido, alguns estudos realizados com judocas belgas de elite (CLAESSENS, BEUNEN, LEFEVRE, MERTENS \& WELLENS, 1986; CLAESSENS, BEUNEN, SIMONS, WELLENS, GELFOLD \& NUYTS, 1984) e com judocas da seleção brasileira universitária (FRANCHINI, TAKITO, DUTRA NETO \& KISS, 1997) também registraram resultados semelhantes aos verificados por ARAUJO, GOMES e NOVAES (1978) e CLAESSENS et alii (1987), confirmando a relevância do componente de mesomorfia para o alto desempenho no judô.

Ainda sobre a caracterização do somatotipo de judocas de alto nível, em um estudo realizado por SILVA, AMORIM, SOARES e MONTEIRO (1999), judocas pertencentes a seleção brasileira masculina participante dos Jogos Pan-americanos de Winnipeg 1999, apresentaram valores de 2,7 \pm 1,3 para o componente de endomorfia; 7,9 \pm 1,6 para o componente de mesomorfia; e de 1,1 \pm 0,6 para 0 componente de ectomorfia.

Entretanto, um fator que merece ser registrado é que o somatotipo muda com o decorrer da idade (CARTER \& HEATH, 1990). Portanto, ao avaliar judocas envolvidos em processos de promoção do talento esportivo, é preciso considerar que nos períodos da infância e início da adolescência deve-se guardar cuidado para interpretações de longo prazo, pois o indivíduo ainda pode estar sujeito às transformações morfológicas decorrentes do processo natural de crescimento e desenvolvimento e, inclusive, da interação desses processos com o treinamento.

\subsubsection{Considerações acerca do desempenho físico no judô}

O sucesso para o desempenho no judô de alto rendimento depende de um elevado nível técnico-tático, tendo como suporte físico a capacidade aeróbia, potência e capacidade anaeróbias, força e flexibilidade (LITTLE, 1991). Quanto ao metabolismo energético, o judoca precisa ter um bom sistema glicolítico de produção de energia e capacidade aeróbia adequada para manter um bom desempenho durante o período da luta (THOMAS, COX, LEGAL, VERDE \& SMITH, 1989). Neste sentido, conforme TAYLOR e BRASSARD (1981) a grande necessidade de produção de energia a partir da via glicolítica tem sido demonstrada pelas altas concentrações 
de lactato sangüíneo verificadas em judocas, sobretudo nos estudos que analisaram as concentrações de lactato sangüíneo durante a luta propriamente dita (FRANCHINI, TAKITO, LIMA, HADDAD, KISS, REGAZZINI \& BÖHME, 1998).

Contudo, uma taxa excessiva de lactato implica em prejuízo para o desempenho esportivo do judoca, uma vez que o mesmo está relacionado à fadiga e conseqüente interrupção da atividade (McARDLE, KATCH \& KATCH, 1991) podendo, portanto, determinar a vitória ou a derrota em competições (CAVAZANI, 1991).

Quanto a potência média e quanto a potência de pico, tanto absoluta quanto relativa, verificada através do teste anaeróbio de Wingate para membros superiores, a maioria dos estudos parecem indicar que até aproximadamente 15-16 anos de idade existe uma maior diferença quando se compara com os dados verificados em atletas adultos, principalmente em função de diferenças nos estágios de maturação sexual e das conseqüentes diferenças qualitativas na musculatura (FRANCHINI, 2001; INBAR \& BAR-OR, 1986). Entretanto, depois dos 17 anos de idade os atletas tendem a apresentar capacidade e potência anaeróbias semelhantes.

Ademais, conforme FRANCHINI (2001), judocas apresentam valores de potência durante o teste para membros superiores acima da média observada para sujeitos saudáveis durante o teste para membros inferiores. Conforme, THOMAS et alii (1989), este comportamento ocorre em função da extrema solicitação dos membros superiores durante o treinamento e a luta de judô.

Quanto a observação do desempenho em atletas de diferentes níveis competitivos, o nível competitivo dos atletas parece estar associado ao desempenho no teste de Wingate, pois, de acordo com HORSWILL, HICKNER e GALEA (1989), foram encontradas diferenças para o desempenho no teste de Wingate para membros superiores entre atletas de luta olímpica considerados de elite e não elite, sendo que o mesmo fato parece ocorrer em relação a grupos de judocas observados, conforme a TABELA 2. 
TABELA 2 - Desempenho no teste de Wingate para membros superiores em atletas de diferentes níveis e nacionalidades, valores de média e desvio padrão (FRANCHINI, 2001).

\begin{tabular}{|c|c|c|c|c|c|}
\hline $\begin{array}{l}\text { Autor(es) e } \\
\text { modalidades }\end{array}$ & Atletas & $\begin{array}{l}\text { PMa } \\
\text { (W) }\end{array}$ & $\begin{array}{c}\text { PMr } \\
(\mathrm{W} / \mathrm{kg})\end{array}$ & $\begin{array}{l}\mathrm{PPa} \\
\text { (W) }\end{array}$ & $\begin{array}{c}\mathrm{PPr} \\
(\mathrm{W} / \mathrm{kg})\end{array}$ \\
\hline $\begin{array}{l}\text { LITTLE (1991) } \\
\text { Judô }\end{array}$ & $\begin{array}{l}\text { Juvenis } \\
\text { Juniores } \\
\text { Seniores }\end{array}$ & $\begin{array}{l}282 \pm 70 \\
395 \pm 62 \\
447 \pm 87\end{array}$ & $\begin{array}{l}4,90 \pm 0,99 \\
5,75 \pm 0,59 \\
5,62 \pm 0,50\end{array}$ & $\begin{array}{l}407 \pm 172 \\
573 \pm 117 \\
675 \pm 133\end{array}$ & $\begin{array}{l}7,07 \pm 1,55 \\
8,39 \pm 1,08 \\
8,46 \pm 0,71\end{array}$ \\
\hline $\begin{array}{l}\text { SHARP } \\
\text { KOUTEDAKIS } \\
\text { (1987) } \\
\text { Judô }\end{array}$ & Seleção Inglesa & $736 \pm 221$ & $8,50 \pm 0,50$ & $916 \pm 301$ & $10,6 \pm 0,8$ \\
\hline $\begin{array}{l}\text { THOMAS et alii } \\
\text { (1989) } \\
\text { Judô }\end{array}$ & $\begin{array}{l}\text { Seleção } \\
\text { Canadense }\end{array}$ & $653 \pm 87$ & $8,66 \pm 1,17$ & $852 \pm 131$ & $11,3 \pm 0,8$ \\
\hline $\begin{array}{l}\text { TERBIZAN } \\
\text { SELJVOLD } \\
(1996) \\
\text { Luta }\end{array}$ & $\begin{array}{l}<15 \text { anos } \\
16 \text { anos } \\
17 \text { anos }\end{array}$ & $\begin{array}{l}364 \pm 77 \\
410 \pm 84 \\
432 \pm 91\end{array}$ & $\begin{array}{l}- \\
- \\
-\end{array}$ & $\begin{array}{l}- \\
- \\
-\end{array}$ & $\begin{array}{l}- \\
- \\
-\end{array}$ \\
\hline $\begin{array}{l}\text { HORSWILL et alii } \\
\text { (1989) } \\
\text { Luta }\end{array}$ & $\begin{array}{l}\text { Elite } \\
\text { Não-elite }\end{array}$ & $\begin{array}{l}376 \pm 21 \\
331 \pm 23\end{array}$ & $\begin{array}{l}5,9 \pm 0,1 \\
5,2 \pm 0,2\end{array}$ & $\begin{array}{l}472 \pm 27 \\
405 \pm 28\end{array}$ & $\begin{array}{l}7,48 \pm 0,43 \\
6,39 \pm 0,45\end{array}$ \\
\hline $\begin{array}{l}\text { HORSWILL, } \\
\text { MILLER, SCOTT, } \\
\text { SMITH, WELK e } \\
\text { VAN HANDEL } \\
\text { (1992) } \\
\text { Luta }\end{array}$ & $\begin{array}{l}\text { Seleção } \\
\text { Americana }\end{array}$ & - & $6,8 \pm 0,9$ & - & $7,80 \pm 1,00$ \\
\hline
\end{tabular}

Conforme a TABELA 2, é possível verificar que os valores de potência média dos três grupos de maior nível competitivo (seleções canadense e inglesa de judô e seleção norte americana de luta olímpica) são semelhantes aos valores da potência de pico dos demais grupos, indicando que estes atletas possuem elevada capacidade para realizar trabalho com os membros superiores. 
De acordo com RONTOYANNIS (1988), parece haver relação entre a capacidade aeróbia e o ritmo de remoção do lactato sangüíneo, tornando essa variável relevante para o desempenho no judô.

De acordo com MATSUDO e MATSUDO (1992), o $\mathrm{VO}_{2}$ máx é um importante fator a ser considerado na detecção de talentos para o judô. Conforme os autores, através do emprego da Estratégia Z CELAFISCS, judocas brasileiros de alto nível de rendimento apresentaram valores de $\mathrm{VO}_{2}$ máx cerca de 3,5 desvios padrão acima da média populacional.

Neste sentido, TAYLOR e BRASSARD (1981), também indicam o componente aeróbio como uma variável relevante para o desempenho em lutas de judô, por possuírem duração de cinco minutos cronometrados e sobretudo por competições que envolvem os atletas em seis até oito lutas em um mesmo dia.

Conforme FRANCHINI (2001), embora a potência aeróbia seja importante para o desempenho no judô, não se verifica a exigência de valores muito elevados (acima de $65 \mathrm{ml}$ kg/ min para o masculino), nem há indicação de que um $\mathrm{VO}_{2}$ de pico acima desses valores possa beneficiar o atleta e trazer vantagem para o desempenho na luta. Ademais, alguns estudos indicam que o treinamento concomitante da potência aeróbia e da força/ potência muscular resulta na diminuição da capacidade de desenvolver a força/ potência muscular, indicando que a manutenção da capacidade e potência aeróbias, sem que haja prejuízo para a força dinâmica e para o desempenho no judô, requer a realização de corridas de aproximadamente $3,2 \mathrm{~km}$ a $10,2 \mathrm{~km} / \mathrm{h}$ uma vez por semana (NAKAO, INOUE \& MURAKAMI, 1995).

Quanto a resistência muscular localizada, não há muitos estudos realizados especificamente em atletas de judô. Em um estudo realizado por PAULA (1987), a resistência muscular de membros superiores e tronco e a resistência muscular na flexão e extensão dos cotovelos parece ser um bom discriminante entre atletas melhores e piores classificados no ranking.

Em relação à força dinâmica, o teste de 1 RM (1 repetição máxima) tem sido bastante utilizado para avaliar a força dinâmica e para a prescrição do treinamento. Conforme FRANCHINI (2001), um judoca peso pesado de nível internacional apresentou os seguintes resultados em testes de 1 RM: (a) supino - 
$111 \mathrm{~kg}$; (b) rosca direta - $61 \mathrm{~kg}$; (c) remada alta - $66 \mathrm{~kg}$; (d) remada baixa - $102 \mathrm{~kg}$; (e) pulley costas - 86 kg; (f) pulley tríceps - 48 kg; (g) leg press - 391 kg; (h) mesa romana $-86 \mathrm{~kg}$.

Quanto à análise da força explosiva, alguns estudos tem utilizado a realização do salto vertical para a estimativa da potência muscular em judocas (THOMAS et alii, 1989). Os resultados encontrados são semelhantes na maioria dos estudos e estão situados entre 50 e $55 \mathrm{~cm}$.

A força isométrica também tem sido considerada como uma variável relevante para o desempenho no judô, principalmente em relação a força de preensão manual, importantíssima para o momento da pegada. Contudo, conforme BORGES (1989), não foi encontrada relação entre a força de preensão manual e o resultado da luta, devido a complexidade da luta que não é definida apenas pela ação isolada de uma variável (FRANCHINI, 2001). Conforme FRANCHINI et alii (1997), os valores de preensão manual direita e esquerda em atletas de elite variam

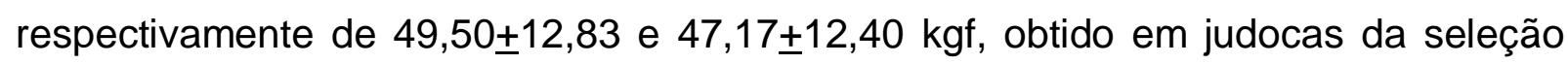

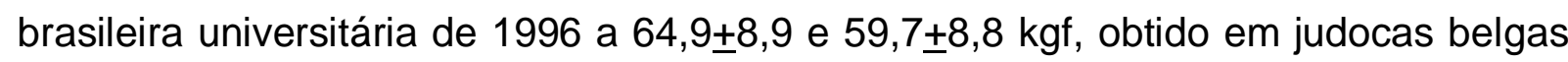
de alto nível (CLAESSENS et alii, 1984). Ademais, conforme BORGES (1989) e FRANCHINI et alii (1997), os valores de preensão manual tendem a aumentar com o aumento da massa corporal e com o aumento da estatura do atleta. Neste sentido, em estudos realizados acerca da força isométrica de tração lombar e de tração escápulo-umeral foi verificado que à medida que a categoria de peso aumenta, maior é a força de tração lombar e de tração escápulo-umeral, indicando a maior força absoluta dos atletas mais pesados (IIDA et alii,1998).

Em relação à flexibilidade, o teste de sentar e alcançar tem sido o mais utilizado para avaliar a flexibilidade de judocas (CLAESSENS et alii, 1984, 1986; LITTLE, 1991; THOMAS et alii, 1989). Em um estudo realizado por CLAESSENS et alii (1984), foram encontrados valores de média e desvio padrão de $28 \pm 6,3 \mathrm{~cm}$ para judocas belgas com menos de $71 \mathrm{~kg}$. IIDA et alii (1998) verificaram valores de média e desvio padrão de 53,5 $\pm 8,1 \mathrm{~cm}$ em uma amostra de judocas japoneses universitários. Conforme FRANCHINI (2001), em um estudo realizado com judocas da seleção brasileira universitária de judô $(n=5)$, foram encontrados os valores de média e desvio padrão de $36,2 \pm 4,7 \mathrm{~cm}$. 
Em relação ao estudo de IIDA et alii (1998) citado anteriormente, com judocas japoneses universitários pertencentes a diferentes categorias competitivas ( $\mathrm{n}$ = 729), foi possível verificar que a flexibilidade obtida no teste de sentar e alcançar não diferiu entre as distintas categorias, indicando que a variável flexibilidade parece não ser importante para o desempenho em todas elas.

\subsubsection{Considerações sobre a iniciação esportiva no judô}

É uma discussão permanente da ciência do esporte determinar a faixa etária mais adequada para se iniciar o processo de treinamento sistemático e específico em uma única modalidade esportiva (ARENA \& BÖHME, 2000).

Conforme BAXTER-JONES (1995), DE ROSE JUNIOR (1995), PAES (1992), ROWLAND (1996) e ZAKHAROV e GOMES (1992), a faixa etária em que os jovens atletas iniciam o treinamento específico e a competição pode variar conforme as tradições existentes em cada país, bem como de acordo com a modalidade esportiva considerada.

Neste sentido, de maneira genérica, BOMPA (1999), GRECO e BENDA (1998), TANI, MANOEL, KOKUBUN e PROENÇA (1988) e WEINECK (1999), determinam a faixa etária entre 12 e 14 anos como a mais orientada para que a criança comece a participar do treinamento em uma modalidade específica, bem como de eventos competitivos. ROBERTS e TREASURE (1992), complementam que até os 12 anos de idade a criança não deve participar de atividades esportivas específicas e competições formais, pois não possui maturidade suficiente para compreender e assimilar tudo o que está envolvido em um processo competitivo.

Por outro lado, MALINA e BOUCHARD (1991) e RODRIGUES e BARBANTI (1994), embora não estabeleçam idades específicas para a iniciação esportiva especializada, chamam a atenção para o fato de que o treinamento e a competição para jovens não devem ser dimensionados apenas com referência na idade cronológica da criança, mas sobretudo com base nas características físicas, 
emocionais e maturacionais, para que a prática esportiva não se torne uma obrigação, mas sim um aspecto favorável para o seu desenvolvimento.

Neste sentido, os autores acima citados corroboram com (a) as citações anteriores de BLOOM (1985) e CSIKSZENTMIHALYI, RATHUNDE e WHALEN (1997), ao enfatizarem que os anos iniciais da aprendizagem deveriam despertar no jovem, acima de tudo, o prazer pela prática; com (b) BARBANTI (1997), BÖHME (2000, 2002, 2004), BOMPA (1999, 2000), WEINECK (1999) e diversos autores da área do treinamento a longo prazo, acerca do respeito pela "etapa de iniciação e formação geral básica geral", desenvolvida entre os sete e 12/ 13 anos de idade; e com (c) a proposta de autores como GALLAHUE e OZMUN (1998), GRECO (1997), GRECO e BENDA (1998) e TANI et alii (1988) ao defenderem que o processo de aquisição de habilidades motoras gerais deve preceder o processo de aquisição das habilidades específicas relacionadas ao esporte, evitando uma iniciação esportiva inadequada e prematuramente especializada, que acabe por inibir as descobertas motoras da criança, a criatividade das respostas motoras e a ampliação do repertório motor.

Conforme ARENA e BÖHME (2000), no Brasil e mais especificamente no Estado de São Paulo, os processos de iniciação e especialização esportiva têm sido desenvolvidos em grande parte nos clubes esportivos particulares e em centros esportivos administrados por secretarias municipais. Conforme as autoras, estas entidades esportivas exercem um papel fundamental na iniciação e na continuidade da prática esportiva nas categorias menores subseqüentes, objetivando o treinamento a longo prazo.

Neste sentido, o estudo de ARENA e BÖHME (2000), ao explorar o universo dos programas de iniciação e especialização esportiva na grande São Paulo, contrapondo-se à teoria naquilo que seria ideal e saudável para o sucesso do processo de treinamento a longo prazo, encontrou para o judô resultados variando entre as idades de seis e 10 anos de idade nas escolas de esporte das Secretarias Municipais de Esportes e entre cinco e nove anos nas escolas de esporte dos clubes esportivos. Portanto, no referido estudo, registra-se a ocorrência precoce da iniciação especializada (iniciação aos 5/ 6 anos de idade), cerca de um a dois anos antes do período ideal considerado pela literatura, que seria a partir dos sete anos de idade. 
Ademais, foi verificado que as idades de especialização no judô em $67 \%$ das entidades esportivas apuradas, tendem a coincidir com o início das competições na modalidade, ocorrendo de um a dois anos antes da primeira categoria federada competitiva e, consequentemente, caracterizando a especialização esportiva precoce.

Ainda conforme o estudo de ARENA e BÖHME (2000), corroborando com BLOOM (1985), CSIKSZENTMIHALYI, RATHUNDE e WHALEN (1997) e ERICSSON, KRAMPE e TESCH-RÖMER (1993) sobre a importância do conhecimento profissional nos anos iniciais da aprendizagem, é fundamental compreender que iniciar cedo no esporte não é necessariamente começar precocemente o treinamento e a competição regular de uma única modalidade esportiva. Mas sim, iniciar a prática esportiva generalizada, envolvendo a vivência de diferentes modalidades como o caminho mais acertado para a preparação esportiva do jovem em um processo de longo prazo.

Desta maneira, uma formação esportiva iniciada nos primeiros níveis de escolaridade, em concordância com a escola, desenvolvida por professores de educação física devidamente preparados e tendo como objetivo principal o desenvolvimento global, equilibrado e harmonioso da criança, o respeito a individualidade biológica e o conhecimento da especificidade da modalidade esportiva, seriam elementos fundamentais no que tange a qualidade das forças de apoio que são imprescindíveis para o desenvolvimento ideal de crianças e jovens e, consequentemente, para a promoção de talentos esportivos.

Portanto, de acordo com o que pode ser observado durante esta fundamentação teórica, cuja preocupação principal foi a organização de conhecimentos acerca da problemática que envolve o talento e os processos de promoção de talentos para o esporte de alto nível e particularmente para o judô, foi possível constatar que esta modalidade esportiva, assim como outras, ainda carece de estudos que se preocupem em verificar de maneira fundamentada o desenrolar de todo um processo de promoção de talentos, a longo prazo. Em função dessa carência é que se propõe o delineamento do presente estudo, no sentido de buscar 
elucidar e discutir a formação e desenvolvimento de judocas brasileiros talentosos, podendo contribuir com os profissionais de educação física e esporte que ainda têm utilizado, insuficientemente, apenas a experiência e a intuição para selecionar e promover talentos.

A presente pesquisa possuiu um delineamento qualitativo, de natureza retrospectiva, no qual se buscou caracterizar a trajetória de judocas olímpicos brasileiros diante dos modelos de desenvolvimento de talento.

\subsection{Amostra}

A amostra foi composta intencionalmente tomando-se como critério o desempenho dos atletas. Para tanto, foi utilizada uma amostra de seis atletas brasileiros convocados para compor a seleção olímpica masculina de judô nos Jogos Olímpicos de Atenas, 2004. Conforme a aprovação do projeto junto ao Comitê de Ética em Pesquisa da EEFE-USP (ANEXO III), os judocas tomaram contato com os documentos relacionados ao Termo de Consentimento Livre e Esclarecido (ANEXO IV), tendo concordado participar da pesquisa.

O objetivo dessa intencionalidade em relação à amostra se justifica pela necessidade de incorporar na presente pesquisa sujeitos que sejam bons representantes do alto nível de desempenho e, consequentemente, de talento esportivo. Conforme o acompanhamento realizado, por ocasião da elaboração deste trabalho, a seleção olímpica masculina de judô tem apresentado desempenho satisfatório em campeonatos internacionais, ocupando posições relevantes nas diferentes categorias competitivas e, portanto, podendo corroborar como referencial de alto desempenho no judô masculino (nível internacional). Além disso, é uma modalidade que tem demonstrado certa estabilidade no que se refere a resultados 
obtidos no decorrer dos tempos e que merece ser observada sobre a perspectiva dos modelos de desenvolvimento de talento.

\subsection{Instrumento da pesquisa}

Com o objetivo de relacionar a trajetória de judocas olímpicos brasileiros com os modelos de desenvolvimento de talento, foi utilizado como instrumento de pesquisa o método do "Discurso do Sujeito Coletivo" (DSC), LEFÈVRE e LEFÈVRE (2003).

O DSC permitiu uma abordagem qualitativa acerca do processo de desenvolvimento do talento. Conforme LEFÈVRE e LEFÈVRE (2003), o pensamento é algo essencialmente discursivo e só pode ser obtido numa escala coletiva a partir de perguntas abertas elaboradas para um conjunto de indivíduos de alguma forma representativos dessa coletividade e deixar que esses indivíduos se expressem mais ou menos livremente, ou seja, que produzam discursos. Neste sentido, a questão fechada seria insuficiente diante dessa perspectiva, pois não ensejaria a expressão de um pensamento, mas a expressão de uma adesão (forçada) a um pensamento preexistente.

Desta maneira, de acordo com discursos individuais obtidos através da técnica de entrevista estruturada, foi possível construir metodologicamente a expressão do pensamento coletivo. O pensamento coletivo precisa ser pesquisado qualitativamente, justamente por ser uma variável qualitativa e, ao contrário de variáveis quantitativas como peso, estatura etc., não é pré mas pós-construída, ou seja, não se configura como um input, mas como um output da pesquisa.

A metodologia do DSC utilizada é, portanto, uma proposta de organização e tabulação de dados qualitativos de natureza verbal e, no presente estudo, obtidos de depoimentos dos atletas. Para confeccionar os DSCs, LEFÈVRE e LEFÈVRE (2003) criaram as seguintes figuras metodológicas:

a) Expressões-chave $(\mathrm{ECH})$ : pedaços, trechos ou transcrições literais do discurso, demarcadas pelo pesquisador (sublinhadas, iluminadas, 
coloridas) e que revelam a essência do depoimento ou, de forma mais precisa, do conteúdo discursivo dos segmentos em que se divide o depoimento e que, em geral, correspondem às questões da pesquisa. Desta maneira as ECH são a matéria-prima do DSC.

b) Idéias centrais (IC): é um nome ou expressão lingüística que revela e descreve, de forma sintética, precisa e fidedigna, o sentido de cada um dos discursos analisados e de cada conjunto homogêneo de $\mathrm{ECH}$, que vai dar origem, posteriormente, ao DSC. A IC não é uma interpretação, mas uma descrição do sentido de um depoimento ou de um conjunto de depoimentos.

c) Discurso do Sujeito Coletivo (DSC): é um discurso síntese redigido na primeira pessoa do singular e composto pelas $\mathrm{ECH}$ que têm a mesma IC.

Desta forma, o presente estudo incorporou entrevistas abertas estruturadas, que permitiram ao sujeito discorrer livremente sobre o tema proposto, limitado, entretanto, por um roteiro preestabelecido de questões que foram pontuadas durante a entrevista. Neste sentido, com respeito ao levantamento bibliográfico realizado acerca do talento, dos modelos de desenvolvimento de talento e do talento esportivo, foi elaborado o roteiro de entrevista do presente estudo (ANEXO I).

Os depoimentos foram gravados em fita magnética e, posteriormente, transcritos de modo a recuperar a integridade dos mesmos. A transcrição e a organização dos discursos apresentaram-se na mesma ordem em que foram realizadas as entrevistas. Os sujeitos foram identificados pela letra $S$, seguida do número da realização da entrevista (S1; S2; S3, S4, S5 e S6).

$\mathrm{Na}$ segunda etapa, tendo os discursos já transcritos, foram realizados os procedimentos anteriormente descritos para a formulação das $E C H, I C$ e, conseqüentemente, do DSC.

A seguir, de posse dos DSCs, foi possível contrastar e emergir a discussão acerca dos elementos oriundos do discurso com a literatura da área. 
Com intuito de testar a aplicabilidade e o efeito do roteiro de entrevista elaborado, bem como o instrumento de pesquisa do DSC (LEFÈVRE \& LEFÈVRE, 2003) em todas as etapas de desenvolvimento, foi realizado o Estudo Piloto.

O Estudo Piloto contou com uma amostra de judocas de alto nível competitivo, que se aproximou da amostra original no que tange ao desempenho esportivo. Para tanto, foram utilizados seis judocas de nível competitivo nacional e/ou internacional que não participaram da Seleção Brasileira Olímpica Masculina para os Jogos Olímpicos de Atenas, 2004.

Desta maneira, os atletas do Estudo Piloto foram submetidos aos mesmos procedimentos de entrevista adotados no trabalho, permitindo não apenas testar e aferir o instrumental, mas também a aquisição de experiência por parte do pesquisador desde as fases de preparação do ambiente para a entrevista, preparação do entrevistado, entrevista propriamente dita, registro e tabulação dos discursos, formulação das ECHs, formulação das ICs, estabelecimento dos DSCs, bem como dos possíveis desdobramentos em relação à literatura específica do talento, dos modelos de desenvolvimento de talento e do talento esportivo.

Neste sentido, a partir da execução do Estudo Piloto e dos resultados obtidos através dos DSCs construídos, pode-se verificar, além da alta aplicabilidade do método, o alto poder das questões elaboradas para a entrevista, bem como a eficácia de seu produto (ECH, IC e DSC) em relação ao objetivo do presente estudo.

\section{RESULTADOS E DISCUSSÃO}

Os resultados do presente estudo serão apresentados de acordo com o objetivo inerente a cada pergunta da entrevista. O produto de cada pergunta permitiu a captação de idéias centrais (ICs) que possibilitaram a construção dos resultados da pesquisa, isto é, os Discursos do Sujeito Coletivo (DSCs), que serão discutidos nos próximos tópicos (de 4.1 até 4.12 ). 
Antes disso, com o intuito de disponibilizar as expressões-chave $(\mathrm{ECH})$ de cada judoca entrevistado (S1, S2, S3, S4, S5, e S6), relacionadas a cada pergunta (de 1 até 12), foram alocados no ANEXO II, na íntegra, os QUADROS (de 1 até 12) do Instrumento de Análise do Discurso (IAD), contendo o conteúdo total do discurso de cada judoca (expressões-chave - ECH), bem como as idéias centrais (ICs) que puderam ser captadas e etiquetadas (ex.: A, B, C, D etc) de acordo com a equivalência e/ou complementaridade presente no discurso dos distintos sujeitos da pesquisa. Sendo assim, cada IAD representa a matéria prima com a qual foram construídos os resultados da pesquisa, ou seja, os DSCs que emergiram de cada pergunta.

Portanto, num segundo momento, porém em primeiro plano no corpo do presente texto, serão apresentados os próximos tópicos do trabalho (de 4.1 até 4.12). Cada um destes tópicos versará sobre o objetivo central de cada uma das perguntas elaboradas e contará com a apresentação de TABELAS (de 3 até 14) contendo as distintas idéias centrais (ICs), freqüências de cada IC e percentuais relacionados. Neste sentido, em cada tópico, seguido da respectiva TABELA, serão apresentados os resultados que foram construídos sob a forma de DSC de cada IC, acompanhados simultaneamente da discussão dos elementos norteadores da pesquisa em relação à pergunta em questão.

\subsection{Idade de iniciação e tempo de prática}

A idade de iniciação em uma determinada modalidade esportiva é um tema bastante discutido na área da ciência do esporte. Na literatura (ARENA \& BÖHME, 2000; BAXTER-JONES, 1995; DE ROSE JUNIOR, 1995; PAES, 1992, ROWLAND, 1996; ZAKHAROV, 1992), a faixa etária recomendada para o início dos treinamentos sistemáticos pode variar conforme as tradições de um país, bem como de acordo com a especificidade da modalidade esportiva.

Contudo, conforme BOMPA (1999), GRECO e BENDA (1998), TANI et alii (1998) e WEINECK (1999), a faixa etária situada entre 12 e 14 anos seria a mais orientada para que a criança começasse a participar do treinamento em uma 
modalidade específica. Para BARBANTI (1997), BÖHME (2000, 2002, 2004), BOMPA (1999, 2000), WEINECK (1999) e diversos autores da área do TLP, este tipo de consideração sobre a idade de iniciação nos treinamentos em uma única modalidade (entre 12 e 14 anos) é fundamental no sentido de permitir que a criança, no período entre sete e 12/ 13 anos, tenha a possibilidade de participar de uma "etapa de iniciação e formação geral básica" antes que seja especializada precocemente em uma única modalidade.

Não distante deste contexto, o tempo de prática também é um entre outros fatores que costumam ser discutidos pela literatura relacionada ao treinamento esportivo. A própria teoria do TLP traz subentendida a idéia de que 0 tempo de prática possui relação direta com o processo de desenvolvimento do talento esportivo. Diversos autores como BARBANTI (1997), BÖHME (2000, 2002, 2004), BOMPA (1999, 2000), GRECO (1997), WEINECK (1999) têm discutido e/ou apresentado modelos de TLP que, em síntese, consideram que o treinamento para o esporte de alto nível deve se fundamentar num processo com duração média de 6 a 10 anos, conforme a especificidade da modalidade esportiva considerada.

Nessa perspectiva, acerca da idade de iniciação e do tempo de prática de judocas olímpicos brasileiros, pode-se verificar na TABELA 3 as idades individuais de iniciação na modalidade e o tempo de prática acumulado para cada judoca até o presente estudo. São apresentados também, em função da natureza dos dados obtidos, os valores de média e desvio padrão da amostra para idade de iniciação e tempo de prática.

Sendo assim, em função da natureza dos discursos obtidos para a pergunta - Há quanto tempo você pratica Judô? -, em vez da construção do DSC, optou-se pela caracterização da amostra através das idades de iniciação na modalidade e do tempo de prática de cada judoca. 
TABELA 3 - Idade de iniciação e tempo de prática de judocas olímpicos brasileiros.

\begin{tabular}{ccc}
\hline & Idade de iniciação (anos) & Tempo de prática (anos) \\
\hline S1 & 5 & 18 \\
S2 & 7 & 18 \\
S3 & 5 & 27 \\
S4 & 8 & 22 \\
S5 & 7 & 20 \\
S6 & 5 & 27 \\
média & 6,2 & 22 \\
dp & 1,3 & 4,1 \\
\hline
\end{tabular}

De acordo com os valores observados, pode-se verificar que a média de idade para a iniciação no Judô dos judocas olímpicos brasileiros foi de $6,2 \pm 1,3$ anos.

Neste sentido, em um estudo realizado por ARENA e BÖHME (2000) na grande São Paulo, foram encontrados para a iniciação no Judô valores variando entre seis e 10 anos nas escolas de esporte das Secretarias Municipais de Esportes e entre seis e nove anos nas escolas de esporte dos clubes esportivos. Por sua vez, estudos realizados com judocas alemães verificaram valores de 7,1 $\pm 2,1$ anos para 0 início na modalidade (MARTIN, CARL \& LEHNERTZ', 1991 apud BÖHME, 2000). Sendo assim, quanto a valores individuais e médios, a presente amostra se aproxima do que é verificado na prática. Contudo, cabe salientar que tanto na presente amostra quanto nos estudos de ARENA e BÖHME (2000) e MARTIN, CARL e LEHNERTZ $^{9}$ (1991) apud BÖHME (2000), os casos de iniciação em idades muito precoces, ou seja, entre cinco e seis anos de idade, devem ser vistos com cautela se associados a uma especialização esportiva unilateral (precoce).

Neste sentido, corroborando com a essência das colocações de BLOOM (1985), CSIKSZENTMIHALYI, RATHUNDE e WHALEN (1997) e ERICSSON, KRAMPE e TESCH-RÖMER (1993), pode-se assumir que iniciar cedo no esporte não é necessariamente sinônimo de especialização esportiva precoce. Conforme ARENA e BÖHME (2000), no caso específico do Judô, a idade ideal para a iniciação seria a partir dos sete anos de idade, considerando os pressupostos de que a 
iniciação aos sete anos poderia ser desenvolvida sem que houvesse o prejuízo da "etapa de iniciação e formação geral básica", garantindo o início prazeroso na modalidade e ao mesmo tempo controlando fatores de freqüência, duração e planejamento de atividades para que a criança descubra outros desdobramentos motores através da própria prática do Judô, como também de outras atividades motoras que possam ser conjugadas de maneira saudável no cotidiano de vivências da criança.

Quanto ao tempo de prática, o valor médio dos judocas olímpicos brasileiros foi de $22 \pm 4,1$ anos, o que indica a longa trajetória do judoca até o alto nível de desempenho. Neste sentido, é possível considerar que os resultados se aproximam do que é preconizado na teoria do TLP, bem como das teorias relacionadas ao processo de desenvolvimento de talentos (BLOOM, 1985; CSIKSZENTMIHALYI, RATHUNDE \& WHALEN, 1997; ERICSSON, KRAMPE \& TESCH-RÖMER, 1993), nos quais parece ser unânime a idéia de que tempo e qualidade de prática corroboram diretamente para o desenvolvimento do talento em qualquer área do conhecimento, inclusive do talento esportivo. Resgatando o conjunto das colocações de ERICSSON, KRAMPE e TESCH-RÖMER (1993) e de GIBBONS et alii (2002), para desenvolver talento são necessárias 10.000 horas e/ou 10 anos de treinamentos sistemáticos e prática deliberada. Sendo assim, a despeito da prática deliberada, cabe discutir em outros tópicos do presente estudo a qualidade dos trabalhos desenvolvidos, tendo em vista que a presente questão traz limitações para esta parte da discussão, uma vez que nesta oportunidade foi apresentado apenas o caráter quantitativo da prática.

\subsection{Iniciação no J udô}

A respeito do processo de iniciação no Judô é que foi formulada a pergunta - Você pode me contar como foi seu começo no judô? - . Verificar os fatores que levaram os judocas à descoberta da modalidade é interessante no sentido de permitir apurar os distintos motivos e lou estruturas que favoreceram esta aproximação. 
Neste sentido, teoricamente, o processo de iniciação esportiva estaria diretamente relacionado com a fase de detecção de talentos. Conforme descrito durante a revisão de literatura do presente estudo, o processo de detecção do talento esportivo depende da utilização de medidas e meios que possibilitem encontrar um número suficientemente grande de crianças que se disponham a participar de um programa de formação esportiva geral básica, considerado a primeira etapa do TLP (BÖHME, 1995).

No estudo de GIBBONS et alii (2002), foi possível verificar que os atletas olímpicos norte americanos tiveram seu início em modalidades esportivas principalmente através de atividades desenvolvidas com a própria família e amigos, em clubes privados, em programas comunitários e na própria escola.

Entretanto, no Brasil, observa-se que escolas, centros esportivos comunitários, clubes e escolas de esporte, ainda não possuem uma estrutura (física e pessoal) e/ou uma política de ação suficientemente democrática e coerente às necessidades e interesses da criança (GRECO, 1997), colocando em dúvida a gama efetiva de oportunidades que a grande maioria das crianças e adolescentes brasileiros acumula durante a sua formação. Assim, neste contexto relacionado à iniciação esportiva e aos processos de detecção, seleção e promoção de talentos, o Brasil caracteriza-se como gerador de um programa inconsistente, assistemático e não estruturado, no qual estado, empresas, clubes e a própria família, dividem a responsabilidade de subsidiar a estrutura esportiva para o talento esportivo (MATSUDO, 1999; MATSUDO \& MATSUDO, 1997).

Desta forma, em relação à presente amostra de judocas olímpicos brasileiros, seguem apresentadas na TABELA 4 as ICs captadas, a freqüência das respostas e o percentual referente a cada IC para a pergunta - Você pode me contar como foi seu começo no judô? - . 
TABELA 4 - Caracterização das idéias centrais, freqüência e percentual de respostas para a pergunta: Você pode me contar como foi seu começo no judô?

\begin{tabular}{llcc}
\hline & \multicolumn{1}{c}{ IC } & Freqüência & $\%$ \\
\hline A & Apoio da família & 5 & 83,3 \\
B & Proximidade de casa & 3 & 50,0 \\
C & Comportamento & 3 & 50,0 \\
D & Bons professores & 1 & 16,6 \\
\hline
\end{tabular}

Conforme o QUADRO 2 (ANEXO II) e as ICs captadas (TABELA 4) para as somas dos discursos, seguem abaixo os DSCs construídos (1, 2, 3 e 4) para cada IC:

\section{DSC1: IC-A - Apoio da família (S2, S3, S4, S5, S6).}

Meu pai, que fazia Judô, disse que eu precisava fazer algum esporte. 0 pediatra da família recomendou para minha mãe que eu fizesse Judô e Natação. Tinha um tio que também fazia J udô que sugeriu que eu entrasse no J udô. Logo no 2o dia que eu fui, meu irmão foi também, e assim tudo começou. Não que eu já gostasse de Judô, eles me impuseram isso, deu certo e eu comecei a gostar do esporte. Eu não tinha idéia do que era o J udô, não tinha idéia do que era nada, mas eu gostava de artes marciais devido a família já praticar artes marciais.

\section{DSC2: IC-B - Proximidade de casa (S1, S2, S5).}

Nasci numa cidade do interior e não tinha muita opção para a prática esportiva, mas havia uma forte influência da colônia japonesa. Os esportes praticados na época eram o Judô, Atletismo e Beisebol. Então fui atraído pela disciplina do Judô, pela educação, pela perseverança. Foi isso o que mais me cativou. Entrei em uma academia de tradição, academia japonesa mesmo, no meu bairro. 


\section{DSC 3: IC-C - Comportamento (S2, S3, S4).}

Eu entrei no Judô porque eu era uma criança hiperativa. Tinha um comportamento que minha mãe não conseguia me dominar muito em casa e meus pais queriam que eu não ficasse muito tempo na rua. Era aquele discurso que todo pai faz para o filho no sentido de afastar das drogas e do tempo ocioso.

\section{DSC4: IC-D - Bons professores (S5).}

Obs.: o discurso abaixo se refere exclusivamente ao sujeito $\mathrm{S} 5$, pois apenas ele apresentou a IC bons professores, não caracterizando, portanto, um discurso coletivo.

Eu dei sorte, peguei um professor que para iniciação, eu acho, eu considero ele um dos melhores do Brasil. Ele já revelou grandes talentos, não só eu, vários outros. Então é assim, tudo que eu tenho hoje é devido a essa ótima iniciação que eu tive.

Portanto, de acordo com os resultados dos DSCs apresentados, pode-se verificar como relevante a importância da família (83,3\%) no processo de aproximação dos judocas à modalidade. Outros fatores como a proximidade de casa (50\%), as características de comportamento da criança (50\%) e a presença de bons professores na iniciação $(16,6 \%)$ também puderam ser observados nos discursos como agentes dessa busca e/ou aproximação.

Quanto ao DSC1 (apoio da família) e ao DSC3 (comportamento), foi possível verificar o impacto positivo que a estrutura familiar pode provocar na adesão da criança ao processo de iniciação na modalidade. Num primeiro momento, por vezes, a criança nem sabia ao certo se gostava ou não da modalidade, mas o simples fato de encontrar reforço familiar dando apoio adequado e até participando como praticantes da modalidade (ex.: pais, tios, irmãos) parece ter sido fundamental para o processo de iniciação dos judocas.

Outro fator que merece ser comentado quanto ao apoio da família, é a percepção de que um reforço positivo adequado da família pela prática do judô pode 
exercer papel fundamental não somente na aproximação da modalidade, mas sobretudo na geração de um sentimento de prazer pela prática (gostar) e, quando há prazer envolvido, pode-se inferir sobre o alto grau de probabilidade de a criança continuar na atividade. No sentido figurado, quando uma família apresenta o paladar alimentar da carne de fígado na dieta da criança e esta não possui o reforço adequado, ou seja, a família prepara o alimento mas nenhum membro consome e/ ou esboça expressões e comportamentos verdadeiramente positivos sobre a carne de fígado colocada à mesa, a chance da mesma incorporar a carne de fígado na sua prática alimentar cotidiana é provavelmente menor do que uma família que apresenta, adere e consome o alimento com verdadeiro prazer.

Sendo assim, o discurso observado corrobora com o comportamento descrito nos estudos de BLOOM (1985), CSIKSZENTMIHALYI, RATHUNDE e WHALEN (1997), GIBBONS et alii (2002) e LIDOR e LAVYAN (2002) no que tange os anos iniciais de aprendizagem. Conforme os referidos autores, assim como no presente estudo, (a) o apoio e incentivo considerável dos pais, professores e/ ou treinadores foi fundamental para os anos de iniciação, (b) os anos iniciais da aprendizagem foram marcados por um período no qual a prática era divertida e prazerosa, em que a criança aprendia a gostar da atividade, (c) o interesse pela atividade era fundamental para a permanência da criança no estágio inicial, bem como para alcançar o próximo estágio de desenvolvimento, dependendo fortemente do apoio e da orientação de técnicos e professores, (d) para muitas crianças, esse contexto parecia agir como um fator motivacional relevante para o desenvolvimento da área de interesse futuro, e (e) ainda que os professores e treinadores não fossem os mais tecnicamente habilidosos, sob o ponto de vista do trabalho com crianças eram profissionais extremamente capacitados e forneciam reforços afetivos positivos às necessidades inerentes ao período da infância, mantendo a aprendizagem e o desempenho nas atividades.

Neste sentido, quanto ao DSC4 - bons professores - é possível relacionar a referida idéia central aos elementos apresentados no parágrafo acima, na medida em que uma cadeia de apoio composta por familiares e professores e/ ou técnicos parece ser um suporte essencial para que a criança se encoraje e participe de uma modalidade esportiva. Desta maneira, é possível verificar no DSC4 a 
relevância atribuída ao professor que exerceu o trabalho de iniciação no judô. Entretanto, pode-se observar agregada ao mesmo discurso, a idéia de que nem todos possuem a chance de iniciar no judô sob a responsabilidade de um bom professor. Conforme uma fração do DSC4, - Eu dei sorte, peguei um professor que para iniciação, eu acho, eu considero ele um dos melhores... - . Portanto, cabe questionar até que ponto a grande maioria das crianças e adolescentes brasileiros possui a oportunidade de se aproximar do judô e, em se aproximando, qual seria a chance das mesmas serem supervisionadas por profissionais devidamente preparados para atuar nos anos iniciais da aprendizagem. Desta maneira, deixar a qualidade do processo de iniciação no judô (ou de qualquer atividade) entregue à "sorte" ou ao "acaso" é um risco que não democratiza (a) o acesso à prática, (b) a qualidade da prática, (c) a descoberta do prazer e consequentemente, a longo prazo, (d) a possibilidade fundamentada de gerar talentos, não por obra do "acaso", mas por um "motivo". Não distante deste contexto, ao pensar no modelo educacional que perdura em nosso país, é possível verificar as mesmas carências, no qual o destino das descobertas e prazeres de muitas gerações foi e permanece entregue ao "acaso".

Ainda nesta perspectiva, conforme MORAES, DURAND-BUSH e SALMELA (1999), o sucesso de uma pessoa talentosa depende do apoio de diversos segmentos da sociedade, como a própria família, bons mentores e professores e também bons treinadores no caso do esporte. Para HOHMANN, WICK e CARL ${ }^{5}$ (2001) apud BÖHME (2004), corroborando com BLOOM (1985), CSIKSZENTMIHALYI, RATHUNDE e WHALEN (1997), ERICSSON, KRAMPE e TESCH-RÖMER (1993) e MORAES, DURAND-BUSH e SALMELA (1999), deve-se considerar na estrutura de desenvolvimento do talento o suporte social disponível na família, escola, clube e federações na organização da modalidade esportiva.

Neste sentido, conforme a DSC2 (proximidade de casa), observa-se que em relação a presente amostra, estruturas como escola, clube e centros esportivos públicos em nenhum momento foram citadas quanto a sua presença e importância no processo de iniciação no judô. Coincidentemente, o DSC2 traz em seu bojo a idéia de um processo de iniciação dependente da cultura isolada de uma cidade ou da proximidade de uma academia particular perto de casa e não de um programa 
estruturado e democratizado de acesso à prática de diferentes atividades esportivas, geradas inclusive pelo poder público (ARENA \& BÖHME, 2000).

Portanto, mais uma vez, depara-se com o fator "acaso" na geração de oportunidades na fase de iniciação, contrariando os pressupostos de BLOOM (1985), BENTO (1989), CSIKSZENTMIHALYI, RATHUNDE e WHALEN (1997), ERICSSON, KRAMPE e TESCH-RÖMER (1993) e HEBBELINCK (1989), no que se refere a ampla função da escola e do estado, que abrangeria desde a fase das descobertas das potencialidades e deficiências de cada criança, até os processos de seleção de talentos e o preparo específico para uma determinada modalidade esportiva através do TLP. Por outro lado, observa-se que mesmo diante de um processo carente, assistemático e não estruturado, algumas cidades de cultura oriental e microssistemas de academias espalhadas pelo Brasil têm contribuído para os anos iniciais de aprendizagem, ocupando papel relevante na primeira etapa do TLP.

Contudo, confirma-se diante deste registro a carência das estruturas públicas escolares e esportivas disponíveis no Brasil, escassas de recursos físicos e humanos capazes de oferecer oportunidades diversas para crianças e adolescentes (GRECO, 1997; MATSUDO, 1999; MATSUDO \& MATSUDO, 1997).

\subsection{Talento precoce}

A respeito da manifestação do talento, é comum deparar com a idéia popular de que é possível verificar precocemente o talento de uma criança. Particularmente na mídia esportiva, não é raro verificar matérias que apresentam crianças com desempenhos julgados geniais e suficientemente passíveis de determinar que aquele retrato do momento irá perdurar durante todo processo de crescimento, desenvolvimento, maturação e treinamento, induzindo o pensamento coletivo à crença de que o surgimento do talento deve ser precoce e estável, e, portanto, excluindo a idéia de que uma criança inicialmente julgada como "normal" possa, após anos de treinamento, se tornar talentosa.

Neste sentido, especificamente na área do treinamento esportivo, tal perspectiva parece evidente na medida em que na prática, técnicos esportivos e 
"olheiros" se dividem desde cedo na função de observar o desempenho de crianças e, com base nessa observação, determinar escolhas que encaminharão algumas crianças para o processo de iniciação numa modalidade esportiva em detrimento de muitas outras, que por não apresentarem (subjetivamente) os traços mínimos necessários para aquele momento, serão determinadas como "fracas" ou não aptas para o processo de TLP e, consequentemente, poderão ser prematuramente desencorajadas e/ ou amputadas da possibilidade de se desenvolver num dado contexto.

Desta maneira, em relação ao presente estudo, diante da possibilidade de observar a manifestação do talento em judocas olímpicos brasileiros, é que foi elaborada a pergunta - No começo da sua formação você acha que se destacava dos demais praticantes de judô? - . Neste sentido, em relação a referida pergunta, seguem apresentadas na TABELA 5 as ICs captadas, a freqüência das respostas e o percentual referente a cada IC.

TABELA 5 - Caracterização das idéias centrais, freqüência e percentual de respostas para a pergunta: No começo da sua formação você acha que se destacava dos demais praticantes de judô?

\begin{tabular}{cccc}
\hline & \multicolumn{1}{c}{ IC } & Freqüência & $\%$ \\
\hline A & Sim, me destacava & 1 & 16,6 \\
B & Não me destacava & 5 & 83,3 \\
C & Gostava de competir & 1 & 16,6 \\
\hline
\end{tabular}

Conforme o QUADRO 3 (ANEXO II) e as ICs captadas (TABELA 5) para as somas dos discursos, seguem abaixo os DSCs construídos (1, 2 e 3) para cada $\mathrm{IC}$ :

\section{DSC 1: IC-A - Sim, me destacava (S1).}

Obs.: o discurso abaixo se refere exclusivamente ao sujeito $\mathrm{S} 1$, pois apenas ele apresentou a IC sim, me destacava, não caracterizando, portanto, um discurso coletivo. 
Sim, foi desde o começo. Nas competições internas da minha cidade já consegui me destacar e o meu professor até comentou com o meu pai: olha, investe nesse garoto que esse garoto tem potencial, é garoto diferenciado.

\section{DSC2: IC-B - Não me destacava (S2, S3, S4, S5, S6).}

Não, não, não. Eu não tinha nenhum diferencial. Eu sempre fui um atleta que não me destacava. Tinha muita dificuldade em termos de coordenação para os golpes. Eu tinha um pouco de medo, um pouco de receio de cair, esse tipo de coisa. No início eu era um atleta comum, mediano, normal, nada assim expoente da turma. Pude ser campeão regional, campeão de algumas competições amistosas, mas não tinha um grande destaque. Ganhava alguns campeonatos, perdia outros.

\section{DSC3: IC-C - Gostava de competir (S5).}

Obs.: o discurso abaixo se refere exclusivamente ao sujeito $\mathrm{S} 5$, pois apenas ele apresentou a IC gostava de competir, não caracterizando, portanto, um discurso coletivo.

Eu já gostava de competir, não importando se eu perdesse ou ganhasse, o importante para mim era estar participando da competição.

Assim, de acordo com os resultados dos DSCs apresentados, pode-se verificar conforme a TABELA 5, que a maioria dos judocas olímpicos brasileiros não se destacava $(83,3 \%)$ na fase de iniciação no judô; um judoca $(16,6 \%)$ acrescentou que um fator importante na iniciação, antes mesmo de obter destaque através de resultados expressivos, era o gosto pela competição; e apenas um judoca $(16,6 \%)$ confirmou a hipótese do talento se manifestar desde as idades precoces.

Conforme o DSC2 (não me destacava), é bastante enfática nos discursos dos judocas olímpicos brasileiros a idéia de que durante a iniciação não apresentavam nenhum diferencial ou destaque em relação a seus pares. Inclusive, pode-se notar que além de não possuir destaque na modalidade, o comentário sobre o desempenho na iniciação é caracterizado por elementos pejorativos como 
dificuldade de coordenação e até medo de cair. Por sua vez, o DSC3 (gostava de competir) revela o pensamento do prazer pela competição, confirmando a idéia de que antes de ganhar o importante e o prazeroso era competir.

Neste sentido, a manifestação do talento em judocas olímpicos brasileiros se aproxima dos pressupostos de BLOOM (1985), BRITO, FONSECA e ROLIM (2004); CSIKSZENTMIHALYI, RATHUNDE e WHALEN (1997), ERICSSON, KRAMPE e TESCH-RÖMER (1993), GIBBONS et alii (2002) e GUENTHER (2000), na medida em que (a) a precocidade parece não ser um sinal confiável para a predição do talento e (b) que o talento pode ser desenvolvido ao longo de um processo mais duradouro no qual o prazer pela prática é fundamental.

Conforme GUENTHER (2000), menos de um terço das pessoas que são consideradas talentosas em algum domínio do conhecimento foram crianças precoces. Na presente amostra, de acordo com o DSC1 (sim, me destacava), apenas um judoca $(16,6 \%)$ apresentou indicação de destaque precoce.

Em um estudo retrospectivo realizado por BRITO, FONSECA e ROLIM (2004), foi verificado que quanto menor é a categoria competitiva considerada, menor é o número de atletas que confirma, na categoria adulta, o êxito obtido nas categorias de formação.

Portanto, pode ser simples estimar quem atualmente é bom executante, mas saber quem após crescimento, maturação e treinamento adicional adequado irá tornar-se o mais eficiente é algo consideravelmente mais difícil de predizer (SCHMIDT, 1993).

Desta maneira, hipoteticamente, diante de uma avaliação precipitada, infundada, subjetiva e elitista a respeito do desempenho dos referidos judocas no processo de iniciação, poder-se-ia desmotivar e até rejeitar a possibilidade dos mesmos se tornarem, a longo prazo, sujeitos talentosos e quiçá representantes da maior expressão do judô brasileiro numa geração.

Neste sentido, conforme o estudo de BLOOM (1985), de um total de 120 sujeitos observados, poucos foram considerados crianças talentosas por seus professores, treinadores e familiares; e mesmo aqueles considerados talentosos em idades iniciais, posteriormente não foram capazes de demonstrar desempenho 
comparável a pessoas talentosas maduras numa determinada área de conhecimento.

Sendo assim, de acordo com HEBBELINCK (1989), previsões de aptidão podem ser aceitas como válidas, em geral, por apenas dois a quatro anos e, portanto, devem ser observadas como parte de um processo evolutivo e conter constantes revisões. Neste sentido, conforme BÖHME (1994), RÉGNIER, SALMELA e RUSSEL (1993) e SENF (1990), na observação do desenvolvimento do talento é necessário um processo cíclico e contínuo de avaliações, que se deve principalmente à variabilidade morfológica, funcional e psíquica do período que permeia a infância e a adolescência, não permitindo que se façam previsões mais consistentes e duradouras neste período do crescimento e desenvolvimento humano, reforçando a necessidade de acompanhamentos longitudinais.

Ainda diante deste contexto, de acordo com o processo de TLP e especificamente em relação ao período de detecção do talento esportivo, a estratégia mais adequada seria incluir um número suficientemente grande de crianças que se mostrassem dispostas a participar de um programa de formação esportiva geral básica - considerado como primeira etapa do TLP (BARBANTI, 1997; BÖHME, 1995, 2000, 2002, 2004; BOMPA, 1999, 2000; HEBBELINCK, 1989; MARQUES, 1991; WEINECK, 1999).

Desta maneira, quanto aos anos iniciais da aprendizagem, independentemente do grau de desempenho específico demonstrado, parece ser fundamental evitar excluir precocemente crianças que se mostrem dispostas a participar de programas esportivos. Afinal, o prazer pela prática parece ser o ponta pé inicial para o desenvolvimento do talento em qualquer área (BLOOM, 1985; CSIKSZENTMIHALYI, RATHUNDE e WHALEN, 1997). Conforme pôde ser verificado, não há evidências científicas, históricas e práticas de que o talento surge única e exclusivamente de forma precoce no esporte ou em qualquer outro domínio do conhecimento (BLOOM, 1985; CSIKSZENTMIHALYI, RATHUNDE \& WHALEN, 1997; GUENTHER, 2000).

No presente estudo, a grande maioria dos judocas $(83,3 \%)$ não apresentou a manifestação do talento precoce, e, anos depois, como não foram excluídos, puderam chegar ao mais alto desempenho na modalidade. 


\subsection{Fatores motivacionais}

Conforme a revisão de literatura apresentada acerca dos processos de desenvolvimento de talentos e da teoria do TLP, bem como dos resultados apresentados e discutidos no item 4.1 do presente trabalho, foi possível confirmar o alto grau de envolvimento de cada atleta com o treinamento do judô desde as fases iniciais da aprendizagem até os dias atuais. Como foi citado anteriormente, o processo de desenvolvimento do talento pode durar, em média, cerca de seis até 10 anos de treinamento (ABBOTT \& COLLINS, 2004; BARBANTI 1997; BÖHME, 2000, 2002, 2004; BOMPA, 1999, 2000; GIBBONS et alii, 2002; GRECO, 1997; WEINECK, 1999) ou, pelo menos, 10.000 horas de prática deliberada (ERICSSON, KRAMPE \& TESCH-RÖMER, 1993).

Neste sentido, parece razoável verificar quais fatores mantém aderentes jovens atletas em treinamento sistemático no judô durante um longo período de tempo, visto que esse fator é essencial para o cumprimento das diferentes fases do TLP.

Conforme ERICSSON e CHARNESS (1994), com o progresso e o acúmulo do conhecimento científico, tornou-se gradualmente mais evidente que os indivíduos poderiam aumentar o seu desempenho através da educação e do treinamento, se tivessem motivação, objetivo e direcionamento.

Neste sentido, de acordo com $\mathrm{JOCH}^{2}$ (1994) apud BÖHME (2000) e MORAES, DURAND-BUSH e SALMELA (1999), o sucesso de uma pessoa talentosa depende do seu comprometimento, motivação e paixão pela sua área de atuação e, inclusive, do apoio de diversos segmentos da sociedade, sobretudo a própria família.

Sendo assim, diante da possibilidade de verificar quais fatores foram relevantes para aderência dos judocas ao TLP, é que foi elaborada a pergunta - Você pode me contar o que te fez manter o tempo todo o teu interesse no judô? - . Neste sentido, em relação a referida pergunta, seguem apresentadas na TABELA 6 as ICs captadas, a freqüência das respostas e o percentual referente a cada IC. 
TABELA 6 - Caracterização das idéias centrais, freqüência e percentual de respostas para a pergunta: Você pode me contar o que te fez manter o tempo todo o teu interesse no judô?

\begin{tabular}{llcc}
\hline \multicolumn{1}{c}{ IC } & Freqüência & $\%$ \\
\hline A & Amor e prazer & 3 & 50,0 \\
B Profissionalismo & 1 & 16,6 \\
C & Determinação & 3 & 50,0 \\
D Apoio da família & 2 & 33,3 \\
E Viagens & 1 & 16,6 \\
\hline
\end{tabular}

Conforme o QUADRO 4 (ANEXO II) e as ICs captadas (TABELA 6) para as somas dos discursos, seguem abaixo os DSCs construídos (1, 2, 3, 4 e 5) para cada IC:

\section{DSC 1: IC-A - Amor e prazer (S1, S2, S5).}

No início e no meio foi por amor ao esporte mesmo, sempre gostei muito do J udô. Acho que até hoje eu estou aqui porque eu amo o J udô, o que eu faço, o sonho de poder ouvir o Hino Nacional e poder representar o Brasil, eu acho que no J udô isso é o que mais conta.

\section{DSC2: IC-B - Profissionalismo (S5).}

Obs.: o discurso abaixo se refere exclusivamente ao sujeito S5, pois apenas ele apresentou a IC profissionalismo, não caracterizando, portanto, um discurso coletivo.

Depois dos 21 anos, depois do título do campeonato mundial, eu fazia J udô como se fosse profissional, tinha patrocínio, tinha quem me bancava e foi isso que foi me levando até hoje. 


\section{DSC 3: IC-C - Determinação (S1, S2, S6).}

Eu tenho objetivos a serem concretizados, então isso que me estimula. Como treinamos muito, a única coisa que levamos é a honra de estar defendendo o país, de estar defendendo a família, fazendo tudo para estar bem no tatame. Então esse foi o sonho, o combustível para que eu mesmo, com tantas derrotas, nunca desistisse do meu sonho, pois se outros chegaram eu também posso chegar. Eu ainda não consegui tudo e isso me motiva.

\section{DSC4: IC-D - Apoio da família (S3, S6).}

Já desde pequeno meus pais sempre me apoiavam. As vezes eu até jogava um pouquinho de futebol em um clube, até chegava machucado e meu pai me dava bronca, ele não gostava, ele queria que eu fizesse Judô. Teve um momento que eu queria parar, foi na época que eu tinha 13 para 14 anos, foi um momento crítico na minha carreira, onde acho que até os 12 anos eu fazia meio que empurrado. Depois queria parar, acho que a peça fundamental foi a minha mãe. Acho que minha mãe foi uma das pessoas que mais me estimularam, mais me estimulou em toda a minha carreira, desde minha parte inicial até a parte quando me destaquei. Então se não fosse ela, mesmo tendo um potencial, até treinando, se não fosse ela eu teria largado muito cedo.

\section{DSC5: IC-E - Viagens (S4).}

Obs.: o discurso abaixo se refere exclusivamente ao sujeito $\mathrm{S} 4$, pois apenas ele apresentou a IC viagens, não caracterizando, portanto, um discurso coletivo.

Eu acho que o que me fez manter no J udô tanto tempo foi a oportunidade de tentar ganhar as competições e poder fazer as viagens. Acho que isso que me fez me manter no J udô, que realmente eu não gostava de quando comecei. Não gostava de praticar Judô, mas a oportunidade de eu poder ir participar em um outro estado, uma outra cidade, essa oportunidade de ir viajar sem os pais acabou fazendo com 
que eu pegasse gosto por campeonato. Depois chegou a minha adolescência e eu realmente comecei a ganhar as competições e conhecer outros países.

Desta maneira, de acordo com os resultados dos DSCs apresentados, pode-se verificar conforme a TABELA 6, que a presente amostra aderiu ao treinamento no judô devido a fatores como: amor e prazer (50\%), determinação (50\%), apoio da família (33,3\%), profissionalismo $(16,6 \%)$ e acesso a viagens $(16,6 \%)$.

No DSC1 (amor e prazer) e no DSC3 (determinação), corroborando com GIBBONS et alii (2002), é possível verificar a presença do desejo revelado de querer chegar ao topo do desempenho. Embora no DSC1 conste de forma marcante o fator do prazer e do amor pela prática, sobretudo nos anos iniciais e intermédios da aprendizagem, pode-se observar que o desejo pela conquista é a recompensa que impulsiona o sujeito a se manter na atividade. Tal constatação é evidenciada no DSC3, onde a determinação pela busca do melhor resultado supera momentos de derrota encontrados durante o percurso. Ou seja, mesmo diante de possíveis dificuldades e derrotas o judoca se manteve aderente ao processo, pois possuía como meta irrevogável o alcance do mais alto desempenho.

Desta forma, os resultados parecem se aproximar dos trabalhos de ABBOTT e COLLINS (2004), BÖHME (2004) e ERICSSON e CHARNESS (1994), sobretudo em relação às considerações elaboradas sobre os estudos pioneiros de Galton no século XIX, no sentido de valorizar, além da capacidade inata (discutida nos itens anteriores da revisão de literatura), os fatores relacionados à "ânsia para trabalhar" e ao poder de fazer "muito trabalho laborioso", atribuindo à motivação e ao esforço um peso importante diante dos processos de desenvolvimento de talentos.

Portanto, afora a inquietação acerca da decorrência inata e/ ou adquirida do talento (ERICSSON \& CHARNESS, 1994; HOWE, 1999), a motivação para se manter aderente ao estudo/ treinamento numa determinada área de conhecimento parece ser um elemento fundamental para o desenvolvimento do talento.

Neste sentido, assim como no presente trabalho, no estudo de GIBBONS et alii (2002), atletas olímpicos norte americanos apontaram o amor pela competição, 
a prática prazerosa e o desejo pela conquista do sucesso esportivo como os principais fatores de motivação e aderência ao esporte.

Em relação ao DSC4 (apoio da família), é possível notar que a força de apoio da família, além da relevância observada para a fase de iniciação no judô (item 4.2), foi fundamental para a permanência do judoca na modalidade. Conforme o DSC4, em alguns momentos do processo de TLP, sobretudo na faixa etária do início da adolescência, a vontade presente no judoca era de parar os treinamentos no judô. Ademais, é contundente no DSC4 o reconhecimento de que mesmo havendo potencial para o alto desempenho na modalidade, o judoca pensava em abandonar a prática. Entretanto, por efeito do apoio da mãe, o mesmo acabou permanecendo na modalidade. Portanto, mais uma vez, o apoio da família ilustra os discursos dos judocas no sentido de exercer papel fundamental para o desenvolvimento do talento, contribuindo para o processo de iniciação e permanência na modalidade.

Neste sentido, os DSCs 1 e 3 parecem incorporar as idéias de ERICSSON, KRAMPE e TESCH-RÖMER (1993) a respeito da restrição de motivação, que se refere ao reconhecimento de que o processo de treinamento não é inerentemente prazeroso ou imediatamente recompensado. De acordo com os DSCs 1 e 3, nos anos iniciais e intermédios da aprendizagem o prazer pela prática era a grande motivação do judoca, mas no decorrer do processo a determinação de poder chegar ao alto nível de desempenho passou a ser o fator relevante que motivava o judoca a permanecer nos treinamentos. Conforme ERICSSON, KRAMPE e TESCHRÖMER (1993), jovens talentosos se mantêm motivados diante do processo em função da percepção de que a prática deliberada, mesmo não oferecendo necessariamente uma recompensa imediata, pode oferecer um apoio instrumental extremamente representativo para a evolução em direção ao alto desempenho.

Por sua vez, BLOOM (1985) destaca a importância das fontes de motivação e recompensa, bem como das circunstâncias especiais de encorajamento e suporte para o indivíduo em diferentes estágios do seu desenvolvimento. Como foi observado no DSC2 (profissionalismo), o judoca adulto e com resultados expressivos na modalidade, manteve-se profissionalmente aderente ao judô devido à recompensa e ao suporte do patrocinador que financiava não somente as condições para a prática, mas também o salário do judoca. Em relação ao DSC5 (viagens), 
alguns judocas se mantinham aderentes à modalidade, além dos fatores anteriormente citados, por circunstâncias relacionadas a fontes externas de motivação e recompensa. Ou seja, a percepção de que competindo no judô seria possível viajar pelo Brasil e até pelo mundo, trazia ao judoca uma componente que por vezes ultrapassava o próprio prazer em praticar a modalidade.

Portanto, é possível verificar que os fatores acima destacados se aproximam dos elementos fundamentais apresentados por BLOOM (1985), CSIKSZENTMIHALYI, RATHUNDE e WHALEN (1997), ERICSSON, KRAMPE e TESCH-RÖMER (1993), ERICSSON e CHARNESS (1994), GIBBONS et alii (2002) e MORAES, DURAND-BUSH e SALMELA (1999), no que tange a importância da motivação e das forças de apoio para a participação do sujeito no processo de desenvolvimento de talentos.

\subsection{Relações sociais}

Conforme a literatura, o desempenho esportivo depende de normas sociais estabelecidas, o que significa que 0 atleta carrega consigo a sua personalidade, o seu meio social, suas fraquezas e suas forças humanas. Portanto, outro fator que tem sido comentado como relevante para o processo de desenvolvimento do talento esportivo, é o ambiente social de convívio do sujeito (BÖHME, 2004).

Conforme os itens anteriores, foi possível verificar a importância dos aspectos relacionados ao apoio da família, sobretudo dos pais do judoca para a iniciação e permanência do sujeito na modalidade. Entretanto, acerca das demais relações que envolvem o cotidiano do judoca, surge o questionamento sobre a extensão das relações sociais do judoca com outros membros da sociedade e, inclusive, sobre o teor dessas possíveis relações com o universo de desenvolvimento do judoca durante o TLP.

Desta maneira, diante da possibilidade de verificar a interação das relações sociais dos judocas durante o TLP, foi elaborada a pergunta - Me conte como era a participação dos seus pais, familiares e amigos em relação ao judô - . 
Neste sentido, seguem apresentadas na TABELA 7 as ICs captadas, a freqüência das respostas e o percentual referente à cada IC.

TABELA 7 - Caracterização das idéias centrais, freqüência e percentual de respostas para a pergunta: Me conte como era a participação dos seus pais, familiares e amigos em relação ao judô.

\begin{tabular}{llcc}
\hline & \multicolumn{1}{c}{ IC } & Freqüência & $\%$ \\
\hline A & Apoio da família & 6 & 100,0 \\
B & Descrença dos familiares & 1 & 16,6 \\
C & Ambiente do judô e amigos & 3 & 50,0 \\
\hline
\end{tabular}

Conforme o QUADRO 5 (ANEXO II) e as ICs captadas (TABELA 7) para as somas dos discursos, seguem abaixo os DSCs construídos (1, 2 e 3) para cada IC:

\section{DSC1: IC-A - Apoio da família (S1, S2, S3, S4, S5, S6).}

Meu pai e minha mãe nunca me forçaram a trabalhar. Tínhamos muitas dificuldades, mas nem por isso eles falavam para eu parar de fazer J udô. Muito pelo contrário, meus pais sempre me estimularam. 0 J udô infelizmente é um esporte que não tem muito apoio, não tem muito retorno, então tive muito apoio da família mesmo. Minha mãe, para me incentivar quando era criança, também entrou no J udô e acho que a parte melhor é que eles nunca me cobraram resultados, eles sempre me apoiavam. O meu pai nunca mediu esforços para me ajudar. Ele começou a acompanhar muito o Judô e se interessou pela modalidade. Nós discutíamos muito dentro de casa o que tinha que melhorar, até incentivo financeiro, incentivo emocional, sempre viajando nas competições que podia e mesmo quando não podia sempre motivando, mesmo quando distante. Sempre falando que eu tinha oportunidade, que eu tinha condições de conquistar um espaço, de realizar sonhos. Então eu acho que grande parte da minha conquista se deve muito a minha família. Pelo incentivo, porque no esporte caímos muito, deslizamos, e a família sempre por 
trás dando suporte. Judô é isso mesmo, é família, é companheirismo e sem essa família, sem essa comunhão social de todo mundo, nada seria possível no J udô.

\section{DSC2: IC-B - Descrença dos familiares (S3).}

Obs.: o discurso abaixo se refere exclusivamente ao sujeito $\mathrm{S3}$, pois apenas ele apresentou a IC descrença dos familiares, não caracterizando, portanto, um discurso coletivo.

Meus tios, avós e outros familiares falavam para eu parar de fazer J udô, que Judô não dava camisa para ninguém. Todo mundo pensava que J udô era uma briga e muitos criticavam. Diziam que J udô não dá em nada, não dá futuro para ninguém. Tinham essa mentalidade.

\section{DSC3: IC-C - Ambiente do judô e amigos (S4, S5, S6).}

No colégio o pessoal já respeitava a modalidade que eu fazia e dentro do J udô sempre foi uma harmonia muito grande. Eu acho que o J udô é o único esporte que se fazem amigos, não se fazem inimigos. Dentro do tatame e fora todo mundo ficou amigo, então eu tenho certeza que nunca tive problemas após o tatame. Em relação à amizade, acho que todos os meus grandes amigos são do J udô, a grande maioria é do Judô, um vai apoiando o outro. Desde o início e até hoje todos são meus amigos, todos praticam J udô e isso me deu suporte para continuar competindo.

Desta maneira, de acordo com os resultados dos DSCs apresentados, pode-se verificar conforme a TABELA 7, a relevância da família (100\%) e do próprio ambiente do judô e amigos (50\%) para os judocas. Em contrapartida, pode-se observar no DSC2 a descrença dos demais familiares $(16,6 \%)$ como um fator potencialmente comprometedor do processo de desenvolvimento do talento.

Neste sentido, o DSC2 (descrença dos familiares) carrega em seu bojo a desvalorização social a respeito da prática do judô. Tal desvalorização sociocultural é fomentada por preconceitos de rejeição à modalidade, gerados pela desconfiança sobre o valor social do judô. Em uma cultura nacional onde predominantemente o 
futebol absorve todos os destaques, o judô, assim como outras modalidades, é discriminado no pensamento popular como uma atividade talvez menos importante, de categoria inferior e, portanto, não merecedora de tanto empenho e dedicação.

Sendo assim, pode-se inferir sobre o impacto negativo que esse pensamento poderia gerar quando associado não somente aos familiares, mas também aos pais e amigos do sujeito. Isto é, suportar a prática de uma determinada atividade por tanto tempo quando ao seu lado não há ninguém que ofereça reforço e valorização é, supostamente, um desafio muito maior do que estar envolvido num contexto onde pais, familiares e amigos participem positivamente do seu envolvimento na atividade.

Neste sentido, conforme BÖHME (2004), deve-se atentar para as condições sociais limitantes do desempenho esportivo que estão presentes, entre outros fatores, nas atitudes da sociedade em relação ao desempenho e no valor que a modalidade esportiva possui na sociedade.

Não obstante, o presente estudo confirma que a totalidade dos judocas entrevistados (DSC1) manifestou o peso positivo da família durante o processo de desenvolvimento do talento. Tal manifestação pode ser sintetizada pelo pensamento expresso na frase "...J udô é isso mesmo, é família, é companheirismo e sem essa família, sem essa comunhão social de todo mundo, nada seria possível no J udô", no qual a importância da congruência da família em relação ao judô é marcante.

Ademais, o DSC3 (ambiente do judô e amigos) traz uma característica interessante sobre o ambiente social de desenvolvimento do judoca. Conforme o DSC3, embora seja possível notar que não há no discurso a presença de elementos que demonstrem um grande número de amigos fora do judô, o que poderia ser socialmente negativo; existe, por outro lado, a presença de um discurso que indica a peculiaridade do ambiente de desenvolvimento dos judocas, sendo que dentro do próprio judô conseguiram constituir amizades que ultrapassaram os limites do tatame.

Assim, nota-se no DSC3 que os grandes amigos mantidos desde a infância até a idade adulta e que deram suporte uns ao outros para a permanência e evolução na modalidade foram os próprios judocas, que mesmo sendo adversários de tatame souberam compartilhar os obstáculos do processo de treinamento no judô, 
das competições e das seletivas sem deixar a competitividade por uma vaga interferir na relação de amizade. Neste sentido, cabe salientar que a história, a tradição e a filosofia de harmonia e respeito ao ser humano com a qual o judô é desenvolvido (DELIBERADOR, 1996; MONTEIRO, 1998), pode ter auxiliado na manutenção do companheirismo e da amizade entre os judocas, cultivando um ambiente particularmente interessante para o processo de desenvolvimento do talento.

Portanto, a reunião das características observadas no DSC1 (apoio da família) e no DSC3 (ambiente do judô e amigos), formou um dueto social coeso e positivo para o judoca durante o seu processo de desenvolvimento. Em outras palavras, mesmo diante da pouca valorização que o judô pode estar sofrendo na cultura da sociedade em geral, esse dueto funcionou como um microssistema capaz de potencializar as condições sociais necessárias para o desempenho, gerando cultura suficiente para que as famílias agregadas construíssem o suporte e as perspectivas de uma nova geração de judocas.

\subsection{Outras atividades}

Ainda numa extensão do item 4.5 (relações sociais), com intuito de observar com maior riqueza de detalhes o universo de desenvolvimento do talento no judô, além das relações familiares e de amizade que se demonstraram preponderantes, buscou-se através da pergunta - Me conte como era o seu dia a dia e diga o que você fazia no tempo livre restante em que não estava no judô - verificar as outras atividades presentes no cotidiano de experiências e descobertas do judoca.

Neste sentido, seguem apresentadas na TABELA 8 as ICs captadas, a freqüência das respostas e o percentual referente a cada IC. 
TABELA 8 - Caracterização das idéias centrais, freqüência e percentual de respostas para a pergunta: Me conte como era o seu dia a dia e diga o que você fazia no tempo livre restante em que não estava no judô.

\begin{tabular}{llcc}
\hline & \multicolumn{1}{c}{ IC } & Freqüência & $\%$ \\
\hline A & Atividades motoras diversas & 2 & 33,3 \\
B & Judô & 3 & 50,0 \\
C & Estudos & 4 & 66,6 \\
D & Trabalhar & 1 & 16,6 \\
E & Vida social & 2 & 33,3 \\
\hline
\end{tabular}

Conforme o QUADRO 6 (ANEXO II) e as ICs captadas (TABELA 8) para as somas dos discursos, seguem abaixo os DSCs construídos (1, 2, 3, 4 e 5) para cada IC:

\section{DSC1: IC-A - Atividades motoras diversas (S1, S6).}

Quando eu era criança sempre fui moleque, muito ativo. Eu brincava na rua no final de semana, brincava de futebol, brincava de taco, jogava vôlei, alguma brincadeira dançante perto do bairro, fazia de tudo. Eu sempre gostei de esporte, então eu sempre gostei de estar fazendo tudo. Hoje o que eu faço é apenas jogar uma bola. Também joguei bola, e quase entrei para o profissional. Só que eu larguei porque o que mais tocava o meu coração mesmo era o J udô. Atualmente, fora o J udô, o que tem me dado mais tranqüilidade é o Tênis.

\section{DSC2: IC-B - J udô (S2, S3, S5).}

No início a gente se diverte, brinca. Depois fica muito complicado ter tempo para fazer algum outro tipo de atividade, eu me dediquei muito mesmo ao J udô, treinando de segunda a sábado e muita competição no domingo. Então a minha obrigação era ir para a escola e treinar. Não me sobrava muito tempo. Era só final de semana que a gente tinha e passava descansando em casa. Inclusive 
quando estava em casa, assistia fitas de Judô para tentar aprender mais. Quando ingressei no Projeto (...), eu vi que tinha que me dedicar ainda mais aos treinamentos. No Projeto (...) eu treinava 2, 3 vezes ao dia. Então é uma vida normal, dia de semana só treino, $100 \%$ treino, de manhã, de tarde e a noite, uma coisa meio que desgastante.

\section{DSC 3: IC-C - Estudos (S2, S3, S5, S6).}

Desde o princípio a minha obrigação era ir para a escola e treinar. Mais recentemente, quando fui para o Clube (...), comecei a fazer faculdade também.

\section{DSC4: IC-D - Trabalhar (S3).}

Obs.: o discurso abaixo se refere exclusivamente ao sujeito S3, pois apenas ele apresentou a IC trabalhar, não caracterizando, portanto, um discurso coletivo.

Meu pai não tinha condições de me dar nada, então eu comecei a dar aula de J udô com 13, 14 anos. Então nos meus tempos livres eu dava aula de J udô. Algumas férias trabalhei até com o meu avô, como servente de pedreiro, quando meu pai ficou desempregado. Logo quando eu comecei a me destacar, eu comecei a ganhar uma ajuda de custo pelo clube. Quando eu fiquei com mais idade comecei a trabalhar na bolsa de valores. Então até perto da minha primeira Olimpíada eu trabalhava, estudava e treinava, uma coisa desgastante.

\section{DSC5: IC-E - Vida social (S4, S5).}

Difícil ir para a balada, mas o Judô nunca foi um empecilho. Principalmente na adolescência, no auge da puberdade, você quer bagunçar. Acho que tem que saber se adequar às condições que você tem. Por isso eu nunca deixei a parte social minha ser prejudicada pelo Judô. Era a válvula de escape, não só minha, mas de todos os atletas que estavam comigo. Por vezes o fim de semana era o tempo livre para dar uma bagunçadinha. Eu saía com os meus amigos, ia ao cinema, ao teatro, participava de uma festa. Hora de treinar é hora de treinar, se 
depois do treino tinha condições de ficar uma, duas horas e ir numa festa, tudo bem. Eu ia, participava da festa e depois voltava para a minha casa. Acho que por isso até que eu acabei fazendo muitos amigos.

Assim, a respeito de outras atividades realizadas durante o processo de desenvolvimento dos judocas, os resultados dos DSCs apresentados expressam (conforme a TABELA 8) que 66,6\% da amostra mencionou ter compartilhado o processo de TLP com os estudos; $50 \%$ discursaram acerca da predominância do judô no dia a dia; 33,3\% comentaram sobre a realização de outras atividades motoras durante o processo; 33,3\% indicaram que procuraram manter uma vida social normal; e 16,6\% mencionaram que, paralelamente aos treinamentos, tinham que trabalhar.

De acordo com o DSC4 (estudos), é possível verificar que boa parte da amostra entrevistada (66,6\%) manteve os estudos durante o processo de treinamento. Tal fator merece destaque, sobretudo por constatar a chegada de alguns destes judocas ao curso superior. Portanto, além de se manterem aderentes ao processo de treinamento, os judocas também tiveram oportunidade e se desenvolveram durante os diferentes momentos do ensino escolar e universitário.

Isso parece indicar que as famílias de alguma maneira ofereciam apoio, valorizavam a escola e davam importância para a formação dos filhos. Ademais, é bastante evidente no DSC4, que uma condição inquestionável para o processo de desenvolvimento destes judocas era o estudo concomitante, conforme o seguinte trecho do DSC4: "Desde o princípio a minha obrigação era ir para a escola e treinar...". Desta forma, mesmo sem uma pesquisa mais profunda acerca da caracterização sociocultural de cada família, se percebe a importância que foi atribuída aos estudos, fato que pode ter contribuído para a formação universal do cidadão e não apenas do judoca. Neste sentido, se o desempenho esportivo do judoca é a soma emitida por sua personalidade, seu meio social, suas fraquezas e forças humanas, essa soma teoricamente pode ter uma magnitude superior quando acrescida de cultura, estudo e conhecimento, podendo favorecer a expressão do talento. 
Por outro lado, conforme o DSC2 (Judô), é possível verificar que na fase de iniciação no judô havia mais tempo para se divertir e brincar, mas com o passar do tempo a dose de dedicação ao treinamento sistemático da modalidade foi aumentando. Assim, num contraponto à natureza da pergunta, que era investigar o que o judoca fazia no tempo livre em que não estava no judô, se observa que além do tempo destinado aos estudos, o restante do tempo disponível era relacionado quase que integralmente ao treinamento no próprio judô. Ou seja, não sobrava tempo para outras atividades.

Desta forma, o DSC2 se aproxima dos referenciais de BLOOM (1985) no que tange a natureza dos anos iniciais, intermédios e finais da aprendizagem. Conforme o autor, nos anos iniciais da aprendizagem há um envolvimento divertido e prazeroso pela prática. Posteriormente, nos anos intermédios e finais da aprendizagem, os jovens demonstram maiores graus de concentração, empenho e comprometimento com as metas, iniciando a prática deliberada voltada para 0 desenvolvimento do alto desempenho.

Contudo, é possível destacar o seguinte trecho do DSC2: “...dia de semana só treino, $100 \%$ treino, de manhã, de tarde e a noite, uma coisa meio que desgastante".

Logo, corroborando com BLOOM (1985), a trajetória de desenvolvimento dos judocas investigados nem sempre esteve associada diretamente com experiências prazerosas. Há, como no trecho destacado no parágrafo acima, situações negativas oriundas do processo de desenvolvimento do talento. Conforme BLOOM (1985), sem o reforço e o estímulo adequado da família, dos professores e técnicos, essas situações de desgaste diante do processo de treinamento, possuem extensões psicológicas capazes de gerar índices elevados de desistência da área específica de interesse. Desta forma, no presente estudo, o resultados discutidos nos itens 4.2 (iniciação no judô) e 4.4 (fatores motivacionais) contribuíram com o reforço positivo necessário para a permanência e desenvolvimento do judoca na modalidade.

Por outro lado, além da prática do judô que se demonstrou marcante no DSC2, o DSC1 (atividades motoras diversas) indica a realização de experiências motoras diversas (ex.: brincadeiras de rua, futebol, tênis). Entretanto, apenas 33,3\% da amostra $(n=2)$ apresentou o referido discurso, deixando dúvida quanto a gama 
variada de oportunidades que os judocas receberam durante o programa de formação esportiva geral básica, fundamental para anos iniciais da aprendizagem.

A exemplo disso, no estudo de GIBBONS et alii (2002), foi possível verificar que atletas olímpicos norte americanos, até os 14 anos de idade, praticavam cerca de três modalidades esportivas, demonstrando a aquisição de diferentes vivências motoras ao longo do que seria a "etapa de iniciação e formação geral básica". Contudo, foi verificado que o número de modalidades praticadas diminuía com o passar da idade.

Em relação ao DSC5 (vida social), também se observa que um número reduzido de judocas (33,3\%; $n=2)$ formulou esse discurso. Entretanto, é interessante perceber a maneira que os judocas encontraram para ponderar os momentos de treino e os momentos de lazer, sem deixar que um interferisse na qualidade do outro e vice-versa, ressaltando a importância da vivência de ambos para o sucesso do desenvolvimento do talento.

Assim, o DSC5 chama a atenção para a necessidade do atleta ser antes de tudo um sujeito e, como tal, inerente e carente ao seu meio social, não podendo ser abstraído dessa natureza. Ademais, é notável no DSC5 a consideração feita ao período da adolescência. Período este, repleto de mudanças biológicas e comportamentais que impulsionam o jovem à busca de sua independência familiar, emocional e financeira. Nesse ínterim, é natural que o jovem se sinta interessado pelos atrativos dos passeios e festas, das viagens, das amizades, do namoro e, porque não, da vida. Estas interações trarão descobertas relevantes sobre a relação dele próprio com seu meio de convívio sociocultural, podendo contribuir para a modelação e afirmação de sua personalidade, bem como para a formação de um sujeito mais equilibrado em relação às suas necessidades e, conseqüentemente, mais preparado para o processo de desenvolvimento do talento.

Por sua vez, o DSC4 (trabalhar) traz o relato de um judoca sobre os trabalhos paralelos que executou durante o processo treinamento do judô. Conforme o DSC4, o judoca precisava trabalhar para auxiliar no sustento financeiro da família. Por outro lado, nos resultados encontrados no estudo de BLOOM (1985), para os anos intermédios da aprendizagem, o sustento moral e financeiro dos filhos era de papel dos pais e tal apoio garantia a aderência direcionada dos adolescentes em 
relação aos aspectos motivacionais da aprendizagem, a realização, o comprometimento, o sacrifício e o tempo de prática deliberada.

Sendo assim, o item seguinte do presente trabalho se reservou a apresentar e discutir os resultados específicos relacionados aos aspectos financeiros que teriam participado do processo de desenvolvimento do talento em judocas brasileiros.

\subsection{Aspectos financeiros}

Conforme CARL ${ }^{3}$ (1988) apud BÖHME (1999), o desempenho esportivo pode sofrer interferência tanto de condições limitantes pessoais, relativas ao próprio atleta (ex.: escola/ estudo; profissão; amigos/ lazer; família), como de condições limitantes sociais, relativas às condições materiais e sociais disponíveis no seu meio ambiente (ex.: atitudes da sociedade para o desempenho; valor social da modalidade esportiva; meios financeiros disponíveis; treinador disponível; sistema de formação do treinador; nível de conhecimento na ciência do esporte).

Neste sentido, de acordo com os itens 4.5 e 4.6 do presente trabalho, foi possível apresentar e discutir, com base nos discursos dos judocas, as influências que algumas dessas condições limitantes (pessoais e sociais) trouxeram para 0 processo de desenvolvimento do talento no judô.

O DSC4 (trabalhar) referente ao item 4.6, revelou que o judoca precisou conjugar treinamento e trabalho em sua rotina, pelo menos até a chegada na sua primeira Olimpíada. Conforme o referido discurso, tal rotina tornava o cotidiano desgastante e, portanto, passível de prejuízos para o desempenho.

No estudo de GIBBONS et alii (2002), atletas olímpicos norte americanos apontaram os aspectos financeiros como uma importante limitação do processo de desenvolvimento esportivo. Neste sentido, conforme os resultados encontrados por GIBBONS et alii (2002), a pressão financeira foi um dos principais fatores a contribuir para a desistência de atletas de alto nível do processo de treinamento a longo prazo.

Sendo assim, ainda nessa perspectiva, com o objetivo de verificar a influência específica dos meios financeiros disponíveis para o desempenho esportivo 
no desenvolvimento dos judocas, é que foi elaborada a pergunta - Me conte como foi o teu sustento financeiro desde o seu início no judô até os dias atuais -.

Desta forma, seguem apresentadas na TABELA 9 as ICs captadas, a freqüência das respostas e o percentual referente a cada IC.

TABELA 9 - Caracterização das idéias centrais, freqüência e percentual de respostas para a pergunta: Me conte como foi o teu sustento financeiro desde o seu início no judô até os dias atuais.

\begin{tabular}{llcc}
\hline & \multicolumn{1}{c}{ IC } & Freqüência & $\%$ \\
\hline A & Apoio da família & 6 & 100,0 \\
B & Academia, clube, patrocínios & 6 & 100,0 \\
C & Trabalho & 2 & 33,3 \\
\hline
\end{tabular}

Conforme o QUADRO 7 (ANEXO II) e as ICs captadas (TABELA 9) para as somas dos discursos, seguem abaixo os DSCs construídos (1, 2 e 3) para cada IC:

\section{DSC 1: IC-A - Apoio da família (S1, S2, S3, S4, S5, S6).}

O começo foi difícil. Era só a minha família que bancava. Quando eu era garoto não tinha tanto problema porque as competições eram dentro de São Paulo, então não custava muito caro participar. Já na adolescência, eu e minha família tínhamos que arrumar uma forma de pagar. Então meu pai fazia bingo para ajudar nas despesas. Então no começo meu pai podia pagar e eu vivi em baixo das custas dele, infelizmente. Meu pai sempre procurou dar esse suporte financeiro. Antes eu só dependia do meu pai, não tenho do que reclamar, porque meu pai sempre me deu de tudo. Por isso eu acho que sou privilegiado pela estrutura e pelo apoio da minha família. 


\section{DSC2: IC-B - Academia, clube, patrocínios (S1, S2, S3, S4, S5, S6).}

0 professor com quem iniciei viu que eu tinha um potencial e me deu uma bolsa, eu não pagava mais nada. Então eu continuei a treinar por causa desse motivo. A academia ajudava fazendo um monte de coisas para eu poder seguir e participar. Quando fui campeão, fui contratado pelo Clube (...) e ai eu comecei a ter um pouquinho de dinheiro. Não é o que eu acho que um atleta de Judô deveria ganhar, mas é dentro da realidade brasileira, então eu não reclamo. Além do clube, o patrocinador e a prefeitura também começaram a me dar um apoio, porque eu comecei a ganhar os títulos importantes. Isso mudou a minha vida financeiramente. Fui me tornando independente. Assim consegui tudo que eu tenho: material, minha casa, minha estrutura, enfim minha manutenção. Então eu posso dizer que hoje eu estou feliz com o J udô, não posso reclamar da minha vida.

\section{DSC 3: IC-C - Trabalho (S3, S6).}

Comecei a dar aula de J udô quando tinha 15 anos. Mais para frente, me alistei e o Exército me pegou. Fiquei 8 anos no Exército, porque eu fiquei lutando também pelo Exército. Então foi uma fase que me ajudou muito. Eu fazia muito bico de segurança para poder me sustentar. Acabei casando e cheguei até a fazer alguns desfiles. Depois surgiu um concurso militar e acabei ingressando.

Desta maneira, em relação aos aspectos financeiros que permearam o processo de desenvolvimento do talento no judô, é possível verificar conforme a TABELA 9, a participação da própria família (DSC1; 100\%) e de academias, clubes e patrocinadores (DSC2; 100\%) gerando a força de apoio financeiro necessária para a manutenção do judoca no processo de TLP. Por sua vez, o DSC3 (33,3\%) corrobora com o DSC4 (trabalhar) referente ao item 4.6, acrescentando o discurso de judocas que foram buscar no trabalho o complemento financeiro necessário para o sustento no judô.

Sendo assim, de acordo com o DSC1 (apoio da família) e com DSC2 (academia, clube, patrocínios), é possível confirmar que a ausência de programas 
esportivos estruturados para o desenvolvimento do processo de detecção, seleção e promoção de talentos, também traz inconsistência para a geração de recursos financeiros que possam subsidiar o atleta em desenvolvimento.

Especificamente em relação ao DSC1 (apoio da família), corroborando com os pressupostos de BLOOM (1985), se percebe que desde a fase de iniciação no judô as famílias se responsabilizavam pelas despesas decorrentes do treinamento e competição. Assim, durante os anos iniciais da aprendizagem as famílias tinham mais condições de manter o apoio financeiro, pois as despesas não eram muito grandes em função do menor número de competições e viagens envolvidas. Entretanto, durante os anos intermédios e finais do treinamento as despesas com treinamento, competições e viagens aumentavam e dificultavam a possibilidade da família gerar, por conta própria, o suporte financeiro necessário. Neste sentido, mesmo diante de dificuldades econômicas, as famílias e os próprios judocas se organizavam para buscar estratégias alternativas (ex.: bingo) para arrecadação de dinheiro que pudesse ser revertido para o pagamento de mensalidades, inscrições e viagens.

Conforme o estudo de BLOOM (1985), quanto ao desenvolvimento do talento em diferentes domínios do conhecimento, o sustento moral e financeiro dos filhos era de papel dos pais e garantia a aderência direcionada dos adolescentes em relação aos aspectos motivacionais da aprendizagem, a realização, o comprometimento, o sacrifício e o tempo de prática deliberada, fundamentais nesse estágio.

Contudo, ainda no DSC1, o trecho "...meu pai sempre me deu de tudo. Por isso eu acho que sou privilegiado pela estrutura e pelo apoio da minha família", destaca o pensamento de que se por um lado alguns judocas tiveram em suas famílias os recursos financeiros necessários para a manutenção e progressão no judô, por outro a mesma frase revela em sua essência que nem todos, por mais talentosos que possam ser, possuem esse "privilégio" e, portanto, têm limitadas as chances de desenvolver o alto desempenho na modalidade.

Ademais, evidente que tal inconsistência nos programas esportivos é mais um reflexo da desigualdade sociocultural que há tempos assola as famílias e segmenta as possibilidades de moradia, saúde, escola, lazer, esporte e cultura de 
boa parte da população brasileira, no qual apenas os mais "privilegiados" têm oportunidade de se aproximar de diferentes contextos e estruturas, descobrir potencialidades e, porque não, desenvolver talentos.

No DSC2 (academia, clubes e patrocínios), é possível verificar que por vezes o judoca recebe algum tipo de auxílio, oriundo de ações isoladas (ex.: bolsa para treinar na academia) ou decorrentes da fase em que o judoca já atingiu o alto nível de desempenho (ex.: patrocínio, clube, prefeitura). Portanto, assim como em itens anteriores do presente trabalho, no processo de desenvolvimento do talento no judô, se confirma a idéia de que estado, empresas, clubes e a própria família, dividem a responsabilidade de subsidiar a estrutura esportiva para o talento esportivo (MATSUDO, 1999; MATSUDO \& MATSUDO, 1997).

Entretanto, essa divisão de responsabilidades não é planejada, mas sim dependente, além da própria família, das iniciativas isoladas de um clube ou projeto, de estímulos públicos sazonais e de patrocinadores que geralmente se associam à imagem de atletas adultos que já estão formados e atingiram o alto desempenho. Portanto, não há o encadeamento sistemático dessas ações ao longo do processo de desenvolvimento do talento, sobretudo em relação aos anos iniciais e intermédios da aprendizagem.

Neste sentido, em contraste com a presente pesquisa, um percentual elevado de atletas olímpicos norte americanos recebia apoio financeiro proveniente de fundos governamentais e do Comitê Olímpico dos Estados Unidos. O apoio financeiro recebido era destinado a investimentos em treinamento, competições, técnicos, equipamentos e suplementos (GIBBONS et alii, 2002).

Neste sentido, o DSC3 (trabalho) apresenta o discurso de judocas que, mesmo no alto nível do desempenho, precisaram trabalhar e/ ou exercer atividades paralelas para poderem se sustentar, reforçando o pensamento acerca da falta de encadeamento em relação aos recursos financeiros disponíveis para a otimização do processo de desenvolvimento do talento no judô. 


\subsection{Genética X Meio Ambiente}

Conforme a revisão de literatura do presente trabalho, foi possível verificar que os estudos mais recentes sobre a manifestação talento ainda revelam em seu bojo a inquietação acerca da dicotomia e/ou da interação entre as parcelas do inato e do adquirido (ERICSSON \& CHARNESS, 1994; HOWE, 1999). Porém, uma tendência que vem se consolidando, tem apontado para importância das influências ambientais e da motivação como aspectos centrais para o desenvolvimento do talento (ABBOTT \& COLLINS, 2004; BLOOM, 1985; CSIKSZENTMIHALYI, RATHUNDE \& WHALEN, 1997; ERICSSON, KRAMPE \& TESCH-RÖMER, 1993) em diferentes domínios do conhecimento.

Todavia, ainda sobre o estigma popular do talento, é comum deparar com explicações que atribuem exclusivamente ao dom natural a manifestação do alto desempenho. No esporte especificamente, é corriqueiro encontrar comentários que estimulam o pensamento coletivo a aceitar que um determinado sujeito já nasce, por exemplo, para ser jogador de futebol.

A respeito dessa problemática sobre a natureza do talento, é que foi elaborada a pergunta - A que você atribui o teu talento para o judô? - . Sendo assim, seguem apresentadas na TABELA 10 as ICs captadas, a freqüência das respostas e o percentual referente a cada IC.

TABELA 10 - Caracterização das idéias centrais, freqüência e percentual de respostas para a pergunta: A que você atribui o teu talento para 0 judô?

\begin{tabular}{llcc}
\hline & \multicolumn{1}{c}{ IC } & Freqüência & $\%$ \\
\hline A & Técnica & 3 & 50,0 \\
B & Determinação & 5 & 83,3 \\
\hline
\end{tabular}

Conforme o QUADRO 8 (ANEXO II) e as ICs captadas (TABELA 10) para as somas dos discursos, seguem abaixo os DSCs construídos (1 e 2) para cada IC: 


\section{DSC1: IC-A - Técnica (S1, S4, S5).}

Desde criança eu tenho facilidade para aprender. Eu sempre aprendi muito rápido e acho que isso é que fez a diferença por elevar rapidamente o nível técnico. Eu olhava outros judocas competindo e queria assimilar como eram os golpes que eles aplicavam. Inclusive, depois dos treinos e competições, perguntava como eram os golpes para eles. Fui fazendo isso e adequando para o meu corpo, para minha técnica. Então eu acabo achando que o meu J udô tem um pouquinho do J udô tradicional, do J udô Japonês, porque vai ter os golpes bonitos e também do Judô Europeu, que é um Judô um pouco mais de força, que engata na perna, os golpes de sacrifício. Tudo isso é por causa de ser brasileiro, que você consegue essa ginga, ter a flexibilidade de mesclar as técnicas.

\section{DSC2: IC-B - Determinação (S1, S2, S3, S5, S6).}

O aprendizado melhor é o infinito e sempre quando eu chego em algum lugar eu falo que tenho que melhorar. Sempre tem que subir, não pode ultrapassar o limite, só que se empurrarmos o limite cada vez mais para cima poderemos tirar algo mais da gente. Por isso, eu não sei se eu tenho talento não. 0 que tenho é muita teimosia e muita dedicação. Acho que tenho muita força de vontade e eu trabalho duro para conseguir o que quero. Então acho que meu talento foi fabricado na base de muito treino, corrida, sala de musculação e muita fé. As dificuldades me motivaram a treinar mais e mostrar que sou bom. Destaco a minha vontade de ganhar, de vencer, de querer provar para mim mesmo, não para os outros, para mim, que eu teria condições de ser forte. Acho que foi esse o meu grande diferencial. Ainda hoje acho que a ambição de conquistar a medalha olímpica é que está fazendo eu continuar.

Assim, conforme a TABELA 10, os judocas atribuíram à determinação $(83,3 \% ; n=5)$ e à técnica na modalidade $(50 \% ; n=3)$ o grande diferencial para o talento no judô. 
Desta maneira, de acordo com o DSC1 (técnica), é possível verificar que a facilidade para aprender as técnicas específicas do judô ofereceu ao sujeito a possibilidade de se destacar e progredir na modalidade.

Neste sentido, conforme CSIKSZENTMIHALYI, RATHUNDE e WHALEN (1997), HOWE (1999) e GUENTHER (2000), as pessoas podem diferenciar-se umas das outras, apresentando uma maior facilidade para desenvolver e alcançar a excelência em determinado campo de ação. Entretanto, acrescentam que não só a quantidade de dom inicial deve ser considerada, mas também o que cada pessoa faz do mesmo. Neste sentido, um dom natural que não é aperfeiçoado durante a vida pode ser desperdiçado. Portanto, uma gama diversificada de oportunidades do meio se faz necessária para que o sujeito, caso tenha motivação para tanto, possa se aproximar, descobrir e expressar suas capacidades e até o talento.

Conforme SCHÜLLERDUDEN SPORT (1987) e WEINECK (1991), especificamente em relação ao esporte, indivíduos que apresentam facilidade na aprendizagem de movimentos adquirem um melhor domínio da técnica e, conseqüentemente, aumentam o repertório motor, podendo ser classificados como um talento motor geral.

Portanto, corroborando com BLOOM (1985), o talento motor geral pode ser um indicativo satisfatório para a motivação do sujeito na prática da atividade, sobretudo nos anos iniciais da aprendizagem, contribuindo para o desenvolvimento da área de interesse futuro. Todavia, o talento motor geral ainda não caracteriza que o sujeito é ou será necessariamente um talento esportivo (indivíduos que apresentam potencial acima da média populacional) ou um talento esportivo específico (indivíduos que apresentam requisitos físicos e psicológicos prévios para um determinado esporte). Para tanto, o mesmo ainda carece ser observado ao longo do tempo em relação à evolução do crescimento, desenvolvimento, maturação, treinamento e desempenho, bem como ter a seu favor as forças de apoio necessárias para o desenvolvimento num determinado domínio do conhecimento.

Ainda sobre o DSC1 e a facilidade para aprender uma determinada técnica, com a devida cautela e resguardo quanto à necessidade de estudos mais aprofundados e contundentes nessa área, se pode relacionar esta fração do conhecimento como um traço genético (GARDNER, 1996, 1999, 2002). Desta 
maneira, de acordo com BÖHME (2004), ERICSSON e CHARNESS (1994) e HOWE (1999), o treinamento pode afetar alguns componentes do desempenho, mas pode não afetar outros. Sendo assim, se o desempenho obtido após treinamento extensivo é limitado por componentes que não podem ser modificados, é adequado afirmar que fatores estáveis, geneticamente determinados, estabelecem o nível final de desempenho. Se todas as mudanças possíveis de desempenho relacionadas com o treinamento são obtidas após um período limitado de prática, logicamente as diferenças finais de desempenho devem refletir talentos inatos e capacidades naturais.

Outro fator relacionado ao DSC1 que parece ter contribuído sobremaneira para o talento na modalidade, é a consideração relacionada à aprendizagem dos movimentos no judô. Conforme o DSC1, o judoca brasileiro não se restringiu a assimilação das técnicas oriundas do judô tradicional japonês e tão pouco da escola européia de judô, mas sim considerou em seu repertório uma mescla de técnicas capaz de trazer a flexibilidade necessária para surpreender o adversário. Neste sentido, conforme RUBIO (2004), apesar da relevância da tradição dos imigrantes japoneses para o desenvolvimento da modalidade no Brasil, a escola brasileira de judô se firmou como uma das mais potentes e talentosas do mundo.

Em relação ao DSC2 (determinação), se observa de maneira contundente que as expressões justificam o talento no judô como um produto da combinação "muita determinação, força de vontade e treinamento". Conforme o DSC2, os judocas chegam a enfatizar que não são talentosos, mas sim possuem "muita teimosia e trabalham duro" para alcançar seus objetivos. Ademais, também é possível verificar que a determinação presente é gerada por fatores intrínsecos de obstinação e resiliência para superar as dificuldades e os obstáculos relacionados ao processo de treinamento e competições. Ou seja, o judoca quer, em primeiro lugar, provar para ele próprio que pode e é capaz, resistindo ao processo até que se alcance o desempenho esperado para aquele patamar do desempenho e seguindo para os novos desafios.

Sendo assim, a determinação presente nos judocas se aproxima dos referenciais de ABBOTT e COLLINS (2004), BLOOM (1985), BÖHME (2004), CSIKSZENTMIHALYI, RATHUNDE e WHALEN (1997), ERICSSON, KRAMPE e 
TESCH-RÖMER (1993), ERICSSON e CHARNESS (1994), SILVA e RÚBIO (2003), que apontam que a capacidade inata, a ânsia para trabalhar e o poder adequado de fazer muito trabalho laborioso são fundamentais para a manifestação do talento. Neste sentido, conforme ERICSSON e CHARNESS (1994), indivíduos podem aumentar o seu desempenho através da educação e do treinamento, se tiverem motivação, objetivo e direcionamento adequado para a superação diante dos processos de TLP.

\subsection{Competência profissional}

Conforme BLOOM (1985), a evolução do desempenho de cada criança depende da quantidade de apoio e estímulos que recebe dos pais, professores de boa qualidade, treinadores, mentores e de ambientes satisfatórios de desenvolvimento. O apoio da família, bem como o ambiente de desenvolvimento dos judocas olímpicos brasileiros foram observados e discutidos em outros itens do presente trabalho $(4.2,4.5$ e 4.7$)$.

De acordo com GIBBONS et alii (2002), a respeito dos técnicos esportivos, os atletas olímpicos norte americanos citaram a habilidade para ensinar e a habilidade para motivar como as principais qualidades que um técnico deve possuir.

Assim, com o intuito de analisar o papel de professores e/ ou técnicos no processo de desenvolvimento do talento no judô, é que foi elaborada a pergunta Fale um pouco sobre os teus professores e/ou técnicos e o papel deles na sua formação - . Desta forma, seguem apresentadas na TABELA 11 as ICs captadas, a freqüência das respostas e o percentual referente a cada IC. 
TABELA 11 - Caracterização das idéias centrais, freqüência e percentual de respostas para a pergunta: Fale um pouco sobre os teus professores e/ou técnicos e o papel deles na sua formação.

\begin{tabular}{llcc}
\hline & \multicolumn{1}{c}{ IC } & Freqüência & $\%$ \\
\hline A & Iniciação & 6 & 100,0 \\
B & Treinamento & 4 & 66,6 \\
\hline
\end{tabular}

Conforme o QUADRO 9 (ANEXO II) e as ICs captadas (TABELA 11) para as somas dos discursos, seguem abaixo os DSCs construídos (1 e 2) para cada IC:

\section{DSC1: IC-A - Iniciação (S1, S2, S3, S4, S5, S6).}

Eu tive alguns técnicos. Acho que os mais importantes foram aqueles que me iniciaram no J udô. Eu agradeço muito a eles por terem dado muita ênfase na minha disciplina e no respeito com os mais velhos, aos valores éticos e morais. Além disso, eles me fizeram gostar do esporte e eu acho que foi o principal para a minha formação para a carreira de judoca.

\section{DSC2: IC-B - Treinamento (S2, S3, S5, S6).}

Depois da iniciação outros professores cuidaram da lapidação da pedra bruta. Tentaram colocar mais velocidade no meu J udô, lapidar um pouco mais os meus golpes, dando continuidade ao trabalho. Na minha fase profissional, fase competidora, o (...) foi o cara que mais me ajudou. Ele não era profissional de Educação Física, mas ele já tinha participado de Olimpíada, foi um grande atleta também. Além dele, nos anos que o (...) assumiu a Seleção tive um desenvolvimento muito grande, obtendo muitas conquistas significativas. Hoje meus professores cuidam da minha parte física e técnica. Por isso, a minha formação no J udô é um emaranhado que hoje resulta no que eu sou. 
Conforme a TABELA 11, foram construídos o DSC1, que versa sobre os técnicos da fase de iniciação no judô e o DSC2, a respeito dos técnicos da fase de treinamento para o alto desempenho na modalidade.

De acordo com o DSC1 (iniciação), é possível verificar o alto grau de valor atribuído aos técnicos da fase de iniciação no judô. Sendo assim, conforme o DSC1, os técnicos da iniciação foram os mais importantes pois conseguiram transmitir (a) valores de disciplina e respeito, e (b) o gosto pela modalidade.

Desta forma, os valores de disciplina e respeito gerados pelos técnicos durante a fase de iniciação no judô, revelam que a história, a tradição e a filosofia do judô oriental têm se perpetuado ao longo das gerações, inclusive no Brasil, agregando ao judoca iniciante não apenas o aspecto competitivo característico do esporte, mas sobretudo a formação do homem. Tal fator também pôde ser observado no item 4.5 (relações sociais), no qual o discurso dos judocas já evidenciava o caráter filosófico da aprendizagem no judô e, portanto, agrega-se ao técnico de judô uma competência educacional particular e distinta de outras modalidades, podendo exercer influência sobre a formação da personalidade do judoca.

Além da competência educacional inerente aos técnicos de judô, é notável no DSC1, que os técnicos da fase de iniciação foram capazes de gerar nos praticantes o gosto e o prazer pela modalidade, contribuindo para a aderência dos mesmos nos próximos períodos do TLP.

Sobre esta perspectiva, conforme BLOOM (1985), quanto aos anos iniciais e intermédios da aprendizagem, as crianças devem aprender a gostar das atividades, dependendo principalmente do apoio de pais e professores para manterem o interesse e progredirem para o próximo estágio de desenvolvimento.

Para CSIKSZENTMIHALYI, RATHUNDE e WHALEN (1997), corroborando com BLOOM (1985), a motivação estabelecida através do apoio de professores qualificados é capaz de gerar e desenvolver comportamentos de autodisciplina e confiança, fundamentais para o confronto diante dos obstáculos inerentes ao processo de aprendizagem. Desta maneira, a competência educacional dos técnicos de judô pode ter contribuído para provocar o mesmo efeito de motivação, autodisciplina e confiança sobre os judocas iniciantes. 
Ademais, durante os anos iniciais e intermédios da aprendizagem os professores não precisam ser os mais tecnicamente habilidosos, porém sob o ponto de vista do trabalho com crianças devem ser profissionais extremamente capacitados e fornecerem reforços afetivos positivos às necessidades inerentes ao período da infância, mantendo a aprendizagem e o desempenho nas atividades (BLOOM, 1985).

Por sua vez, o DSC2 (treinamento) destaca a idéia de que, após a fase de iniciação, os judocas transitaram para outros técnicos com o objetivo de buscar treinamentos que pudessem lapidar as técnicas adquiridas.

Portanto, o DSC2 também se aproxima do estudo de BLOOM (1985) no que se refere à passagem para os anos finais da aprendizagem. Para o autor, após os anos iniciais e intermédios da aprendizagem, indivíduos talentosos devem transitar para ter acesso a melhores professores, treinamentos e ambientes competitivos que promovam desafios crescentes e, consequentemente, permitam maiores graus de prática, direcionados para o sucesso futuro.

Portanto, sobre a competência profissional dos técnicos durante os anos iniciais, intermédios e finais da aprendizagem, assim como no presente trabalho, os estudos de BLOOM (1985) e CSIKSZENTMIHALYI, RATHUNDE e WHALEN (1997) indicam que a maioria das crianças começava a instrução com um professor local e posteriormente, quando em níveis superiores de desempenho, absorviam o impacto positivo e motivacional de treinadores cada vez mais qualificados, preparando-se para o desempenho futuro.

\subsection{Prescrição, avaliação e controle do TLP}

Para BENDA (1998), BLOOM (1985), CSIKSZENTMIHALYI, RATHUNDE e WHALEN (1997), ERICSSON, KRAMPE e TESCH-RÖMER (1993) e VIEIRA e VIEIRA (2000), detectar e revelar talentos é apenas uma das etapas de um processo contínuo que envolve a elaboração e o planejamento de programas para o desenvolvimento das potencialidades detectadas, buscando garantir, no futuro, 0 aprofundamento máximo das suas capacidades e, consequentemente, o melhor desempenho. 
Desta maneira, conforme BÖHME et alii (2001), o treinamento a longo prazo (TLP) possui como objetivo a formação esportiva de futuras gerações de atletas para o esporte de rendimento. Neste sentido, o intervalo compreendido entre as categorias de base e o esporte de alto nível, desempenha papel fundamental no processo de detecção, seleção e promoção de talentos esportivos. Para tanto, há necessidade de procedimentos sistêmicos, devidamente fundamentados, durante todo processo de TLP.

Assim, a prática esportiva mundial tem demonstrado que o desempenho esportivo para o alto nível de rendimento só pode ser alcançado, quando os fundamentos relevantes para o mesmo são desenvolvidos durante os períodos da infância e adolescência, o que pressupõe o planejamento sistemático de um processo de TLP (BÖHME, 2000, 2002; LANARO FILHO, 2001; WEINECK, 1999).

Contudo, na atuação prática, ainda é comum que esses processos sejam norteados apenas pela própria experiência e intuição dos técnicos esportivos envolvidos (HEBBELINCK, 1989; MASSA, 1999).

Sendo assim, com o objetivo de verificar a presença de métodos fundamentados de treinamento durante os distintos períodos do TLP, é que foi elaborada a pergunta - $O$ teu treinamento era planejado ou não: fale sobre ele - . Desta forma, seguem apresentadas na TABELA 12 as ICs captadas, a freqüência das respostas e o percentual referente a cada IC.

TABELA 12 - Caracterização das idéias centrais, freqüência e percentual de respostas para a pergunta: $O$ teu treinamento era planejado ou não: fale sobre ele.

\begin{tabular}{llcc}
\hline & \multicolumn{1}{c}{ IC } & Freqüência & $\%$ \\
\hline A & Não era planejado & 6 & 100,0 \\
B & Atualmente sim & 6 & 100,0 \\
\hline
\end{tabular}

Conforme o QUADRO 10 (ANEXO II) e as ICs captadas (TABELA 12) para as somas dos discursos, seguem abaixo os DSCs construídos (1 e 2) para cada IC: 


\section{DSC1: IC-A - Não era planejado (S1, S2, S3, S4, S5, S6).}

Quando criança o treinamento era meio empírico, aquele estilo tradicional, do tipo: vai fazendo, sem planejamento nenhum. Hoje eu tenho consciência que o treinamento tem que ser planejado para você render e ter uma vida mais longa no esporte. Mesmo durante os anos que comecei a competir e ganhar algumas medalhas o treinamento era de uma forma aleatória, empírica. Ainda não tinha embasamento científico. Então antes eu treinava bastante Judô, mas a parte física eu fazia quando eu queria ou quando eu conseguia um preparador físico. Fazia a maioria das coisas do meu jeito. Algumas vezes eu ia para uma academia com vontade de treinar, quando chegava lá ao invés de treinar eu ficava conversando e não fazia nada ou eu fazia uma série só. Portanto, antigamente era tudo arcaico. Não tinha um planejamento visando competição. Antigamente treinava-se duas horas debaixo do sol quente e não podia beber água, e todo mundo achava que estava certo. Meu treinamento planejado foi acontecer apenas depois da minha primeira Olimpíada. Antes disso eu não tinha um cronograma certo de treinamento, não tinha uma periodização de treinamento, não tinha microciclo, não tinha nada.

\section{DSC2: IC-B - Atualmente $\operatorname{sim}(\mathrm{S1}, \mathrm{S2}, \mathrm{S3}, \mathrm{S4}, \mathrm{S5}, \mathrm{S6})$.}

No Projeto (...) tivemos uma programação. Mas não era uma programação individual, era uma programação aberta, para os alunos que estavam no Projeto (...), mas tínhamos uma programação de início, meio e fim. Eu acho que para a época era uma das melhores programações. Apenas de uns três anos para cá que o meu treinamento vem sendo uma coisa mais regrada, onde eu tenho uma parte física, uma parte tática e uma parte técnica. Hoje as coisas são mais estudadas, os próprios antigos técnicos estão tendo uma outra mentalidade sobre o J udô competitivo. Comecei a ter professores capacitados, professores formados, mestres, doutores que ajudam na minha preparação. Hoje eu faço uma parte física mais elaborada, mais planejada e posso sentir pelo retorno que tenho com o meu preparador. Então hoje estamos no caminho certo, mas ainda acho que tem que evoluir mais. Acho que quando você tem estudo dentro do esporte você consegue ter 
bons resultados. Percebo a melhora até do meu descanso, da minha recuperação, eu acho que eu tenho evoluído bastante por isso.

Conforme a TABELA 12, foi unânime a idéia de que o treinamento não era planejado (DSC1; 100\%) e que apenas mais recentemente os treinamentos passaram a ser organizados (DSC2; 100\%).

Especificamente em relação ao DSC1 (não era planejado), é marcante a colocação dos judocas em relação a não possuírem nenhum tipo de planejamento para o TLP. É possível encontrar no DSC1 alguns termos que atestam essa fragilidade, como: empírico, "vai fazendo", aleatório, arcaico, sem cronograma, sem macrociclo.

Por outro lado, o DSC2 (atualmente sim), indica que em períodos mais recentes os judocas começaram a receber maior suporte e planejamento para a participação nos treinamentos e competições. Isso parece corroborar com a fase de transição percebida no item 6.9 (competência profissional) e nos trabalhos de BLOOM (1985) e CSIKSZENTMIHALYI, RATHUNDE e WHALEN (1997), em que os judocas transitaram para melhores técnicos, estruturas e ambientes competitivos com o intuito de lapidarem suas estruturas técnicas e táticas para o desempenho de alto nível.

Entretanto, mesmo diante desta transição para melhores estruturas (físicas, materiais, técnicos especializados e ambientes competitivos), se percebe no DSC2 que os anos intermédios da aprendizagem (BLOOM, 1985) ou, conforme a literatura do TLP, o segundo nível de treinamento específico (BARBANTI, 1997; BÖHME, 2000, 2002, 2004; BOMPA, 1999, 2000; WEINECK, 1999) ainda eram carentes de planejamento. Ou seja, a maioria dos judocas seguiu para um modelo de treinamento que apresentava algum tipo de periodização, contudo era um planejamento feito para todo o grupo de judocas, sem respeitar a individualidade e, portanto, se pode inferir que não atingia e/ ou beneficiava a todos da mesma maneira. Ademais, é possível verificar no DSC1 e no DSC2, que alguns judocas só tiveram a oportunidade de participar de treinamentos sistemáticos nos anos finais da aprendizagem e, em alguns casos, tardiamente, após a participação na primeira Olimpíada. 
Portanto, se estabelece na presente amostra o risco descrito na revisão de literatura. Isto é, quando a prática vitoriosa possui a dicotomia de não se tornar mais acalentadora por satisfazer apenas a anseios imediatos - resultado - e, no que tange ao processo de promoção do talento, colabora para a permanência da lacuna resultado $X$ processo -, não se tem a elevação do conhecimento na área e tão pouco a possibilidade de colher os desdobramentos passíveis da interpretação e reprodução desse conhecimento. Assim, nestes casos, se possui apenas o resultado, muitas vezes não explicado e ausente de uma rotina metodológica consistente, fundamentada, multifatorial, de acompanhamento cíclico e contínuo, provida de avaliações e registros, em longo prazo.

Desta forma, assim como em outras modalidades esportivas, se pode questionar sobre a existência de algum arquivo confiável (banco de dados) que possa fornecer dados retrospectivos sobre o processo de crescimento, desenvolvimento, maturação, treinamento e desempenho de judocas que passaram por processos de treinamento a longo prazo (TLP) e chegaram ao alto desempenho esportivo. Portanto, embora se possa verificar o resultado, não se retém o processo.

Entretanto, no DSC2 é possível verificar uma perspectiva mais promissora para os processos de TLP no judô. Conforme os judocas, mesmo técnicos de gerações anteriores têm se atualizado e unido aos seus trabalhos a presença de profissionais que agregam os conhecimentos científicos necessários para uma melhor prescrição, avaliação e controle do TLP. Neste sentido, cabe ressaltar a importância da formação do profissional de educação física e esporte, que deve estar preparado não apenas para aplicar o TLP, mas inclusive para consumir e contribuir com o registro científico do seu trabalho, gerando conhecimentos que possam ser compartilhados, discutidos, reproduzidos e aperfeiçoados, fazendo do resultado o fruto de um processo explicado.

\subsection{Papel da competição}

Conforme a literatura esportiva, a competição deve estar incorporada ao processo de TLP. Não faria sentido o processo de treinamento de jovens atletas sem 
que neste estivessem previstos objetivos e competições que despertassem 0 interesse estável e o conhecimento da modalidade esportiva escolhida por parte do praticante (BARBANTI, 1997; BÖHME, 2000, 2002, 2004; BOMPA, 1999, 2000; 1988; WEINECK, 1999).

Neste sentido, de acordo com SCHNABELL, HARRE e BORDE ${ }^{10}$ (1994) apud BÖHME (1999), o desempenho esportivo se relaciona profundamente com o processo de treinamento esportivo e com a competição.

Sendo assim, com o objetivo de explorar o papel das competições no processo de desenvolvimento de judocas brasileiros talentosos, é que foi elaborada a pergunta - Como foram as competições no seu treinamento? Você se destacava logo no começo ou o destaque veio com o tempo? - . Assim, seguem apresentadas na TABELA 13 as ICs captadas, a freqüência das respostas e o percentual referente a cada IC.

TABELA 13 - Caracterização das idéias centrais, freqüência e percentual de respostas para a pergunta: Como foram as competições no seu treinamento? Você se destacava logo no começo ou o destaque veio com o tempo?

\begin{tabular}{llcc}
\hline & \multicolumn{1}{c}{ IC } & Freqüência & $\%$ \\
\hline A & Destaque com o tempo & 5 & 83,3 \\
B & Competição como parte do treinamento & 3 & 50,0 \\
C & Destaque desde cedo & 1 & 16,6 \\
\hline
\end{tabular}

Conforme o QUADRO 11 (ANEXO II) e as ICs captadas (TABELA 13) para as somas dos discursos, seguem abaixo os DSCs construídos (1, 2 e 3) para cada IC:

\section{DSC1: IC-A - Destaque com o tempo (S1, S2, S3, S4, S5).}

Não, eu acho que as coisas foram acontecendo devagar. Quando criança eu nunca fui um destaque. Eu me considerava um atleta normal, sem muito a oferecer. Minhas performances em competições foram aumentando de acordo com o 
meu treinamento. Foi uma escala, quanto mais eu comecei a treinar mais eu comecei a evoluir nas competições. Tem quem pense que existem atletas que já são campeões desde o início, mas no meu caso e de muitos outros começamos perdendo, tanto que na minha primeira competição eu perdi. Enfim, fui crescendo conforme eu fui treinando, melhorando e aperfeiçoando a minha condição técnica. 0 legal disso é que tudo foi crescente, não foi uma coisa isolada, então eu acredito que a vida do atleta é assim, ele vai aos poucos, galgando, e quando chega lá em cima vem a parte difícil que é tentar manter esse nível alto.

\section{DSC2: IC-B - Competição como parte do treinamento (S4, S5, S6).}

Nas competições eu não me preocupo se eu vou ganhar ou não, eu tento analisar a competição, tento observar os meus adversários, aprender com cada um deles, com respeito e tirando proveito para a minha superação em direção aos maiores desafios e obstáculos das seletivas e competições mais importantes. Eu acho que o importante, para a iniciação é poder estar participando de competições. Tem que estar competindo, eu acho que uma competição que você faz é equivalente a 10, 20 treinos, então tem que estar competindo, a competição vai te dar base para lá na frente você estourar.

\section{DSC3: IC-C - Destaque desde cedo (S6).}

Obs.: o discurso abaixo refere-se exclusivamente ao sujeito $\mathrm{S6}$, pois apenas ele apresentou a IC destaque desde cedo, não caracterizando, portanto, um discurso coletivo.

Sempre nas competições eu nunca deixei de trazer medalha. Sempre, desde o infantil, desde o mirim toda competição estava beliscando uma de ouro, uma de prata, uma de bronze. Acho que isso me fez ser um bom competidor. Toda competição que eu lutei até hoje eu sempre ganhei uma medalha.

Assim, de acordo com os resultados dos DSCs apresentados, pode-se verificar conforme a TABELA 13, que a maioria dos judocas olímpicos brasileiros 
apenas se destacaram em competições com o passar do tempo (DSC1: 83,3\%; $n=5$ ); 1 judoca (DSC3: 16,6\%) se destacou desde o início na modalidade; e alguns judocas comentaram sobre o papel da competição durante o treinamento (DSC2: 50\%; $n=3$ ).

A respeito do DSC1 (destaque com o tempo) e do DSC3 (destaque desde cedo), é possível verificar que os discursos corroboram com os resultados anteriormente discutidos no item 6.3 (talento precoce) do presente trabalho, no qual observaram-se, em mesma proporção, o DSC2 (não me destacava; 83,3\%) e o DSC1 (sim, me destacava; 16,6\%).

Entretanto, acerca do objetivo de verificar o papel da competição durante o processo de treinamento, o DSC1 (destaque com o tempo) revela a idéia de que o resultado em competições foi crescendo de acordo com a evolução do processo de TLP. Ou seja, quanto maior a dedicação aos treinamentos, maior a evolução nas competições. Ademais, o DSC1 acrescenta que a evolução nas competições se manifestava de maneira consistente e crescente, associada à exigência do TLP.

Neste sentido, no DSC2 (competição como parte do treinamento) se verifica que as competições realizadas durante a fase de iniciação no judô tinham como caráter principal a participação, parecendo indicar que nesta fase os judocas tomavam gosto pela prática de competir e não necessariamente vencer. Além disso, também é possível perceber no DSC2 que a competição era mais um momento de aprendizado, no qual o judoca podia aprender e desenvolver novas técnicas e estratégias táticas a partir da observação dos próprios adversários, acumulando, independentemente de ganhar ou perder, experiências para usufruir em desafios futuros mais importantes.

Portanto, mais uma vez, os resultados encontrados parecem se aproximar da literatura relacionada aos processos de desenvolvimento de talentos no que tange a possibilidade do talento se desenvolver diante de um processo de treinamento de longo prazo, no qual não é pressuposto para o alto desempenho o talento precoce, mas sim o prazer pela prática (BLOOM, 1985; CSIKSZENTMIHALYI, RATHUNDE \& WHALEN, 1997; ERICSSON, KRAMPE \& TESCH-RÖMER, 1993).

Além disso, o estudo de MARTIN, CARL e LEHNERTZ ${ }^{9}$ (1991) apud BÖHME (2000) apresenta a média de idade de 19,8 anos como o período de obtenção dos melhores resultados competitivos no Judô. Tal perspectiva parece se 
aproximar da amostra pesquisada, pois a maioria dos judocas apresentou resultados significativos apenas com a aproximação dos anos finais da aprendizagem e/ou terceiro nível do TLP (de 17/ 18 anos em diante), considerado o treinamento de alto nível (BARBANTI, 1997; BÖHME, 2000, 2002, 2004; BOMPA, 1999, 2000; WEINECK, 1999).

\subsection{Estresse competitivo}

Conforme BLOOM (1985) e CSIKSZENTMIHALYI, RATHUNDE e WHALEN (1997), sobre o processo de desenvolvimento do talento, em algumas situações as tarefas inerentes ao processo de treinamento podem ficar muito difíceis de realizar devido à carência de informação e preparo por parte de professores e treinadores, prejudicando o desenvolvimento do talento. Neste sentido, de acordo com CSIKSZENTMIHALYI, RATHUNDE e WHALEN (1997), o isolamento de muitos jovens estudantes talentosos de biologia, matemática e física fizeram com que eles desistissem do processo, pois trabalhavam sozinhos nos laboratórios. Por sua vez, no esporte e na arte os fatores negativos inerentes à competição ocorriam em detrimento do processo de desenvolvimento de alguns jovens promissores.

Em relação ao esporte, diversos estudos têm discutido a relevância dos fatores psicológicos para o desempenho competitivo (ABBOTT \& COLLINS, 2004; DE ROSE JÚNIOR, 1993; MARQUES, 1991; MARQUES \& ROSADO, 2005; RÉGNIER, SALMELA \& RUSSEL, 1993; WEINECK, 1999).

Sendo assim, com o intuito de verificar a interferência do estresse competitivo em judocas olímpicos brasileiros, é que foi elaborada a pergunta - Toda competição é meio estressante não é? Como é isso para você? -. Desta forma, seguem apresentadas na TABELA 14 as ICs captadas, a freqüência das respostas e o percentual referente a cada IC. 
TABELA 14 - Caracterização das idéias centrais, freqüência e percentual de respostas para a pergunta: Toda competição é meio estressante não é? Como é isso para você?

\begin{tabular}{llcc}
\hline & \multicolumn{1}{c}{ IC } & Freqüência & $\%$ \\
\hline A & Estresse, ansiedade & 5 & 83,3 \\
B & Motivação, superação, confiança & 6 & 100,0 \\
\hline
\end{tabular}

Conforme o QUADRO 12 (ANEXO II) e as ICs captadas (TABELA 14) para as somas dos discursos, seguem abaixo os DSCs construídos (1 e 2) para cada IC:

\section{DSC1: IC-A - Estresse, ansiedade (S1, S2, S3, S4, S5).}

Quando você é jovem e não tem um calendário cheio de competições você acaba encarando numa boa. A partir do momento que a competição passa a ser uma em cima da outra é que acaba sendo maçante. Não pelo corpo, mas pela cabeça. Acho que cansa porque a competição tem toda uma preparação mental, você se prepara, você se concentra e você sempre acaba cansando. Até hoje sinto aquele frio na barriga e tenho que ir ao banheiro todas as lutas antes para liberar um pouco a adrenalina. Eu acho que quando o atleta objetiva uma posição alta não tem como não sentir um certo receio. Eu conseguia lidar com essas situações de cobrança. Lógico, ficava com ansiedade, mas eu conseguia administrar um pouco mais isso, e mostrar que não posso dar branco. Atualmente, para não passar mais por isso, estou tentando voltar às minhas origens. Ou seja, estou tentando tirar um pouco do peso da responsabilidade que está presente em cada competição. Antes, tive momentos que acabei me cobrando demais e não me saí tão bem quando quis vencer todos por ipon. Eu vi que não é assim, você tem que acabar deixando o trabalho fluir. Nos últimos anos eu senti um pouco mais. Depois que você adquiri um título a medalha acaba pesando um pouquinho. No meu caso pesou bastante. Comecei a competir querendo apenas jogar de ipon e ganhar. Então nesses últimos anos comecei a me machucar bastante, eu comecei a sentir muito o peso disso, que 
hoje eu sei que me fez mal, tanto é que eu estou parado faz um ano afastado de competição, devido a isso.

\section{DSC2: IC-B - Motivação, superação, confiança (S1, S2, S3, S4, S5, S6).}

No início eu ia para competição com aquele gelo na barriga. Eu acho que é isso que motiva o atleta a estar competindo, mas eu tinha prazer, era um estresse tolerável, um estresse gostoso de se sentir. Nestes últimos dias estive viajando e competindo em vários lugares diferentes e agora estou aqui competindo de novo; eu estou meio cansado, então tenho que tirar motivação lá de dentro e imaginar o meu objetivo para me estimular e tirar proveito de toda competição. 0 vitorioso é aquele que transforma esse receio em combustível para que ele alcance o seu objetivo. Então eu acho que é uma virtude que eu tenho. Eu treinava 24 horas, eu pensava 24 horas nos meus adversários, às vezes pensava mais neles do que na minha família inteira. Uma coisa que a imprensa sempre destacou em mim é meu jeito frio de competir. Eu estou sempre na minha, ganhando ou perdendo não me deixo afetar e me concentro no que estou fazendo. Se o árbitro tiver errando e eu estiver perdendo, estarei sempre do mesmo jeito e vou procurar vencer o cara do meu jeito. Hoje em dia também tenho tentando resgatar o prazer que me trouxe ao J udô, procurando aproveitar cada momento com mais tranqüilidade. Procuro lutar por amor ao esporte que eu sempre fiz, e como eu não vou ter patrocínio, eu não vou ter um clube por trás me cobrando, eu acho que vai ser até mais fácil para mim agora.

Assim, de acordo com os resultados expressos na TABELA 14, se pode verificar que os judocas olímpicos brasileiros apresentam características de estresse e ansiedade (DSC1: 83,3\%; $n=5$ ) e de motivação, superação e confiança (DSC2: $100 \% ; n=6)$.

Desta maneira, é possível notar no DSC1 (estresse e ansiedade) que o desgaste psicológico necessário para o preparo mental diante de uma competição é muito intenso. Além disso, situações decorrentes da pressão por melhores resultados, das seletivas, dos patrocinadores, entre outros fatores, eram capazes de gerar, inclusive, a queda do desempenho competitivo do judoca. 
Portanto, assim como nos estudos de BLOOM (1985), CSIKSZENTMIHALYI, RATHUNDE e WHALEN (1997) e ERICSSON, KRAMPE e TESCH-RÖMER (1993), a trajetória de desenvolvimento dos judocas investigados nem sempre esteve necessariamente associada a experiências prazerosas. Ou seja, situações negativas oriundas do processo de desenvolvimento do talento podem contribuir para uma mudança do estado-de-espírito dos judocas, com extensões psicológicas que podem gerar índices elevados de desistência no judô.

Neste sentido, é notável no DSC1 o discurso do judoca que por efeito dos fatores anteriormente citados (ex: cobrança por melhores resultados, patrocinadores, entre outros) se manteve afastado do judô por um período de um ano e somente mais recentemente, com o devido controle dos agentes geradores do estresse psicológico negativo, está pensando em retomar as atividades competitivas.

Neste sentido, conforme MARQUES (1991) e WEINECK (1999), procedimentos equivocados durante a fase de promoção do talento, podem fazer com que o jovem atleta abandone a prática esportiva pela saturação psicológica, devido a quantidades inadequadas e exaustivas de treinamento e a alta exigência em competições.

Em contrapartida, o DSC2 (motivação, superação e confiança) demonstra que mesmo diante de situações de estresse e ansiedade, os judocas conseguiram se superar diante dos obstáculos inerentes ao processo de TLP e competições, se mantendo na atividade. Conforme o DSC2, o estresse se mantinha num grau tolerável, que ainda possibilitava o prazer pela prática. Ou seja, era o estresse positivo gerado pela competição que se manifestava no judoca, permitindo que este entrasse no ambiente da competição e, com a devida concentração, se preparasse para o alto desempenho competitivo, sobretudo não deixando que os aspectos ressaltados no DSC1 prevalecessem diante do processo e prejudicassem 0 desempenho competitivo.

Sendo assim, a exemplo do "O Fluxo de Experiência Ótima" citado por CSIKSZENTMIHALYI, RATHUNDE e WHALEN (1997), o presente estudo parece coerente com a idéia de que (a) nenhum adolescente desenvolverá talentos se não se divertir trabalhando e, ao mesmo tempo, (b) nenhum adolescente poderá evitar os conflitos inerentes ao desenvolvimento do talento. Neste sentido, contar com a força 
de apoio adequada de pais e técnicos parece ser fundamental para o suporte do adolescente diante do processo de TLP, pois nem sempre o mesmo será automaticamente prazeroso. Portanto, o apoio dos pais e de técnicos devidamente preparados se faz necessário para que se possa gerar situações que estimulem os jovens a continuarem motivados diante dos desafios crescentes decorrentes do processo de detecção, seleção e promoção de talentos esportivos.

\section{CONSIDERAÇÕES FINAIS}

As questões inicialmente propostas sobre os modelos de desenvolvimento do talento descritos na literatura e a trajetória de desenvolvimento de judocas olímpicos brasileiros foram contempladas com o apoio das considerações realizadas a respeito da temática do talento, do talento esportivo, do desempenho esportivo, do processo de treinamento a longo prazo e, sobretudo, das discussões que emergiram da análise do Discurso do Sujeito Coletivo de Judocas Olímpicos Brasileiros.

Entre as principais reflexões a respeito dos modelos de desenvolvimento do talento, se pode revelar o alto grau de importância atribuído pela literatura aos fatores ambientais e à motivação como aspectos centrais do desenvolvimento do talento em qualquer segmento da sociedade.

Diante deste contexto, rejeitando a hipótese puramente inata do talento, se coloca em evidência que a formação de talento em qualquer domínio do conhecimento é altamente dependente de um processo de desenvolvimento, possuindo como alicerce as oportunidades oferecidas pelo meio, o apoio da família, a qualidade dos professores/ técnicos, os recursos físicos e materiais disponíveis, o prazer pela prática, a determinação, o trabalho de longo prazo e a prática deliberada.

Não obstante, o processo de treinamento a longo prazo e as fases de detecção, seleção e promoção de talentos esportivos se aproximaram dos princípios apontados nos modelos de desenvolvimento de talento descritos na literatura.

Especificamente em relação à análise do processo de desenvolvimento de judocas olímpicos brasileiros, é possível considerar que: 
a) $\mathrm{A}$ idade de iniciação $(6,2 \pm 1,3$ anos $)$ e o tempo de prática $(22 \pm 4,1$ anos $)$ de judocas olímpicos brasileiros se aproxima do que é preconizado na teoria do TLP, bem como das teorias relacionadas ao processo de desenvolvimento de talentos. Contudo, cabe salientar que os casos de iniciação em idades muito precoces, ou seja, entre cinco e seis anos de idade, devem ser vistos com cautela se associados a uma especialização esportiva unilateral (precoce).

b) O processo de iniciação no judô foi caracterizado pelo apoio da família $(83,3 \%)$, proximidade de casa $(50 \%)$, comportamento $(50 \%)$ e bons professores (16,6\%). Estes fatores corroboram com as expectativas teóricas ressaltadas na análise dos modelos de desenvolvimento de talento e destacam a relevância da família para a iniciação da criança numa determinada modalidade esportiva. Em contrapartida, os resultados indicam a necessidade de gerar oportunidades próximas ao ambiente de desenvolvimento da criança. Coincidentemente, em pelo menos $50 \%$ dos casos observados no presente estudo, o fator proximidade de casa foi preponderante para a aproximação da criança. Contudo, estas aproximações ocorreram ao acaso e foram produto de iniciativas isoladas, ou seja, sem vínculo com nenhum projeto planejado de desenvolvimento da modalidade.

c) Assim como a literatura tem revelado, a maioria dos judocas olímpicos brasileiros analisados (83,3\%) não foram talentos precoces. Desta maneira, antes do emprego de qualquer estratégia que possa vir a excluir equivocadamente futuros talentos, fica evidente a necessidade de durante anos iniciais da aprendizagem oferecer oportunidade de prática prazerosa para que as crianças possam aderir a um programa de iniciação esportiva geral básica. Portanto, não houve relação entre o desempenho inicial e o desempenho futuro adquirido, demonstrando a importância do processo de desenvolvimento do talento como um fenômeno de longo prazo, composto por avaliações cíclicas e contínuas.

d) O prazer (50\%), a determinação (50\%) e o apoio da família (33,3\%) exerceram grande influência para a aderência do judoca ao processo de treinamento a 
longo prazo e competições. Estes achados corroboram com os pressupostos motivacionais apontados pela literatura como relevantes para o processo de desenvolvimento do talento.

e) Quanto às relações sociais estabelecidas pelos judocas durante o processo de desenvolvimento na modalidade, foi possível verificar que (1) o apoio da família (100\%) e (2) o ambiente do judô e amigos (50\%) formaram um dueto social coeso e positivo para o judoca durante o seu processo de desenvolvimento. Em outras palavras, mesmo diante da pouca valorização que o judô pode estar sofrendo na cultura da sociedade em geral, esse dueto funcionou como um microssistema capaz de potencializar as condições sociais necessárias para o desempenho, gerando cultura suficiente para que as famílias agregadas construíssem o suporte e as perspectivas de uma nova geração de judocas.

f) Sobre os aspectos financeiros disponíveis para o processo de desenvolvimento no judô, assim como o expresso na literatura sobre o cenário nacional de desenvolvimento do esporte, o estado, as empresas, os clubes e a própria família, se dividiram na responsabilidade de subsidiar a estrutura esportiva para o talento esportivo. Contudo, essa divisão de responsabilidades não foi planejada, mas sim dependente, além da própria família, das iniciativas isoladas de um clube ou projeto, de estímulos públicos sazonais e de patrocinadores que geralmente se associaram à imagem de atletas adultos que já estão formados e atingiram o alto desempenho. Portanto, não há 0 encadeamento sistemático dessas ações ao longo do processo de desenvolvimento do talento, sobretudo em relação aos anos iniciais e intermédios da aprendizagem.

g) Quanto ao discurso dos judocas olímpicos brasileiros acerca da atribuição do talento, se pode destacar a determinação (83/3\%) como o principal fator de explicação para a obtenção do alto desempenho esportivo na modalidade. Desta maneira, se observa de forma contundente que o talento no judô é um produto da combinação formada por "muita determinação, força de vontade e 
treinamento". Os judocas chegam a enfatizar que não são talentosos, mas sim possuem "muita teimosia e trabalham duro" para alcançar seus objetivos. Ademais, também é possível verificar que a determinação presente é gerada por fatores intrínsecos de obstinação e resiliência para superar as dificuldades e os obstáculos relacionados ao processo de treinamento e competições. Ou seja, o judoca quer, em primeiro lugar, provar para ele próprio que pode e é capaz, resistindo ao processo até que se alcance o desempenho esperado para aquele patamar do desempenho e seguindo para os novos desafios.

h) Em relação aos profissionais que participaram do processo de desenvolvimento dos judocas olímpicos brasileiros, foi possível verificar o alto grau de valor atribuído aos técnicos da fase de iniciação no judô. Conforme os judocas, os técnicos da iniciação foram os mais importantes pois conseguiram transmitir (a) valores de disciplina e respeito, e (b) gosto pela modalidade. Sendo assim, a motivação estabelecida através do apoio de professores qualificados é capaz de gerar e desenvolver comportamentos de autodisciplina e confiança, fundamentais para o confronto diante dos obstáculos inerentes ao processo de aprendizagem. Desta maneira, a competência educacional dos técnicos de judô pode ter contribuído para provocar o mesmo efeito de motivação, autodisciplina e confiança sobre os judocas iniciantes.

i) Corroborando com a literatura, após os anos iniciais e intermédios da aprendizagem, os judocas talentosos transitaram para terem acesso a melhores professores, treinamentos e ambientes competitivos que promovessem desafios crescentes e, consequentemente, permitissem maiores graus de prática. Portanto, a maioria dos judocas começou a instrução com um professor local e posteriormente, quando em níveis superiores de desempenho, absorveram o impacto positivo e motivacional de treinadores cada vez mais qualificados, preparando-se para o desempenho futuro.

j) Acerca do planejamento do processo de treinamento dos judocas olímpicos brasileiros, foi possível verificar que inicialmente, durante os anos iniciais da 
aprendizagem, os judocas não possuíam uma rotina de treinamentos devidamente planejada e estruturada. Posteriormente, a maioria dos judocas migrou para um modelo de treinamento que apresentava algum tipo de periodização. Contudo, era um planejamento feito para todo o grupo de judocas, sem respeitar a individualidade e, portanto, se pode inferir que não atingia e/ ou beneficiava a todos da mesma maneira. Ademais, alguns judocas só tiveram a oportunidade de participar de treinamentos sistemáticos nos anos finais da aprendizagem e, em alguns casos, tardiamente, após a participação na primeira Olimpíada.

k) Em relação aos fatores de estresse e ansiedade, foi verificado que as situações decorrentes da pressão por melhores resultados, das seletivas, dos patrocinadores, entre outros fatores, foram capazes de gerar, inclusive, a queda do desempenho por parte de alguns judocas. Portanto, corroborando com a literatura, a trajetória de desenvolvimento dos judocas investigados nem sempre esteve necessariamente associada a experiências prazerosas. Ou seja, situações negativas oriundas do processo de desenvolvimento do talento podem contribuir para uma mudança do estado-de-espírito dos judocas, com extensões psicológicas capazes de gerar índices elevados de desistência no judô, podendo comprometer o êxito do processo de desenvolvimento do talento. Por outro lado, de maneira positiva, a presente amostra de judocas conseguiu demonstrar que mesmo diante de situações de estresse e ansiedade, os judocas se superavam diante dos obstáculos inerentes ao processo de TLP e competições, se mantendo na atividade devido a elevados índices de motivação, superação e confiança.

Portanto, de acordo com as características observadas na análise do processo de desenvolvimento de judocas olímpicos brasileiros, mesmo ausente de um modelo nacional sistemático e consistente de desenvolvimento do talento esportivo, foi possível verificar que o microssistema composto pela cultura de uma cidade e/ou de trabalhos isolados de clubes ou academias próximas, associado com o apoio emocional e financeiro das famílias e de muito prazer e determinação por 
parte do judoca, foi capaz de gerar o ambiente ideal para a formação do talento no judô.

Desta forma, em relação ao processo de desenvolvimento de talentos no judô, se pode afirmar que o Brasil, seja por iniciativa pública ou por iniciativa privada, não se aproxima dos modelos observados na literatura, sobretudo em relação a existência de programas nacionais de desenvolvimento esportivo devidamente elaborados, encadeados e estruturados, com recursos físicos, materiais e humanos disponíveis para a geração de oportunidades diferenciadas de prática esportiva, inclusive do judô. Por outro lado, no que tange os aspectos relacionados ao apoio da família, ao prazer pela prática e à determinação dos judocas olímpicos brasileiros, o presente estudo corrobora com a literatura, revelando a importância que os fatores psicossociais exerceram no processo de desenvolvimento do judoca talentoso. 


\section{REFERÊNCIAS}

ABBOTT, A.; COLLINS, D. Eliminating the dichotomy between theory and practice in talent identification and development: considering the role of psychology. Journal of Sports Sciences, London, v.22, p.395-408, 2004.

ARAÚJO, C.G.S.; GOMES, P.S.C.; NOVAES, E.V. O somatotipo de judocas brasileiros de alto nível. Caderno Artus de Medicina Desportiva, Rio de Janeiro, n.1, p.21-30, 1978.

ARENA, S.S.; BÖHME, M.T.S. Programas de iniciação e especialização esportiva na grande São Paulo. Revista Paulista de Educação Física, São Paulo, v.14, n.2, p.18495, 2000.

BARBANTI, V.J. Treinamento físico: bases científicas. São Paulo: Manole, 1996. Teoria e prática do treinamento esportivo. São Paulo: Edgard Blucher, 1997.

BAXTER-JONES, A.D.G. Growth and development of young athletes. Sports Medicine, Auckland, v.20, n.2, p.59-64, 1995.

BENDA, R.N. A detecção, seleção e promoção de talentos esportivos em uma abordagem sistêmica. In: GARCIA, E.S.; LEMOS, K.L.M.; GRECO, P.J. (Eds.). Temas atuais III: educação física e esportes. Belo Horizonte: Health, 1998. p.95-107.

BENTO, J.O. Detecção e fomento de talentos. Revista Brasileira de Ciência e Movimento, São Caetano do Sul, v.3, n.3, p.84-93, 1989.

BEYER, E. Wörterbuch der Sportwissenschaft. Schorndorf: Verlag Karl Hofmann, 1987.

BLOOM, B.S. Developing talent in young people. New York: Ballentine, 1985. 
BÖHME, M.T.S. Talento esportivo I: aspectos teóricos. Revista Paulista de Educação Física, São Paulo, v.8, n.2, p.90-100, 1994.

. Talento esportivo II: determinação de talentos esportivos. Revista Paulista de Educação Física, São Paulo, v.9, n.2, p.138-46, 1995.

- Detecção, seleção e promoção de talentos esportivos: determinação de critérios de desempenho nos aspectos bio-psico-social. São Paulo: EEFEUSP, 1996. (Projeto de pesquisa interdisciplinar do Departamento de Esporte).

Aptidão física de jovens atletas do sexo feminino analisada em relação a determinados aspectos biológicos, idade cronológica e tipo de modalidade esportiva praticada. 1999. Tese (Livre Docência) - Escola de Educação Física e Esporte, Universidade de São Paulo, São Paulo.

. O treinamento a longo prazo e o processo de detecção, seleção e promoção de talentos esportivos. Revista Brasileira de Ciências do Esporte, Porto Alegre, v.21 n.2/3 p. 4-10, 2000.

. O talento esportivo e o processo de treinamento a longo prazo. In: DE ROSE JUNIOR, D. (Org.). Esporte e atividade física na infância e na adolescência: uma abordagem multidisciplinar. Porto Alegre: Artmed, 2002. p.109-122.

. Talento esportivo. In: GAYA, A.; MARQUES, A.; TANI, G. (Orgs.). Desporto para crianças e jovens: razões e finalidades. Porto Alegre: UFRGS, 2004. p. 235-249

O tema talento esportivo na ciência do esporte. Revista Brasileira de Ciência e Movimento, Brasília. Submetido a publicação, 2005. 
BÖHME, M.; BOJIKIAN, L.; MARTINS, R.; TEIXEIRA, C.; MASSA, M.; KISS, M. Use of cluster analysis in sport talent selection. In: ANNUAL CONGRESS OF THE EUROPEAN COLLEGE OF SPORT SCIENCE, 6.; CONGRESS OF THE GERMAN SOCIETY OF SPORT SCIENCE, 15., 2001. Cologne. Book of Abstracts... Cologne: European College of Sport Science/ German Society of Sport Science, 2001. p.916.

BOMPA, T.O. Talent identification. Ottawa: Coaching Association of Canada, 1985. (Science Periodical on Research and Technology in Sport) Kinetics, 1999.

Periodization: theory and methodology of training. Champaign: Human Total training for young champions: proven conditioning programs for athletes ages 6 to 18. Champaign: Human Kinetics, 2000.

BORGES, O.A. Estudo sobre a eficácia do "kumi-kata" em lutas de judô. 1989. Dissertação (Mestrado) - Escola de Educação Física, Universidade de São Paulo, São Paulo.

BURWITZ, L.; MOORE, P.M.; WILKINSON, D.M. Future directions for performancerelated sports research: an interdisciplinary approach. Journal of Sports Sciences, London, v.12, p.93-109, 1994.

BRITO, N.; FONSECA, A.M.; ROLIM, M. Os melhores atletas nos escalões de formação serão igualmente os melhores no escalão sênior? Análise centrada nos rankings femininos das diferentes disciplinas do atletismo ao longo das últimas duas décadas em Portugal. Revista Portuguesa de Ciências do Desporto, Porto, v.4, n.1, p.17-28, 2004.

CALLISTER, R.; CALLISTER, R.J.; FLECK, S.J.; DUDLEY, G.A. Physiological and performance responses to overtraining in elite judo athletes. Medicine and Science in Sports and Exercise, Indianapolis, v.22, n.6, p.816-24, 1990. 
CALLISTER R.; CALLISTER, R.J.; STARON, R.S.; FLECK, S.J.; TESCH, P.; DUDLEY, G.A. Physiological characteristics of elite Judo athletes. International Journal of Sports Medicine, Stuttgart, v.12, p. 196-203, 1991.

CARTER, J.E.L. Somtotypes of olympics athletes. Basel: Karger, 1984. p.80-109. (Medicine and Sport Science, v. 2: Kinanthropometry of olympics athletes)

CARTER, J.E.L.; HEATH, B.H. Somatotyping: development and applications. Cambridge: Cambridge University Press, 1990.

CASTROPIL, W. Judô competitivo: estudos científicos. Ippon - Jornal de Judô, São Paulo, ano 1, n.2, p.15, 1996. Suplemento 1.

CAVAZANI, R.N. Lactato antes e após sucessivos combates de judô. 1991. Monografia (Bacharelado em Educação Física) - Depto. de Educação Física, Instituto de Biociências, Universidade Estadual Paulista, Rio Claro.

CENTRO de excelência esportiva. In: MINISTÉRIO DO ESPORTE. Disponível em: < http://portal.esporte.gov.br/snear/cenesp >. Acesso em: 15 Dez., 2005.

ClAESSENS, A.; BEUNEN, G.; LEFEVRE, J.; MERTENS, G.; WELLENS, R. Body structure, somatotype, and motor fitness of top-class belgian judoists and karateka: a comparative study. In: REILLY, T.; WATKINS, J.; BORMS, J. (Eds.). Kinanthropometry III: Proceedings of the Commonweath and International Conference on Sport, Physical Education, Dance, Recreation and Health. London: E. F. R. Spon, 1986. p.53-7. 
CLAESSENS, A.; BEUNEN, G.; SIMONS, J.M.; WELLENS, R.; GELFOLD, D.; NUYTS, M.M. Body structure, somatotype, and motor fitness of top-class belgian judoists. In: DAY, J.A.P. (Ed.). The 1984 Olympic Scientific Congress Proceedings: perspectives in kinanthropometry. Champaign: Human Kinetics, 1984. p. 155-63.

CLAESSENS, A.; BEUNEN, G.; WELLENS, R.; GELDOF, G. Somatotype and body structure of world top judoists. The Journal of Sports Medicine and Physical Fitness, Torino, v.27, p.105-13, 1987.

CÔTÉ, J. The influence of the family in the development of talent in sport. The Sport Psychologist, Champaign, v.13, p.395-417, 1999.

CSIKSZENTMIHALYI, K; RATHUNDE, K; WHALEN, S. Talented teenagers: the roots of success and failure. Cambridge: Cambridge University Press, 1997.

DAVIDS, K.; LEES, A.; BURWITZ, L. Understanding and measuring coordination and control in kicking skills in soccer: implications for talent identification and skill acquisition. Journal of Sports Sciences, London, v.18, p. 703-714, 2000.

DE ROSE JUNIOR, D. Importância da preparação psicológica no esporte competitivo. In: SIMPÓSIO PAULISTA DE EDUCAÇÃO FÍSICA, 1993, Rio Claro. Anais... Rio Claro: UNESP, 1993. p.63.

A competição na infância e adolescência. Revista Metropolitana de Ciências do Movimento Humano, São Paulo, v.2, n.2, p.6-13, 1995.

DELIBERADOR, A.P. Judô: metodologia da participação. Londrina: Lido, 1996.

DESCOBERTA do talento esportivo. In: MINISTÉRIO DO ESPORTE. Disponível em: < http://portal.esporte.gov.br/snear/talento_esportivo >. Acesso em: 15 Dez., 2005. 
ERICSSON, K. A.; CHARNESS, N. Expert performance: its structure and acquisition. In: CECI, S.J.; WILLIANS, W.M. (Eds.) The nature-nurture debate: the essential readings. Oxford: Blackwell, 1994.

ERICSSON, K. A.; KRAMPE, R. T.; TESCH-RÖMER, C. The role of deliberate practice in the acquisition of expert performance. Psychological Review, Massachusetts, n.3, 363-406, 1993.

FERNADES FILHO, J.; ABRAMOVA, T.F. A utilização de índices dermatoglíficos na seleção de talentos. Revista Treinamento Desportivo, Curitiba, v.2, n.1, p.41-6, 1997.

FERREIRA, A. B. H. Mini dicionário da língua portuguesa. Rio de Janeiro: Nova Fronteira, 1996.

FERREIRA, M.C.M.; MARKUNAS, M.;NASCIMENTO, P. R. A prática na formação de atletas no basquetebol feminino. In: DE ROSE JÚNIOR, D.; TRICOLI, V. (Orgs.). Basquetebol: uma visão integrada entre ciência e prática. São Paulo: Manole, 2004.

FILIN, V.P. Desporto juvenil, teoria e metodologia. Londrina: CID, 1996.

FILIN, V.P.; VOLKOV, V.M. Seleção de telentos nos desportos. Londrina: Midiograf, 1998.

FRANCHINI, E. O ensino aprendizagem do judô. Corpoconsciência, Santo André, n.1, p.31-40, 1998. Suplemento 1.

. Bases para detecção e promoção de talentos na modalidade de judô. In: PRIMEIRO prêmio INDESP de literatura esportiva. Brasília: Instituto Nacional de Desenvolvimento do Desporto, 1999. v.1, p.15-104.

. Judô: desempenho competitivo. São Paulo: Manole, 2001. 
FRANCHINI, E.; TAKITO, M.Y. Avaliação da composição corporal. Ippon - Revista de Judô, São Paulo, ano 2, n.10, p.9, 1997. Suplemento 1.

FRANCHINI, E.; TAKITO, M.Y.; DUTRA NETO, R.; KISS, M.A.P.D.M. Composição corporal e força isométrica da seleção brasileira universitária de judô. In: SIMPÓSIO PAULISTA DE EDUCAÇÃO FÍSICA, 6., 1997, Rio Claro. Anais... Rio Claro: UNESP, 1997, p. 63.

FRANCHINI, E.; TAKITO, M.Y.; LIMA, J.R.P.; HADDAD, S.; KISS, M.A.P.D.M.; REGAZZINI, M.; BÖHME, M.T.S. Características fisiológicas em testes laboratoriais e resposta da concentração de lactato sangüíneo em 3 lutas em judocas das classes Juvenil A, Júnior e Sênior. Revista Paulista de Educação Física, São Paulo, v.12, n.1, p. 5-16, 1998.

FREITAS, F.M.C. Judô: crítica radical. Motrivivência, Florianópolis, v.1, n.2, p.35-43, 1989.

GABLER, H.; RUOFF, B. Zum Problem der Talentbestimmung im Sport. Rahmentheoretische Vorüberlegungen. Sportwissenschaft, Schorndorf, v.9, n.2, p.164-80, 1979.

GALLAHUE, D.L.; OZMUN, J.C. Understanding motor development: infants, children, adolescents, adults. Madison: WCB Brown \& Benchmark, 1998.

GARDNER, H Mentes que criam: uma anatomia da criatividade observada através das vidas de Freud, Einstein, Picasso, Stravinsky, Eliot, Graham e Gandhi. Porto Alegre: Artes Médicas, 1996.

Arte, mente e cérebro: uma abordagem cognitiva da criatividade. Porto alegre: Artmed, 1999. 
. Estruturas da mente: a teoria das inteligências múltiplas. Porto alegre: Artes Médicas, 2002.

GIBBONS, T.; HILL, R.; MCCONNELL, A.; FORSTER, T.; MOORE, J. The path to excellence: a comprehensive view of development of U. S. Olympians who competed from 1984 - 1998. (Initial Report: results of the talent identification and development questionnaire to $U$. S. Olympians athlete development and coaching and sport sciences divisions, 2002). Disponível em: < http://www.usolympicteam.com/codp >. Acesso em: 15 Dez., 2005.

GRECO, P.J. Fase central do sistema de formação e treinamento desportivo. In: GRECO, P.J.; SAMULSKI, D.; CARAN, E. Temas atuais em educação física e esportes I. Belo Horizonte: Health, 1997. p.13-32.

GRECO, P.J.; BENDA, R.N. Iniciação esportiva universal I: da aprendizagem motora ao treinamento técnico. Belo Horizonte: Escola de Educação Física da UFMG, 1998.

GUALDI-RUSSO, E.; GRAZIANI, I. Anthropometric somatotype of Italian sport participants. The Journal of Sports Medicine and Physical Fitness, Torino, v.33, n.3, p. 282-91, 1993.

GUEDES, D.P.; GUEDES, J.E.R.P. Crescimento, composição corporal e desempenho motor de crianças e adolescentes. São Paulo: CLR Balieiro, 1997.

GUENTHER, Z. C. Desenvolver capacidades e talentos: um conceito de inclusão. Rio de Janeiro: Vozes, 2000.

HEBBELINCK, M. Identificação e desenvolvimento de talentos no esporte: relatos cineantropométricos. Revista Brasileira de Ciência e Movimento, São Caetano do Sul, v.4, n.1, p.46-62, 1989. 
HELSEN, W. F.; STARKES, J. L.; HODGES, N. J. Team sports and the theory of deliberate practice. Journal of Sport \& Exercise Psychology, Champaign, v.20, p.1234, 1998.

HOHMANN, A.; SEIDEL, I. Scientific aspects of talent development. International Journal of Physical Education, Schorndorf, v.40, p.9-20, 2003.

HOLT, N.L.; MORLEY, D. Gender differences in psychosocial factors associated with athletic success during childhood. The Sport Psychologist, Champaign, v.18, p.138153, 2004.

HORSWILL, C.A.; HICKNER, R.C.; GALEA, P. Comparison of maximum aerobic power, maximum anaerobic power, and skinfold thickness of elite and nonelite junior wrestlers. International Journal of Sports Medicine, Stuttgart, v.10, n.3, p. 165-8, 1989.

HORSWILL, C.A.; MILLER, J.E.; SCOTT, J.R.; SMITH, C.M.; WELK, G.; VAN HANDEL, P. Anaerobic and aerobic power in arms and legs of elite senior wrestlers. International Journal of Sports Medicine, Stuttgart, v.13, n.8, p. 558-61, 1992.

HOWE, M.J.A. Innate talents: reality or myth?. In: CECI, S.J.; WILLIAMS, W.M. (Eds.). The nature - nurture debate: the essential readings. Oxford: Blackwell, 1999.

IIDA, E.; WAKAYAMA, H.; NAKAJIMA, T.; MATSUMOTO, D. Rating scales of fundamental physical fitness for college judoists: composition and application. In: NATIONAL JUDO CONFERENCE - INTERNATIONAL RESEARCH SYMPOSIUM. 1998. Annals... Colorado Springs: United States Olympic Training Center, 1998, p.12. 
INBAR, O.; BAR-OR, O. Anaerobic characteristics in male children and adolescents. Medicine and Science in Sport and Exercise, Indianapolis, v.18, n.3, p. 264-9, 1986.

LANARO FILHO, P. Referenciais para detecção, seleção e promoção de talentos esportivos em GRD. 2001. 121f. Dissertação (Mestrado) - Escola de Educação Física e Esporte, Universidade de São Paulo, São Paulo.

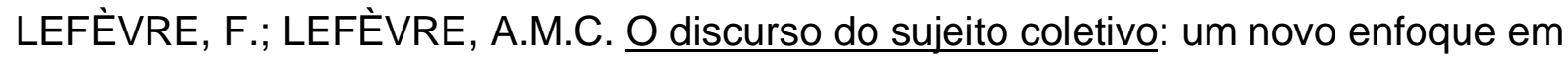
pesquisa qualitativa (Desdobramentos). Caxias do Sul: EDUCS, 2003.

LIDOR, R.; LAVYAN, N. A retrospective picture of early sport experiences among elite and near-elite israeli athletes: developmental and psychological perspectives. International Journal of Sport Psychology, Roma, v.33, p.269-289, 2002.

LIMA, J.G. A descoberta do talento . Revista Veja, São Paulo, edição 1860, ano 37 , n.26, p.90-7, 30 junho 2004.

LITTLE, N.G. Physical performance attributes of Junior and Senior women, Juvenile, Junior and Senior men judokas. The Journal of Sports Medicine and Physical Fitness, Torino, v.13, p. 510-20, 1991.

MACARDLE, W.D.; KATCH, F.I.; KATCH, V.L. Fisiologia do exercício: energia, nutrição e desempenho humano. Rio de Janeiro: Guanabara Koogan, 1991.

MAGILL, R.A. Motor learning, concepts and applications. Dubuque: Wm. C. Brown, 1980.

MAIA, J.A.R. O prognóstico de desempenho do talento esportivo: uma análise crítica. Revista Paulista de Educação Física, São Paulo, v.10, n.2, p.179-93, 1996.

MALINA, R.M. Talent identification and selection in sport. Spotlight on Youth Sports, Spring, v.20, n.1, p.1-3, 1997. 
MALINA, R.M.; BOUCHARD, C. Growth, maturation and physical activity. Champaign: Human Kinetics, 1991.

MARKUNAS, M. Aspectos psicológicos no desenvolvimento de talentos esportivos. 2005. Dissertação (Mestrado) - Escola de Educação Física e Esporte, Universidade de São Paulo, São Paulo.

MARQUES, A. Da importância das fases iniciais de escolaridade na detecção e selecção de talentos desportivos em Portugal. In: BENTO, J.; MARQUES, A. As ciências do desporto e a prática desportiva: desporto de rendimento, desporto de recreação e tempos livres. Porto: Faculdade de Ciências do Desporto e da Educação Física, Universidade do Porto, 1991. v. 2, p.15-21.

Bases para estruturação de um modelo de detecção e selecção de talentos desportivos em Portugal. Espaço, Porto, v.1, n.1, p.47-58, 1993.

MARQUES, A.C.P.; ROSADO, A.F.B. Situações estressantes nos atletas de basquetebol de alta competição. Revista Brasileira de Educação Física e Esporte, São Paulo, v.19, n.1, p.71-87, 2005.

MASSA. M. Seleção e promoção de talentos esportivos em voleibol masculino: análise de aspectos cineantropométricos. 1999. 154f. Dissertação (Mestrado) Escola de Educação Física e Esporte, Universidade de São Paulo, São Paulo.

MASSA, M.; BÖHME, M.T.S.; UEZU, R.; SILVA, L.R.R.; TANAKA, N.I. A utilização de análises univariadas e multivariadas na classificação de atletas de voleibol masculino envolvidos em processos de promoção de talentos. In: FÓRUM BRASIL ESPORTE, 2000, Londrina. Anais... Londrina: Universidade Estadual de Londrina, 2000, p.101. 
MASSA, M.; TANAKA, N.I.; BERTI, A.F.; BÖHME, M.T.S; MASSA, I.C.M. Análises univariadas e multivariadas na classificação de atletas de voleibol masculino. Revista Paulista de Educação Física, São Paulo, v.13, n.2, p.131-145, 1999.

MATSUDO, S.M.; MATSUDO, V.K.R. O componente aeróbio na seleção de talentos esportivos. In: SIMPÓSIO INTERNACIONAL DE CIÊNCIAS DO ESPORTE: Exercício e qualidade de vida, 18., 1992, São Caetano do Sul. Anais... São Caetano do Sul: UNIFEC do ABC, 1992, p.56.

MATSUDO, V.K.R. Prediction of future athletic excellence. In: BAR-OR, O. The child and adolescent athlete. Oxford: Blackwell Science, 1996. p.92-109. (The Encyclopaedia of Sports Science)

. Detecção de talentos. In: GHORAYEB, N.; BARROS, T. O exercício: preparação fisiológica, avaliação médica, aspectos especiais e preventivos. São Paulo: Atheneu, 1999. p.337-49.

MATSUDO, V. K. R.; MATSUDO S. M. Ciência e detecção de talentos. Âmbito Medicina Esportiva, São Paulo, n.30, abril, 1997.

MATSUDO, V.K.R.; RIVET, R.E.; PEREIRA, M.H.N. Standard score assessment of physique and performance of Brazilian athletes in a sixtiered competitive sports model. Journal of Sports Sciences, London, v.5, p.49-53, 1987.

MATVEEV, L.P. Treino desportivo: metodologia e planejamento. São Paulo: FMU, 1997.

MONTEIRO, L.B. O treinador de judô no Brasil. Rio de Janeiro: Sprint, 1998.

MORAES, L.C.; DURAND-BUSH, N.; SALMELA, J.H. Modelos de desenvolvimento de talentos. In: SAMULSKI, D.M., (Ed.). Novos conceitos em treinamento esportivo. Belo Horizonte: Publicações INDESP, 1999. p.173-190. 
NAKAO, M.; INOUE, Y.; MURAKAMI, H. Longitudinal study of the effect of high intensity weight training on aerobic capacity. European Journal of Applied Physiology, Berlin, v.70, p. 20-5, 1995.

PAES, R.R. Aprendizagem e competição precoce: o caso do basquetebol. Campinas: Editora da UNICAMP, 1992.

PAULA, J.C. Elaboração de uma bateria de testes para predizer a performance de judocas. Kinesis, Santa Maria, v.3, n.1, p. 55-74, jan-jul/ 1987.

PRETO, J.G.P.F. Contribuições para a avaliação do nível técnico de execução em voleibol: problemas conceptuais e metrológicos. Motricidade Humana, Lisboa, v.6, n.1/2, p.69-80, 1990.

RÉGNIER, G.; SALMELA, J.; RUSSEL, S.J. Talent detection and development in sport. In: SINGER, R.N.; MURPHEY, M.; TENNAUE, K.L. (Eds.). Handbook of research in sport psychology. New York: MacMillan, 1993. p.290-313.

ROBERTS, G.C.; TREZURE, D.C. Children in sport. Sport Science Review, Champaign, v.1, n.2, p.46-64, 1992.

ROCHA, M.A.; DOURADO, A.C.; GONÇALVES, H.R. Estudo do somatotipo da seleção brasileira de voleibol categorias - infanto-juvenil e juvenil - 1995. Revista da Associação dos Professores de Educação Física de Londrina, Londrina, v.11, n.19, p.21-30, 1996.

RODRIGUES, R.L.; BARBANTI, V.J. Atividade esportiva e a criança: principais lesões do aparelho locomotor. In: CONCEIÇÃO, J.A.N. Saúde escolar: a criança, a vida e a escola. São Paulo: Sarvier, 1994. p.171-80. 
RONTOYANNIS, G.P. Lactate elimination from the blood during active recovery. The Journal of Sports Medicine and Physical Fitness, Torino, v.28, n.2, p. 115-23, 1998.

ROWLAND, T.W. Developmental exercise physiology. Champaign: Human Kinetics, 1996.

RUBIO, K. Heróis Olímpicos Brasileiros. São Paulo: Zouk, 2004.

SALMELA, J.H.; MORAES, L.C. Development of expertise: the role of coaching, families and cultural contexts. In: STARKES, J.L.; ERICSSON, A.K. (Eds.). Expert performance in sports. Champaign: Human Kinetics, 2003. p.275-293.

SCHMIDT, R. A. Aprendizagem e performance motora: dos princípios à prática. São Paulo: Movimento, 1993.

SCHÜLLERDUDEN SPORT. Der Sport. Mannheim: Meyers Lexikonverlag, 1987.

SENF, G. Eignungsdiagnostik-und Normprogramme für die prozeßbegleitende Auswahl im Verlauf des Grundlagen-trainings. Grundlagen sportartspezifischer Aunswahl, T.U.P. der K.K., v.39, n.1, p.21-6, 1990.

SHARP, N.C.C.; KOUTEDAKIS, Y. Anaerobic power and capacity measurements of the upper body in elite judo players, gymnasts and rowers. Australian Journal of Science and Medicine in Sport, Sydney, v.19, n.3, p.9-13, 1987.

SILVA, L. R. R.; MARI, E. T. L.;. UEZU, R.; BÖHME, M. T. S.; MASSA, M. A utilização da análise de cluster e discriminante no processo de seleção do talento esportivo. In: FÓRUM BRASIL ESPORTE, 2000, Londrina. Anais... Londrina: Universidade Estadual de Londrina, 2000. p.100.

SILVA, M.L.; RÚBIO, K. Superação no esporte: limites individuais ou sociais? Revista Portuguesa de Ciências do Desporto, Porto, v.3, n.3, p.69-76, 2003 
SILVA, S.; AMORIM, P.R.; SOARES, M.A.; MONTEIRO, W. Perfil morfológico de atletas brasileiros participantes dos Jogos Pan-Americanos de Winnipeg. In: SIMPÓSIO INTERNACIONAL DE CIÊNCIAS DO ESPORTE: Atividade Física: da comunidade ao alto rendimento, 1999, São Paulo. Anais... São Paulo: CELAFISCS, 1999. p.130.

SOBRAL, F. População, seleção e performance: uma estratégia de investigação em ciências do desporto. Espaço, Porto, v.1, n.1, 23-30, 1993.

STARKES, J.L. The road to expertise: is practice the only determinant? International Journal of Sport Psychology, Roma, v. 7 p. 23-27, 2000.

TANAKA, N.I.; BERTI, A.F. Relatório de análise estatística sobre o projeto: análise de um critério de seleção utilizada no processo de detecção de talentos para o voleibol. São Paulo: IME-USP, 1998.

TANI, G.; MANOEL, E.J.; KOKUBUN, E.; PROENÇA, J.E. Educação física escolar: fundamentos de uma abordagem desenvolvimentista. São Paulo: EPU/EDUSP, 1988.

TAYLOR, A.W.; BRASSARD, L. A physiological profile of the Canadian Judo Team. The Journal of Sports Medicine and Physical Fitness, Torino, v.21, p.160-4, 1981.

TERBIZAN, D.J.; SELJEVOLD, P.J. Physiological profile of age-group wrestlers. The Journal of Sports Medicine and Physical Fitness, Torino, v.36, n.3, p. 178-85, 1996.

THOMAS, S.G.; COX, M.H.; LEGAL, Y.M.; VERDE, T.J.; SMITH, H.K. Physiological profiles of Canadian National Judo Team. Canadian Journal of Sport Sciences, Toronto, v.14, n.3, p.142-7, 1989. 
VIEIRA, L.F.; VIEIRA, J.L.L. A relação entre timing vital e social de talentos esportivos: um estudo com atletas paranaenses do atletismo. Revista da Educação Física/ UEM, Maringá, v.11, n.1, p.119-128, 2000.

Talentos esportivos: estudo dos atributos pessoais dos atletas paranaenses do atletismo. Revista de Educação Física/ UEM, Maringá, v.12, n.1, p.7-17, 2001.

VIEIRA, L.F.; VIEIRA, J.L.L.; KREBS, R.J. A trajetória de desenvolvimento de um talento esportivo: estudo de caso. Revista Kinesis, Santa Maria, n.21, p.47-55, 1999.

WEINECK, J. Biologia do esporte. São Paulo: Manole, 1991. . Treinamento ideal. São Paulo: Manole, 1999.

ZAKHAROV, A.; GOMES, A.C. Ciência do treinamento desportivo. Rio de Janeiro: Palestra, 1992. 
ANEXO I - Roteiro de Entrevista

1) OBJ ETIVO: obter o tempo de prática

Pergunta: Há quanto tempo você pratica judô?

2) OBJ ETIVO: obter discurso acerca do processo de iniciação no judô

Pergunta: Você pode me contar como foi seu começo no judô?

Obs.: Em caso de resposta monossilábica será realizado o pedido - Explique melhor

- se necessário a mesma fórmula será repetida nas outras perguntas).

3) OBJ ETIVO: obter discurso acerca do talento precoce

Pergunta: No começo da sua formação você acha que se destacava dos demais praticantes de judô?

4) OBJ ETIVO: obter discurso acerca de fatores motivacionais durante o TLP Pergunta: Você pode me contar o que te fez manter o tempo todo o teu interesse no judô?

5) OBJ ETIVO: obter discurso acerca das relações sociais durante o processo de TLP

Pergunta: Me conte como era a participação dos seus pais, familiares e amigos em relação ao judô.

6) OBJ ETIVO: obter discurso acerca da realização de outras atividades durante o processo de TLP

Pergunta: Me conte como era o seu dia a dia e diga o que você fazia no tempo livre restante em que não estava no judô.

7) OBJ ETIVO: obter discurso acerca de aspectos financeiros durante o TLP

Pergunta: Me conte como foi o teu sustento financeiro desde o seu início no judô até os dias atuais. 
ANEXO I - Roteiro de Entrevista (continuação)

8) OBJ ETIVO: obter discurso acerca da relação genética $X$ meio ambiente e o talento na modalidade

Pergunta: A que você atribui o teu talento para o judô?

9) OBJETIVO: obter discurso acerca da competência profissional nas diferentes fases do treinamento a longo prazo (TLP)

Pergunta: Fale um pouco sobre os teus professores e/ou técnicos e o papel deles na sua formação.

10) OBJETIVO: obter discurso acerca da forma de prescrição, avaliação e controle do TLP

Pergunta: O teu treinamento era planejado ou não? Fale sobre ele.

11) OBJETIVO: obter discurso acerca do papel da competição durante o processo de TLP

Pergunta: Como foram as competições no seu treinamento? Você se destacava logo no começo ou o destaque veio com o tempo?

12) OBJ ETIVO: obter discurso sobre o stress competitivo.

Pergunta: Toda competição é meio estressante não é? Como era isso para você? 
ANEXO II - Quadros (de 1 até 12) do Instrumento de Análise do Discurso (IAD)

QUADRO 1: IAD - Instrumento de Análise de Discurso, referente ao conteúdo de todas as respostas da pergunta - Há quanto tempo você pratica judô?

\begin{tabular}{|c|c|c|}
\hline & EXPRESSÕES-CHAVE & IDÉIAS CENTRAIS \\
\hline S1 & $\begin{array}{l}\text { Eu pratico Judô há } 18 \text { anos }(A) \text {. Comecei a fazer Judô com } \\
5 \text { anos de idade (B) pelo incentivo do meu irmão mais } \\
\text { velho que também é judoca até hoje. Isso foi na cidade } \\
\text { dos meus pais. Então faz } 18 \text { anos que estou nessa } \\
\text { caminhada. }\end{array}$ & $\begin{array}{l}-18 \text { anos } \\
-5 \text { anos }\end{array}$ \\
\hline S2 & $\begin{array}{l}\text { Até hoje eu tenho } 18 \text { anos de Judô }(A) \text {, eu comecei em } \\
\text { 1987. Na época } 7 \text { para } 8 \text { anos (B). }\end{array}$ & $\begin{array}{l}-18 \text { anos } \\
-7 \text { anos }\end{array}$ \\
\hline S3 & $\begin{array}{l}\text { São } 27 \text { anos de prática de Judô. Comecei com } 5 \text { anos de } \\
\text { idade. }\end{array}$ & $\begin{array}{l}-27 \text { anos } \quad \text { A } \\
-5 \text { anos B }\end{array}$ \\
\hline S4 & $\begin{array}{l}\text { Eu tenho } 22 \text { anos de prática de Judô }(A) \text {. Comecei com } 8 \\
\text { anos (B) e estou atualmente com } 30 \text { anos. No fim do ano } \\
\text { eu faço } 31 \text { anos e acabam se completando } 22 \text { anos de } \\
\text { Judô. }\end{array}$ & $\begin{array}{l}-22 \text { anos } \\
-8 \text { anos }\end{array}$ \\
\hline S5 & 20 anos (A). Comecei com 7 anos de idade (B). & $\begin{array}{l}-20 \text { anos } \quad \text { A } \\
-7 \text { anos } \quad \text { B }\end{array}$ \\
\hline S6 & $\begin{array}{l}\text { Eu estou com } 27 \text { anos de tatame (A). Comecei com } 5 \\
\text { anos de idade (B). }\end{array}$ & $\begin{array}{l}-27 \text { anos A } \\
-5 \text { anos }\end{array}$ \\
\hline
\end{tabular}


ANEXO II - Quadros (de 1 até 12) do Instrumento de Análise do Discurso (IAD) (continuação)

QUADRO 2: IAD - Instrumento de Análise de Discurso, referente ao conteúdo de todas as respostas da pergunta - Você pode me contar como foi seu começo no judô?

\begin{tabular}{|c|c|c|}
\hline & EXPRESSÕES-CHAVE & IDÉIAS CENTRAIS \\
\hline S1 & $\begin{array}{l}\text { No começo foi a arte que me encantou muito. Minha } \\
\text { cidade tinha colônia japonesa e fui atraído pela disciplina, } \\
\text { pela educação, pela perseverança. Foi isso o que mais } \\
\text { me cativou primeiro (B). Depois, a competição, a vontade } \\
\text { de competir, a vontade de ser o número } 1 \text {. Então são } \\
\text { essas coisas que me motivam até hoje na minha carreira. }\end{array}$ & $\begin{array}{l}\text { - cultura da cidade } \\
\text { B }\end{array}$ \\
\hline S2 & 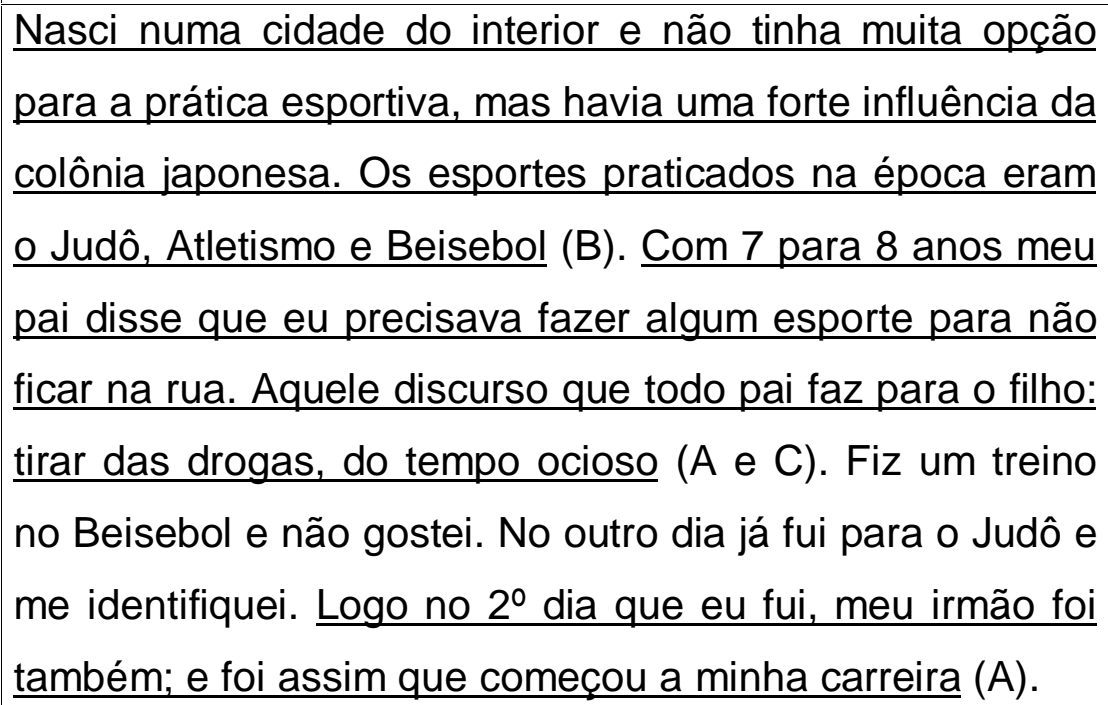 & $\begin{array}{l}\text { - cultura da cidade } \\
\text { B } \\
\text { - apoio do pai/ irmão } \\
\text { A } \\
\text { - comportamento C }\end{array}$ \\
\hline S3 & $\begin{array}{l}\text { Eu entrei porque eu era uma criança hiperativa. Tinha um } \\
\underline{\text { comportamento que minha mãe não conseguia me }} \\
\underline{\text { dominar muito em casa }(C) \text {. Tinha um tio que fazia Judô }} \\
\text { que sugeriu que entrasse no Judô }(A) \text { que ajudaria na } \\
\text { disciplina. Foi esse o motivo que eu entrei no Judô. }\end{array}$ & $\begin{array}{l}\text { - comportamento } \mathbf{C} \\
\text { - apoio da família A }\end{array}$ \\
\hline
\end{tabular}


ANEXO II - Quadros (de 1 até 12) do Instrumento de Análise do Discurso (IAD) (continuação)

\begin{tabular}{|c|c|c|}
\hline 54 & $\begin{array}{l}\text { Meu começo no Judô foi através da iniciativa dos meus } \\
\text { pais que queriam que eu não ficasse muito tempo na rua } \\
\text { (A e C). Então por isso que eles me colocaram no Judô, } \\
\text { porque na época meu pai fazia Judô, então por isso foi } \\
\text { escolhida essa modalidade (A). Não que eu gostasse de } \\
\text { Judô, eles me impuseram isso e deu certo e eu comecei a } \\
\text { gostar do esporte (A). }\end{array}$ & - apoio dos pais $\mathbf{A}$ \\
\hline S5 & $\begin{array}{l}\text { Primeiro eu já gostava de artes marciais. Eu não tinha } \\
\text { idéia do que era o Judô, não tinha idéia do que era nada, } \\
\text { mas eu gostava de artes marciais devido a família já } \\
\text { praticar artes marciais (A). Entrei em uma academia de } \\
\text { Tradição, academia japonesa mesmo, no meu bairro (B), } \\
\text { e lá eu comecei minha trajetória. Eu dei sorte, peguei um } \\
\text { professor que para iniciação, eu acho, eu considero ele } \\
\text { um dos melhores do Brasil, já revelou grandes talentos, } \\
\text { não só eu, vários outros. Então é assim, tudo que eu } \\
\text { tenho hoje é devido a essa ótima iniciação que eu tive, } \\
\text { uma boa base pra mim (D). }\end{array}$ & $\begin{array}{l}\text { - apoio da família A } \\
\text { - proximidade de } \\
\text { casa B } \\
\text { - bons professores } \\
\text { D }\end{array}$ \\
\hline S6 & $\begin{array}{l}\text { Comecei na cidade (...), interior de São Paulo, em } 1977, \\
\text { por recomendação médica. Como } 5 \text { anos de idade é uma } \\
\text { fase de fazer algum esporte, o pediatra da família } \\
\text { recomendou para minha mãe que eu fizesse Judô e } \\
\text { Natação (A). A natação até hoje eu não sei nadar muito }\end{array}$ & $\begin{array}{l}\text { - recomendação } \\
\text { médica/ apoio dos } \\
\text { pais A }\end{array}$ \\
\hline
\end{tabular}


ANEXO II - Quadros (de 1 até 12) do Instrumento de Análise do Discurso (IAD) (continuação)

QUADRO 3: IAD - Instrumento de Análise de Discurso, referente ao conteúdo de todas as respostas da pergunta - No começo da sua formação você acha que se destacava dos demais praticantes de judô?

\begin{tabular}{|c|c|c|}
\hline & EXPRESSÕES-CHAVE & IDÉ IAS CENTRAIS \\
\hline S1 & $\begin{array}{l}\text { Sim, foi desde o começo. Nas competições internas da } \\
\text { minha cidade já consegui me destacar e o meu professor } \\
\text { até comentou com o meu pai: olha, investe nesse garoto } \\
\text { que esse garoto tem potencial, é garoto diferenciado(A). } \\
\text { E desde então meu pai incentivou não só eu como meu } \\
\text { irmão mais velho também. }\end{array}$ & $\begin{array}{l}\text { - sim, me destacava } \\
\text { A }\end{array}$ \\
\hline S2 & $\begin{array}{l}\text { Eu vejo que a minha carreira deu um "upgrade" maior } \\
\text { depois que eu vim para São Paulo. No início eu era um } \\
\text { atleta comum, normal, só campeão regional, campeão } \\
\text { de algumas competições amistosas, mas não tinha um } \\
\text { grande destaque (B), foi esse o motivo que em } 1996 \text { eu } \\
\text { fiz um teste no Projeto (...) com a iniciativa da Secretaria } \\
\text { de Esportes e Lazer do Estado de São Paulo, e morei } 5 \\
\text { anos no Projeto (...), e lá que eu vi mesmo que eu } \\
\text { poderia chegar a ser um atleta de alto nível. }\end{array}$ & $\begin{array}{l}\text { - não me destacava } \\
\text { B }\end{array}$ \\
\hline S3 & $\begin{array}{l}\text { Não, eu era um atleta mediano, era um atleta normal, } \\
\text { não é nada assim expoente da turma, um atleta mediano } \\
\underline{\text { mesmo, não era campeão }} \text { (B). }\end{array}$ & $\begin{array}{l}\text { - não me destacava } \\
\text { B }\end{array}$ \\
\hline
\end{tabular}


ANEXO II - Quadros (de 1 até 12) do Instrumento de Análise do Discurso (IAD) (continuação)

\begin{tabular}{|c|c|c|}
\hline S4 & $\begin{array}{l}\text { Não, não, não. Eu sempre fui um atleta que não me } \\
\text { destacava (B). Na época eu era equivalente ao quarto } \\
\text { ou quinto, que seria a quarta ou quinta equipe. Eu fui } \\
\text { começar a poder ter um certo destaque na faixa da } \\
\text { adolescência, através de quando comecei a ter os meus } \\
\underline{16,17 \text { anos que realmente eu comecei a ter o meu lugar }} \\
\underline{\text { de destaque, antes disso nada, eu era o quarto ou quinto }} \\
\underline{\text { da equipe }(B) .}\end{array}$ & $\begin{array}{l}\text { - não me destacava } \\
\text { B }\end{array}$ \\
\hline S5 & $\begin{array}{l}\text { Não, no começo eu não me destacava muito. Era } \\
\text { normal, ganhava alguns campeonatos, perdia outros. } \\
\text { Não tinha nenhum diferencial (B), acho que meu maior } \\
\text { diferencial foi eu estar querendo sempre, desde o início, } \\
\text { competindo, estar participando de competição. Eu } \\
\text { lembro que no início eu queria todo final de semana } \\
\text { estar participando de competição, então acho que esse } \\
\text { foi o meu diferencial. Eu via os atletas da minha idade } \\
\text { que não gostavam muito de competir e eu não, eu já } \\
\text { gostava de competir, não importando se eu perdesse ou } \\
\text { ganhasse, o importante para mim era estar participando } \\
\text { da competição (C). }\end{array}$ & $\begin{array}{l}\text { - não me destacava } \\
\text { B } \\
\text { - gostava de competir } \\
\text { C }\end{array}$ \\
\hline S6 & $\begin{array}{l}\text { Não, no início eu tive muita dificuldade em termos de } \\
\text { coordenação para os golpes. Eu tinha um pouco de } \\
\text { medo, um pouco de receio de cair, esse tipo de coisa } \\
\text { (B). Então eu comecei a pegar o ritmo do negócio. Teve } \\
\text { uma época que eu fui para (...), é uma cidade próxima a } \\
\text { (...), e lá que eu comecei a me destacar perante aos }\end{array}$ & $\begin{array}{l}\text { - não me destacava } \\
\text { B }\end{array}$ \\
\hline
\end{tabular}


ANEXO II - Quadros (de 1 até 12) do Instrumento de Análise do Discurso (IAD) (continuação)

QUADRO 4: IAD - Instrumento de Análise de Discurso, referente ao conteúdo de todas as respostas da pergunta - Você pode me contar o que te fez manter o tempo todo o teu interesse no judô?

\begin{tabular}{|c|c|c|}
\hline & EXPRESSÕES-CHAVE & IDÉ IAS CENTRAIS \\
\hline S1 & $\begin{array}{l}\text { Acho que até hoje eu estou aqui porque eu amo esporte, } \\
\text { amo Judô, o que eu faço e muitas coisas que } \\
\text { aconteceram na minha carreira que me motivaram (A). } \\
\text { As conquistas, acho que você representar o país, você o } \\
\text { nome da sua família, então são sonhos que eu tinha } \\
\text { quando criança e que eu pude realizar através do Judô. } \\
\text { E eu tenho objetivos ainda a serem concretizados, então } \\
\text { isso que me estimula, em saber que eu cheguei lá, saber } \\
\text { que eu tenho a oportunidade de continuar essa história e } \\
\text { eu adoro Judô, eu adoro competir e faço de tudo mesmo } \\
\text { para estar em cima do tatame representando o meu país } \\
\text { (C). }\end{array}$ & $\begin{array}{l}\text { - amor/ desejo/ sonho/ } \\
\text { A } \\
\text { - determinação C }\end{array}$ \\
\hline S2 & $\begin{array}{l}\text { O sonho de um dia poder ouvir o Hino Nacional e poder } \\
\text { representar o Brasil, eu acho que no Judô isso é o que } \\
\text { mais conta (A). Como agente treina muito a única coisa } \\
\text { que agente leva é a honra mesmo de estar defendendo } \\
\text { o país, de estar defendendo a sua família. Então esse foi } \\
\text { o sonho, o combustível para que eu mesmo, com tantas } \\
\text { derrotas, nunca desistisse do meu sonho que ainda não } \\
\text { consegui, mas ainda me motiva, ainda é o meu } \\
\text { combustível pra que eu aprenda tudo um dia e tente dar } \\
\text { o meu melhor (C). }\end{array}$ & $\begin{array}{l}\text { - sonho A } \\
\text { - determinação C }\end{array}$ \\
\hline
\end{tabular}


ANEXO II - Quadros (de 1 até 12) do Instrumento de Análise do Discurso (IAD) (continuação)

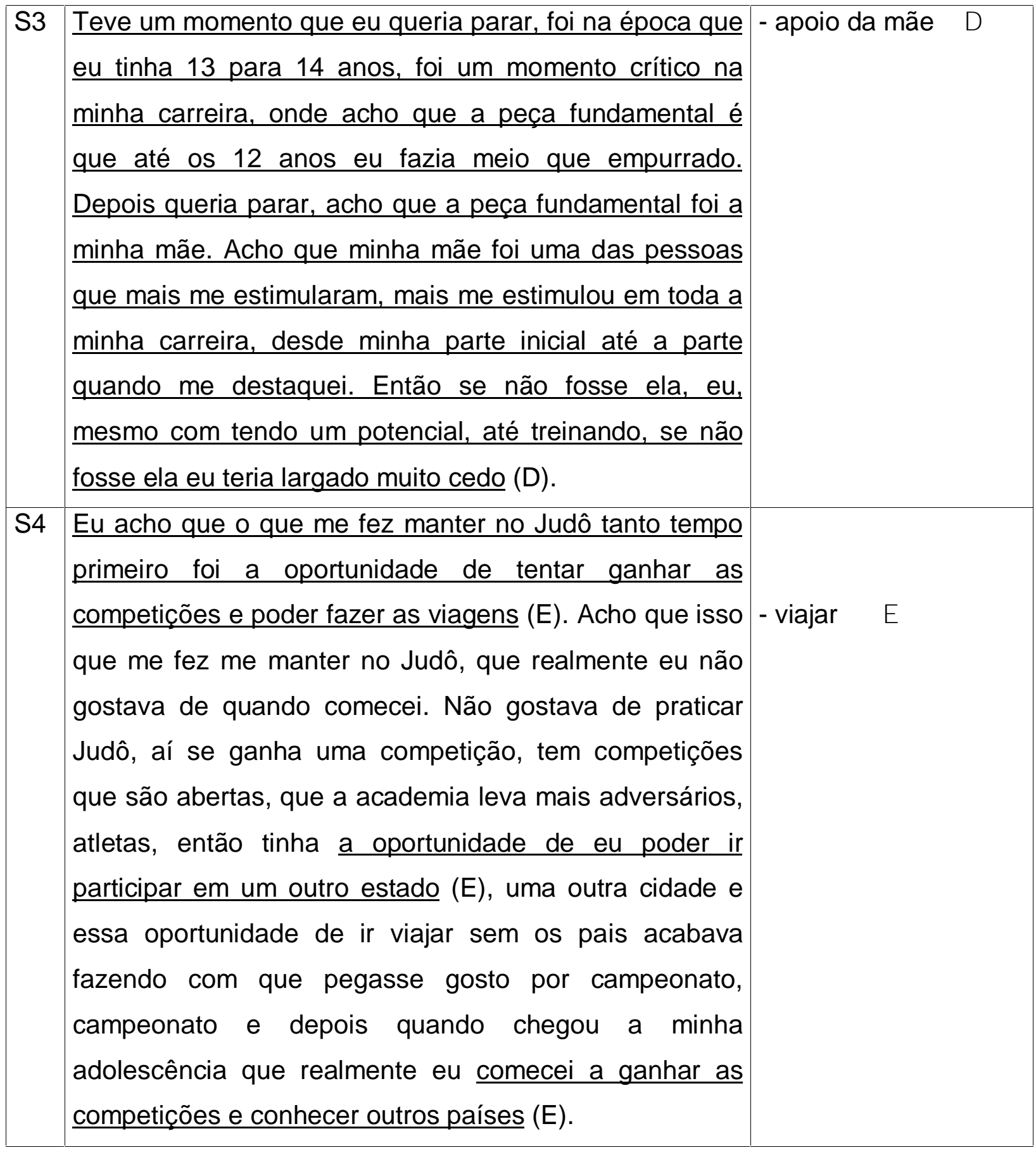


ANEXO II - Quadros (de 1 até 12) do Instrumento de Análise do Discurso (IAD) (continuação)

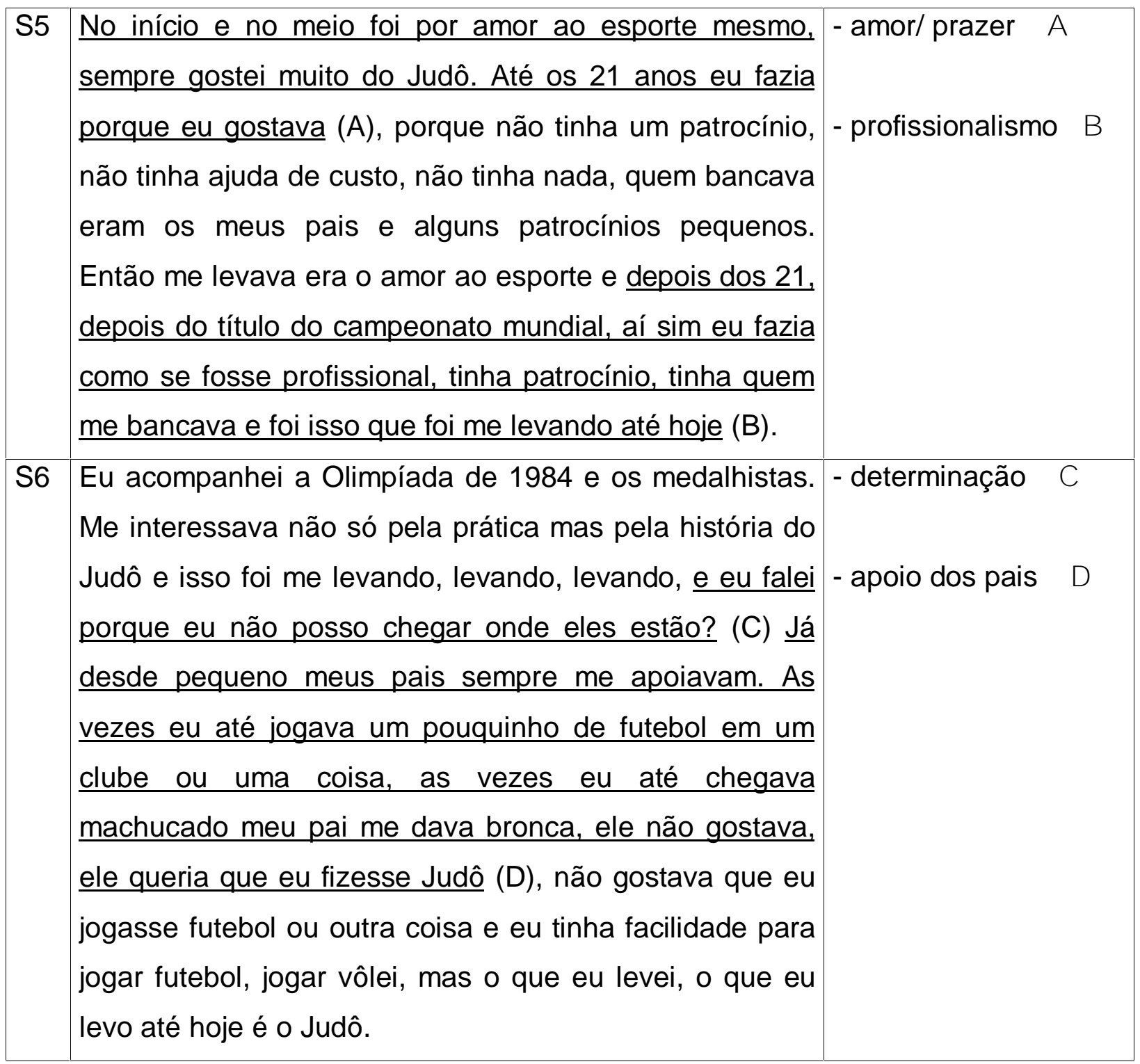


ANEXO II - Quadros (de 1 até 12) do Instrumento de Análise do Discurso (IAD) (continuação)

QUADRO 5: IAD - Instrumento de Análise de Discurso, referente ao conteúdo de todas as respostas da pergunta - Me conte como era a participação dos seus pais, familiares e amigos em relação ao judô.

\begin{tabular}{|c|c|c|}
\hline & EXPRESSÕES-CHAVE & IDÉIAS CENTRAIS \\
\hline S1 & 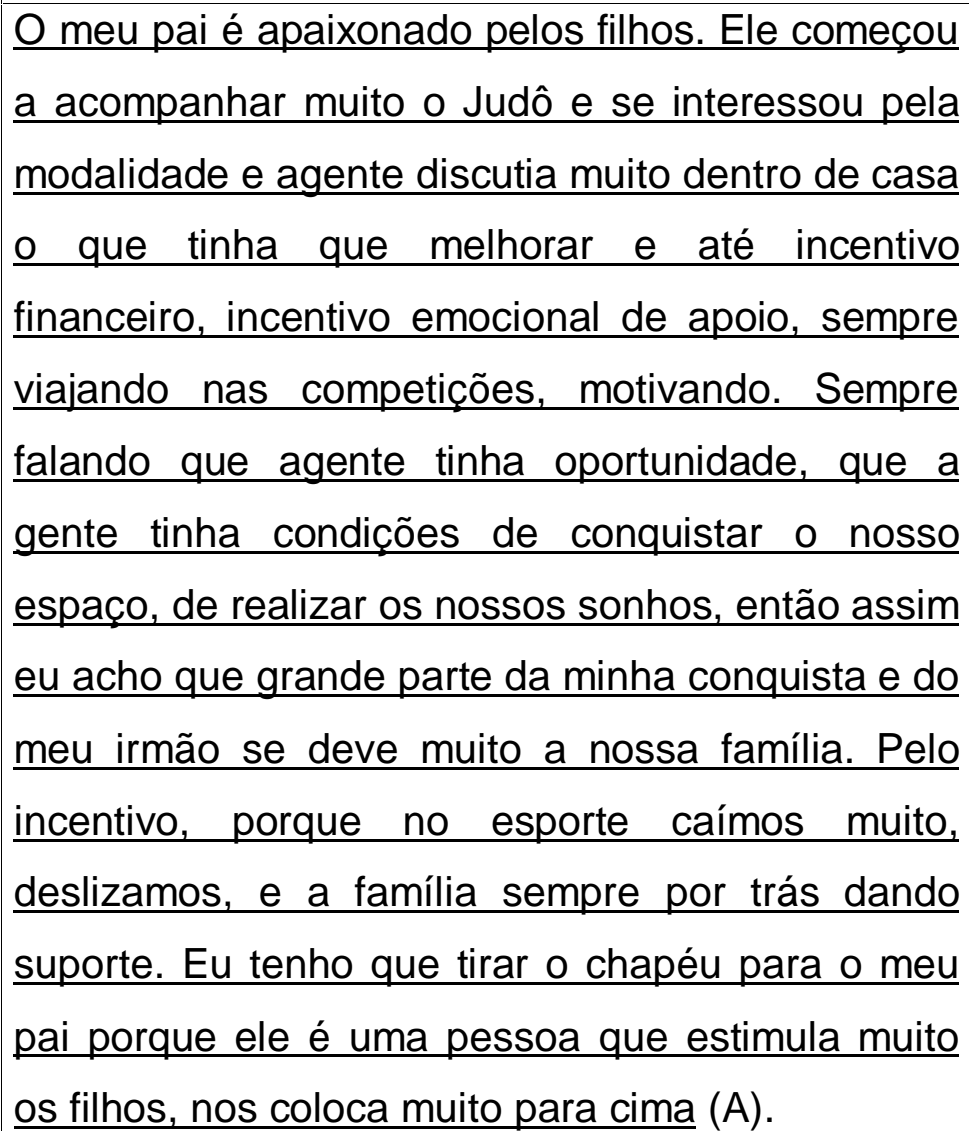 & - apoio dos pais $\mathbf{A}$ \\
\hline
\end{tabular}


ANEXO II - Quadros (de 1 até 12) do Instrumento de Análise do Discurso (IAD) (continuação)

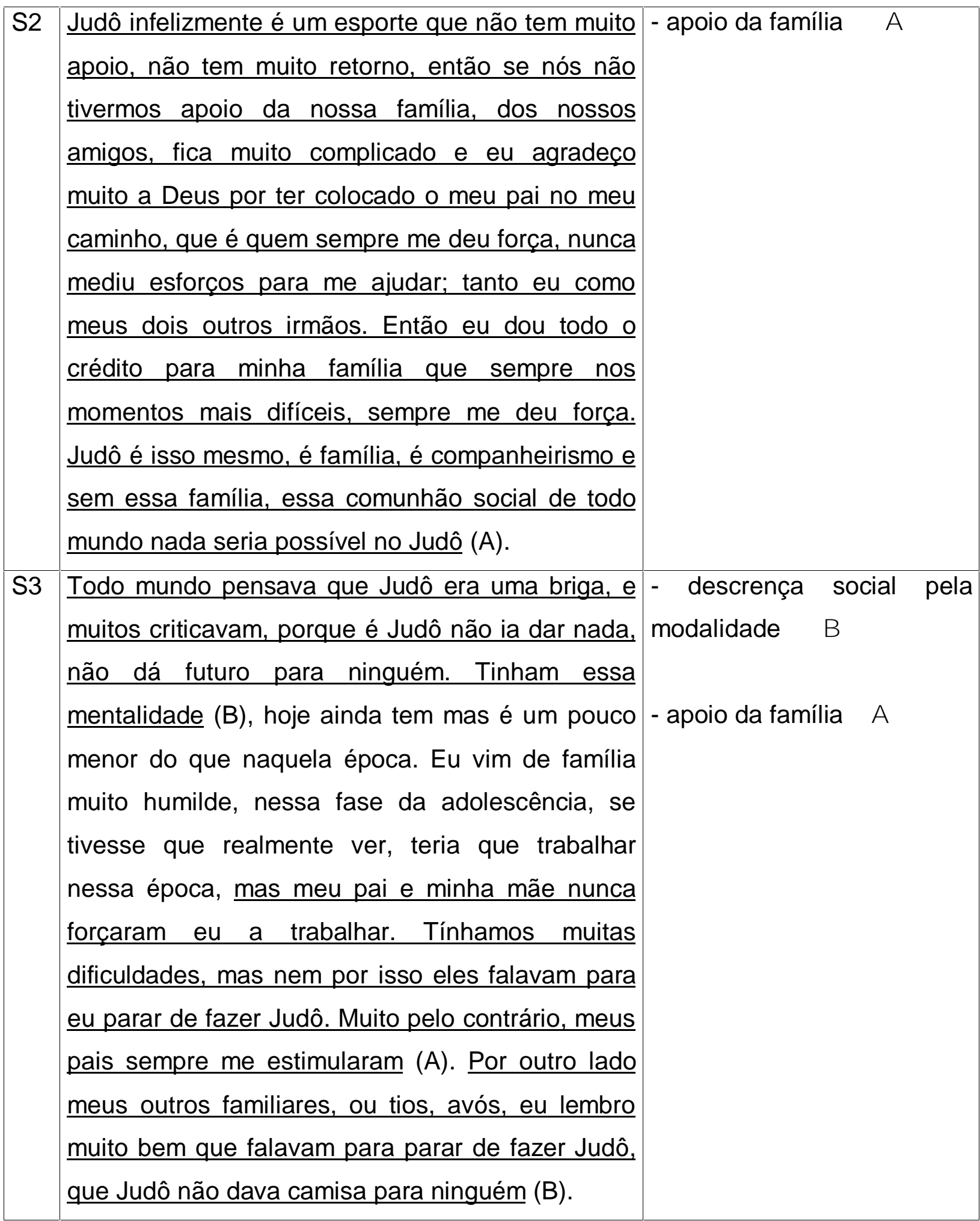


ANEXO II - Quadros (de 1 até 12) do Instrumento de Análise do Discurso (IAD) (continuação)

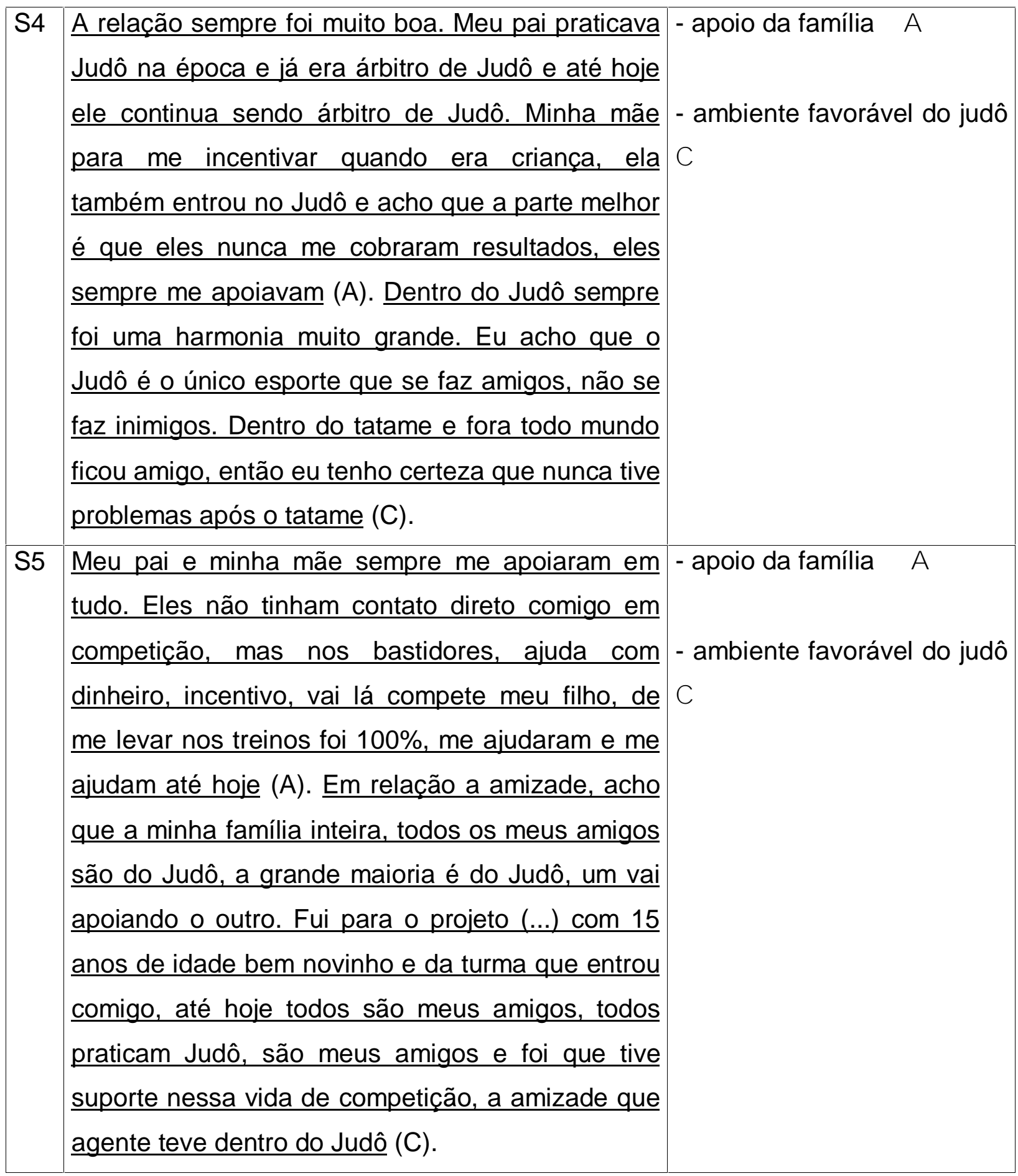


ANEXO II - Quadros (de 1 até 12) do Instrumento de Análise do Discurso (IAD) (continuação)

S6 $\left|\begin{array}{l|ll}\frac{\text { No início meus pais acompanhavam muito pois }}{\text { tudo era próximo da região, depois que eu passei }} \\ \frac{\text { para o Juvenil eles pararam de acompanhar de }}{\text { vido a distância }(A) \text {. No colégio o pessoal jáa }} \\ \frac{\text { respeitava a modalidade que eu fazia }(C) .}{2}\end{array}\right|$ - respeito dos amigos C

QUADRO 6: IAD - Instrumento de Análise de Discurso, referente ao conteúdo de todas as respostas da pergunta - Me conte como era o seu dia a dia e diga o que você fazia no tempo livre restante em que não estava no judô.

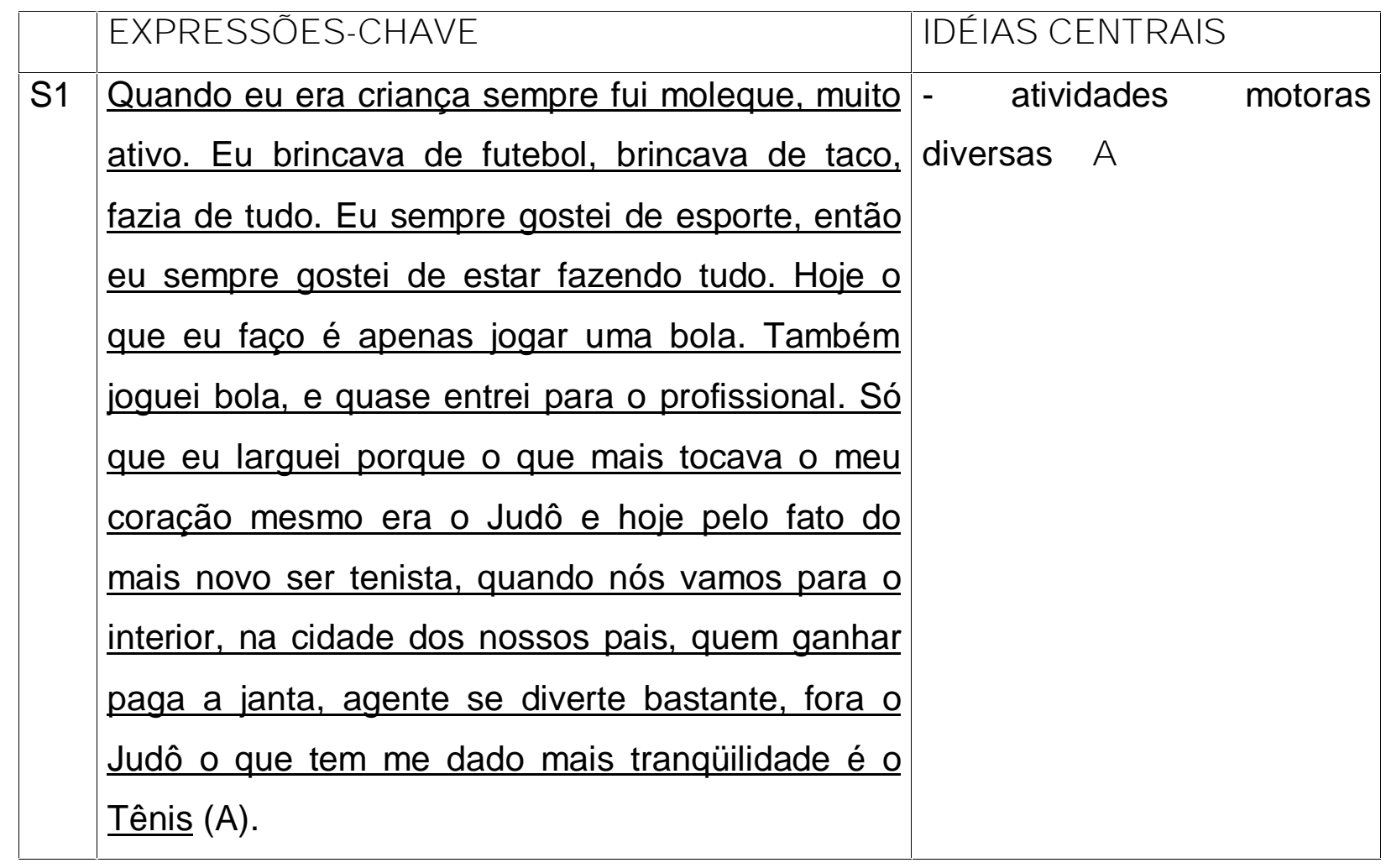


ANEXO II - Quadros (de 1 até 12) do Instrumento de Análise do Discurso (IAD) (continuação)

\begin{tabular}{|c|c|c|}
\hline S2 & $\begin{array}{l}\text { Até } 1996 \text { vivi muito na barra do meu pai e da } \\
\text { minha mãe. Meu pai, mesmo não sendo militar, } \\
\text { acho que adotou essa disciplina. Era muito } \\
\underline{\text { complicado ter tempo para fazer algum outro tipo }} \\
\underline{\text { de atividade, eu me dediquei muito mesmo ao }} \\
\underline{\text { Judô, treinando de segunda a sábado e muita }} \\
\underline{\text { competição no domingo. Então não me sobrava }} \\
\underline{\text { muito tempo. Era mais Judô mesmo e quando }} \\
\underline{\text { estava em casa assistia fita de Judô para tentar }} \\
\text { aprender e tudo mais. Em } 1997 \text { quando eu } \\
\underline{\text { ingressei no Projeto (...), eu vi que eu tinha que me }} \\
\underline{\text { dedicar ainda mais aos treinamentos. Até } 2002, \text { no }} \\
\underline{\text { Projeto, eu treinava } 2,3 \text { vezes ao dia (B). Em } 2003} \\
\underline{\text { fui para o Clube (...) e comecei a fazer faculdade }} \\
\text { (C) e aí que sobrou um pouco mais de tempo. Eu } \\
\text { conseguia dosar o meu treino melhor com } \\
\text { embasamento científico que eu tenho e com uma } \\
\text { pessoa que cuida da minha parte física e da parte } \\
\text { técnica. }\end{array}$ & - apenas judô B \\
\hline
\end{tabular}


ANEXO II - Quadros (de 1 até 12) do Instrumento de Análise do Discurso (IAD) (continuação)

\begin{tabular}{|c|c|c|}
\hline 33 & $\begin{array}{l}\text { Teve uma fase que não precisava trabalhar, era } \\
\text { fácil, até uns } 13 \text { anos. A minha obrigação era ir } \\
\text { para a escola e treinar (B e C). Mas chegou uma } \\
\text { fase que eu queria ter o meu dinheiro, pois meu } \\
\text { pai não tinha condições de me dar nada, então eu } \\
\text { comecei a dar aula de Judô com } 13,14 \text { anos. } \\
\text { Então nos meus tempos livres eu dava aula de } \\
\text { Judô. Algumas férias trabalhei até com o meu avô, } \\
\text { como servente de pedreiro, quando meu pai ficou } \\
\text { desempregado (D). Logo quando eu comecei a me } \\
\text { destacar, eu comecei a ganhar uma ajuda de } \\
\text { custo pelo clube. Quando eu fiquei com mais idade } \\
\text { comecei a trabalhar na bolsa de valores, então até } \\
\text { perto da minha primeira Olimpíada eu trabalhava, } \\
\text { estudava e treinava, uma coisa meio que } \\
\text { desgastante (B, C e D). }\end{array}$ & $\begin{array}{l}\text { - Estudos C } \\
\text { - treinar Judô B } \\
\text { - trabalhar D }\end{array}$ \\
\hline
\end{tabular}


ANEXO II - Quadros (de 1 até 12) do Instrumento de Análise do Discurso (IAD) (continuação)

\begin{tabular}{|l|l} 
S4 Judô nunca foi um empecilho. Acho que tem \\
que saber se adequar as condições que você tem. \\
Eu nunca deixei a parte social minha ser \\
prejudicada pelo Judô (E) então se era para eu \\
sair com os meus amigos eu saia, se era para eu ir \\
para o cinema eu ia, se tinha um peça para eu ir \\
eu ia, então é aquela coisa: hora de treinar é hora \\
de treinar se depois do treino tinha condições de \\
ficar uma, duas horas e ir numa festinha tudo bem, \\
eu ia, participava da festinha e depois voltava para \\
a minha casa. Acho que por isso até que eu \\
acabei fazendo bastante amigos. Acho que você \\
tem que saber fazer o que você gosta, se você \\
acha que vai se sentir bem saindo da competição \\
e indo pra festa isso não vai te prejudicar, por sinal \\
vai te dar uma energia maior para quando chegar \\
na segunda feira e você tiver que treinar. Se você \\
está disposto e bem animado, porque você vai \\
para casa, vai acabar fazendo muitas outras \\
coisas, acaba não descansando não se diverte, \\
chega na segunda feira você está mais cansado \\
do que o normal.
\end{tabular} \mid


ANEXO II - Quadros (de 1 até 12) do Instrumento de Análise do Discurso (IAD) (continuação)

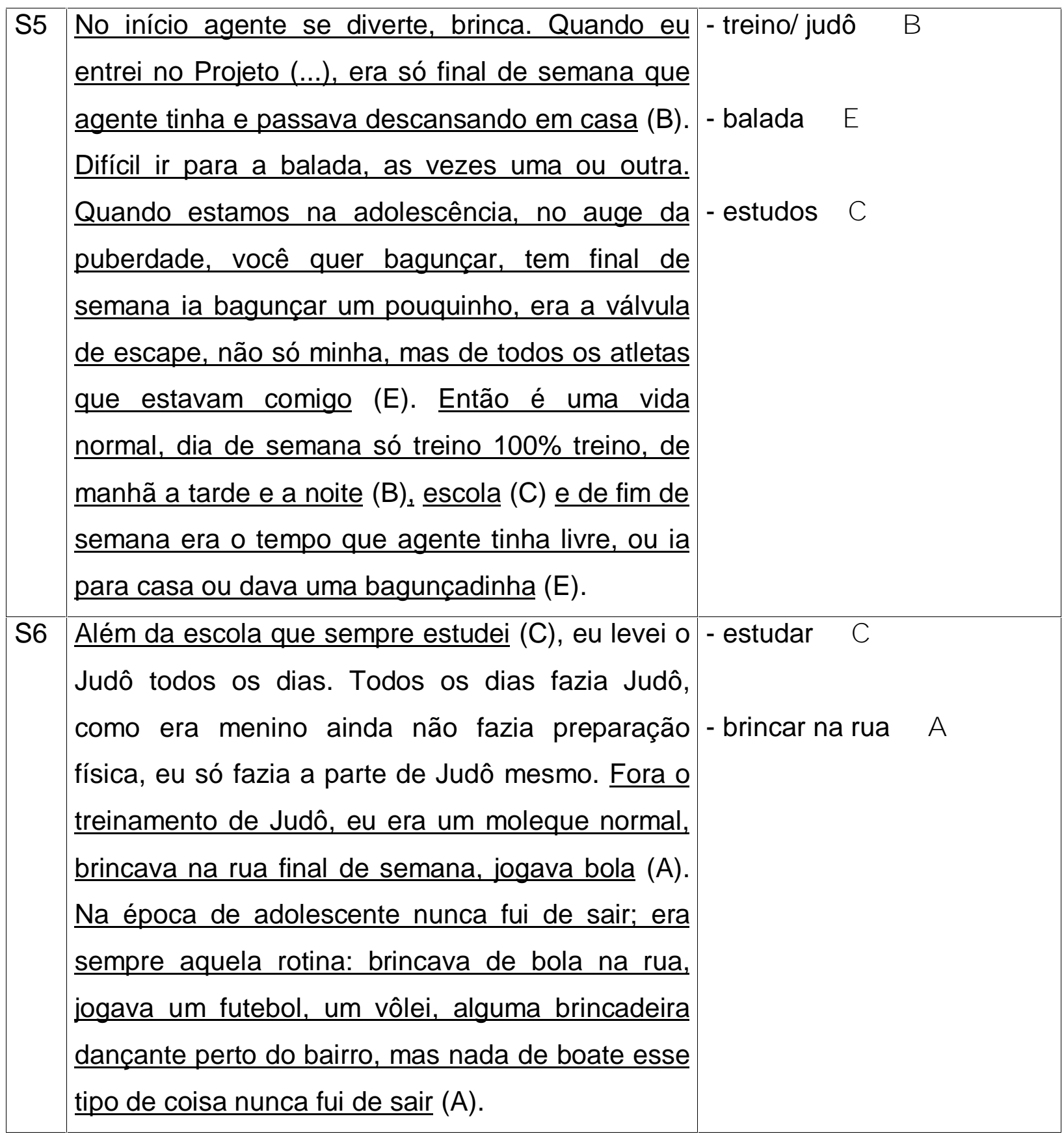


ANEXO II - Quadros (de 1 até 12) do Instrumento de Análise do Discurso (IAD) (continuação)

QUADRO 7: IAD - Instrumento de Análise de Discurso, referente ao conteúdo de todas as respostas da pergunta - Me conte como foi o teu sustento financeiro desde o seu início no judô até os dias atuais.

\begin{tabular}{|c|c|c|c|}
\hline & EXPRESSÕES-CHAVE & \multicolumn{2}{|c|}{ IDÉIAS CENTRAIS } \\
\hline S1 & $\begin{array}{l}\text { Meu pai sempre deu esse suporte financeiro }(A) \text { e } \\
\text { em } 1998 \text {, quando eu fui campeão mundial júnior } \\
\text { com } 16 \text { anos, fui contratado pelo Clube (...) e ai eu } \\
\text { comecei a ter um pouquinho de dinheiro }(B) . \\
\text { Porque antes eu só dependia do meu pai. Por isso } \\
\text { eu acho que sou privilegiado pela estrutura da } \\
\underline{\text { minha família }(A) \text { e por tudo o que o Judô me }} \\
\text { ofereceu. }\end{array}$ & Apoio da família & $\mathbf{A}$ \\
\hline S2 & $\begin{array}{l}\text { De } 1987 \text { até } 2000 \text { vivi em baixo das custas do meu } \\
\text { pai, infelizmente }(A) \text {. Mas eu não tenho do que } \\
\text { reclamar, porque meu pai sempre me deu de tudo. } \\
\text { Em } 2001 \text { eu comecei a ter apoio do Clube (...), que } \\
\underline{\text { não é o que eu acho que um atleta de Judô }} \\
\underline{\text { deveria ganhar, mas é dentro da realidade }} \\
\text { brasileira hoje, então eu não reclamo (B). }\end{array}$ & Apoio da família & B \\
\hline
\end{tabular}


ANEXO II - Quadros (de 1 até 12) do Instrumento de Análise do Discurso (IAD) (continuação)

\begin{tabular}{|c|c|c|}
\hline S3 & $\begin{array}{l}\text { Meu pai no começo pagava, depois teve uma } \\
\text { época que eu deixei de ir um pouco, por que não } \\
\text { tinha dinheiro pra pagar academia (A). O professor } \\
\underline{\text { com quem iniciei viu que eu tinha um potencial e }} \\
\underline{\text { me deu uma bolsa, eu não pagava mais nada. }} \\
\underline{\text { Então eu continuei a treinar por causa desse }} \\
\underline{\text { motivo (B). Também comecei a dar aula na faixa }} \\
\underline{\text { de uns } 15 \text { anos até os } 18 \text { anos. Depois, em 1991, }} \\
\underline{\text { me alistei e o Exército me pegou. Fiquei } 8 \text { anos no }} \\
\underline{\text { Exército, porque eu fiquei lutando também pelo }} \\
\underline{\text { Exército. Então foi uma fase que me ajudou muito }} \\
\text { (C). } \underline{\text { O clube e o patrocinador também começaram }} \\
\underline{\text { a me dar um apoio, porque eu comecei a ganhar }} \\
\underline{\text { os títulos, sobretudo a medalha olímpica em } 1996,} \\
\underline{\text { mudou a minha vida financeiramente. Eu consegui }} \\
\underline{\text { tudo que eu tenho: material, minha casa, enfim }} \\
\underline{\text { minha estrutura, minha manutenção. Tudo graças }} \\
\underline{\text { ao Judô, um tostão, tudo que eu tenho, tudo que }} \\
\underline{\text { eu comprei hoje, foi graças ao Judô (B). }}\end{array}$ & $\begin{array}{l}\text { - apoio do professor/ clube/ } \\
\text { patrocínio B } \\
\text { - trabalho C }\end{array}$ \\
\hline
\end{tabular}


ANEXO II - Quadros (de 1 até 12) do Instrumento de Análise do Discurso (IAD) (continuação)

\begin{tabular}{|c|c|c|}
\hline S4 & $\begin{array}{l}\text { O começo foi difícil. Principalmente quando eu era } \\
\text { garoto, não tinha tanto problema porque as } \\
\text { competições eram dentro de São Paulo, então não } \\
\text { custava muito caro pegar e poder participar. Já na } \\
\text { adolescência eu e minha família tínhamos que } \\
\text { arrumar uma forma de pagar (A). Então meu pai } \\
\text { fazia bingo (A), a academia ajudava fazendo um } \\
\text { monte de coisas para eu poder seguir e participar } \\
\text { (B). Depois de } 1995 \text { não tive mais problema, pois } \\
\text { eu fui para o Clube (...), onde eles davam essa } \\
\underline{\text { condição para mim (B). Eu tive minha liberdade }} \\
\underline{\text { financeira dos meus pais a partir de } 1996, \text { com } 18} \\
\underline{19 \text { anos que eu comecei a ter a minha liberdade }} \\
\text { financeira. Antes era o meu pai (A). }\end{array}$ & $\begin{array}{l}\text { - apoio da família A } \\
\text { - apoio do clube/ academia } \\
\text { B }\end{array}$ \\
\hline S5 & $\begin{array}{l}\text { No inicio só a família me bancava. Era o } \\
\text { dinheirinho da passagem de ida e volta para (...) } \\
\text { era o dinheirinho para eu tomar um lanchinho por } \\
\text { dia (A). Comecei a ter uma ajuda boa depois do } \\
\text { título do Campeonato Mundial em 1997, eu já } \\
\underline{\text { estava com 20,21 anos de idade, ai sim eu tive }} \\
\text { uma ajuda melhor, consegui me bancar sozinho, } \\
\text { tinha a ajuda da Prefeitura e algum patrocínio para } \\
\text { viajar para os campeonatos fora, mas isso só } \\
\text { depois da medalha no Campeonato Mundial, } \\
\text { antes, nada disso (B). }\end{array}$ & $\begin{array}{l}\text { - apoio da família A } \\
\text { - apoio de patrocínios e } \\
\text { Prefeitura B }\end{array}$ \\
\hline
\end{tabular}


ANEXO II - Quadros (de 1 até 12) do Instrumento de Análise do Discurso (IAD) (continuação)

\begin{tabular}{|c|c|c|c|c|}
\hline S6 & 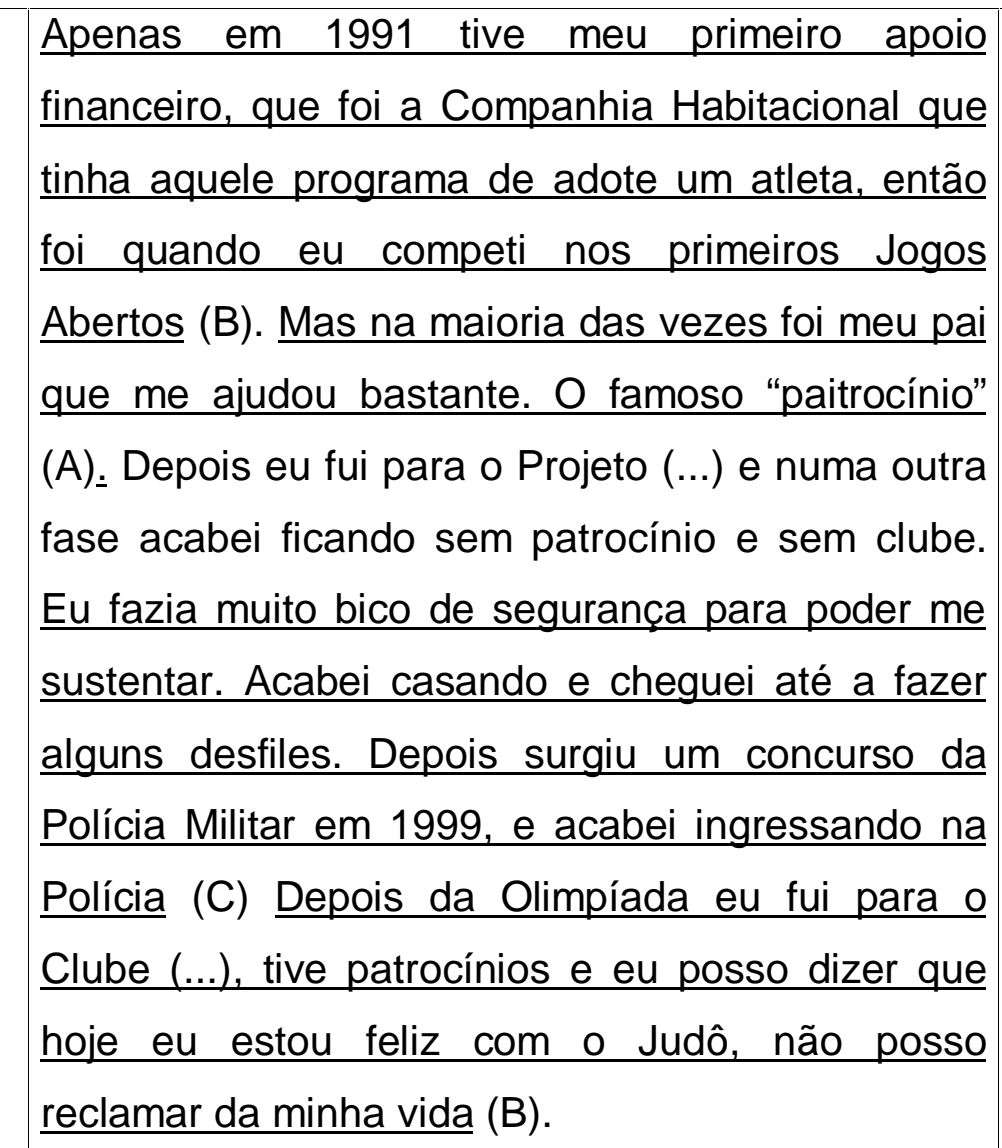 & $\begin{array}{l}\text { - apoio da fam } \\
\text { - trabalho C } \\
\text { - apoio o } \\
\text { patrocínios }\end{array}$ & $\begin{array}{l}\text { nília } \\
\text { a }\end{array}$ & lube \\
\hline
\end{tabular}


ANEXO II - Quadros (de 1 até 12) do Instrumento de Análise do Discurso (IAD) (continuação)

QUADRO 8: IAD - Instrumento de Análise de Discurso, referente ao conteúdo de todas as respostas da pergunta - A que você atribui o teu talento para o judô?

\begin{tabular}{|c|c|c|}
\hline & EXPRESSÕES-CHAVE & IDÉ IAS CENTRAIS \\
\hline S1 & $\begin{array}{l}\text { Desde criança eu tenho facilidade para aprender. } \\
\text { Eu sempre aprendi muito rápido e acho que isso é } \\
\text { que fez a diferença por elevar rapidamente o nível } \\
\text { técnico (A). O aprendizado melhor é o infinito e } \\
\text { sempre quando eu chego em algum lugar eu falo } \\
\text { que tenho que melhorar. Sempre tem que subir, } \\
\text { não pode ultrapassar o limite, só que se } \\
\text { empurrarmos o limite cada vez mais para cima } \\
\text { poderemos tirar algo mais da gente (B). }\end{array}$ & $\begin{array}{l}\text { - facilidade para aprender } \\
\text { A } \\
\text { - determinação B }\end{array}$ \\
\hline S2 & $\begin{array}{l}\text { Eu não sei se eu tenho talento não. Acho que eu } \\
\text { tenho muita força de vontade muita fé em Deus e } \\
\text { trabalho duro para conseguir o que eu quero. } \\
\text { Porque na maneira que eu vejo, o meu Judô é de } \\
\text { muita tenacidade, de muita vibração, que são as } \\
\text { características da minha vida pessoal. Sou muito } \\
\text { coração, então acho que meu talento foi fabricado } \\
\text { a muito treino, corrida, sala de musculação e a } \\
\text { muita fé em Deus também (B). }\end{array}$ & - determinação \\
\hline
\end{tabular}


ANEXO II - Quadros (de 1 até 12) do Instrumento de Análise do Discurso (IAD) (continuação)

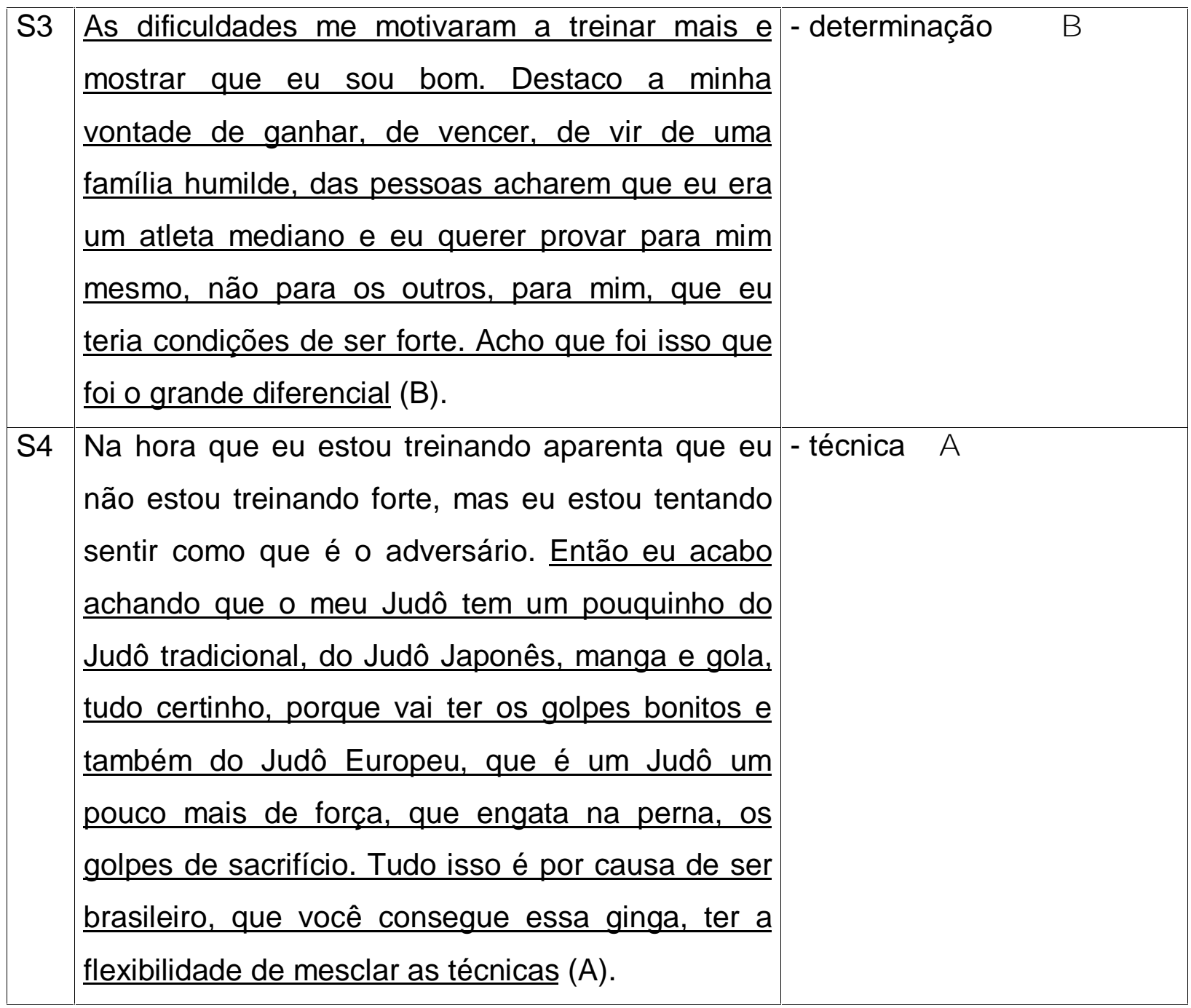


ANEXO II - Quadros (de 1 até 12) do Instrumento de Análise do Discurso (IAD) (continuação)

\begin{tabular}{|c|c|c|}
\hline S5 & $\begin{array}{l}\text { Bom, eu acho que é a força de vontade que eu tive } \\
\text { de correr atrás do que eu queria. Eu me lembro } \\
\text { muito que quando eu era criança, sentava na beira } \\
\text { da área do pessoal mais velho que competia, eu } \\
\underline{\text { me inspirava muito neles } \quad \text { (B). Olhava eles }} \\
\underline{\text { competindo e isso foi me dando força. Eu tinha }} \\
\underline{\text { que saber como que eram os golpes que eles }} \\
\text { aplicavam e fui perguntando, não só a eles mas } \\
\text { aos atletas que não tinham muita expressão, mas } \\
\underline{\text { tinham muita técnica. Por vezes ficava uma hora }} \\
\underline{\text { depois do treino perguntando como eram os }} \\
\text { golpes e tudo mais. Fui fazendo isso e adequando } \\
\text { para o meu corpo, para minha técnica, para o meu } \\
\text { jeito de lutar (A). }\end{array}$ & - determinação \\
\hline S6 & $\begin{array}{l}\text { Olha, é muita teimosia e muita dedicação. Eu } \\
\text { demorei } 8 \text { anos para chegar em uma seleção } \\
\text { principal, é claro que por vezes chegava em uma } \\
\text { semifinal de seletiva, numa final perdia, sempre } \\
\text { alguém batendo, batendo na trave. Então eu fui } \\
\underline{\text { sempre persistindo, mesmo sem patrocínio e }} \\
\underline{\text { trabalhando eu competia nas seletivas (B). Eu }} \\
\underline{\text { tenho medalha de mundial, mundial militar, }} \\
\underline{\text { universitária, pan-americano e acho que a }} \\
\text { ambição de ter uma medalha olímpica é que está } \\
\text { fazendo eu continuar até hoie (B) }\end{array}$ & $\begin{array}{l}\text { - dedicação/ amor pelo } \\
\text { esporte } \quad \text { B }\end{array}$ \\
\hline
\end{tabular}


ANEXO II - Quadros (de 1 até 12) do Instrumento de Análise do Discurso (IAD) (continuação)

QUADRO 9: IAD - Instrumento de Análise de Discurso, referente ao conteúdo de todas as respostas da pergunta - Fale um pouco sobre os teus professores e/ou técnicos e o papel deles na sua formação.

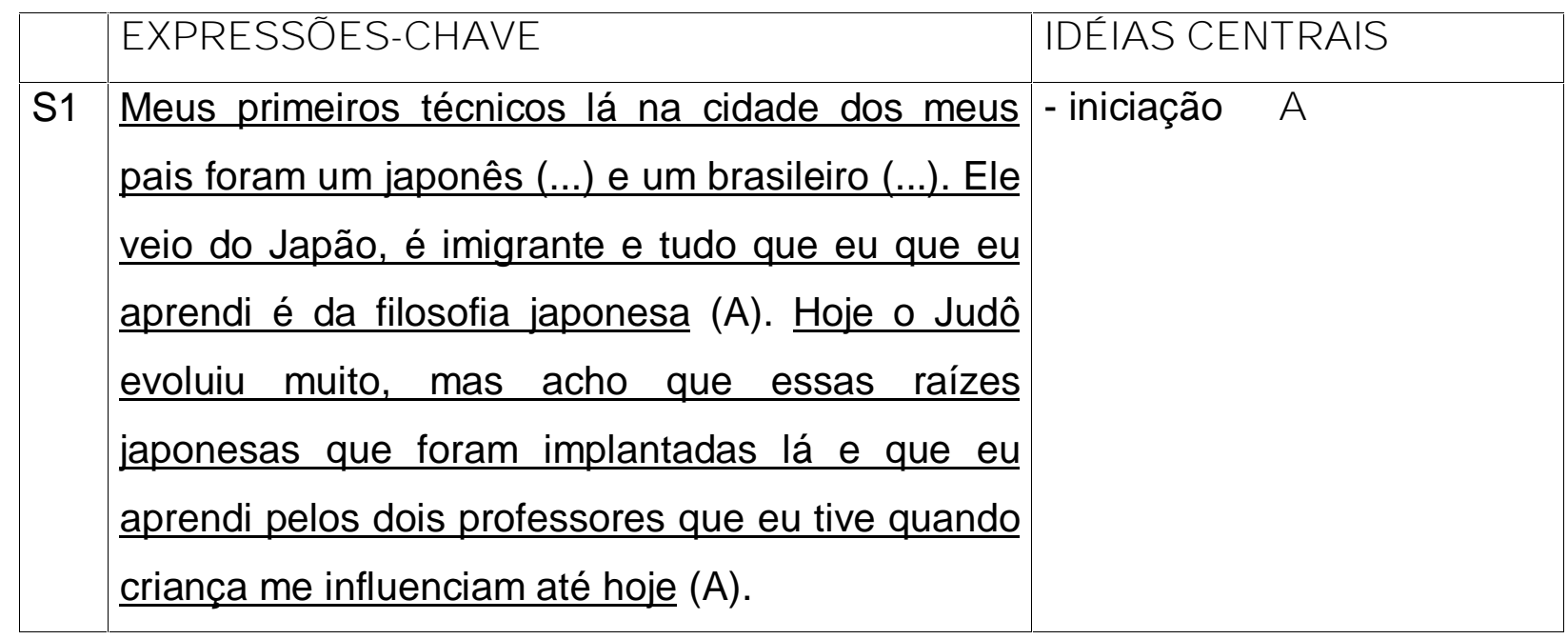


ANEXO II - Quadros (de 1 até 12) do Instrumento de Análise do Discurso (IAD) (continuação)

\begin{tabular}{|c|c|c|}
\hline S2 & $\begin{array}{l}\text { Assim como a nossa vida educacional, nós temos } \\
\text { professores do pré, do jardim, depois da primeira } \\
\text { série, ensino médio, fundamental. Acho que o } \\
\text { Judô também é assim, os meus primeiros } \\
\text { professores foram o (...), o (...) e o professor (...) e } \\
\text { eu agradeço muito a eles por terem dado muita } \\
\text { ênfase a minha disciplina e ao respeito com os } \\
\text { mais velhos, aos valores éticos e morais (A). A } \\
\text { partir de } 1999 \text { o professor (...) já cuidou mais da } \\
\text { lapidação da pedra bruta. Tentou colocar mais } \\
\underline{\text { velocidade no meu Judô, lapidar um pouco mais }} \\
\underline{\text { os meus golpes. Em } 2000 \text { os professores (...), (...) }} \\
\underline{\text { também deram continuidade ao trabalho do }} \\
\underline{\text { professor (...). Hoje meus professores são o (...) e }} \\
\underline{\text { o (...) que cuidam da minha parte física e técnica. }} \\
\underline{\text { Por isso, a minha formação é um emaranhado que }} \\
\text { hoje resulta no que eu sou (B). }\end{array}$ & - iniciação A \\
\hline
\end{tabular}


ANEXO II - Quadros (de 1 até 12) do Instrumento de Análise do Discurso (IAD) (continuação)

\begin{tabular}{|c|c|c|}
\hline S3 & $\begin{array}{l}\text { Eu tive alguns técnicos. Acho que um dos mais } \\
\text { importantes foi o (...), que foi que me iniciou no } \\
\text { Judô. Ele me fez gostar do esporte e eu acho que } \\
\text { ele foi uma das pessoas principais (A). Depois } \\
\text { teve a (...) e o (...), que são dois irmãos, a (...) } \\
\text { passou um período um pouco curto na minha } \\
\text { carreira, mas também foi importante, porque me } \\
\text { deu a oportunidade de eu poder ir junto trabalhar e } \\
\text { treinar ao mesmo tempo, então ela também foi } \\
\text { uma pessoa que ajudou. E o (...) que é o cara que } \\
\text { eu acho que na minha fase profissional, fase } \\
\text { competidora, foi o cara que mais me ajudou. Ele } \\
\text { não era profissional de Educação Física, mas ele } \\
\text { já tinha participado de Olimpíada, foi um grande } \\
\text { atleta também (B). }\end{array}$ & $\begin{array}{l}\text { - gostar do judô na iniciação } \\
\text { A }\end{array}$ \\
\hline S4 & $\begin{array}{l}\text { Teoricamente tive dois professores, que foi o (...) e } \\
\text { o (...).Fiquei com eles até } 1995 \text {, depois fui para o } \\
\text { Clube (...) e os professores eram o (...) e o (...). } \\
\text { Hoje esses são os meus professores, mas acho } \\
\text { que é o (...) e o (...) são os professores que mais } \\
\text { me passaram as coisas }(\mathrm{A}) .\end{array}$ & $\begin{array}{l}\text { - professores da iniciação } \\
\text { A }\end{array}$ \\
\hline
\end{tabular}


ANEXO II - Quadros (de 1 até 12) do Instrumento de Análise do Discurso (IAD) (continuação)

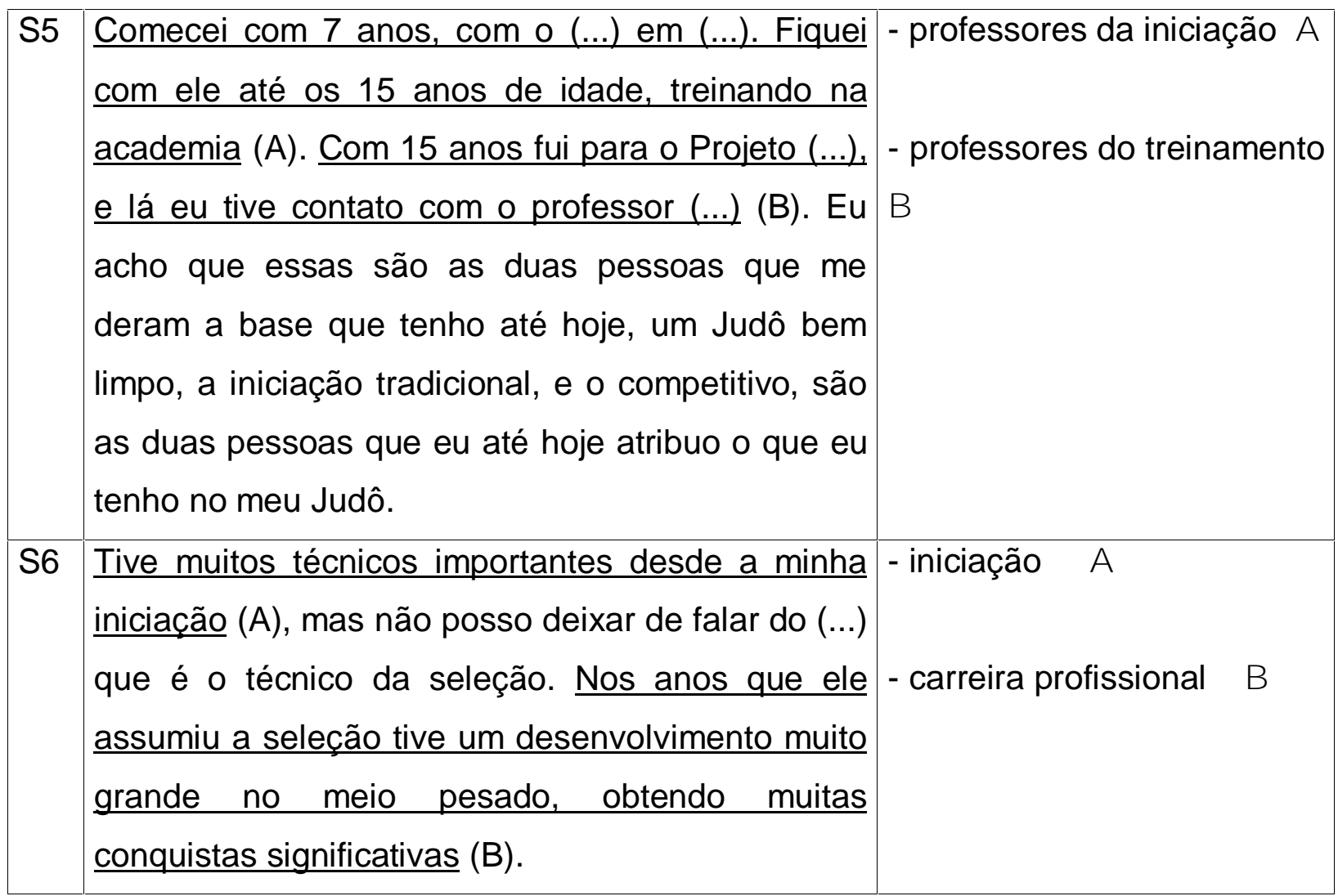


ANEXO II - Quadros (de 1 até 12) do Instrumento de Análise do Discurso (IAD) (continuação)

QUADRO 10: IAD - Instrumento de Análise de Discurso, referente ao conteúdo de todas as respostas da pergunta - O teu treinamento era planejado ou não: fale sobre ele.

\begin{tabular}{|c|c|c|c|}
\hline & EXPRESSÕES-CHAVE & IDÉ IAS CENTRAIS & \\
\hline S1 & $\begin{array}{l}\text { Quando criança o treinamento era meio empírico, } \\
\text { aquele estilo tradicional, do tipo: vai fazendo }(\mathrm{A}) . \\
\text { Hoje eu tenho consciência que o treinamento tem } \\
\text { que ser planejado para você render e ter uma vida } \\
\text { mais longa no esporte. Até Sidney eu fazia poucos } \\
\text { treinos planejados }(\mathrm{A}) \text {. Hoje eu faço uma parte } \\
\underline{\text { física mais elaborada, mais planejada e posso }} \\
\underline{\text { sentir pelo feedback que eu tenho com o meu }} \\
\text { preparador. Percebo a melhora até do meu } \\
\underline{\text { descanso, da minha recuperação, eu acho que eu }} \\
\text { tenho evoluído bastante por isso (B). }\end{array}$ & $\begin{array}{l}\text { - não era planejado } \\
\text { - atualmente sim }\end{array}$ & B \\
\hline S2 & $\begin{array}{l}\text { De } 1987 \text { até } 1996 \text { era de uma forma aleatória, } \\
\text { empírica. Ainda não tinha embasamento científico } \\
\text { pois no interior os professores não tem uma visão } \\
\text { tão esclarecida do que a ciência pode ajudar (A). } \\
\text { Depois de } 1997 \text { até hoje eu comecei a ter } \\
\text { professores capacitados, professores formados, } \\
\text { mestres, doutores que ajudam tanto na parte } \\
\text { física, como na técnica (B). }\end{array}$ & $\begin{array}{l}\text { - não era planejado } \\
\text { - atualmente sim }\end{array}$ & B \\
\hline
\end{tabular}


ANEXO II - Quadros (de 1 até 12) do Instrumento de Análise do Discurso (IAD) (continuação)

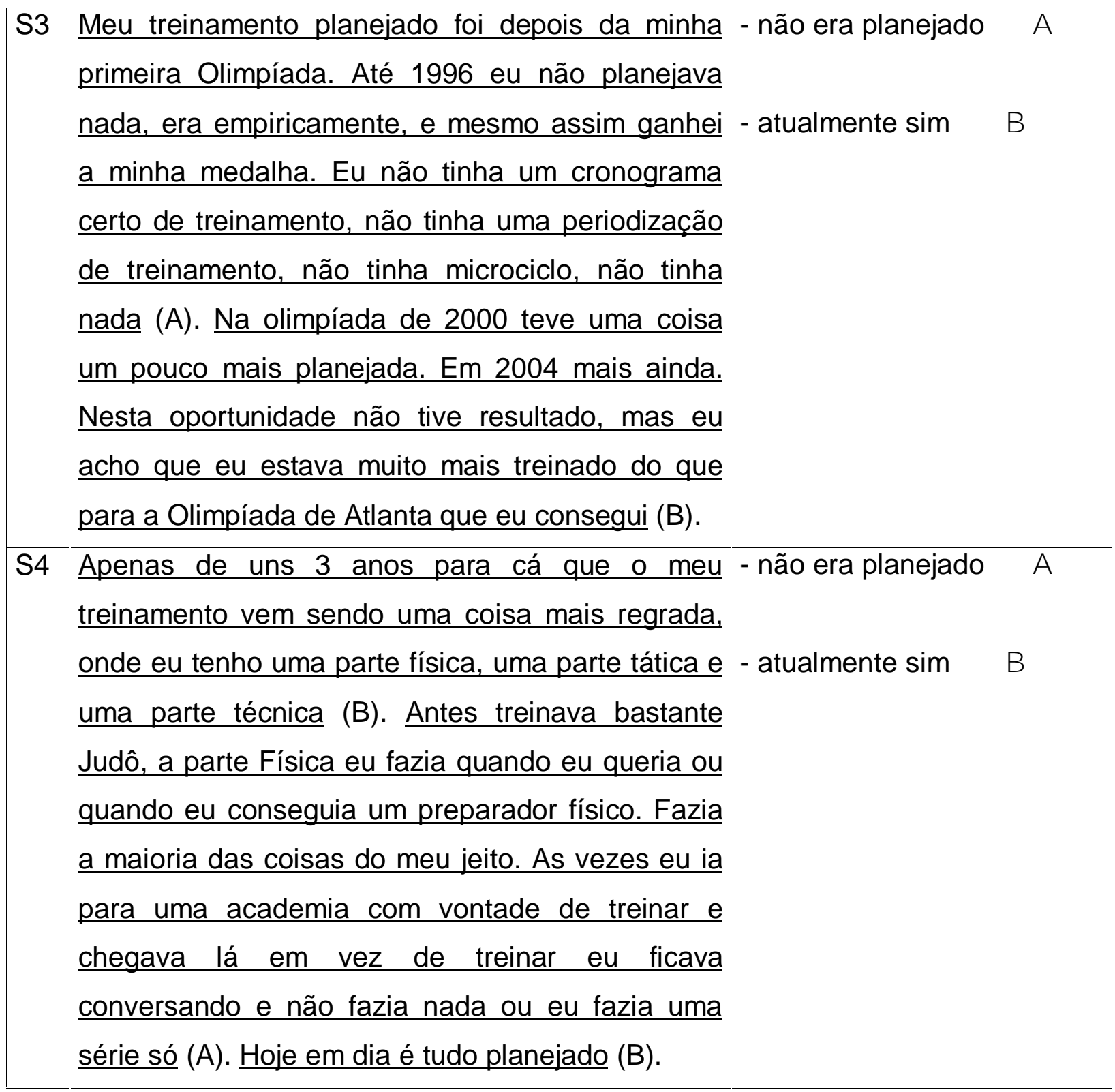


ANEXO II - Quadros (de 1 até 12) do Instrumento de Análise do Discurso (IAD) (continuação)

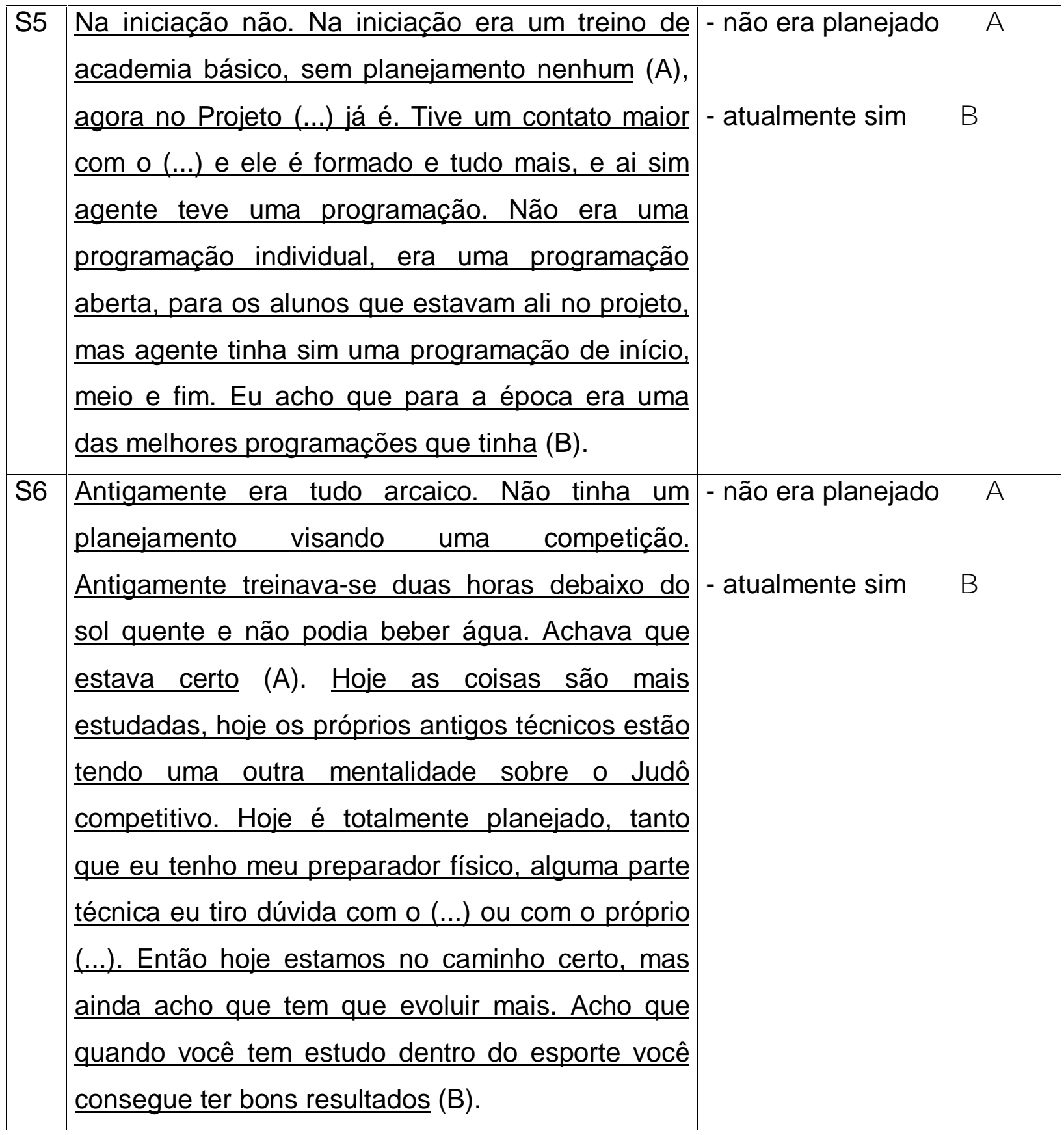


ANEXO II - Quadros (de 1 até 12) do Instrumento de Análise do Discurso (IAD) (continuação)

QUADRO 11: IAD - Instrumento de Análise de Discurso, referente ao conteúdo de todas as respostas da pergunta - Como foram as competições no seu treinamento? Você se destacava logo no começo ou o destaque veio com o tempo?

\begin{tabular}{|l|l|l|}
\hline EXXRESSÕES-CHAVE & IDÉ IAS CE NTRAIS \\
\hline $\begin{array}{l}\text { Não, eu acho que as coisas foram acontecendo } \\
\frac{\text { devagar (A). Apesar de que eu conquistei as }}{\text { coisas muito cedo, em } 1998 \text { eu fui campeão dos }}\end{array}$ & - destampo A \\
$\begin{array}{l}\text { Jogos Mundiais da Juventude com } 16 \text { anos e fui } \\
\text { campeão Mundial Junior, que é sub-21, com 16 } \\
\text { anos também (A). Então as coisas foram } \\
\text { acontecendo rapidamente e percebi que eu podia, } \\
\text { logo em 2000, na Olimpíada de Sidney chegar } \\
\text { sendo então vice-campeão olímpico, super novo. } \\
\text { Até agora em Atenas eu era o atleta mais jovem } \\
\text { da história do Judô a conquistar medalha. Lá atrás } \\
\text { eu batalhei muito, treinei muito, deixei de fazer } \\
\text { muitas coisas que eu gostava para me dedicar ao } \\
\text { Judô: deixei de balada, até de namorar para me } \\
\text { dedicar aquilo que eu queria, que era o esporte. } \\
\text { Eu sabia que se você não pagar o preço por aquilo } \\
\text { que você quer as coisas não vem, então as coisas } \\
\text { aconteceram cedo, pela minha dedicação, minha } \\
\text { perseverança e fazer com muito amor. }\end{array}$ \\
\hline
\end{tabular}


ANEXO II - Quadros (de 1 até 12) do Instrumento de Análise do Discurso (IAD) (continuação)

\begin{tabular}{|c|c|c|}
\hline S2 & 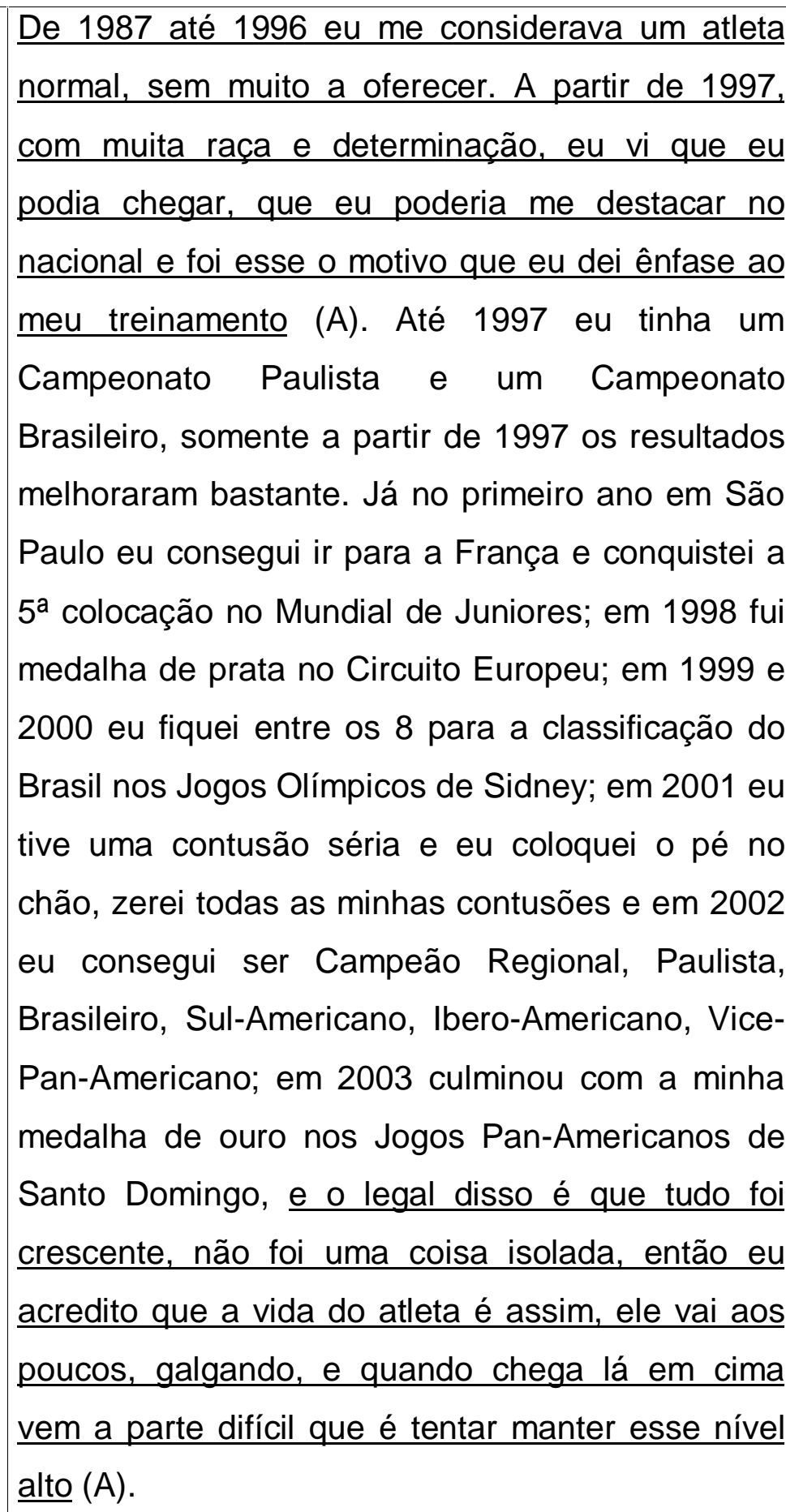 & - destaque com o tempo A \\
\hline
\end{tabular}


ANEXO II - Quadros (de 1 até 12) do Instrumento de Análise do Discurso (IAD) (continuação)

\begin{tabular}{|c|c|c|}
\hline S3 & $\begin{array}{l}\text { Minhas performances em competições foram } \\
\text { aumentando de acordo com o meu treinamento. } \\
\text { Foi uma escala, quanto mais eu comecei a treinar } \\
\text { mais eu comecei a evoluir nas competições. Tem } \\
\underline{\text { quem pense que existem atletas que já são }} \\
\underline{\text { campeões desde o início, mas no meu caso e de }} \\
\underline{\text { muitos outros começamos perdendo, tanto que na }} \\
\underline{\text { minha primeira competição eu perdi. Enfim, fui }} \\
\underline{\text { crescendo conforme eu fui treinando, melhorando, }} \\
\underline{\text { aperfeiçoando a minha condição técnica. Somente }} \\
\underline{\text { a partir de } 1990 \text { é que eu comecei a ser o }} \\
\underline{\text { destaque no Brasil e internacionalmente }(A) \text {. }}\end{array}$ & - destaque com o tempo A \\
\hline S4 & $\begin{array}{l}\text { Eu nunca fui um destaque. A minha primeira } \\
\text { medalha foi uma medalha de bronze quando eu } \\
\text { tinha } 13 \text { anos; então teve um período grande até a } \\
\text { minha próxima medalha que foi quando eu tinha já } \\
17 \text { anos e fui campeão. Daí em diante eu não } \\
\text { parei mais (A). Fui Campeão Paulista, Campeão } \\
\text { Brasileiro e, conseqüentemente, vieram as } \\
\text { competições internacionais que eu tenho muitas } \\
\text { medalhas importantes. Nas competições eu não } \\
\text { me preocupo se eu vou ganhar ou não, eu tento } \\
\text { analisar a competição, tento observar os meus } \\
\underline{\text { adversários, aprender com cada um deles, com }} \\
\underline{\text { respeito e tirando proveito para a minha superação }} \\
\underline{\text { em direção aos maiores desafios e obstáculos das }} \\
\underline{\text { seletivas e competições mais importantes (B). }}\end{array}$ & $\begin{array}{l}\text { - destaque com o tempo A } \\
\text { competição como parte do } \\
\text { treinamento B }\end{array}$ \\
\hline
\end{tabular}


ANEXO II - Quadros (de 1 até 12) do Instrumento de Análise do Discurso (IAD) (continuação)

\begin{tabular}{|c|c|c|}
\hline S5 & $\begin{array}{l}\text { Não no início. Eu até queria competir tudo, mas } \\
\text { não tinha grandes resultados (A). Quando eu } \\
\text { entrei no Projeto (...), com } 15 \text { anos de idade, } \\
\text { também queria saber só de competir, foi quando } \\
\text { eu comecei a ganhar (A). Acho que fiquei dois ou } \\
\text { três anos sem perder nenhuma luta na categoria } \\
\text { juvenil. Eu acho que o importante, para a iniciação } \\
\text { é poder estar participando de competições. Tem } \\
\text { que estar competindo, eu acho que uma } \\
\text { competição que você faz é equivalente a 10, } 20 \\
\text { treinos, então tem que estar competindo, a } \\
\text { competição vai te dar base pra lá na frente você } \\
\text { estourar (B). }\end{array}$ & $\begin{array}{l}\text { - competição como parte } \\
\text { importante do treinamento } \\
\text { B }\end{array}$ \\
\hline S6 & $\begin{array}{l}\text { Sempre nas competições eu nunca deixei de } \\
\text { trazer medalha. Sempre, desde o infantil, desde o } \\
\text { mirim toda competição tava beliscando uma de } \\
\text { ouro, uma de prata, uma de bronze. Acho que isso } \\
\text { que me que me fez ser um bom competidor (C). } \\
\text { Acho que competir desde pequeno foi que me deu } \\
\text { bastante experiência para enfrentar seletivas (B). } \\
\text { Toda competição que eu lutei até hoje eu sempre }\end{array}$ & $\begin{array}{l}\text { - me destacava C } \\
\text { - competição como parte } \\
\text { importante do treinamento } \\
\text { B }\end{array}$ \\
\hline
\end{tabular}


ANEXO II - Quadros (de 1 até 12) do Instrumento de Análise do Discurso (IAD) (continuação)

QUADRO 12: IAD - Instrumento de Análise de Discurso, referente ao conteúdo de todas as respostas da pergunta - Toda competição é meio estressante não é? Como é isso era isso para você?

\begin{tabular}{|c|c|c|}
\hline & EXPRESSÕES-CHAVE & IDÉ IAS CENTRAIS \\
\hline S1 & $\begin{array}{l}\text { Quando você é jovem e não tem um calendário } \\
\text { cheio de competições você acaba encarando } \\
\text { numa boa. A partir do momento que a competição } \\
\text { passa a ser uma em cima da outra é que acaba } \\
\text { sendo maçante. Não pelo corpo, mas pela cabeça. } \\
\text { Acho que cansa porque a competição tem toda } \\
\text { uma preparação mental, você se prepara, você se } \\
\text { concentra e você sempre acaba cansando (A). Por } \\
\text { exemplo, nestes últimos dias estive viajando e } \\
\text { competindo em vários lugares diferentes e agora } \\
\text { estou aqui competindo de novo; eu estou meio } \\
\text { cansado, então tenho que tirar motivação lá de } \\
\text { dentro e imaginar o meu objetivo para me } \\
\text { estimular tirar proveito de toda competição (B). }\end{array}$ & $\begin{array}{l}\text { - sim, é cansativo } \\
\text { - motivação B }\end{array}$ \\
\hline S2 & 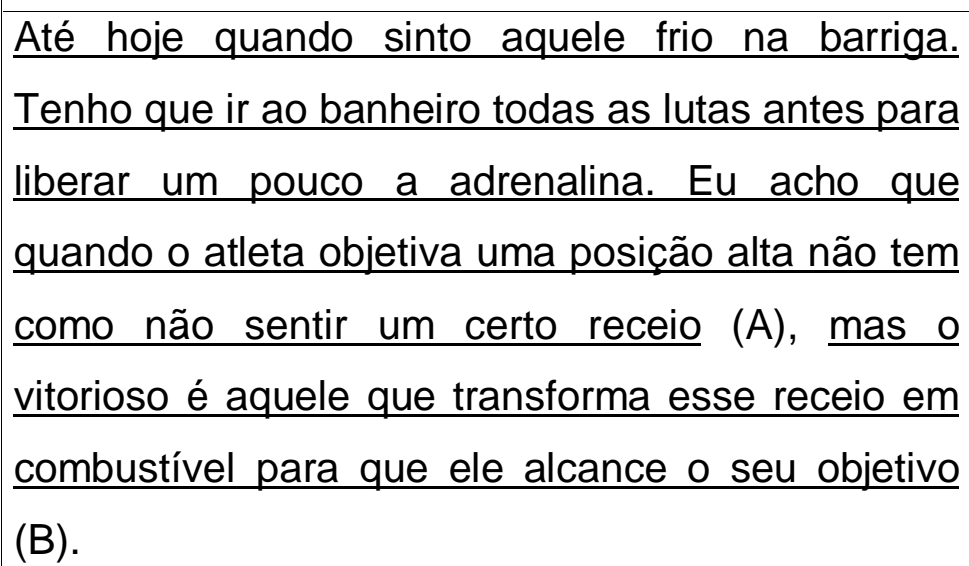 & $\begin{array}{l}\text { - sim, é estressante } \mathbf{A} \\
\text { - superação B }\end{array}$ \\
\hline
\end{tabular}


ANEXO II - Quadros (de 1 até 12) do Instrumento de Análise do Discurso (IAD) (continuação)

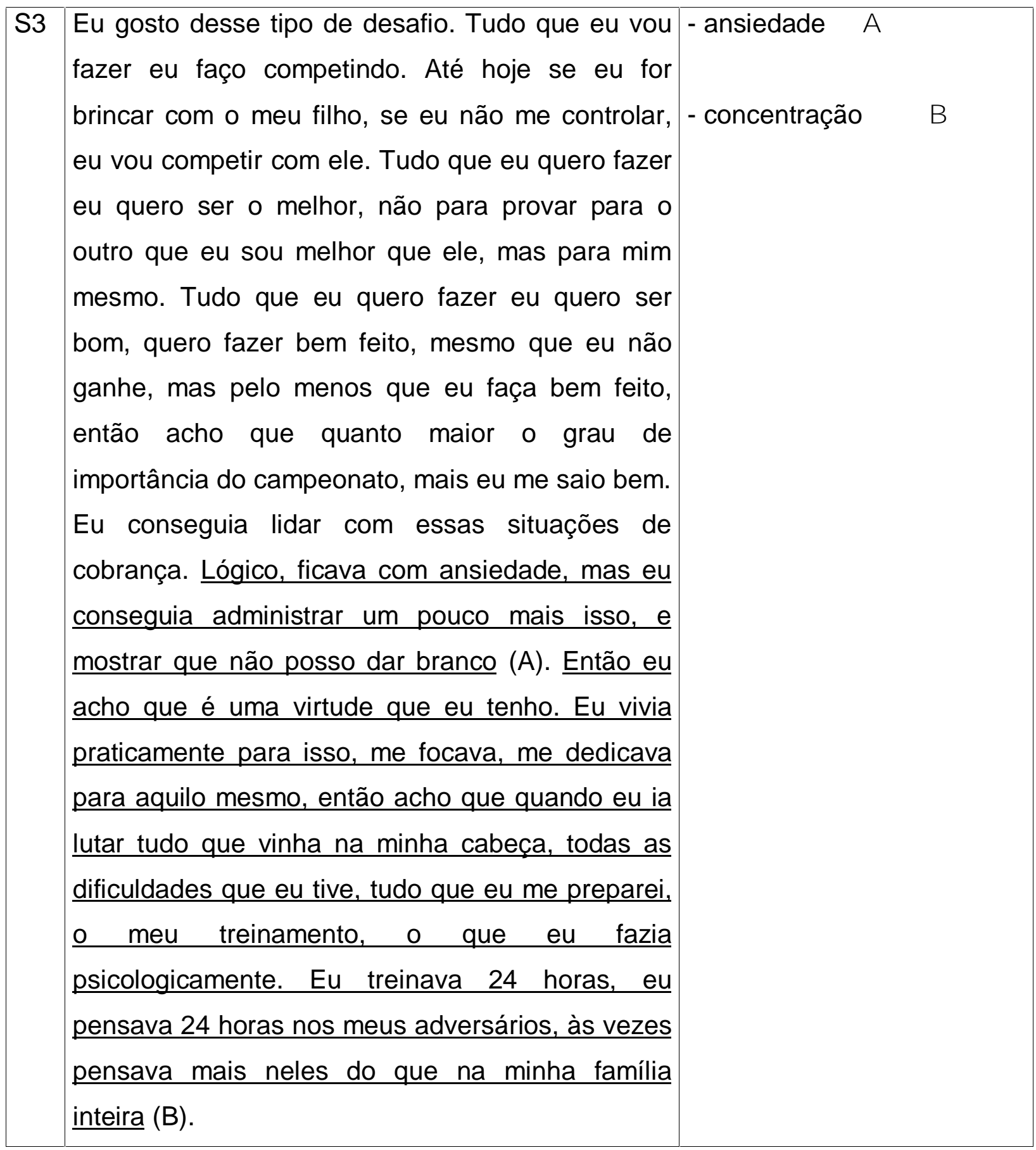


ANEXO II - Quadros (de 1 até 12) do Instrumento de Análise do Discurso (IAD) (continuação)

\begin{tabular}{|c|c|c|}
\hline S4 & $\begin{array}{l}\text { Para não passar mais por isso, estou hoje } \\
\text { tentando voltar às minhas origens. Ou seja, estou } \\
\text { tentando tirar um pouco do peso da } \\
\text { responsabilidade que está presente em cada } \\
\text { competição (A). Tenho feito isso procurando } \\
\text { resgatar o prazer que me trouxe ao Judô e hoje } \\
\text { procuro aproveitar cada momento com mais } \\
\text { tranqüilidade (B). Antes, tive momentos que acabei } \\
\text { me cobrando demais e não me saí tão bem } \\
\text { quando quis vencer todos por ipon. Eu vi que não } \\
\text { é assim, você tem que acabar deixando o trabalho } \\
\text { fluir (A). }\end{array}$ & $\begin{array}{l}\text { - sim, é estressante A } \\
\text { - motivação B }\end{array}$ \\
\hline
\end{tabular}


ANEXO II - Quadros (de 1 até 12) do Instrumento de Análise do Discurso (IAD) (continuação)

\begin{tabular}{|c|c|c|}
\hline S5 & $\begin{array}{l}\text { Nos últimos anos eu senti um pouco mais. Depois } \\
\text { que você adquiri um título a medalha acaba } \\
\text { pesando um pouquinho. No meu caso pesou } \\
\text { bastante. Comecei a competir querendo apenas } \\
\text { jogar de ipon e ganhar. Então nesses últimos anos } \\
\underline{\text { comecei a me machucar bastante, eu comecei a }} \\
\underline{\text { sentir muito o peso disso, que hoje eu sei que me }} \\
\text { fez mal, tanto é que eu estou parado faz um ano } \\
\underline{\text { afastado de competição, devido a isso (A). No }} \\
\underline{\text { início eu ia para competição com aquele gelo na }} \\
\underline{\text { barriga. Eu acho que é isso que motiva o atleta a }} \\
\underline{\text { estar competindo, mas eu tinha prazer, era um }} \\
\underline{\text { estresse tolerável, um estresse gostoso de se }} \\
\underline{\text { sentir (B). Nos últimos anos não, o estresse era }} \\
\underline{\text { uma cobrança muito pesada (A). Eu estou um }} \\
\text { tempo afastado, me corrigindo para não me } \\
\text { preocupar mais com relação à cobrança, lutar por } \\
\underline{\text { amor ao esporte que eu sempre fiz, e como eu não }} \\
\underline{\text { vou ter patrocínio, eu não vou ter um clube por trás }} \\
\underline{\text { me cobrando, eu acho que vai ser até mais fácil }} \\
\text { para mim agora (A e B). }\end{array}$ & - sim, é estressante $\mathbf{A}$ \\
\hline S6 & $\begin{array}{l}\text { Uma coisa que a imprensa sempre destacou em } \\
\text { mim é meu jeito frio de competir. Eu estou sempre } \\
\underline{\text { na minha, ganhando ou perdendo não me deixo }} \\
\underline{\text { afetar e me concentro no que estou fazendo. Se o }} \\
\underline{\text { árbitro tiver errando e eu estiver perdendo, estarei }} \\
\underline{\text { sempre do mesmo jeito e vou procurar vencer o }} \\
\underline{\text { cara do meu jeito (B). }}\end{array}$ & - autoconfiança \\
\hline
\end{tabular}


ANEXO III - Aprovação no Comitê de Ética e Pesquisa 
ANEXO IV - Termo de Consentimento Livre e Esclarecido

\author{
ESCOLA DE EDUCAÇÃO FÍSICA E ESPORTE \\ UNIVERSIDADE DE SÃO PAULO \\ TERMO DE CONSENTIMENTO LIVRE E ESCLARECIDO
}

\title{
I - DADOS DE IDENTIFICAÇÃO DO SUJ EITO DA PESQUISA OU RESPONSÁVEL LEGAL
}

1. NOME DO INDIVÍDUO:

DOCUMENTO DE IDENTIDADE № : SEXO: .M F

DATA NASCIMENTO: .......................

ENDEREÇO:

BAIRRO:

CEP:

TELEFONE: DDD

.CIDADE

APTO

.).

2.RESPONSÁVEL LEGAL:

NATUREZA(grau de parentesco, tutor, curador, etc.)

DOCUMENTO DE IDENTIDADE :

DATA NASCIMENTO.: .....................

ENDEREÇO:

SEXO: $M \quad F$

BAIRRO:

CEP: CIDADE: № …......... APTO:

.TELEFONE: DDD(......).....

\section{II - DADOS SOBRE A PESQUISA CIENTÍFICA}

1. "DESENVOLVIMENTO DE JUDOCAS BRASILEIROS TALENTOSOS"

2. PESQUISADOR RESPONSÁVEL: Profa.Dra. Maria Tereza Silveira Böhme

3. CARGO/FUNÇÃO: Professora Livre-Docente da EEFE-USP

4. AVALIAÇÃO DO RISCO DA PESQUISA:

$\begin{array}{lll}\text { RISCO MÍNIMO } & x & \text { RISCO MÉDIO } \\ \text { RISCO BAIXO } & & \text { RISCO MAIOR }\end{array}$

(probabilidade de que o indivíduo sofra algum dano como conseqüência imediata ou tardia do estudo)

5. DURAÇÃO DA PESQUISA: cerca de 1 hora

Easy PDF Creator is professional software to create PDF. If you wish to remove this line, buy it now. 
ANEXO IV - Termo de Consentimento Livre e Esclarecido (continuação)

\section{III - EXPLICAÇÕES DO PESQUISADOR AO INDIVÍDUO OU SEU REPRESENTANTE LEGAL SOBRE A PESQUISA, CONSIG NANDO:}

1. A pesquisa justifica-se diante da ausência de dados científicos que sirvam de referenciais ou expliquem o processo de formação e desenvolvimento de judocas brasileiros talentosos. Sendo assim, a pesquisa tem por objetivo:

a) Analisar a relação entre o desenvolvimento de judocas brasileiros talentosos e os modelos de desenvolvimento de talento descritos na literatura.

2. Procedimentos: A coleta de dados incluirá respostas a uma entrevista estruturada.

3. Os riscos e desconforto são inexistentes.

4. Os benefícios obtidos referem-se à análise dos processos de desenvolvimento de judocas brasileiros de alto nível, podendo contribuir com a elaboração dos processos de promoção de talentos no judô.

\section{IV - ESCLARECIMENTOS DADOS PELO PESQUISADOR SOBRE GARANTIAS DO SUJ EITO DA PESQUISA:}

1. O atleta avaliado terá acesso, a qualquer tempo, às informações sobre procedimentos, riscos e benefícios relacionados à pesquisa, inclusive para dirimir eventuais dúvidas;

2. O atleta avaliado terá liberdade de retirar seu consentimento a qualquer momento e de deixar de participar do estudo, sem que isto traga prejuízo à continuidade da assistência;

3. A identidade dos atletas estão sob salvaguarda da confidencialidade, sigilo e privacidade;

4. Os atletas avaliados contam com a disponibilidade de assistência no HU ou HCFMUSP, por eventuais danos à saúde, decorrentes da pesquisa.

V - Professor Gerente: Prof. Ms. Marcelo Massa - massa1@ uol.com.br

Professor Responsável: Profa.Dra. Maria Tereza Silveira Böhme - terbohme@usp.br

Escola de Educação Física e Esporte da Universidade de São Paulo - EEFEUSP

Av. Professor Mello Moraes, 65 - Cidade Universitária, Butantã - São Paulo - Tel. 30912135.

\section{VI - CONSE NTIME NTO PÓS-ESCLARE CIDO}

Declaro que, após convenientemente esclarecido pelo pesquisador e ter entendido o que me foi explicado, consinto em participar do presente Projeto de Pesquisa.

São Paulo, de de 